\title{
Living apart together across borders : how Ghanaian couples form, transform, or dissolve in the context of international migration
}

Citation for published version (APA):

Caarls, K. (2015). Living apart together across borders : how Ghanaian couples form, transform, or dissolve in the context of international migration. [Doctoral Thesis, Maastricht University]. Datawyse / Universitaire Pers Maastricht. https://doi.org/10.26481/dis.20150701kc

Document status and date:

Published: 01/01/2015

DOI:

10.26481/dis.20150701kc

Document Version:

Publisher's PDF, also known as Version of record

Please check the document version of this publication:

- A submitted manuscript is the version of the article upon submission and before peer-review. There can be important differences between the submitted version and the official published version of record.

People interested in the research are advised to contact the author for the final version of the publication, or visit the DOI to the publisher's website.

- The final author version and the galley proof are versions of the publication after peer review.

- The final published version features the final layout of the paper including the volume, issue and page numbers.

Link to publication

\footnotetext{
General rights rights.

- You may freely distribute the URL identifying the publication in the public portal. please follow below link for the End User Agreement:

www.umlib.nl/taverne-license

Take down policy

If you believe that this document breaches copyright please contact us at:

repository@maastrichtuniversity.nl

providing details and we will investigate your claim.
}

Copyright and moral rights for the publications made accessible in the public portal are retained by the authors and/or other copyright owners and it is a condition of accessing publications that users recognise and abide by the legal requirements associated with these

- Users may download and print one copy of any publication from the public portal for the purpose of private study or research.

- You may not further distribute the material or use it for any profit-making activity or commercial gain

If the publication is distributed under the terms of Article $25 \mathrm{fa}$ of the Dutch Copyright Act, indicated by the "Taverne" license above, 


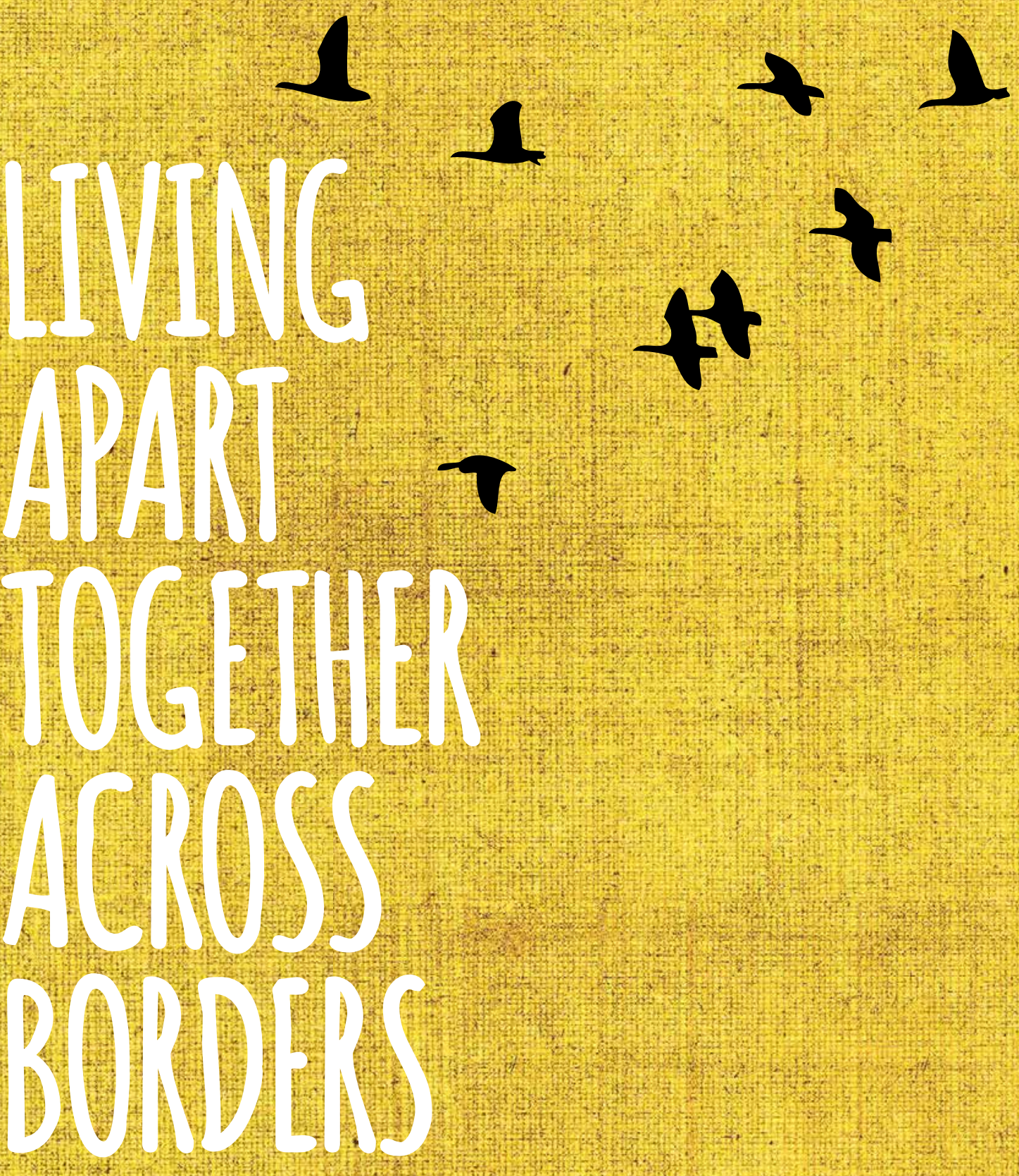

Haw Ghanaian cauples form,

transform, or dissolve in the cantext of international migration

Kim Caarls 
(C) Kim Caarls, 2015

Cover design \& layout Plan $C \cdot$ planc.nl

Printed by Datawyse $\cdot$ Universitaire Pers Maastricht 


\title{
Living Apart Together Across Borders
}

\author{
How Ghanaian couples form, transform, \\ or dissolve in the context of international migration
}

\section{DISSERTATION}

To obtain the degree of Doctor at Maastricht University, on the authority of the Rector Magnificus, Prof. dr. L.L.G. Soete, in accordance with the decision of the Board of Deans, to be defended in public on Wednesday, 1 July 2015 at 16:00 hrs.

by

Kim Caarls 


\section{Supervisor}

Prof. dr. V. Mazzucato

\section{Co-supervisor}

Dr. B. Dito

\section{Assessment Committee}

Prof. dr. M.P. Vink (Chair)

Prof. dr. K.M. Donato, Nashville, USA

Prof. dr. R. Skeldon

Dr. A. González-Ferrer, Madrid, Spain

The dissertation is part of the MAFE project, which received funding from the European Community's Seventh Framework Programme under grant agreement 217206. 



\section{ACKNOWLEDGEMENTS}

While writing this final part of my thesis, my partner is playing with our little girl who refuses to go to sleep. Earlier this evening, we had a video call with my parents, her grandparents, who are traveling through Europe. After a while, my brother and his family, who live in a different city, joined the conversation too. It is amazing to see how selfevident this long-distance communication has become. Even for our little girl, who also has weekly video calls with her father when he is working and staying in Maastricht. Reminiscing about all this while finishing a thesis on family life makes me realise once more how important family is in my own life, no matter where we are.

I would like to start by expressing my gratitude to my promoter, Valentina Mazzucato, who has offered me the opportunity to work on this interesting research project. Valentina, I'm grateful for your valuable feedback and that you always managed to push me just a little further, helping me search for the story behind the numbers. I also have many fond memories of the conferences we visited together - pushing gastronomic boundaries while eating really strange (crawling) seafood in Senegal, or being impressed by your African dance moves -, and the lovely dinners with our TMG group over the years.

At the start of this endeavour, I was co-supervised by Djamila Schans. Djamila, your enthusiasm helped me off to a great start. I'm glad that we still managed to keep in touch and I'm grateful to have you on my corona. Although I was sad to see Djamila leave, I was pleased to see Bilisuma Dito replacing her. Bilisuma, not only did we have many lively conversations about the perks and pitfalls of academic life, we also shared a passion for good food and I'm still hoping I can one day surprise you with successfully following your recipe for home-baked injera's.

I would also like to take this opportunity to thank the members of the assessment committee, Maarten Vink, Ronald Skeldon, Katharine Donato and Amparo GonzálezFerrer. Thank you for your careful reading of my dissertation and providing me with useful comments.

My project was part of the larger MAFE-project. Thanks to all MAFE team members for their useful and supportive comments as well as the lovely drinks and dinners we had wherever we met. Cris and Amparo, thank you for hosting me in Paris and Madrid, I've learned a lot during these visits. Obviously, this whole thesis is only here because all the respondents - in the Netherlands, the UK, and Chana - who were willing to offer their 
time and share so much information. Also thanks to all the research interviewers and assistants who sat down with the respondents and helped to ensure an overall smooth data collection. Not to forget, thanks to all the people who were willing to share their personal stories about transnational marriages with me in Ghana. Also thanks to those in Ghana, who were there to celebrate my own, shortly transnational, marriage.

I started my academic career in Nijmegen, where my research interests were sparked during fieldwork in Ghana for my Bachelor's thesis. During our roadtrip through Ghana at the end of this period, my paranymphs - Marieke \& Sonja - and I decided to continue with the Research Master Social Cultural Sciences. A decision that was also inspired by prof. dr. Ruerd Ruben, who supervised me during my first survey research and my Master thesis. Continuing with the research master turned out to be a great decision. I have greatly enjoyed two years with an inspiring group of people. Most importantly, the research master provided me with the opportunity to carry out fieldwork in Rwanda together with Sonja, which has truly been an unforgettable experience. It convinced us to pursue an academic career, which brought us both to Maastricht (where Marieke followed us shortly thereafter).

Maastricht has been a great place to work and live and I have met and worked with many wonderful people. My paranymphs have made my life in Maastricht so much fun with the many after-work drinks, late nights in De Tribunal, dinners and afterparties at our place, often joined by the lively company of Gösta, Orçun, Rik, Miranda and Karlijn. I couldn't have wished for better or more supportive colleagues. In fact, it soon became clear that we shared much more than an office and our research interests, and I'm grateful for the beautiful friendship that has came out of this. My other office mates and fellow PhD's, particularly Koen, Nicolle, and Özge, it was so nice to have worked alongside you and to share the struggles of $\mathrm{PhD}$ life. Thanks to all my colleagues in the various research groups (TMG, GTD), who provided me with an engaging working environment. Teaching, and in particular being part of developing the new Globalisation and Development Master, with Wiebe, Chris, and Lou, has been an enriching professional experience. Bart \& Marleen, it has been so lovely getting to know you. I loved sharing our 'moestuin', although we had to admit we weren't very successful gardeners. Marleen, I cherish our early morning laps in the swimming pool, where time flew by because of all the things we had to talk about.

A new job at the Netherlands Interdisciplinary Demographic Institute (NIDI) has brought me to The Hague, where I have started working with Helga de Valk. I know it took a bit longer than expected, but thank you Helga, for giving me the space to finish this dissertation. I've already enjoyed working with you (and the 'migration \& migrants' team) over the past months and I'm looking forward to the time ahead. Special thanks also to Joop de Beer, Harry van Dalen and Tineke Fokkema for helping me prepare for the defense. 
I have also been extremely blessed with having a great group of friends in my life. Even though I realise these words will not do justice to our friendship, I would like to thank you: Lieke, for always listening to me with so much love and patience; Josje and Lisa, for all our great conversations and fun evenings where I could blow of some steam; Maartje, your positive energy is truly an inspiration; Marinka and Jorg, thank you both for your warm hospitality and especially thanks for lending me your lovely home when I needed peace and quiet to finish this book; Hans, thanks for making sure I kept reading good literature; Zeedijk (Nienke), no matter how far apart we live, you're always there.

I'm also glad that so many friends from Maastricht joined us to The Hague, and I'm especially glad that I have my paranymphs so close by. Marieke, sengs mate, for your unconditional support. The past years weren't always easy, but you were never more than a phone call away - it's so special to be able to share so much with someone. Sonja, it has been amazing to not only share the academic road with you, but also the road to motherhood. I see our friendship reflected in the 'peuterliefde' between Tomas and Dene. Orçun, Rik, Susanne and Dirk: I'm glad to have you living around the corner. We already know how to enjoy life outside of work, and I'm looking forward to many more lazy beach-days and nights. It's also great to have Bert \& Carla living so close by now, who have always encouraged me. Thanks to Zoubida, for helping me get this book in such a beautiful shape.

Special thanks go to my family, who probably sometimes wondered what I was doing, but who nonetheless believed in me: Toine en Mieke, dank je wel dat jullie mij altijd hebben gestimuleerd en gesteund, zo ook tijdens het schrijven van dit "werkstuk". Thanks also to Rob \& Anne, and to my extended family members: Sonja \& Demis and my dear family in law. Tom, thank you, for your patience and having put up with me while I was glued to my computer, for being a critical friend when I needed one, for the many inspiring conversations we have had throughout the years - about work and life -, for your conscientious reading of parts of my thesis, for having confidence in me when I lost it, and for loving me. Ikhebjelief! And thanks to my little girl Dene, you give the best hugs and the sweetest kisses in the world! 



\section{TABLEOFCONTENTS}

1 Introduction: families living apart together across borders

1.1 Introduction 13

$\begin{array}{lll}1.2 & \text { Societal relevance and scientific contributions } & 15\end{array}$

$\begin{array}{ll}1.3 & \text { Overview of the thesis } \\ \end{array}$

2 Migration and the family: an overview of previous studies 22

2.1 Introduction 23

2.2 A transnational perspective 24

$\begin{array}{lll}2.3 & \text { Migration \& family life } & 27\end{array}$

2.4 A life course approach 35

2.5 Sending and receiving country contexts 36

2.6 Concluding remarks 39

3 Data \& methods $\quad \mathbf{4 2}$

3.1 Introduction 43

3.2 The MAFE project 43

3.3 The MAFE-Ghana survey 44

3.4 Reflections on the data 54

3.5 Sociodemographic characteristics of the MAFE-Ghana samples 60

$\begin{array}{lll}3.6 & \text { Data analysis } 60\end{array}$

4 Transnational families between Ghana, the Netherlands and the UK 62

$\begin{array}{lll}4.1 & \text { Introduction } & 63\end{array}$

$\begin{array}{lll}4.2 & \text { Literature review } & 64\end{array}$

4.3 Ghanaian households \& their migrant family members

4.4 Family life: Chanaian migrants in Europe $\quad 79$

$\begin{array}{lll}4.5 & \text { Transnational families and reunification } & 80\end{array}$

$\begin{array}{lll}4.6 & \text { Conclusion \& discussion } & 97\end{array}$

5 Relational trajectories and living arrangements among Ghanaians:

$\begin{array}{ll}\text { the role of international migration } & 100\end{array}$

$\begin{array}{lll}5.1 & \text { Introduction } & 101\end{array}$

$\begin{array}{ll}\text { 5.2 Relationships \& migration in Ghana } & 103\end{array}$

$\begin{array}{ll}5.3 & \text { Living apart together across borders } \\ & 104\end{array}$ 
5.4 Relational trajectories: a life course approach 105

5.5 Data \& methods 106

5.6 Findings 110

5.7 Conclusion \& discussion $\quad 116$

6 Transnational marriages and reunification: Ghanaian couples between Ghana and Europe 120

$\begin{array}{lll}6.1 & \text { Introduction } & 121\end{array}$

$\begin{array}{lll}6.2 & \text { The sending country context } & 122\end{array}$

$\begin{array}{ll}6.3 & \text { Living apart together across borders } \\ 6.423\end{array}$

$\begin{array}{ll}6.4 & \text { The receiving context } \\ 6.5 & 125\end{array}$

6.5 Ghanaian migration 127

6.6 Data \& methods 128

$\begin{array}{lll}6.7 & \text { Findings } & 133\end{array}$

$\begin{array}{lll}6.8 & \text { Discussion } & 138\end{array}$

7 Does international migration lead to divorce? Ghanaian couples in Ghana and abroad 144

$\begin{array}{lll}7.1 & \text { Introduction } & 145\end{array}$

$\begin{array}{lll}7.2 & \text { Theoretical framework } & 146\end{array}$

$\begin{array}{lll}7.3 & \text { Data \& methods } & 150\end{array}$

$\begin{array}{lll}7.4 & \text { Findings } & 156\end{array}$

$\begin{array}{lll}7.5 & \text { Discussion } & 161\end{array}$

8 Conclusions $\quad 166$

$\begin{array}{lll}8.1 & \text { Introduction } & 167\end{array}$

8.2 Findings and implications for the study of transnational families 168

$\begin{array}{ll}8.3 & \text { Ideas for future research }\end{array}$

$\begin{array}{ll}\text { References } & 180\end{array}$

$\begin{array}{ll}\text { Appendices } & 200\end{array}$

Appendix A. Living arrangements of Ghanaian migrants in Europe 200

Appendix B. Estimating the probability of reunification in the receiving country 203

Appendix C. Time to divorce (Kaplan-Meier estimates) 204

Nederlandse samenvatting $\quad 206$

$\begin{array}{ll}\text { Valorisation addendum } & 212\end{array}$

$\begin{array}{ll}\text { About the author } & 218\end{array}$ 


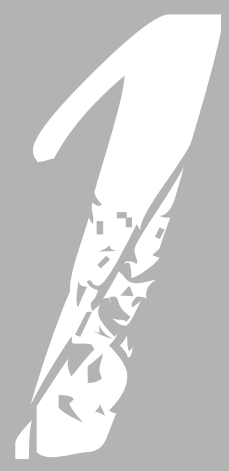

INTRODUCTION:

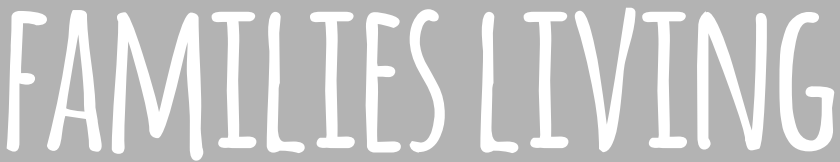

APART TOGETHER

ACROSS BORDERS 


\subsection{Intraductian}

In 2010, I interviewed Ghanaian men and women in Ghana who had experienced or at that time were in transnational relationships, relationships in which the partners are geographically separated across nation-state borders. These interviews were part of the initial exploratory stage of the research, during which I attempted to gain an understanding of how couples experienced living apart together across borders (LATAB). This dissertation is based on quantitative analyses of survey data, but these qualitative interviews are useful in illustrating the variety of transnational arrangements and experiences that prevail amongst LATAB couples.

One of the men I spoke with was Emmanuel. We met one afternoon on a bench under a tree, next to the marketplace in his neighbourhood. Emmanuel was in his mid4Os, married, with two children. His wife had migrated to Europe 10 years earlier, and she had been living there since. He openly discussed his experiences and spoke lovingly of his wife. Although they had been living geographically separately for more than 10 years, they still maintained a close emotional connection. It helped, of course, that she managed to visit him regularly. He visited her once in Europe, together with their children. Although he would have liked to travel to her more often, having his tourist visa rejected various times had discouraged him.

I asked him about his ideas for the future, in particular whether he and his wife had considered living together again. 'Who knows', he replied, shrugging his shoulders. He explained that his wife had a good, steady job in Europe, and he had his own Information and Communication Technology (ICT) business in Ghana. Their children lived with him, and he took care of them with the help of his mother and his sister, who lived on the same compound. The children went to school in Ghana, and because both parents preferred the Ghanaian education system, migrating to Europe was not an option. Because the job opportunities his wife had in Europe were not available for her in Ghana, they did not consider her returning home a valid option.

Emmanuel's story is not unique. Contemporary migration flows are characterised by geographical distance between family members. Emmanuel's story illustrates that these families can manage to live apart together across borders for long periods of time. It shows some of the considerations that influence the decision to live apart together, such as preferences regarding education systems and economic opportunities. It further exposes the challenges of managing family life transnationally, such as the legal obstacles that make it difficult to visit each other.

Emmanuel's story portrays the case of a middle-class family. Both he and his wife were highly educated, and their decision to live apart was largely the result of both partners' desire to pursue their careers. They were fortunate in the sense that they had 
the financial means and that his wife possessed the necessary legal documents to travel back and forth, even though Emmanuel and his children could not visit her. This is certainly not the case for all transnational couples. Rather, the interviews I conducted in Chana showed a wide diversity of transnational family forms and a variety of reasons for people to be in such families. I encountered cases in which it was the husband who had migrated, as well as cases in which the wife migrated. Similar to the findings of other studies on transnational relationships, some couples endured long geographical separations (see e.g., Baizan, Beauchemin \& González-Ferrer, 2014; Beauchemin et al., 2014; Gupta, 2002). I also encountered couples who desired to reunify, and whereas some interviewees expressed that they wished to reunify with their partners in Europe, others preferred that their spouse return home. Others, such as Emmanuel, expressed no desire to reunify, at least not in the short term, because they were satisfied with the current arrangements. Recent findings from transnational family studies have also emphasised these different reunification preferences (see, e.g., Baizan et al., 2014; Beauchemin et al., 2014; Bledsoe \& Sow, 2011; Landolt \& Wei Da, 2005).

Although Emmanuel's story is quite positive, I also encountered cases in which living apart together across borders did not function to the satisfaction of both spouses, mutual mistrust had resulted in tensions between spouses, and others were too poor to travel internationally. As has been reflected in transnational family studies conducted since the 2000s, factors such as class, education, and legal status are important influences on these transnational relationships (see, e.g., Bryceson \& Vuorela, 2002; Dito, Mazzucato \& Schans, in press; Fresnoza-Flot, 2009; Gupta, 2002; Mahler, 2001; Poeze \& Mazzucato, 2012). This dissertation is one of the first studies to look at these issues on a large scale and to use a multi-site design for the case of African migrants. It addresses the following questions:

- What types of family arrangements are prevalent among Ghanaians in the context of international migration between Ghana and Europe? To what extent do families reunify, and, if they do, do they always reunify in the country to which they migrated? (Chapter 4)

- What are the relationship formation, transformation and dissolution patterns of Ghanaians in their young adulthood? To what extent does international migration shape these relationship trajectories? (Chapter 5)

- To what extent do couples reunify in Europe? Which factors play a role in their decisions to remain transnational or to reunify in the receiving country? (Chapter 6)

- Do transnational couples have a greater likelihood of divorce as a result of their migration experience? (Chapter 7) 


\subsection{Sacietal relewance and scientific cantrilutions}

Family arrangements have become increasingly complex in the past forty years, with familial norms changing and new types of families emerging (Fokkema \& Liefbroer, 2008). In Western countries, consensual unions are replacing marriages, families are formed at later ages, and newer forms of unions such as living apart together (LAT) are emerging (Duncan \& Phillips, 2011; Fokkema \& Liefbroer, 2008; Latten \& Mulder, 2013; Levin, 2004; Roseneil, 2006). Additionally, women's employment and changing norms around childbearing make residential nuclear families less obvious (Bures, 2009). This variety of conjugal processes poses new challenges for researchers who want to assess the social significance of these phenomena and how and when they occur across the life course (Antoine et al., 2009).

The literature on these new family forms has typically not focused on migrant families, but migrant families also exhibit forms of family life that diverge from the nuclear family model; migration further contributes to changes in family life. International migration flows have resulted in living arrangements under which family members live dispersed across borders, and these families have been conceptualised as transnational. Despite the spatial distance, these families still maintain "a sense of collective welfare and unity, namely 'familyhood', even across national borders" (Bryceson \& Vuorela, 2002 , p. 3). The phenomenon of the transnational family life is not new, but recent times have significantly altered the way families interact in spite of the geographical distance through technological innovations, such as communication technologies and travel opportunities.

The topic of family migration has led to fierce political debates over the past decades because it touches upon issues of border security, integration, and multiculturalism. Family migration has, likely in response to the limited possibilities of acquiring legal status in other ways, become one of the main legal routes by which migrants enter Europe or the US (Kraler, Kofman, Kohli \& Schmoll, 2011; Organisation for Economic Co-operation and Development (OECD), 2014). At the same time, family migration, including spousal migration, is frequently considered problematic because it is linked with images of subordinate, dependent spouses who are mostly female and who migrated as a result of forced, arranged or even fraudulent marriages (Grillo, 2008; Fleischer, 2008; Kofman, Saharso \& Vacchelli, 2013; Van Dijk, 2004). Consequently, managing family migration has become a major policy concern of migration policy makers (Kraler, 2010), but insight into family migration patterns or the functioning of families in the context of international migration is still limited. 
This thesis aims to contribute to the literature in five ways. First, although previous studies underline the significance of transnational families (e.g., Bryceson \& Vuorela, 2002; König \& De Regt, 2010; Mazzucato, 2013), and despite the increasing academic attention given to these families, figures concerning the prevalence of these transnational families remain scarce. Transnational family studies that emerged in the 2000 s provided rich and detailed ethnographic accounts of the implications of arranging family life across borders for the different family members involved (e.g., Charsley, 2005; Gallo, 2006; George, 2000; Hirsch, 2003). Because most of these studies examine cases of transnational family life, an open question remains regarding the extent of the phenomenon and of the different forms it takes (Clark, Click \& Bures, 2009; Mazzucato \& Schans, 2011). With this thesis, I hope to contribute by adding quantitative insights into the prevalence and structure of families who are living apart together across borders.

Central to this thesis is a transnational approach in which migrants are conceptualised as embedded in, and influenced by, multiple contexts that overarch nation-state boundaries (e.g., Basch, Glick Schiller \& Szanton-Blanc, 1994; Levitt \& Jaworksy, 2007; Mazzucato, 2008a). This thesis incorporates data collected in both a migrant-sending country and two receiving countries. This structure leads to a second contribution: the inclusion of a sending country perspective, which is important for two reasons. First, it is crucial to consider not only migrants but also those who remain in the sending country (Levitt, 2001a, 2001b; Levitt \& Glick Schiller, 2004). Prior to the emergence of transnational migration studies, migration scholars typically focused on those who migrated, paying scant attention to those who did not migrate but were attached through family ties to those who did (Grillo \& Mazzucato, 2008; Kanaiaupuni, 2000). The inclusion of non-migrants is particularly relevant in relation to transnational families because family members who stay behind are an integral part of transnational relationships. They can play an important role in maintaining households across borders, for instance, by being involved in decision-making processes, financial or otherwise, or by arranging or providing care for dependents who are left-behind, such as children or elderly parents.

A second reason for including the sending country perspective is that it allows for investigating whether transnational family life is actually different from that of families who live in close proximity, which requires insight into the family lives of those who did not move. This will be addressed in this thesis by incorporating anthropological insights on the role of family norms in Ghana. To gain insight into the effects of migration on families, it is important to understand the sending country society and the (familial) norms that prevail, as well as the societal changes that take place in the sending country (see, e.g., Hirsch, 2003; Kanaiaupuni, 2000; Coe, 2011; Zentgraf \& Chincilla, 2012). These norms can play an important role in shaping decisions about family 
life, whether transnational or not. Additionally, collecting and analysing data on nonmigrants provides a relevant comparison group when seeking to understand the effect of migration. This comparison is required to see whether differences between migrants and native populations are the result of the migration or whether wider societal processes in both contexts are responsible.

Third, in addition to including a sending country context, this thesis also adopts a comparative approach by examining different receiving contexts. Such a comparison allows for an investigation of the ways in which the receiving context shapes transnational family life. This thesis concentrates on a comparison between Ghanaian migrants in the Netherlands and the UK. Both countries have been among the primary destinations of Ghanaian migrants since the 1990 (Akyeampong, 2000), but there are important differences between the two countries in terms of migration policies (Strik, De Hart \& Nissen, 2013). Additionally, this thesis compares migration to Europe or North America with migration to other African countries. Previous studies have indicated that migration to Western countries can lead to changes in gender norms (e.g., Hill, 2004; Hirsch, 2003; Jolly \& Reeves, 2005; Manuh, 1999; Zontini, 2010). Furthermore, migration within Africa and migration to Western countries differ in aspects such as greater difficulties with travelling (because of stringent visa regulations and expensive flights) between Western countries and Chana.

Fourth, this thesis offers insight into African transnational family life. Although there has been considerable attention paid to transnational family life, these works have concentrated on migration from either Asian countries or Latin America and to the US (e.g., Dreby \& Atkins, 2010; Glick, 2010). Little research has been conducted on transnational families within an African-European context, although these flows constitute significant migration systems (Koser, 2003), and the majority of these studies are very recent (see, e.g., Åkesson, Carling \& Drotbohm, 2012; Baizan et al., 2014; Beauchemin et al., 2014; Haagsman \& Mazzucato, 2014; Mazzucato, Schans, Caarls \& Beauchemin, 2014a; Mazzucato et al., 2014b; Fleischer, 2008; Poeze \& Mazzucato, 2013; Ricco, 2008; Tiemoko, 2004). Moreover, these flows differ from other migration flows in many aspects, specifically concerning transnational family relationships. Not only does Europe present a different receiving context compared with the US (Portes \& Rumbaut, 1990), the entry of Africans into Europe differs from that of migrants who arrived earlier via guest worker schemes (Mazzucato, 2008a). Additionally, a more independent and fluid character characterises family life in many West African countries (Bleek, 1987; Clark, 1994; Oppong, 1980; Takyi \& Gyimah, 2007), which may be different from the contexts studied in Asia or Latin America and which might result in distinct effects of migration on family life.

Finally, this study also aims to contribute to the literature on migration and family 
life by adopting a life course approach, which acknowledges the dynamic nature of both family life and migration (Billari \& Piccarreta, 2005; Elder, 1985; Giele \& Elder, 1998; Kohli, 2007; Kulu \& Milewski, 2007; Mayer, 2000; Mayer \& Tuma, 1990; Wingens, Windzio, De Valk \& Aybek, 2011). Although the life course approach has been extensively applied in sociological studies on union and family formation, and on the transition to adulthood, it has been applied rather scarcely in quantitative migration studies (Wingens et al., 2011). Migration studies generally focus on a specific moment in time, such as the situation of migrants prior to or after they migrated. Using retrospective data, this thesis considers families' changing historical contexts to understand the consequences of migration for their family lives.

\subsection{Overwieu of the thesis}

This thesis aims to provide insight in the formation, transformation and dissolution of transnational relationships. The empirical chapters in this thesis are each independent papers that have been published in or submitted to peer-reviewed books and/or journals (see the footnotes at the beginning of each empirical chapter). Some overlap is thus unavoidable, especially in presenting the context of the study. All references and the appendices have been placed at the end of the thesis to facilitate the reading.

Two chapters precede these empirical chapters: In Chapter 2, I discuss how transnational family life in general, and transnational couples in particular, have been discussed in the literature. Although this thesis concentrates on couples who live apart together across borders, these transnational couples do not exist in a vacuum. To situate transnational couples, I also engage with a wider body of literature that addresses transnational family life, discussing literature from transnational family studies, family sociology, demography, legal and policy studies, and historical-anthropological works on Ghanaian family. By taking stock of current scholarly work on this subject matter, I identify how this thesis aims to contribute to the existing research.

In addition, Chapter 2 provides background information about migration and family life in Ghana. I present historical-anthropological literature that addresses the different prevailing family systems in Ghana. The importance of the extended family is stressed, as are the widespread practices of non-residential marriage and child fostering. Additionally, I also present background information on Ghanaian migration, here concentrating specifically on two main receiving countries: the Netherlands and the UK. This background section provides contextual information that will support the 
interpretation of the results of the analyses from the empirical chapters.

In Chapter 3, I elaborate on the data and methods. This thesis is part of the wider 'Migration between Africa and Europe' (MAFE) project,' which is a large international, inter-university program funded by the European Union's 7th Framework Program for Research ( $\left.\mathrm{FP}_{7}\right)$. Underlying this project is the recognition that migration is not unidirectional, that is, not from African to Europe but between Africa and Europe (Beauchemin, 2012). Therefore, data collection took place in both sending and receiving countries using a retrospective survey that captured the life histories of migrants, returnees and non-migrants. The MAFE project collected data on three migration flows: the Congolese, Senegalese and Ghanaian flows. Data were collected in three migrantsending countries and six receiving countries. This thesis employs the data collected on the Ghanaian migration flow, with surveys conducted in two main urban areas in Ghana (Accra and Kumasi) and in urban areas in the Netherlands and the UK.

The following four empirical chapters each have a different focus, requiring different analytical samples and methods. Table 1.1 presents an overview of these four chapters, briefly describing for each chapter: the research focus, the population of interest, the type of data used, in which country the data were collected, and the main method employed.

Chapter 4 starts with a contextualisation of transnational couples by presenting a descriptive overview of transnational families, including both nuclear and extended family members. This chapter seeks to investigate the prevalence of migratory contacts among Ghanaian households and finds that nearly half of the households in Ghana had at least one household member overseas, including both nuclear and extended family members. Migrants and the households in Ghana both received and provided support to each other. Yet sending remittances did not imply having received support, countering the notion of remittances as a form of 'pay back' from the migrant to the household. This chapter further shows that many current migrants arrived in the Netherlands or the UK without a spouse or children. This challenges the idea that family reunification is the way for most migrants to enter Europe. Among those with nuclear families, transnational living arrangements were found to be quite prevalent, and these arrangements are long lasting.

The next three chapters focus more deeply on particular aspects related to couples in transnational families. Chapter 5 aims to provide insights into the patterns of relationship formation, transformation or dissolution among Ghanaians in young adulthood (from age 21 to 35). The chapter identifies four types of relational trajectories, which are predominated by: 1) co-residential marriages, 2) singles, 3) non-residential marriages, and 4) mixed trajectories. Second, the chapter investigates the inter-linkage between

1 For more information on the MAFE project, see mafeproject.site.ined.fr/. 
relationship histories and the role of international migration by comparing Ghanaians with and without migration experience. Using this typology as the dependent variable, the association between international migration and these 4 types of relational trajectories was assessed. The results show that non-residential relationships are common among migrants and non-migrants, illuminating that this type of relationship is not necessarily generated through international migration. Instead, it might be emblematic of the high mobility of Ghanaians, both within Ghana and internationally. However, although both migrants and non-migrants practice non-residential relationships, it is most common among migrants, and migrant women in particular.

Chapter 6 continues by looking at those couples who live together apart across borders, questioning the factors that explain why some couples stay transnational whereas others reunify in the receiving country. The findings of this chapter highlight the significance of couples who live apart together across borders and that staying geographically separate can be a lasting arrangement. Using event history analyses, this chapter examines the influence of a number of factors on the probability of reunification. The education level of the left-behind spouse proved to be an important factor, attesting to the importance of adopting a transnational lens. The period after stricter family reunification legislation was implemented is associated with fewer reunifications, indicating the law's effectiveness, but the legal status of migrants does not appear to make a difference, which suggests that both de jure and de facto reunification take place. Additionally, maintaining a transnational lifestyle increases the likelihood that couples will stay transnational, indicating that it is more than laws that affect people's decisionmaking around transnational family life.

Although living apart together across borders works for some couples, for others it can be a real challenge, and some relationships might not sustain the context of migration. Chapter 7 examines the extent to which the stability of couples' relationships can be explained by international migration. Using event history analyses, this chapter set out to investigate whether it matters who in the couple migrates and in which order. Looking at migration from a couples' perspective revealed that migration does not necessarily results in divorce. Migration does increase the risk of divorce when women migrate without their husbands, or when both partners migrate simultaneously. This indicates that there are gender differences concerning the impact of migration on divorce, which might be related to norms concerning marriage and gender roles in Ghana. Possibly, situations in which a husband migrates internationally are experienced as being similar to the traditional situation in Ghana in which spouses practice multilocal residency. As such, this chapter stresses the importance of taking into account the contexts of both the sending and receiving countries.

Finally, in Chapter 8, I draw conclusions on how Ghanaian couples form, transform 
or dissolve in the context of international migration. I conclude with a discussion of the limitations of the study, and I provide several avenues for future research on migration and family life.

Tabel 1.1. Overview of the empirical chapters (4-7)

\begin{tabular}{|c|c|c|c|c|c|}
\hline $\begin{array}{l}\text { Empirical } \\
\text { chapters }\end{array}$ & Research focus & $\begin{array}{l}\text { Population of } \\
\text { interest }\end{array}$ & Type of data & $\begin{array}{l}\text { Country } \\
\text { of data } \\
\text { collection }\end{array}$ & $\begin{array}{l}\text { Analytical } \\
\text { Method }\end{array}$ \\
\hline $\begin{array}{l}\text { 4. Transnational } \\
\text { families } \\
\text { between } \\
\text { Ghana, the } \\
\text { Netherlands } \\
\text { and the UK }\end{array}$ & $\begin{array}{l}\text { Describing the } \\
\text { prevalence, } \\
\text { composition } \\
\text { and functioning } \\
\text { of transnational } \\
\text { families }\end{array}$ & $\begin{array}{l}\text { Households; } \\
\text { Current migrants } \\
\text { in the Netherlands } \\
\text { and the UK }\end{array}$ & $\begin{array}{l}\text { Household } \\
\text { data \& } \\
\text { biographic } \\
\text { data }\end{array}$ & $\begin{array}{l}\text { Ghana, the } \\
\text { Netherlands } \\
\text { and the UK }\end{array}$ & $\begin{array}{l}\text { Descriptive } \\
\text { statistics: } \\
\text { Frequency } \\
\text { tables, } \\
\text { Cross-tabs, } \\
\text { Kaplan Meier } \\
\text { estimates }\end{array}$ \\
\hline $\begin{array}{l}\text { 5. Relational } \\
\text { trajectories } \\
\text { and living } \\
\text { arrangements } \\
\text { among } \\
\text { Ghanaians }\end{array}$ & $\begin{array}{l}\text { Exploring } \\
\text { relational } \\
\text { trajectories of } \\
\text { migrants and } \\
\text { non-migrants in } \\
\text { young adulthood }\end{array}$ & $\begin{array}{l}\text { Current migrants, } \\
\text { returnees, and non- } \\
\text { migrants between } \\
21 \text { and } 35\end{array}$ & $\begin{array}{l}\text { Biographic } \\
\text { data }\end{array}$ & $\begin{array}{l}\text { Ghana, the } \\
\text { Netherlands } \\
\text { and the UK }\end{array}$ & $\begin{array}{l}\text { Sequence } \\
\text { analyses, } \\
\text { Optimal } \\
\text { matching, } \\
\text { Multinomial } \\
\text { regression }\end{array}$ \\
\hline $\begin{array}{l}\text { 6. Transnational } \\
\text { marriages and } \\
\text { reunification }\end{array}$ & $\begin{array}{l}\text { Investigating } \\
\text { the probability } \\
\text { of reunification } \\
\text { in the receiving } \\
\text { country for } \\
\text { LATAB-couples }\end{array}$ & $\begin{array}{l}\text { Transnational } \\
\text { couples between } \\
\text { Ghana, the } \\
\text { Netherlands and } \\
\text { the UK }\end{array}$ & $\begin{array}{l}\text { Biographic } \\
\text { data }\end{array}$ & $\begin{array}{l}\text { the } \\
\text { Netherlands } \\
\text { and the UK }\end{array}$ & $\begin{array}{l}\text { Kaplan Meier } \\
\text { estimates, } \\
\text { Event history } \\
\text { analysis }\end{array}$ \\
\hline $\begin{array}{l}\text { 7. Does } \\
\text { international } \\
\text { migration lead } \\
\text { to divorce? }\end{array}$ & $\begin{array}{l}\text { Examining } \\
\text { the role of } \\
\text { migration on } \\
\text { the probability } \\
\text { of divorce } \\
\text { for Ghanaian } \\
\text { couples }\end{array}$ & $\begin{array}{l}\text { Couples: 1) } \\
\text { without migration } \\
\text { experience, 2) for } \\
\text { which only the } \\
\text { husband migrated, } \\
\text { 3) for which only the } \\
\text { wife migrated, 4) for } \\
\text { which both spouses } \\
\text { migrated, but the } \\
\text { husband preceded } \\
\text { the wife, and 5) } \\
\text { for which both } \\
\text { spouses migrated } \\
\text { simultaneously. }\end{array}$ & $\begin{array}{l}\text { Biographic } \\
\text { data }\end{array}$ & $\begin{array}{l}\text { Ghana, the } \\
\text { Netherlands } \\
\text { and the UK }\end{array}$ & $\begin{array}{l}\text { Kaplan Meier } \\
\text { estimates, } \\
\text { Event history } \\
\text { analysis }\end{array}$ \\
\hline
\end{tabular}




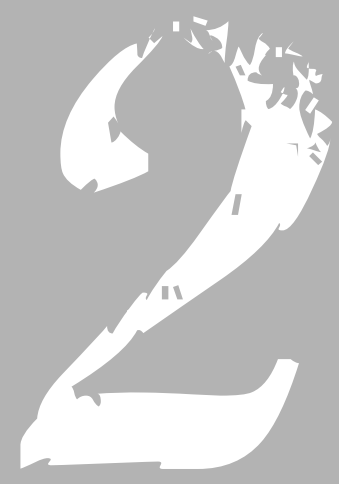

MIGRATION

AND THE FAMILY:

AN OVERVIEW OF

PREVIOUS STUDIES 


\subsection{Intraductian}

This chapter presents an overview of the research on family life and migration with a particular focus on couple relationships and from various disciplines. Different bodies of literature have all shed light on transnational families, albeit from different angles, but they have remained largely unconnected (see also Kraler et al., 2011; Wingens et al., 2011). In this overview, I bring together these scholarly works, revealing how they contribute to our understanding of the functioning of transnational families.

A transnational perspective has been prominent in the study of migration and family life. I elaborate on this perspective in Section 2.2 of this chapter by first presenting a brief overview of the 'transnational turn' in migration studies and how, from this turn, a rich body of literature emerged on transnational families. I further demonstrate the main merits of using a transnational lens for studying the way families are shaped and function across borders.

In Section 2.3, I identify a number of important areas of research on family life and migration that are relevant to this thesis. First, I examine the literature on forms of family life, presenting previous works on how families become transnational and how they continue to function despite the geographical distance. Second, I present works that have scrutinised the various ways couples' relationships influence, and are influenced by, migration. Here, I also discuss the literature that pertains to couples who experience tensions as a consequence of migration and how this can be related to divorce. Third, I demonstrate the main works that have emphasised how gender norms and roles can change in response to migration.

In Section 2.4, I discuss the life course approach. This approach has been somewhat rarely applied in studies on migration, which is to a large extent related to the lack of appropriate datasets that would allow for analysing migration and family through a life course approach. I explain how this approach can advance our understanding of transnational family life by capturing how transnational family life changes over time.

Because they do not operate in a vacuum, I present background information about the policy contexts in which families operate in Section 2.5. I illuminate the main findings from scholarly works that use legal and policy analyses to understand the role of migration policies on family migration. 


\subsection{A transnatianal perspective}

The transnational turn in migration studies, which emerged during the 1990s, helped to recognise the connections between migrants and their family members back home. A transnational lens on family life is therefore particularly useful when considering that the lives of these transnational families take place between two or more countries. The following sections elaborate on this transnational turn, and the subsequent development of the field of transnational family studies.

The transnational turn in migration studies

Conceptualising migration as transnational came as a response to research on international migration that studied the impact on receiving and sending countries separately. Broadly speaking, migration studies in the 1970 s and 1980 s concentrated either on immigrant assimilation into the receiving countries or on the impact of migration on sending countries (Glick Schiller, Basch \& Blanc-Szanton, 1992; Mazzucato, Van Dijk, Horst \& De Vries, 2004). Scholars narrowly studied migration from the perspective of the nation-state, which has been referred to as 'methodological nationalism' (Wimmer \& Glick Schiller, 2002). As such, ideas about the nation-state shaped the way scientific endeavours were carried out, creating blindfolds that kept researchers from capturing processes that take place beyond the boundaries of the nation-state.

Scholars in the 1990s recognised the ineffectiveness of a narrow approach to migration. They acknowledged that migrant lives do not take place neatly within the boundaries of a nation-state (Dahinden, 2009; Faist, 2000; Glick Schiller, Basch \& Blanc Szanton, 1995; Guarnizo, Sánchez \& Roach, 1999; Mazzucato et al., 2004). On the contrary, one of the key contributions of transnationalism scholars was the recognition that migrants' lives are lived between the sending and receiving countries. Glick Schiller et al. (1995), who were among the first to theorise about transnationalism, defined transnational migration as "the process by which immigrants forge and sustain simultaneous multi-stranded relations that link together their societies of origin and settlement." (p. 48). Additionally, transnationalism scholars asserted that migration does not consist of one or a few distinct moves, but rather that migration is ongoing and continuous (Basch et al., 1994).

Although many welcomed the conceptualisation of migration as transnational, some criticism was also noted. Three main critiques stand out. First, numerous scholars argued for narrowing the concept of transnationalism because of the non-discriminatory nature of the concept. As Portes, Guarnizo and Landolt stated, "If all or most things that immigrants do are defined as 'transnationalism', then none is because the term becomes synonymous with the total set of experiences of this population" (1999, p. 219). They 
proposed to instead concentrate on sustained economic and political activities. Others have discussed the economic, political and sociocultural relationships of migrants across borders, thus distinguishing between the degrees of institutionalisation, frequency, intensity and scope of transnational activities (e.g., Guarnizo et al., 1999; Itzigsohn, Dore Cabral, Hernandez Medina \& Vazquez, 1999; Levitt, 2001a; Riccio, 2001). What these conceptualisations share is the acknowledgement that migrants are connected with their sending countries and vice versa. Additionally, these variations reveal the heterogeneity of transnational practices and stress the importance of investigating the different forms transnationalism takes.

The second point of critique is that transnationalism is nothing new and that crossborder connections are inherent in international migration (e.g., Kivisto, 2001; Waldinger \& Fitzgerald, 2004). However, as Foner (1997) demonstrated, taking a historical perspective, although the phenomenon of transnational migration is not new, recent times have changed the way migrants interact in spite of the geographical distance through technological innovations, such as communication technologies, money transfer technologies, and travel opportunities. Consequently, the intensity and frequency of the flows of people, goods, money, and ideas have shifted and migrants' social, cultural and economic lives are no longer bounded by their nation-states (Foner, 1997; Levitt \& Jaworksy, 2007; Mazzucato, 2008a; Mazzucato et al., 2004; Vertovec, 2001, 2004a).

Third, although these transnationalism scholars set out to question the role of the nation-state, Waldinger and Fitzgerald (2004) claimed that migrants should only be studied at the level of the nation-state. Yet transnationalism scholars have not denied the important role that states play in migrants' lives. Rather, they have recognised that states shape the way migrants are able to engage in transnational activities (e.g., Glick Schiller \& Levitt, 2006; Mazzucato et al., 2004). In addition to discussing the role of nation-states, these scholars argue that migrants also engage in activities, whether economic, social, or religious, that transcend the nation-state. By means of technological communication innovations, migrants can be simultaneously engaged in more than one country (Levitt \& Glick Schiller, 2004; Mazzucato, 2008a).

Another important contribution from the field of transnationalism is that a transnational perspective includes those who do not move (Levitt, 2001a, 2001b; Levitt $\&$ Glick Schiller, 2004). Those who are left-behind play a fundamental role in the lives of migrants, and vice versa (e.g., Grillo \& Mazzucato, 2008; Levitt, 2001a, 2001b; Toyota, Yeoh \& Nguyen, 2007; Vertovec, 2004a). Non-migrants are also part of transnational practices, and their lives are often shaped by the social and financial remittances they receive from migrants abroad (Hirsch, 2003; Levitt, 2001a). At the same time, it has also been documented how social and financial remittances flow from those who are left-behind to their migrant family members or friends (e.g., Mazzucato, 2011). Left- 
behinds can influence migration or reunification decision-making processes (Baizan et al., 2014; Beauchemin et al., 2014; Willis \& Yeoh, 2000), and they are jointly responsible for managing transnational households (Kanaiaupuni, 2000). Being part of a transnational family can also imply being dependent on childcare in the sending country (so-called 'transnational child care arrangements'; for an overview of literature on this topic, see e.g., Mazzucato \& Schans, 2011). Thus, to understand international migration and its consequences for family life, non-migrants need to be included in the analysis. The inclusion of non-migrants is especially relevant in relation to transnational families because family members who stayed behind are part and parcel of transnational relationships. I will elaborate on this in the following section.

\section{A transnational lens for studying families across borders}

Initially, studies on transnationalism paid only limited attention to family life, instead mainly focusing on the political and economic activities that migrants engaged in, which connected their countries of origin with where they resided (Al-Ali, Black \& Koser, 2001; Guarnizo et al., 1999; Itzigsohn et al., 1999; Portes et al., 1999; Vertovec, 1999). Yet one of the key processes that appear beyond the confines of the nation-state is transnational family life. Transnationalism scholars became increasingly interested in the particularities of transnational family life in the early 2000 s (Bryceson \& Vuorela, 2002; Mazzucato, 2013), and since then, scholars from different disciplinary backgrounds have recognised the variety of ways family and kinship ties are affected by international migration (Kraler et al., 2011). With their compilation of studies on transnational families, Bryceson and Vuorela (2002) were among the first to concentrate on the relationship between migration and family life while explicitly adopting a transnational lens. They defined transnational families that negotiate family arrangements across geographic and cultural spaces. Despite the spatial distance, these families maintain "a sense of collective welfare and unity, namely 'familyhood', even across national borders" (Bryceson \& Vuorela, 2002, p. 3).

Transnational families are not a new phenomenon either. However, new technologies have changed the intensity and frequency of how families who are living apart together across borders interact (Foner, 1997; Mazzucato et al., 2004; Vertovec, 2001). Yet not all families have equal access to communication technologies, or to information and resources (Bryceson \& Vuorela, 2002; Mahler, 2001). International migration can bring to fore major differences between migrants and non-migrants, and transnational families must conciliate the inequality between family members. For example, modern travel and communication technologies are not equally accessible (Mahler, 2001). Migrants often have more means of communication available compared with non-migrants, which creates inequalities between migrants and their non-migrant relatives. Moreover, these 
inequalities are gendered: because most migrants are male, and migrants have more access to communicating technologies, men benefit more than women (Mahler, 2001). Because families can be composed of both migrant and non-migrant members, it is essential to realise these inequalities within families that relate to access, mobility, and power.

The recent attention to transnational families has advanced our knowledge concerning the implications of international migration for family life. Transnational family studies have paid particular attention to the everyday lived experiences of migrants and their families and to how geographical distance affects familial and kinship relations. These studies have generally placed relational dynamics and their emotional implications at the forefront. In particular, scholars have investigated transnational motherhood (e.g., Bernhard, Landolt \& Goldring, 2009; Coe, 2011; Dreby, 2006; Fresnoza-Flot, 2009; Horton, 2009; Parreñas, 2001, 2005; Schmalzbauer, 2004), transnational fatherhood (e.g., Dreby, 2006; Pribilsky, 2004; Waters, 2010), the experiences of left-behind children (e.g., Dreby, 2007; Graham \& Jordan, 2011; Heymann et al., 2009; Jordan \& Graham, 2012; Parreñas, 2005; Schmalzbauer, 2004; Suárez-Orozco, Todorova \& Louie, 2002), and transnational couples (e.g., Charsley, 2005; Gallo, 2006; George, 2000; Hirsch, 2003; Manuh, 1999; Pribilsky, 2004).

Emerging studies in the field of transnationalism have also recognised that transnational care-giving arrangements encompass more than either biological parent and that other kin often play important caregiver roles (Bernardi, 2011; Evergeti \& Ryan, 2011; Mazzucato \& Schans, 2011). A burgeoning body of literature has also addressed wider transnational processes of care, emphasising that transnational care can also be multidirectional and take place between generations (Baldassar \& Merla, 2014). However, these works have typically focused on parent-child separation, whereas this thesis concentrates on geographical separation between spouses. A discussion of these studies is therefore beyond the scope of this thesis.

\subsection{Migratian d family life}

The previous section discussed in general how a transnational approach has been applied to the study of migration and particularly to the study of migrant families. In this section, I first focus on the forms that family life can take. Next, I focus on families who live apart together across borders. Subsequently, I discuss the relationship between migration and gender, after which I elaborate on the specific implications of international migration for couple relationships. 


\section{Forms of family life across borders}

There is little quantitative information about the forms of transnational family life owing to the lack of adequate data for such analyses. Much research is based on qualitative in-depth case studies that investigate the particularities of transnational families within one specific sending country and one receiving country (Levitt, 2001b). These studies, however, 'sample on the dependent variable' (Vertovec, 2004b, p. 3), and as such, they are not able to assess the prevalence of transnational families or the relative importance of the different forms of these families (Levitt, 2001b; Mazzucato \& Schans, 2011; Portes, 2001). Many large-scale quantitative surveys typically do not have transnational family life as their focus, and as such, the categories for capturing these types of families are often missing. Yet once we are able to categorise these families, we can then study how migration impacts the different forms they can take.

Couple relationships in the context of migration can take many different forms. Migration can result in couples living in non-residential relationships, and this type of relationship has been predominantly studied among Western populations in Western countries. In Western countries, consensual unions are replacing marriages and newer forms, such as LAT, are emerging, challenging the assumption that partnership and co-residence coincide (Duncan \& Phillips, 2011; Latten \& Mulder, 2013; Levin, 2004; Roseneil, 2006). The variety of conjugal processes poses researchers with new challenges in assessing the social significance of these phenomena and how and when they occur across the life course (Antoine et al., 2009). However, rather than simply documenting union formation, it is important to also capture additional information, such as the exact type of union (e.g., married or unmarried) and the type of living arrangement (e.g., living together, living apart together, or living apart together across borders).

Where demographers have generally studied LAT relationships in Western contexts, anthropologists have concentrated on non-residential relationships in African contexts. In many African countries, spouses do not necessarily co-reside, typically with each spouse living with his or her family (Clark, 1994; Coe, 2011; Fortes, 1950; Manuh, 1999; Oppong, 1970). Yet these two types of research have remained largely separate from each other. They each provide different explanations for this type of relationship: although non-residential relationships in Africa are generally attributed to kinship ties (Fortes, 1950; Meekers, 1992; Oppong, 1983), explanations in Western countries generally suggest individualisation and partners' desires to be autonomous. The distinction between LAT relationships that exist because of economic constraints and those that exist because both partners choose this particular lifestyle (Levin, 2004) is one that has received limited attention regarding LAT relationships in Africa. Origincontext familial norms might encourage transnational relationships among migrants from countries where multilocal residence is a socially accepted and widespread practice 
among couples. However, motivations to live apart together across borders might also align with motivations found among LAT couples in Western contexts. The following section will elaborate on couples who live apart together across borders.

\section{Living apart together across borders}

Both anthropological studies on African multilocal families and sociological and demographic studies on Western non-residential relationships focus primarily on relationships that occur within nation-state borders. This means that they have largely overlooked living apart together across borders relationships, with some exceptions.

One of the first scholars to explicitly consider how families have become transnational and continue to exist in spite of the geographical distance was HongdagneuSotelo (1994) in her study on Mexican undocumented migrants in the US Attempting to explain the diversity of forms that families can take in the context of migration, she delineated three main types of migration: 1) independent, which captures single men or women who migrate independently into the US; 2) family unit, which refers to families who migrate together; and 3) family stage, which captures families in which the husband migrated first and his wife and children migrated in a subsequent stage. With these typologies, Hondagneu-Sotelo showed how Mexican families are created and recreated across borders, and her study emphasised the importance of considering who migrates when.

Migration to the US is extremely common among Mexicans, and living apart together between Mexico and the US is an essential part of the lives of many Mexican couples. Gupta (2002) studied spousal separation as a consequence of migration among Mexican couples. Typically, the husband migrates to the US, leaving his wife and (often young) children behind. They eventually reunify by either the husband's returning to Mexico or reunification in the US. Gupta concluded that "international migration is an ordinary way of life. Migrants cope with their bi-national living arrangement and accept it as a normal part of their married lives" (2002, p. v).

Developments in the field of ICTs have facilitated family life while living apart together across borders. Emerging studies have demonstrated how relationships are maintained from a distance, and the impact ICTs has on these relationships (Dekker \& Engbersen, 2014; Madianou, 2012; Panagakos \& Horst, 2006; Wilding, 2006). For example, Madianou (2012) has shown that for Filipino mothers in the UK, the Internet has enabled and empowered their mothering at a distance. However, despite the proliferation of advanced communication technologies through the Internet, such as online video calls, many migrants still depend on international telephone calls, which have become increasingly cheaper over the years (Horst, 2006; Vertovec, 2004c). Especially when considering the unequal access to Internet, in particular in many developing regions, 
such as in large parts of Africa (Dekker \& Engbersen, 2014; Wilding, 2006), telephone calls typically remain the most important way for families to stay in touch with their geographically separated kin or friends.

Recently, researchers began to question the characteristics that are associated with couples who live transnationally versus couples who reunify. A number of scholars argued that family reunification is not necessarily available for or desired by all migrants (Baizan et al., 2014; Beauchemin et al., 2014; Bledsoe \& Sow, 2011; Landolt \& Wei Da, 2005). Baizan et al. (2014) studied the reunification behaviour of Senegalese migrants in Europe and showed that LATAB relationships are common among Senegalese male migrants in Europe. Beauchemin et al. (2014) similarly demonstrated that LATAB relationships are frequent: Senegalese, Congolese and Ghanaian male migrants in Europe are more likely to stay geographically separated than to reunify with their partners.

Van der Klis and Mulder (2008) also demonstrated the role of gender ideologies in their study on commuter partnerships in the Netherlands, which included LATAB couples. Concentrating on more highly educated couples, often with higher-level occupations, they found that couples' gender ideologies strongly influenced their choices for, and the outcomes of, commuter partnerships. In egalitarian relationships, both spouses benefit from a non-residential living arrangement, but this was not the case for couples with non-symmetrical gender beliefs, whereby one spouse (typically the wife) suffered from this living arrangement. Their study emphasises the importance of including a gender perspective while studying the forms and implications of transnational relationships. The following sections discuss the relationship between gender and migration, and the implications of migration for transnational couples, in greater detail.

\section{Gender Q migration}

The increasing feminisation of migration as an important feature of contemporary migration should be taken into account in studies of transnational family life (e.g., Anarfi et al, 2003; Donato, Trent, Gabaccia \& Leinonen, 2011; Martin, 2004; Unites Nations, 2006; Zlotnik, 2003). Although women have accounted for nearly half of the international migrants since the 1960s, figures on the number of female migrants have been increasing since then (Zlotnik, 2003); there is, however, variation by regional and national origin (Donato et al., 2011). In addition to the increase in the number of female migrants worldwide, changing patterns have also been documented, with more women migrating alone (UN, 2006).

The relationship between gender and migration has been the subject of various studies (e.g., Donato, Gabaccia, Holdaway, Manalansan \& Pessar, 2006; Hondagneu- 
Sotelo, 1994, 1999; Itzigsohn \& Giorguli-Saucedo, 2005; Pessar \& Mahler, 2003).' Hondagneu-Sotelo (1994) was one of the first to stress the importance of studying how gender relations affect the migration processes of both men and women. In their introduction of a special issue (Gender and Migration Revisited, International Migration Review), Donato et al. (2006) reviewed the ways in which gender has been analysed in migration studies, historically as well as today. They demonstrated that many current migration scholars have begun to view migration as a gendered phenomenon, moving beyond studying sex as a dichotomous variable and stressing the importance of including "more nuanced and culturally situated understandings of the ways in which migration affects gender dynamics" (Donato et al., 2006, p. 20).

Studies on migration and gender have revealed how men and women relate differently to their migration experiences (e.g., Anarfi, Kwankye, Ofoso-Mensah \& Tiemoko, 2003; Hondagneu-Sotelo, 1999; Wong, 2006), that men and women may have different motivations to migrate (e.g., Kanaiaupuni, 1999; Massey, Fischer \& Capoferro, 2006), how men and women respond differently to the contexts on arrival (e.g., Boyd \& Grieco, 2003; Feliciano, 2008), and how transnational practices take different forms for men and women (e.g., Goldring, 2001; Itzigsohn \& Giorguli-Saucedo, 2005). Typically, studies have reported that the implications for family life when women migrate are particularly problematic, especially concerning transnational motherhood (Bernhard et al., 2009; Coe, 2011; Dreby, 2006; Fresnoza-Flot, 2009; Horton, 2009; Parreñas, 2001, 2005). Schmalzbauer (2004), examining the caretaking structures of transnational families, concentrated on migrant women from Honduras. These women remit to secure the livelihoods of their families back home, but they must simultaneously cope with both the emotional and the physical stress of being geographically separated from their families.

Although men's experiences have been studied to a lesser extent, scholars have also shown the emotional difficulties they experience while separated from their families (Poeze \& Mazzucato, 2012; Pribilsky, 2004). Many studies have shown how dominant gender ideologies expect mothers to continue to provide emotional care from a distance, whereas fathers are expected to provide financially (see also Carling, Menjívar \& Schmalzbauer, 2012). Additionally, gendered expectations about motherhood result in mothers' making greater sacrifices to care from a distance (Abrego, 2009). However, this does not mean that mothers do not remit while they are abroad, or that fathers are emotionally unaffected by parent-child separation. Moreover, gendered norms about family life are different across the world, resulting in different experiences of family separation (e.g., Coe, 2011; Mazzucato, 2013).

1 A complete review of the literature on gender and migration is beyond the scope of this chapter, but a number of comprehensive overview articles have been written; see, e.g., Donato et al. (2006), Curran, Shafer, Donato and Garip (2006), Jolly and Reeves (2005), Kofman, Phizacklea, Raghuram and Sales (2000), and Pessar and Mahler (2003). 
Yet it is equally important to consider that gender does not always affect migration experiences in the sense that certain behaviours or attitudes of migrant men and women are similar. Gambaurd (2000) argued that in the case of female Sri Lankan migrants, although women became the breadwinners, gender relations remained largely unchanged. González-Ferrer (2011) studied the reunification behaviour of migrants in Spain, and she found no differences between the probability of reunification between migrant men and women. ${ }^{2}$ As Suárez-Orozco and Qin (2006) argued, the finding that outcomes are similar for men and women is just as interesting as finding differences between the sexes, and "research should always consider whether, and if so, how, when, and why it makes a difference being (...) female rather than male" (p. 184).

\section{Implications of migration for couples' relationships}

Family life and migration are both inevitably linked to gender norms and roles. Gender norms can affect the migration experience for both sexes, and these experiences can be empowering, disempowering, or both (Gallo, 2006; Hirsch, 2003; Zontini, 2010; Wong, 2006). In her study on Moroccan and Filipino women in Italy and Spain, Zontini (2010) demonstrated how, for many of her interviewees, migration presented a way to escape restrictive family relationships and dominant gender ideologies. At the same time, these women were often confronted with a gendered labour market in the receiving country, which restricted their work opportunities to mainly domestic work (in spite of their previous educational attainments). Gallo showed how Malayan men in Italy feel disempowered as they struggle with their masculine identities as a result of "downward mobility and being "dependent husbands" (2006, p. 368).

Although gender norms influence the experience of migration, gender roles between partners are also subject to change as a consequence of migration. Gender roles are renegotiated within couples, and transnational relationships involve a good deal of deliberation (either implicit or explicit) about role divisions between partners, about the distribution of responsibilities for work and care tasks, and about decisions about who will and who will not migrate (Levitt \& Glick Schiller, 2004). Female migration often changes the household's main wage earner; by becoming breadwinners through migration, women often change prevailing gender roles (Zontini, 2010). Gallo (2006), looking at migration from South India to Italy, examined the consequences of pioneering women's migration and the subsequent role changes for their husbands, which affected their masculine identities. The vulnerability of men in transnational marriages, according to Gallo, comes from the impossibility of not being able to live conjugal life according to

2 Differences were found in the pace of reunification: women reunify sooner with their husbands in the receiving country than men reunify with their wives (González-Ferrer, 2011). 
'traditional' standards but also from balancing newfound ideals of the 'modern husband' with personal ideas about being the main breadwinner.

Many scholars have noted the strained spousal relationships that are attributable to the migration experience as a consequence of changed gender roles (e.g., Fouron \& Glick Schiller, 2001; Mahler, 2001; Manuh, 1999; Pribilsky, 2004). Charsley (2005), for example, studied 'unhappy husbands', referring to Pakistani migrant husbands who join their wives in the UK and who, as a consequence of their migration, face enormous social and cultural difficulties relating to the restructuring of gender relations. Similarly, George (2000) demonstrated how the new earning power of Indian women in the US challenged existing the gender norms that prevailed in Kerala, India. Consequently, when their husbands migrated to the US, their relationships became strained.

Looking at joint spousal migration, Manuh (2001) reported about the challenges that Ghanaian couples faced while in Toronto. Manuh documented that gender relations became stressed because remittances became an area in which the struggle for control over spouses' earnings took place, with couples disagreeing about the purposes for which their resources were going to be used. Unlike in Ghana, resources were pooled in Canada (for example through joint bank accounts). This is very different from the way couples organise their household finances in Chana, where men and women tend to keep their incomes divided (Manuh, 1999, 2001; Wong, 2006). Combining the resources resulted in marital tensions for a number of reasons: women could no longer independently make decisions regarding their incomes, and men could no longer assume their role as the main wage earners (Wong, 2006). Consequently, pressures arose about financial obligations towards the respective lineages.

Waters' (2010) study stressed another example of how migration transformed gender relationships. She examined men who were left-behind with their children in Canada by their wives who returned to Asia, where they could pursue their careers. These moves transformed not only the couples' relationships but the men themselves as well: from 'distant father to lone parent', and from 'businessmen to homemakers'. Her findings emphasised the transformative nature of transnationalism and how transnational lifestyles can be a strategic choice for 'privileged' migrants.

Hirsch (2003) demonstrated that Mexican women could experience greater freedom from constraining gender norms once they had migrated to the US because their migration provided them with greater leverage in their marriages: "En el Norte la mujer manda" (in the [United States] the woman gives the orders) (p. 180). This proverb refers to certain women in the US, and it is closely intertwined with the migration and socioeconomic statuses of these women. Yet these positive outcomes of migration do not necessarily coincide with happier marriages. As Hirsch showed, those who did experience greater freedom were also those who were more likely to experience marital instability. 
Migration and living transnationally does not necessarily result in negative outcomes for marriages. Hyman, Guruge and Mason (2008) found, in their study on Ethiopian migrants in Toronto, that although migration for some resulted in marital instability, for others, migration resulted in increased autonomy for women, mutual dependence, joint decision-making and more intimacy. Pribilsky's (2004) anthropological study of Ecuadorian transnational couples in which the husband had migrated to the US found that although these couples faced tensions at first, they indicated that after time, migration had actually improved their relationships. Although it is commonly assumed that male migration to the US leads to separation and divorce, these couples eventually managed to live 'side-by-side' across borders while maintaining their transnational households.

Migration can also place considerable stress on relationships such that they result in divorce. Yet the role of international migration on the probability of divorce has received relatively little attention (Glick, 2010). A number of studies have provided insights into the effect of migration on relationships, although they generally concentrate on internal migration and often in Western contexts. For example, migration is considered a stressful life event that increases the risk of union dissolution (Boyle, Kulu, Cooke, Gayle \& Mulder, 2008). This stress of migration is further exacerbated by the fact that, according to the traditional models used in these studies, migration typically benefits the man's career (Boyle, Cooke, Halfacree \& Smith, 1999; Cooke, 2003; Boyle, Cooke, Halfacree \& Smith, 2001).

There are some exceptions among the studies that have investigated the role of international migration on divorce. Frank and Wildsmith (2005) examined Mexican transnational couples in which the men migrated to the US and the women stayed behind in Mexico. They found that men with extensive migration experience to the US have higher risks for union dissolution. Interestingly, this implies that migration as such is not a sufficient causal factor in explaining union dissolution. Only extensive periods in the US increase the risk of union dissolution among these Mexican couples; couples with low levels of migration experience are no different from couples without that experience.

Hill (2004) and Landale and Ogena (1995) examined the stability of unions for migrant women, and Landale and Ogena (1995) found that migration leads to marital instability for Puerto Rican women. Additionally, low social integration among recent migrants (weak social ties) further enhanced the risk for divorce. Hill (2004) examined female migrants from Central America and Mexico to the US She asserted that marriage and divorce decisions are temporally linked to migration: single women are more likely to migrate during the first years of marriage compared with before, and the likelihood of a first divorce after migration is greater than at any other time. Hill further demonstrated that some women divorce directly after migration, possibly because of 
the stress of the migration or because the migration was used as a means to escape the social stigmatisation that is associated with divorce. The duration of a stay abroad also increases the risk of divorce. As Hill hypothesised, the risk of divorce for women with longer stays in the US is elevated as a consequence of their exposure to different normative values concerning divorce in the US

Finally, it is also important to note that whereas marriages can become stressed because of migration, migration can also be a response to stressed marriages. That is, migration might reflect a desire to escape (restrictive) marriages (Hirsch, 2003; Jolly \& Reeves, 2005; Manuh, 1999; Zontini, 2010). In some cases, migration can be a means to effectively divorce, in response to a local context in which divorce is not possible (Constable, 2003). Migration can also serve as a way to (re)attain marriage. This could be a response of being considered 'unmarriageable' at origin, which can be the case for, e.g., divorcees, or older women (Constable, 2003). Additionally, attaining marriages through migration can be a response to the limited possibilities of acquiring legal status otherwise. Fleischer (2008), for example, conducted research on Cameroonian male migrants' marriage strategies in Germany, where these limited possibilities have resulted in Cameroonian men's relying on marriage to German citizens as the only means to obtain residency.

\subsection{A life caurse appraach}

Scholars have acknowledged the importance of studying transitions and experiences in the life course, not only as separate events but also as sequences of events that evolve over life (Elder et al., 2003; Geist \& McManus, 2008; Giele \& Elder, 1998; Kulu \& Milewski, 2007; Wingens et al., 2011). This means recognising that events in the life course are linked, are influenced by significant others, and take place in specific historical, geographical and institutional contexts (Billari \& Piccarreta, 2005; Giele \& Elder, 1998). A life course approach thus takes both the individual's agency and the structural situation over time into account (Elder, 1985; Giele \& Elder, 1998; Kohli, 2007; Mayer \& Tuma, 1990; Mayer, 2000; Wingens et al., 2011).

Although the life course approach has seldom been applied in quantitative migration studies (Elder et al., 2003; Wingens et al., 2011), a number of studies over recent decades have attempted to disentangle the interrelatedness of migration with family life events from a life course perspective (e.g., Clark \& Withers, 2007; Geist \& McManus, 2008; Gupta, 2002; Kulu \& Milewski, 2007; Kulu \& González-Ferrer, 2014; Wingens et al., 2011). Much of this literature concentrates on the lives of immigrants. 
These studies generally concentrate on comparing family patterns between immigrant families and native populations (mostly US-born) (Glick, 2010).

Applying a life course approach means recognising that migration is an event that occurs at a particular moment in time at a particular moment in a migrant's life. The timing of migration can affect the timing and occurrence of other events over the course of one's life, and vice versa (e.g., Kulu \& Milewski, 2007; Mulder \& Wagner, 1998; Wingens et al., 2011). Although most migration studies focus on one specific point in time, such as the situation of migrants after migration, migration decisions are often closely related to decisions in other life domains, such as marriage or divorce. Furthermore, migrants not only face historical time but do so in different geographical settings (Wingens et al., 2011). In the following section, I will discuss how the aspects of the sending and receiving country contexts can affect transnational family life.

\subsection{Sending and receiving cauntry cantexts}

This section discusses the importance of considering the sending country context by understanding familial norms and practices and the receiving country context by concentrating on the role of policies.

\section{The sending country context}

Transnationalism scholars have emphasised the importance of studying the sending country context to understand the impact of family separation through migration. The familial context, referring to the prevailing norms, practices and traditions about family life must be recognised to evaluate the costs and benefits of living transnationally (Mazzucato \& Schans, 2011; Zentgraf \& Chinchilla, 2012). For example, Hirsch (2003) looked at non-migrants by studying the sending country context. She showed that migration from Mexico to the US is not the only reason for changes in gender ideologies; younger generations of Mexicans, both men and women, have developed new perspectives on gender roles and relationships. This result emphasised that processes of change can occur simultaneously and that changes in gender ideologies are not necessarily related to the migration experience.

Similarly, Coe (2011) presented a detailed ethnographic account of Ghanaian families who had experienced either internal or international migration and families who had experienced both; commonalities exist because both types of migration can result in families that live geographically separated. In some sense, international migration is an extension of previous experience with internal migration, yet the crossing of national 
borders brings with it new challenges for family life. The physical distance and the difficulties that come with international border crossings make it problematic to visit back and forth, as would be the case with internal migration. Consequently, Coe found that social and familial relations became strained.

Bledsoe (2006) combined anthropological insights with demographic data to explain the apparent paradox of high-fertility Gambians in low-fertility Spain. She asserted that this is the result of Gambians' balancing their kinship practices within the boundaries of family reunification policies. These studies illustrate that adopting a transnational lens and incorporating the sending country context in our analyses is crucial for understanding migration processes. In the following section, I will discuss in greater detail how families, and couples in particular, are affected by international migration.

\section{The receiving country context}

As argued in the previous sections, transnational ties between migrants and their families back home have always existed (Foner, 1997; Waldinger \& Fitzgerald, 2004). However, a number of factors have contributed to the proliferation of families who live geographically dispersed across countries (Bernhard et al., 2009; Coe, 2014; Sassen, 2003). Migration and immigration policies, in both receiving and sending countries, are partly responsible for the dispersal of families (Bernhard et al., 2009). Although technologies have generally eased the way money and goods are sent abroad, and travelling has become easier and cheaper, there still remain large differences between people concerning their mobility (Bledsoe \& Sow, 2008).

Nation-states can have a constraining role in the lives of migrants by imposing strict visa requirements for entry. In contrast with citizens who live within the Schengen Area, who are allowed to travel without restrictions, visas, or passports, or tourists from North America, who are able to enter Europe with a passport, migrants from third-world countries, those with "high migration potential", are subjected to extensive scrutiny and are often required to have expensive visas to enter Europe (Bledsoe \& Sow, 2008, p. 5), and these visa regulations make it difficult if not impossible for family members to travel. Moreover, family reunification policies affect the possibility for family members to live together in the receiving countries. As such, these migration policies affect the spread of transnational families.

Most countries have recognized family reunification as a basic right for migrants, with the exception of most Middle East and Gulf States, where possibilities for family reunification or marriage migration are virtually absent (Ghosh, 2009; Fargues, 2011). These countries typically forbid family reunion for lower skilled migrants, such as domestic or construction workers (Lori, 2012). In response to these limited opportunities 
for family reunion, the proportion of female migrants has significantly decreased compared to countries in Western Europe or the United States (Kofman \& Raghuram, 2015). Considering transnational family, it is important to take these different migration regimes into account, since legal reunification is not possible for migrants everywhere. Nonetheless, migrants also reunify outside the legal framework (Baizan et al., 2014; Beauchemin et al., 2014; González-Ferrer, 2011). Additionally, if legal reunification is possible, migrants can also be constrained by socio-economic circumstances or strict conditions that are tied to family reunification polices. This means that transnational family life can be a preferred choice for some, and for others a consequence of socioeconomic or legal circumstances.

Nation-states can further affect migrants' lives by issuing, or not, residence permits or citizenship. Having undocumented status or a temporary status such as a visa not only restricts the opportunity for family reunification but also limits the possibilities for transnational practices such as visiting or remitting money or goods (Freznoza-Flot, 2009; Poeze \& Mazzucato, 2012).3 Maintaining familial relationships back home can be eased through visits, but undocumented migrants often cannot travel. Additionally, undocumented migrants are more often poorer, which further problematizes these transnational family relationships (Dito et al., in press). Making frequent long-distance phone calls can be very expensive, and sending remittances can be extremely difficult, or even impossible, which can stress these long-distance familial relationships (FresnozaFlot, 2009; Poeze \& Mazzucato, 2012).

As Kraler (2010) and Kraler et al. (2011) showed, many policies are socially selective in that they differ by socio-economic factors, such as income, education and occupational status. Considering family reunification, Kraler (2010) described how meeting these conditions vary according to the following factors: income criteria require regular full-time employment, which is generally not available for all migrants. Providing the necessary documents can also be difficult for migrants from less developed countries, "with inefficient and cumbersome bureaucracies and inadequate registration and documentation systems [that] often fail to provide the documents" (Kraler, 2010, p. 55). In particular, Kraler identified pre-entry language tests as most selective in that not only do they only advantage better-educated migrants but they are also less available, especially in developing countries. Moreover, it is more difficult for women to meet the official requirements for reunification because they more often work in part-time jobs with lower wages (Kraler et al., 2011; Van Walsum, 2006; Sørensen \& Guarnizo, 2007).

Despite these legal procedures that to a large extent regulate transnational family

3 Throughout the thesis, 'undocumented' migrants refer to migrants who have arrived or stayed irregularly in the receiving country. 
life, it is important to realise that migration takes place in various ways. A distinction can be made between families that have practiced de jure reunification, i.e., they reunified via legal reunification policies, and families that have practiced de facto reunification (Beauchemin et al., 2014). This latter category can be divided into legal de facto reunification, when family members who wish to reunite enter the country on a legal basis but not via reunification policies, and illegal de facto reunification, when family members enter the country without the appropriate documents (Beauchemin et al., 2014).

Considering the role of legal status in the transnational lives of migrants, there is limited quantitative evidence of the influence of migrants' legal statuses on family life. Having said this, more attention is being paid to this issue among quantitative scholars today (Baizan et al., 2014; Beauchemin et al., 2014; Bernhard et al., 2009; Bledsoe \& Sow, 2011; Dito et al., in press; González-Ferrer, 2011; Haagsman \& Mazzucato, 2014). With migration and family reunification policies becoming more restrictive, it is more pressing to investigate the consequences of these policies for migrants and their family lives. Although it is very difficult to pinpoint the exact role of policies on people's lives, this dissertation provides an exploration of how migrants' legal status is associated with transnational family life.

\subsection{Cancluding remarks}

Various scholarly works have been discussed in this chapter, presenting different perspectives from which transnational family can be studied. In the empirical chapters of this thesis, I attempt to advance on these works by bringing together these different perspectives. In line with transnational family studies, I apply a transnational lens in attempting to understand how Ghanaian families form, transform or dissolve in the context of migration. This will be done in three ways. First, I consider the context in both the sending and the receiving countries. Second, I include those who do not migrate in two ways: a) by comparing migrants with non-migrants because conclusive assessment of the role of international migration compared with non-migrants in the sending country is required to determine whether differences between migrants and the native population result from migration or whether wider societal processes in both contexts are responsible and b) by considering family members who are left-behind but who are part and parcel of the transnational family. Third, I explain the findings in the different empirical chapters by incorporating insights into the familial norms from the sending country. 
In line with scholars on gender and migration, I assess the role of gender in migration's role in family life. I demonstrate how gender relations can alter in the context of migration and how this might affect the stability of couples' relationships. This means considering how couples experience migration, i.e., who migrates when, and situating the findings within a broader understanding of local gender roles and norms. Finally, families are studied from a life course perspective, which means taking into account when migration takes place in the course of life. Additionally, taking note of not only the historical context, I also consider the receiving country context, in particular, the policy context. 


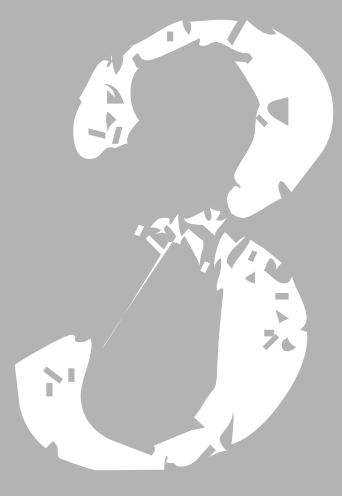

DATA \& METHODS 


\section{I Intraductian}

The analyses in this thesis have been obtained by employing a unique dataset: the MAFEGhana survey. This survey is part of the wider MAFE project: a large international, interuniversity program funded within the EU 7th framework. The data were collected in three migrant-sending countries (Ghana, Congo, and Senegal) and six receiving countries (Italy, France, Spain, Belgium, the UK, and the Netherlands). Underlying this project is the recognition that migration is not unidirectional, that is, not from Africa to Europe but between Africa and Europe (Beauchemin, 2012).' Therefore, data were collected in both sending and receiving countries, capturing current, return, and circular migrations. The MAFE project consists of both household and biographical surveys in each of the countries. The MAFE-Ghana survey took place in Ghana, the Netherlands and the UK (for more information, see the project's website: mafeproject.site.ined.fr/en).

Before elaborating on the MAFE-Ghana data, this section begins with an introduction to the larger MAFE project to present its ambitions and origins. Next, I describe the MAFE-Ghana survey by presenting the main features of the survey, the sampling and data collection procedures for both the household and the biographical survey, the content of the two questionnaires and the main definitions employed in the survey. This is followed by my reflections on the data and methods used. Lastly, I present a brief summary of the main analytical methods employed.

\subsection{The MaFE praject}

One of the aims for the MAFE project was to address a number of the limitations that are present in most datasets related to international migration. First, cross-country comparisons are rarely possible with current international migration datasets. For one, most countries employ different definitions of migrants. For example, the criterion of being foreign-born, which is used in the USA, Canada, and Australia, is different from the criterion of being a foreign national, which is used in many European countries (Castles \& Miller, 2009). ${ }^{2}$ Similarly, definitions of international migration differ between countries,

I I do not consider migration to be unidirectional, and I therefore decided to refer to sending and receiving countries rather than 'origin and destination' or 'home and host'. These latter two categorisations have more fixed connotations, assuming permanence (destination countries) or implying that people cannot feel at home in the receiving country (host countries). Instead, I feel that referring to sending and receiving countries resonates the most with a notion that considers migration between Africa and Europe.

2 On the one hand, the category foreign-born captures individuals who have become naturalised but excludes secondgeneration migrants. On the other hand, the category foreign nationals includes second-generation migrants if they keep their parent's nationality but excludes all migrants who are naturalised. 
with some countries assigning duration (a period of stay of at least 6 months) or taking into account the declared intention to migrate, whereas others consider any crossborder movement to be international migration (Twum-Baah, 2005). Second, the various datasets reveal significant numerical discrepancies. For example, in the year 2000, estimates ranged from 25,000 to 40,000 Chanaians in the Netherlands (Mazzucato et al, 2004; Jones-Bos, 2005). Third, the analysis of hidden populations is extremely difficult, which is why undocumented migrants are often not taken into account in spite of their numerical importance. Reliable statistics on the number of undocumented Ghanaians in the Netherlands are scarce, but previous studies have indicated that the number is substantial. As Mazzucato (2008a) showed, official estimates in the Netherlands in 2000 stated that there were approximately 17,000 Ghanaian migrants, but in the same year, 40,000 Ghanaians registered to vote at their embassy for the presidential elections that year. Finally, current international migration datasets generally do not account for return migration (Beauchemin, 2012).

The MAFE project followed a comprehensive approach whereby migration is captured from various perspectives. Previous comparable projects inspired the MAFE research design (see Beauchemin, 2012). In addition to European and African surveys that concentrated on life event histories, two large-scale projects influenced the MAFE project: the Mexican Migration Project, a longitudinal dataset on migration between Mexico and the US (Massey, 1987) and the Push and Pull Factors of International Migration project, carried out by Eurostat and the Netherlands Interdisciplinary Demographic Institute (NIDI), which collected data on migration from sub-Saharan Africa and Mediterranean countries to the European Union (Groenewold \& Bilsborrow, 2008).

\subsection{The MagE-Ghana swren}

This thesis uses the MAFE-Ghana data. The aim was to collect a transnational sample of individuals from Chana, the Netherlands and the UK and a representative sample of households in Accra and Kumasi, Ghana. In line with the overall MAFE project, three characteristics define the MAFE-Chana project (see also Beauchemin, 2012): 1) retrospective data, 2) that consists of transnational samples that are 3) comparable across countries and between migrants, non-migrants and returnees and collected at different sending and receiving countries. The following section elaborates on these main features. Subsequently, I discuss the different sampling and data collection strategies that were applied in Chana and in the European countries, and I present the key elements of the two questionnaires that were employed: a household questionnaire and an individual 
biographic questionnaire. Finally, I present some key definitions of terms that are employed in this thesis.

\section{Main features of the MAFE-Ghana project}

Three main features characterise the MAFE-Ghana project (see also Beauchemin, 2012). First, a strong feature of the MAFE-Ghana data is that it captured retrospective data. Longitudinal data allow for exploring the time-dependent aspects of the relationship between migrant and various family behaviours (see e.g., Anderson, 2004; Boyle et al., 2008; Flowerdew \& Al-Hamad, 2004; Frank \& Wildsmith, 2005; Glick, 2010; Kulu \& Milewski, 2007; Mazzucato \& Schans, 2011; Smith, 2004). The retrospective information was captured through life event history questionnaires, and information regarding life histories was gathered on a yearly basis.

Second, the MAFE-Ghana project acknowledged the transnational nature of migration in its research design. To overcome the limitation of sampling in either the sending or the receiving country, the MAFE-Ghana survey was carried out at both locations to gather transnational samples. Because international migration implies the crossing of international borders, a multi-country design is suggested as the best option to investigate the causes and consequences of migration (Beauchemin \& González-Ferrer, 2011).

Finally, the multi-country design allowed for information to be collected on current migrants in the receiving countries (the Netherlands and the UK) and on non-migrants, returnees and migrant spouses in the sending country (Ghana). Identical questions were asked of the migrants, non-migrants and returnees to facilitate the comparison between these different individuals. Additionally, the MAFE-Ghana survey collected data in two European countries to assess the role of the receiving country context. ${ }^{3}$ The UK and the Netherlands were chosen as the receiving contexts. Ghanaian migration to the UK has a longer history compared with Ghanaian migration to the Netherlands. The UK represents an 'old host country', with colonial ties to Ghana, whereas the Netherlands represents a 'new host country' (Beauchemin, 2012).

\section{Sampling and data collection strategies in Ghana}

Stratified random samples of households and individuals were drawn from two selected areas. Although the Ghana sample would ideally have been nationally representative, time and budgetary restrictions made this option not feasible. Instead, Accra (the capital) and Kumasi, two of the largest metropolitan areas in Ghana - both of which have high levels of out-migration (Anarfi et al., 2003) - were selected. In total, 17\% of the Ghanaian

\footnotetext{
3 An ideal transnational sample would have included all of the receiving countries per African origin country. However, financial and practical reasons made it necessary to reduce the number of receiving countries to two or three (Beauchemin, 2012). Similarly, the MAFE survey was not a matched survey (such as that discussed in Mazzucato (2008b) for example).
} 
population lived in either of these areas in 2002 (Beauchemin, 2012). The Ghanaian Population and Housing Census (2000) was used as a sampling frame from which 80 enumeration areas were randomly selected using a probability-proportional-to-size (PPS) approach: 20 in Kumasi and 60 in Accra (Schoumaker \& Diagne, 2010). ${ }^{4}$ In the next stage, all households in the selected enumeration areas were listed and classified as: 1) a household without migrants, 2) a household with migrants, or 3) households with return migrants; the combination of 2 and 3 was also possible. Then, 24 households were randomly selected in each enumeration area, with 8 households for each of the three types of households. As a result of these selection procedures, migrant households were oversampled.

All households, with or without migrants, were eligible for the household survey. The household questionnaire was administered to the household head, or, if the head was not present, another knowledgeable household member. This implies that the information from the household questionnaire about the other household members and household contacts was obtained though a proxy respondent.

In Ghana, 1,920 households were selected, and 1,246 were successfully interviewed (for additional details, see Schoumaker \& Diagne, 2010); this gave a response rate of 65\% (Schoumaker, Mezger, Razafindratsima \& Bringé, 2013a). ${ }^{5}$ The Centre for Migration Studies (CMS) of the University of Ghana coordinated the data collection in Ghana. The activities in Ghana, ranging from sampling to data cleaning, took place from May 2009 to April 2010; the data collection covered the period from July 2009 to January 2010. Table 3.1 shows the number of households surveyed in Ghana, distinguishing between different types of households.

For the biographic survey that was collected in Ghana, individuals were selected from these households. Respondents were eligible if they were aged between 25 and 75 years and born in Ghana. Three groups were selected for these individual questionnaires: 1) all return migrants, ${ }^{6}$ 2) all spouses of migrants and 3) one randomly selected other eligible household member. In total, 1,490 individuals were selected, and 1,243 complete biographic questionnaires containing retrospective life histories were collected, which gave a good response rate of $83 \%$ (Schoumaker et al., 2013a). For an overview of these three types of individuals, see Table 3.1 below.

\footnotetext{
4 Probability proportional to size (PPS) is a sampling technique aimed at obtaining a representative sample whereby the probability of selecting a sampling unit (in this case, the enumeration areas) is proportional to the size of its population. PPS is particularly useful when sampling units show great variation in size because it ensures that those in larger sampling units have the same probability of being sampled as those in smaller sampling units (Skinner, 2006).

5 The non-response rate varied between Accra and Kumasi, with Kumasi having considerably higher response rates. For a detailed overview of the response rates for both the household and individual surveys in Ghana, see Schoumaker et al., 2013a, p. 11.

$6 \mathrm{~A}$ return migrant was defined as someone who had left Ghana for the first time at age 18 or over and who had stayed abroad for at least one year.
} 


\section{Table 3.1. Overview of the households and individuals surveyed in Ghana}

\begin{tabular}{|lr} 
Household survey & \\
Non-migrant households & 449 \\
Households with returnees & 346 \\
Households with current migrants & 675 \\
Households with returnees and current migrants & 224 \\
Total number of households & $\mathbf{1 , 2 4 6}$ \\
Individual survey & 840 \\
$\quad$ Non-migrants & 84 \\
Spouses of migrants & 319 \\
$\quad$ Returnees & $\mathbf{1 , 2 4 3}$ \\
Total number of individuals &
\end{tabular}

Source: MAFE-Ghana survey, 2009-2010

\section{Sampling and data collection strategies in Europe}

Current migrants in their receiving countries are known to be difficult to sample, and this pertains in particular to undocumented migrants. Their irregular status makes them difficult to reach, and moreover, their status also often comes with a life full of uncertainty and risk because they constantly fear deportation. This puts them in a vulnerable position, which typically makes them reluctant to participate in survey research, especially when sensitive questions are asked such as regarding their undocumented status, as was the case in the MAFE-Ghana survey. Consequently, no suitable sampling frames are available, and quota sampling was thus used. With small samples, this approach gives good results compared with random selection (Beauchemin, 2012; Schoumaker \& Diagne, 2010).

In the Netherlands, specific regions were selected: Amsterdam, The Hague and Almere.' Although no specific region was selected in the UK, the surveys were mostly conducted in the London metropolitan area. In both countries, these areas represented locations where most Chanaian migrants lived (Beauchemin, 2012). Quotas were set by age and gender in both countries, aiming at $50 \%$ males and $50 \%$ females in the total sample and $25 \%$ for each of the following age groups: $25-34,34-44,44-54$, and $55+$. In the UK, the place of residence was used as well. To improve randomness, respondents were recruited at different locations, such as at the metro station, at churches, or in other public places. Additionally, interviewers from different socio-demographic backgrounds were hired, including male and female interviewers, Ghanaians and non-Ghanaians, and interviewers with different educational and occupational backgrounds; this variation

7 In total, $75 \%$ of the Chanaian population in the Netherlands lives in these cities, with Amsterdam (10,224 registered) being the most popular followed by The Hague (1,983 registered) and Almere $(1,100$ registered) (Centraal Bureau voor de Statistiek (CBS), 2009a). 
increased the likelihood of reaching respondents with different socio-demographic characteristics. In line with the individual questionnaires that were administered in Ghana, eligibility was based on age (between 25 and 75 years) and nativity (respondents had to be born in Ghana). Furthermore, migrants' had to be at least 18 at the time of departure from Chana, ${ }^{8}$ and they had to be in the receiving country for at least one year.

The aim was to sample at least 150 respondents in each receiving country. In the UK, this sample size objective was met $(n=149)$. In the Netherlands, an additional 123 respondents were surveyed $(n=273)$. The findings in the empirical chapters either controlled for survey country or the results were presented for these two countries separately to compensate for the unequal sample size between the UK and the Netherlands. In total, 422 questionnaires were distributed among Chanaian migrants in Europe. Table 3.2 shows the distribution of respondents according to the quotas by age and sex. In both countries, older respondents (aged $55^{+}$) proved the most difficult to survey. In the last phase, interviewers were instructed to focus explicitly on these responders, resulting in 23 and 37 completed interviews with these older respondents, respectively.

Table 3.2. Overview of the individuals surveyed in Europe according to the quotas and by survey country

\begin{tabular}{|c|c|c|c|c|c|c|}
\hline & \multicolumn{2}{|c|}{ Quota } & \multicolumn{2}{|c|}{ MAFE-Ghana: UK } & \multicolumn{2}{|c|}{ MAFE-Ghana: NL } \\
\hline & $n$ & $\%$ & $n$ & $\%$ & $n$ & $\%$ \\
\hline \multicolumn{7}{|l|}{ Gender } \\
\hline Males & 75 & 50 & 77 & 52 & 145 & 53 \\
\hline Females & 75 & 50 & 72 & 48 & 128 & 47 \\
\hline \multicolumn{7}{|l|}{ Age group } \\
\hline $25-34$ & 38 & 25 & 52 & 35 & 84 & 31 \\
\hline $35-44$ & 37 & 25 & 40 & 27 & 87 & 32 \\
\hline $45-54$ & 38 & 25 & 34 & 23 & 65 & 24 \\
\hline $55^{+}$ & 37 & 25 & 23 & 15 & 37 & 14 \\
\hline Total & 150 & 100 & 149 & 100 & 273 & 100 \\
\hline
\end{tabular}

Source: MAFE-Ghana survey, population in the UK and the Netherlands, 2009-2010

8 This criterion was introduced to avoid 'passive migrants', such as children who had migrated with one or both parents or whose parents had decided about their migration (Beauchemin, 2012). 


\section{My involvement in the data collection in the Netherlands}

I was involved in the data collection, data entry and data cleaning in the Netherlands. Valentina Mazzucato and Djamila Schans had already started with the MAFE project in the Netherlands, and I joined the Dutch team in September 2009. To familiarise myself with all stages of the survey, I participated in interviewing, proofreading, and data entry. As daily co-supervisor of the fieldwork, I was responsible for keeping in touch with the interviewers during the fieldwork, checking the quality of the questionnaires, monitoring the progress of the survey, and data cleaning, which took place in consultation with the Institute National D'Études Démographiques (INED).

I accompanied a number of interviewers to administer questionnaires in the Bijlmer neighbourhood of Amsterdam, to gain some first-hand experience with the survey. It was insightful to experience how the respondents were willing to share so many details of their lives. I also admired their patience given that interviews lasted between 1 and 1.5 hours. During the data collection phase, I constantly maintained close contact with the interviewers and proofreaders. I distributed the questionnaires to all interviewers, and the interviewers would return the filled-in questionnaires to me, after which I first reviewed every questionnaire for mistakes or misunderstandings. If necessary, I would contact the interviewers for clarification; otherwise I forwarded the questionnaires to the proofreaders. To ensure the quality of the questionnaires, the proofreaders would carry out an in-depth reading of them, identifying and correcting - if possible — all errors and consulting the interviewers where needed. The proofreaders also ensured that the questionnaires were ready for data entry, meaning that they were consistent, legible, and without empty boxes. Special codes were assigned for different types of missing information. When in doubt, the proofreaders would contact me for advice. As an additional quality check, I proofread 1 out of 10 questionnaires that were returned to me by the proofreaders.

During the data collection, I compiled weekly reports that recorded not only the total number of administered questionnaires but also the numbers by quota. This way, I closely monitored whether all target groups were equally met. Some quotas were more difficult to fill. In particular, older respondents, aged over 55, were hard to find because most Ghanaians in the Netherlands are younger (CBS, 2009b). Moreover, this group of respondents proved more difficult to persuade, and remembering all past events was more challenging and therefore more tiring for them. To be able to adequately represent older Ghanaians, interviewers were asked to put extra effort into targeting this group, which resulted in 37 completed interviews with this age group in the Netherlands. During and after the data collection, a number of data entry agents were appointed to enter the questionnaires into a software program that was specifically designed for the MAFE project. During this phase, I resolved issues with glitches in the data entry program and liaised with the lead institution responsible for data entry, INED. 


\section{Two questionnaires}

Two separate questionnaires were conducted: a household questionnaire and a biographic questionnaire. ${ }^{9}$ Both the household and the biographic questionnaires were administered in the sending countries, but only the biographic questionnaires were administered in the receiving countries. The household questionnaire collected socio-demographic information about all household members and their migratory contacts at the time of the survey. The household head provided the information, or an eligible household member in case the household head was absent. Four thematic modules can be identified: 1) identification of household members, 2) migrants' experiences, 3) transfers received by the household, and 4) housing and assets of the household.

Module 1 collects socio-demographic information about all household members and about the household head's personal network. The household head provided the information collected in Module 2 about migrants' experiences. In contrast to the detailed questions asked in the individual questionnaire, the information gathered on migrants' experiences in the household questionnaire is less detailed, capturing only the dates of first and last departure, and if applicable, dates of return migration, the first and current receiving countries, and the motivation for the last migration. Additionally, Module 2 asked whether and to what extent the household had helped the migrants with their trips, financially or otherwise, how and how much the household is in contact with the migrant abroad, and the current legal status of the migrant. In Module 3, the household head reported on the remittances, both monetary and in-kind, that they had received from their migratory contact in the past 12 months. In Module 4, questions were asked about the household's dwelling and the equipment and assets that were available to the household. ${ }^{10}$

The biographic questionnaire covered 17 modules in total, shown in Table 3.3 below, which distinguished between modules that related directly to the migration experience and modules that captured the respondent's general socio-demographic information. The design of the biographic questionnaire allowed for capturing retrospective information. It was inspired by previous life event surveys that have been carried out in France and in Africa (see Antoine et al., 1999, cited in: Beauchemin, 2012). The questionnaire consisted of two parts: a questionnaire with open and closed questions for each thematic module and an 'ageven' grid," that is, a life history event calendar that corresponds to the questionnaire modules. A line in the 'ageven' grid corresponded to one year, and one column corresponded to a questionnaire module. The combination of these two tools

9 Questionnaires are available on the website of the MAFE project: http://www.mafeproject.com/.

10 Details about the definitions of a 'household', 'household members', 'migratory contacts', 'support and remittances' are presented in the sections below.

11 Ageven' is combination of 'age' and 'event'; see Antoine et al., 1999, cited in: Beauchemin, 2012. 
aided the respondent in recalling his or her life history, and it ensured that the historical information was collected in a consistent way on a year-by-year basis. It also helped the interviewer to check whether the information provided during the interview was coherent.

\section{Table 3.3. Modules in the biographic questionnaire}

\begin{tabular}{|c|c|}
\hline Type of information & Modules \\
\hline $\begin{array}{l}\text { Information regarding the migration } \\
\text { experience }\end{array}$ & $\begin{array}{l}\text { Relationships } \\
\text { Children } \\
\text { Housing history } \\
\text { Activity \& education history } \\
\text { Assets and businesses } \\
\text { International migration attempts } \\
\text { Long \& short stays outside the 'sending country' } \\
\text { Return trips to the 'sending country' of more than } 1 \text { year } \\
\text { Return trips to the 'sending country' of less than } 1 \text { year } \\
\text { International migration of family and friends } \\
\text { Business or leisure trips outside the 'sending country' } \\
\text { Citizenship } \\
\text { Asylum } \\
\text { Work permit } \\
\text { Residence permit } \\
\text { Remittances } \\
\text { Monetary transfers to associations }\end{array}$ \\
\hline
\end{tabular}

\section{Definitions}

The complexity of family life is difficult to capture, especially in the context of international migration. Therefore, various definitions of households, extended families and nuclear families have been used in this thesis to approximate the manifold ways family life can take form. It is important to note that, as was already discussed in Chapters 1 and 2, coresidence is not a necessity for familyhood given that families can live dispersed within countries or across borders. ${ }^{12}$ Additionally, families can be organised along matrilineal or patrilineal kinship ties or they can be characterised by co-residential or non-residential living arrangements.

The majority of this thesis is limited to analyses of couples, but the results of these analyses are embedded within a broader structure of family life. Chapter 4 addresses the prevalence and composition of transnational families. Using the perspective

\footnotetext{
12 For the Ghanaian case, see Chapter 4 for an overview of the literatue on non-residential living arrangements. For other African countries, see, e.g., Antoine et al., 2009; Findley, 1997; Fortes, 1950. For prevalence and acceptance of non-residential living arrangements in Western contexts, see, e.g., Duncan and Phillips, 2011; Latten and Mulder, 2013; Levin, 2004; Roseneil, 2006.
} 
of households in Ghana, we explore the extent to which Ghanaian households are transnational and to what extent and in which ways households keep in touch with their migratory contacts. Using the household survey allows us to look beyond the nuclear family and to examine the importance of the extended family (kin and non-kin) in maintaining transnational ties. Box 3.1 below reveals the definitions, used in Chapter 4 , of a household, its members, and its migratory contacts. Box 3.1 also explains the definitions of the support provided to the migrants and the remittances received from the migrants.

Chapter 4 also investigated the nuclear family using the biographic survey, and only fathers, mothers and their children under age 18 were included in this definition. These nuclear families can be spread across nation-state borders and are then referred to as transnational families. Families can be transnational in different ways, and to reflect this variety, we constructed a typology of transnational nuclear families. Box 3.2 explains how transnational families were defined and how the typology of transnational families was created.

In Chapters 5, 6 and 7, we concentrate on partnerships. Here, couples can live across nation-state borders as well, and they are referred to as transnational couples, or couples living apart together across borders. Additionally, the term transnational here does not refer to the nationalities of the spouses; it only refers to the countries where they live.

Different measures of international migration are used in this thesis. First, international migration can be defined according to the duration of time spent abroad. Consequently, the MAFE project distinguished between short stays, of less than a year, and long stays, of at least one year. When referring to migration in this thesis, we refer to migrants who have been abroad for a period of at least one year. Second, the motivation for a stay abroad can vary, and (short) trips abroad for the purpose of business or leisure are likely to be of a different nature than transit stays. The MAFE survey distinguishes between different types of short stays, 13 and transit stays were not part of the studies in this thesis.

\footnotetext{
13 The four types are: 1) holiday trips, family visits abroad or pilgrimages, 2) business trips or trips for educational purposes, 3) visits to a country where the respondent stopped over in order to migrate to another country, and 4) visits that had the intention of the traveller's settling.
} 


\section{Box 3.1. Defining household members, households' migratory contacts, support}

and remittances

In Chapter 4, we use various units of analysis to partially capture the complexity of family life: (1) households, including nuclear and extended family members, (2) households' migratory contacts, and (3) nuclear families.

First, employing the MAFE household surveys, we look at households, which include both nuclear family members and extended family members, who may be other relatives of the household head, relatives of other household members, or even non-kin. The MAFE project employed a classical definition of household as 'a group of individuals who live together and partly or totally share their resources to satisfy essential needs (housing, food)'. Other individuals are also included in the MAFE household survey: all children of the head, all individuals who live abroad but have a nuclear family relationship with one of the household members, and all other persons who live abroad who are relatives of the household head or his/her spouse (for more details concerning the household survey, see Beauchemin (in press)).

Second, to emphasise the distinction between household members in the strict sense and individuals who live outside of the household but who are included in the survey, we refer to those who live in the household as household members and to those who live outside of the household as migrants or migratory contacts. ${ }^{14}$ In the MAFE household surveys, families with migratory contacts are households that declared a migrant who lived abroad in at least one of the following categories: (1) the children/spouses of the head; (2) partner(s) of a member of the household; (3) relatives of the household head or of his/her partner who have been in regular contact with the household over the past 12 months.

Household heads were asked questions about each migratory contact separately. For each contact, they were asked whether the household had supported the migrant for his or her migration trip. The exact question wording was: Did he/she receive support from your household to finance or organise the migration? Response categories were (1) No, he/she managed to organise everything by himself/herself; (2) Yes, we helped with the preparations (e.g., to obtain the documents); (3) Yes, we helped to pay for the trip; (4) Yes, we supported him/her in another way. These four response categories were translated into a dichotomous variable, (o) No, migrant didn't receive support and (1) Yes, migrant received support.

With regard to remittances, the household head was asked Have you or anyone in your household received any monetary transfers from 'name migrant' over the last 12 months? with response categories: (0) No or (1) Yes.

Source: Box 1 is derived from Mazzucato, Schans, Caarls and Beauchemin (in press)

14 The three categories of individuals who are also captured in the household survey but who live outside of the household form quite a heterogeneous group. Some of these individuals live in Chana but outside of the household, and others live abroad. Although all children and partners are registered, regardless of whether they live elsewhere in Chana or abroad, other relatives of the household head or his/her spouse are only registered when they have been in close contact with the household on a regular basis. 


\section{Box 3.2. Explanation of the 'transnational nuclear family' typology}

Employing the MAFE biographical surveys, we focus on the nuclear family, which we define here as fathers, mothers and their children under age 18 . These nuclear families can be spread across borders and are in those cases referred to as transnational families. By this, we mean a group of persons who are nuclear family members and who live spread across nation-state borders. The term transnational does not refer to the nationality of these family members; it only refers to the countries where they live (for more details concerning the biographical surveys, see Beauchemin (in press)).

Some immigrants in Europe are neither married nor have children (or no children under 18), and as such, they are considered as having (1) 'no nuclear family'. All other migrants have a spouse and/or child under $18 .{ }^{15}$ When migrants have a spouse and/or children under 18 and they all lived together abroad at the time of the survey, without having lived apart, they are considered a (2) 'totally unified family'. This category captures both families that moved to Europe as a whole and families that were formed in Europe (i.e., migrants who got married and/or had children in their receiving countries). Migrants who lived together with their spouses and/or children at the time of the survey after having lived apart (transnationally) for at least one year are considered (3) 'reunified families'. When migrants had either their spouses or at least one of their children not living with them at the time of survey, or when migrants had none of their family members living with them at the time of survey, they were considered (4) 'transnational families'. A transnational family is thus defined not by the nationality of its members but by the fact that at least one of the nuclear family members lives in a different country from that of the migrant.

\subsection{Reflectians an the data}

The MAFE-Ghana survey is a unique dataset with detailed and longitudinal information about Ghanaian migration and family life. Detailed individual life event questionnaires were employed to capture a wealth of information on migration experiences, attempts, transits, transnational practices and legal status. Although these topics are not necessarily new, investigating them longitudinally is (Beauchemin, 2012). Despite the MAFE's innovative features, the research design and the sampling strategy also have some limitations. This section deliberates on these limitations and the consequences they might have for the analyses.

15 In cases of polygamy, we took into account only the most recent spouse. 


\section{Sampling design}

When surveying international migrants and their families, a number of sampling issues present themselves: 1) migrants, returnees and left-behinds are relatively less numerous than non-migrants, which required special efforts to sample sufficient numbers of respondents from these categories, 2) migrants, and especially undocumented migrants, can be vulnerable, and undocumented migrants in particular often constitute 'hidden populations' (Heckathorn, 1997), ${ }^{16}$ and 3 ) the absence of sampling frames in receiving countries makes it impossible to randomly select individual respondents (Schoumaker $\&$ Diagne, 2010). Multiple solutions have already been discussed above, such as the stratified sampling strategy to allow for oversampling of the main target groups, quota sampling, and the use of identical interview selection criteria to reduce the heterogeneity in the transnational samples (Beauchemin, 2012).

Another sampling issue is related to the difference in sampling frames. Whereas in Europe, sampling frames were absent and instead quota sampling was applied, stratified random sampling techniques were used for the sample in Ghana. This implies that comparisons between migrants surveyed in Europe and non-migrants, returnees and migrant spouses need to be treated with caution. At the same time, it is important to acknowledge that in the context of research on international migrants, especially when also considering undocumented migrants, having similar sampling frames in the sending and receiving countries is next to impossible. Despite the different sampling designs, pooling the data on non-migrants with migrants can still result in reasonable comparisons (see also, e.g., Beauchemin et al., 2014; González-Ferrer et al., 2014; Toma $\&$ Vause, 2014; Vickstrom, 2014). Some of these publications used weighted analyses to account for the different sampling designs, although Toma and Vause (2014) reported no difference between their weighted and unweighted models. We control for survey country to account for these different sampling probabilities for the analyses that require using both the Ghanaian and the European samples in this thesis.

In an ideal situation, the MAFE-Ghana survey would have been representative of the entire Ghanaian migration flow, capturing all relevant receiving countries for Ghanaians migrants. Evidently, this was financially and practically impossible (Beauchemin, 2012). Instead, two receiving countries were chosen. Although having included two receiving countries is a unique feature of the MAFE survey, it still remains a limited reflection of the variety of receiving countries of Ghanaian migrants. The MAFE project expressly aimed to study African-European migration flows; therefore, the sample is biased towards Europe, even though a significant number of Ghanaian migrants also reside in North America

16 The small size of the samples in the European countries prohibited the use of alternative sampling methods that are especially designed to reach these 'hidden populations' when no suitable sampling frame is available (for example, respondent driven sampling or intercept point surveys, see, e.g., Heckathorn, 1997; McKenzie \& Mistiaen, 2009). 
and Canada (Twum-Baah, 2005). Having said this, the assumption that Ghanaian migrants in the Netherlands and the UK are similar to migrants elsewhere will be difficult to maintain, which implies carefulness concerning the extent of our generalisations. The survey conducted in Ghana is also not nationally representative, but it is representative of the two major urban areas in Ghana. Most migrants came from these areas or had lived in these cities before migrating internationally, but not all of them.

Finally, we must be cautious when comparing current migrants with returnees. We captured information about previous migration experiences retrospectively for the sample of current migrants, who had been, for example, to the United States or other European countries prior to arriving in the Netherlands. However, the European sample remained biased compared with the sample of returnees, who had migrated to different countries (mostly African) in larger numbers. Returnees from African countries are likely to differ from returnees from European countries because African countries present a different receiving context than that of Europe or North America. The dynamics of the stay abroad could therefore differ because distances are shorter and travelling is cheaper, making back and forth visits more likely. Additionally, neighbouring countries are culturally more proximate to Ghana than to Western countries. To account for the difference between migrations to African versus Western countries, we controlled for the region of migration in Chapter 7 , in which we examined the probability of divorce in a model that was estimated for couples with migration experience only. In Chapter 5, we investigated the role of international migration on the relationship histories of Ghanaians in young adulthood, comparing migrants with non-migrants. Using multinomial models with a relatively small sample size denied the possibility of a model with migrants only, which would have allowed for examining any migration-specific characteristics of our respondents, such as country or region of migration. This means that we should consider the possibility that the role of international migration might be different for those with migration experience to African countries compared with those with migration experience to European countries.

\section{Selectivity}

Studying migration means that one must inevitably address biases. This has to do with the fact that migration decisions, or behaviour related to migration, go hand in hand with other individual or household decisions. For instance, decisions about education are related to receiving remittances, and the direction of causality is therefore unclear: are households with higher levels of education more likely to receive remittances, or do remittances result in households' being able to attain higher levels of education? Additionally, decisions concerning family formation are likely to be related to decisions about migration. As a consequence, the results from statistical analyses might be biased, 
and determining causality becomes difficult. Three major sources of bias can occur when analysing the effect of migration: 1) reverse causality, 2) selection bias, and 3) omitted variables (McKenzie \& Sasin, 2007).

In case of the first, reverse causality, wrong conclusions can be derived from relationships that are found. The problem of reverse causality emerges in Chapter 7 . When investigating the relationship between migration and divorce, divorce is considered the outcome variable. However, it could also be the case that divorce causes people to migrate (see, e.g., Hill, 2004). Additionally, both relationships might exist simultaneously. Nonetheless, this study concentrated on one part of the relationship between migration and divorce, investigating only migrations that took place before the divorce. If the reversed relationship exists as well, our results are likely to underestimate the role of migration.

The second and third sources of bias are related: selection bias and omitted variable bias. First, migrants may fundamentally differ from non-migrants: they 'self select' for migration, for example by being better educated or having a higher socioeconomic status (McKenzie \& Sasin, 2007). Second, because of the omission of relevant covariates because they were unmeasurable, unobservable, or simply not available - the issue of unobserved heterogeneity might have arisen. There is, unfortunately, no simple solution to control for unobserved heterogeneity (Singer \& Willett, 2003). Although a number of approaches have been discussed in the literature, ${ }^{17}$ their usefulness should be questioned: "There is, in general, no way to make reliable assumptions about what has not been observed" (Blossfeld, Golsch \& Rohwer, 2007, p. 247).

When estimating the effect of migration on the probability of divorce (Chapter 7), we compared non-migrants with migrants, but migrants might possess certain unobserved characteristics that make them more likely to divorce. If the risk of divorce were related to migrant selection, migrants would 'self-select' into stable unions or out of unstable unions. To establish whether this is the case would require information about the quality of the relationships (i.e., whether the unions are stable or not) of both migrants and nonmigrants, and this information was not available in the MAFE survey. Therefore, as with most studies, this study could not account for unobserved heterogeneity. If migrants are indeed more likely to divorce, our results likely overestimate the effect of migration on divorce. Despite this limitation, this study is among the few to compare the probability of divorce between migrants and non-migrants.

17 For discussions on unobserved heterogeneity in event history models, see chapter 10 in Blossfeld et al. (2007), chapter 9 in Box-Steffensmeier and Jones (2004), or chapter 12 in Singer and Willett (2003). 


\section{Limitations with retrospective surveys}

Retrospective event history surveys have numerous advantages, especially when compared with cross-sectional and panel data (see Blossfeld et al. (2007) for a discussion on the problems and limitations that occur with these latter two types of data). Retrospective surveys are well suited to covering whole life histories and are much cheaper than panel studies. Yet using retrospective data also has its disadvantages, and some of the main ones will be discussed here.

First, certain types of nonfactual questions are unsuited for retrospective surveys (Blossfeld et al., 2007). In particular, questions pertaining to attitudes and affective states, amongst others, will be difficult for respondents to recall; their answers about past feelings will undoubtedly be coloured by the events that occurred thereafter, rendering them unreliable. Consequently, it was not possible to obtain information about, for example, couples' perceived relationship quality or about their attitudes concerning gender norms. Instead, respondents' actual behaviours were used. One exception to this concerns information about respondents' financial situations. Collecting retrospective information about the exact objective income over the course of someone's life is very difficult, and the information is likely to be unreliable. Instead, this paper used a subjective question that was asked in addition: 'Would you say that during [this period] you had enough to live on? with three response options, $1=$ absolutely, $2=$ it depended, and $3=$ not at all. The respondent had to describe what $\mathrm{s} / \mathrm{he}$ was doing in a particular period, and his or her memory was aided through the use of the event history calendar. According to Razafindrakoto and Roubaud (2000, cited in: Beauchemin, 2012), this type of question is reliable at the time of the survey, although it is unclear how reliable the gathered data are retrospectively.

Recall problems might also arise when respondents are asked about events or behaviours in the past, especially when, as was the case with the MAFE survey, detailed questions are asked about entire life histories. Older respondents in particular are likely to have difficulties with remembering exact dates of events. The length of the questionnaire further complicated this given that the interviews lasted on average between 1 and 1.5 hours.

To minimise recall problems, the life history calendar served as an instrument to aid respondents' recall capabilities. Additionally, research that examined the exactness of retrospective data revealed that certain types of information are relatively accurate, such as information about partnerships histories, fertility, family characteristics, education and employment (Blossfeld et al., 2007). Because these are the topics that were investigated in the thesis, we feel confident about the completeness of the data. 


\section{Asymmetrical information for couples}

Finally, the biographic survey collects individual data, not data on the couple. Although each respondent provided detailed retrospective information concerning all modules (e.g., housing, occupational, and migration histories), such detailed information is not available for spouses. Respondents did provide information about current and past partners, but most of the information that is available refers to the situation at the time the marriage took place. Fortunately, through the questionnaire's network module, complete migration histories of each spouse were obtained.

Tabel 3.4. Sample description at the time of survey, household and biographic surveys

\begin{tabular}{|c|c|c|c|c|c|c|c|c|}
\hline & \multirow{2}{*}{\multicolumn{2}{|c|}{$\begin{array}{c}\text { Household surveya } \\
\text { Ghana }\end{array}$}} & \multicolumn{6}{|c|}{ Biographic survey: Survey country } \\
\hline & & & \multicolumn{2}{|c|}{ Ghana } & \multicolumn{2}{|c|}{ the Netherlands } & \multicolumn{2}{|c|}{ the UK } \\
\hline & $n$ & $\%$ & $n$ & $\%$ & $n$ & $\%$ & $n$ & $\%$ \\
\hline \multicolumn{9}{|l|}{ Migration status } \\
\hline Non migrant & 1,246 & 100.0 & 840 & 67.6 & - & - & - & - \\
\hline Spouse of migrant & - & - & 84 & 6.8 & - & - & - & - \\
\hline Returnee & - & - & 319 & 25.7 & - & - & - & - \\
\hline Current migrant & - & - & - & - & 273 & 100.0 & 149 & 100.0 \\
\hline \multicolumn{9}{|l|}{ Gender } \\
\hline Male & 746 & 59.9 & 495 & 39.8 & 145 & 53.1 & 77 & 51.7 \\
\hline Female & 499 & 40.1 & 748 & 60.2 & 128 & 46.9 & 72 & 48.3 \\
\hline Missing & 1 & 0.1 & - & - & - & - & - & - \\
\hline \multicolumn{9}{|l|}{ Level of education ${ }^{c}$} \\
\hline No schooling & 88 & 7.1 & 142 & 11.4 & 25 & 9.2 & 36 & 24.2 \\
\hline Primary & 102 & 8.2 & 125 & 10.1 & 20 & $7 \cdot 3$ & 11 & 7.4 \\
\hline Secondary & 712 & 57.1 & 733 & 59.0 & 121 & $44 \cdot 3$ & 31 & 20.8 \\
\hline Tertiary & 344 & 27.6 & 243 & 19.6 & 107 & 39.2 & ו & $47 \cdot 7$ \\
\hline \multicolumn{9}{|l|}{ Ethnicity } \\
\hline Akan & 671 & 53.9 & 658 & 52.94 & 218 & $79 \cdot 9$ & 74 & 49.7 \\
\hline Ga-adangwe & 252 & 20.2 & 238 & 19.15 & 18 & 6.6 & 20 & $13 \cdot 4$ \\
\hline Ewe & 171 & 13.7 & 143 & 11.5 & 20 & $7 \cdot 3$ & 17 & 11.4 \\
\hline Other & 95 & 7.6 & 143 & 11.5 & 17 & 6.2 & 38 & $25 \cdot 5$ \\
\hline Missing & 57 & 4.6 & 61 & 4.91 & - & - & - & - \\
\hline \multicolumn{9}{|l|}{ Religion } \\
\hline Catholic & 140 & 11.2 & 123 & 9.9 & 33 & 12.1 & 28 & 18.8 \\
\hline Protestant & 327 & 26.2 & 294 & 23.7 & 62 & 22.7 & 25 & 16.8 \\
\hline Charismatic & 495 & 39.7 & 535 & 43.0 & 139 & 50.9 & 56 & 37.6 \\
\hline Muslim & 154 & 12.4 & 149 & 12.0 & 6 & 2.2 & 3 & 2.0 \\
\hline Other & 129 & 10.4 & 114 & 9.2 & 24 & 8.8 & 34 & 22.8 \\
\hline Missing & 1 & 0.1 & 28 & 2.3 & 9 & 3.3 & 3 & 2.0 \\
\hline
\end{tabular}

Source: MAFE-Ghana biographic survey, 2009-2010.

Notes: ${ }^{a}$ Information presented refers to the household head; ${ }^{b}$ Information presented refers to the time of survey; ${ }^{c}$ Levels of education are derived from the number of years of education (range $0-23$ years): o no schooling, 1-10 some schooling/primary education, 11-15 secondary education, 16> university. 


\subsection{Saciademagraphic characteristics of the MASE-Ghana samples}

Table 3.4 presents an overview of the main socio-demographic characteristics according to each survey country for the household and biographic surveys. The household survey shows the socio-demographic information of the household head. More information about households and their migratory contacts is presented in Chapter 4.

Nearly $60 \%$ of the household heads who were surveyed were men. In general, these household heads had completed secondary-level education or higher at the time of survey. The majority of the respondents are from the Akan ethnic group, which is one of the largest ethnic groups in Ghana (Takyi \& Gyimah, 2007). Ghanaians are predominantly Christian, which is also reflected in our sample. Of the three Christian denominations, the Charismatic church was the most prominent in our sample.

For the biographic survey, the three datasets combined (Ghana, the Netherlands and the UK) yielded 1,665 respondents. Although the collected data are longitudinal, the figures presented below refer to the time of the survey. In Ghana, just over half of the respondents were female, whereas in the Netherlands and the UK, just over half of the respondents were male. The Ghanaians in our sample had mostly completed secondary education or more at the time of the survey. Strikingly, the education level distributions are rather skewed in the UK, where there are relatively more migrants who have had no schooling and relatively more who have had tertiary education. Most respondents were from the Akan ethnic group, and the share of Akans is particularly large in the Netherlands. Similar to the household survey, most respondents belong to one of the three Christian denominations, with the Charismatic church being the most popular.

\subsection{Data analysis}

The empirical chapters that follow are based on multiple data analysis techniques. The relationship between the different research questions and the chosen methods will be elaborated upon in the respective chapters. In this section, I will briefly and more generally describe the various methods used throughout this dissertation.

Chapter 4 presents a detailed description of transnational family life. The information is mainly obtained through standard descriptive statistics, such as frequency tables and cross-tabulations. These statistics provide a picture of transnational family life at certain moments in time, such as at the time of the survey or the time of the first or last 
departure. To further make use of the longitudinal nature of the data, we used survival analyses (see, e.g., Blossfeld et al., 2007; Box-Steffensmeier \& Jones, 2004; Singer \& Willett, 2003). Using the yearly information from the biographical surveys, we estimate the timing and occurrence of reunification with the respondent and his/her spouse or child, distinguishing between reunification in the sending country and in the receiving country.

In Chapter 5, we are interested in the relationship histories of migrants and nonmigrants aged between 21 and 35 over time. Sequence analysis is used because it is a method that allows for studying questions about the order in which certain events take place (Abbott \& Tsay, 2000; Robette \& Thibault, 2008). In addition, a sequence-based approach makes it possible to look at the timing and the ordering of events simultaneously, that is, to scrutinise the life course from a holistic perspective, to understand differences and changes in life courses (Billari \& Piccarreta, 2005; Brzinsky-Fay, Kohler \& Luniak, 2006; Elder, 1985; Kulu \& Milewski, 2007; Macmillan, 2005). We investigated trajectories over time, and additionally, we searched for the existence of patterns, and we also explore which factors influence these patterns (Billari \& Piccarreta, 2005). In Chapter 5, we explored the role of international migration by comparing the trajectories of migrants to those of non-migrants. To compare whether life course trajectories are similar or not, we applied optimal matching (OM) techniques (see, e.g., Abbott \& Tsay, 2000; AnyadikeDanes \& McVicar, 2010; Brzinsky-Fay \& Kohler, 2010; Robette \& Thibault, 2008). Through $\mathrm{OM}$, we identified clusters of similar trajectories, and these clusters were then used as a dependent variable in a multinomial logistic regression (Long \& Freese, 2006) to assess which factors were associated with which clusters.

In Chapter 6, we studied the reunification of couples who lived apart together across borders. In addition to using survival analyses to study the timing of reunification, we applied event history analysis (see, e.g., Blossfeld et al., 2007; Box-Steffensmeier \& Jones, 2004; Singer \& Willett, 2003), and our event of interest was whether the couple had reunified in the receiving country after having lived geographically separated for at least one year. Similarly, Chapter 7 used survival analysis to investigate the prevalence of divorce and subsequently, event history analysis to examine the probability of divorce. 

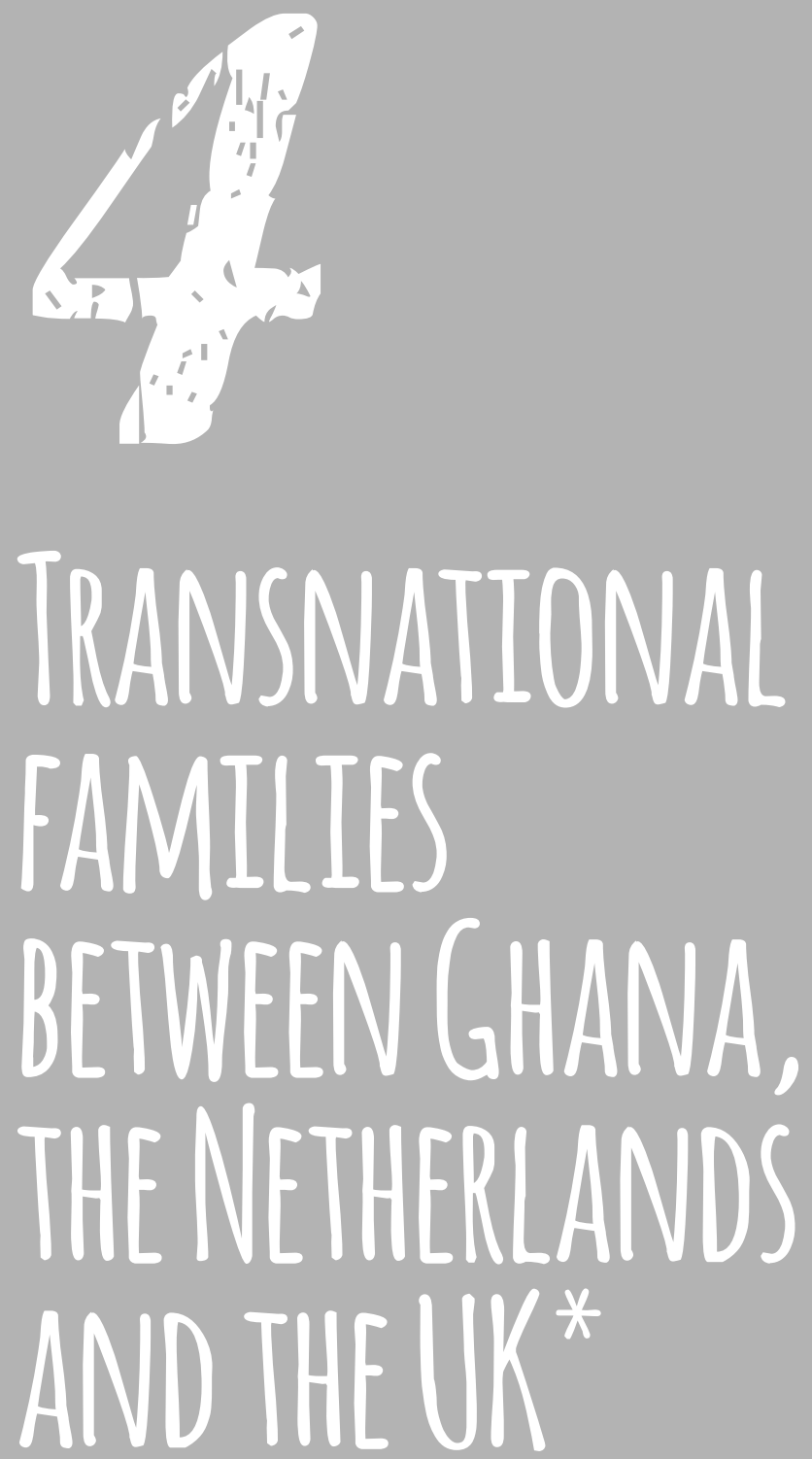

* A slightly different version of this chapter has been accepted for publication as: Caarls, K., Schans, D., Mazzucato, V., Quartey, P., and Tagoe, C.A. (in press). Transnational families between Ghana, the Netherlands and the UK. In: Beauchemin, C. (Ed.). Migration between Africa and Europe. Verlag Berlin Heidelberg, New York: Springer [accepted, under revision]. The sections, tables and figures are re-numbered in order to fit the thesis format. 


\subsection{Intraductian}

Both methodologically and theoretically, families are typically imagined as nuclear and co-residing (Mazzucato \& Schans, 2011). Consequently, transnational families, in which family members live geographically separated across nation-state borders, are regarded of as temporary, and family reunification in the receiving country is considered the desired outcome for these families (Landolt \& Da, 2005; Mazzucato \& Schans, 2011). However, because of a scarcity of quantitative evidence caused by the lack of academic and policy attention to this phenomenon, the exact prevalence and composition of transnational family arrangements is unknown, especially where sub-Saharan African families are concerned (Mazzucato \& Schans, 2011). Using the MAFE-Ghana data, the objective of this chapter is to provide information on transnational family life in the context of international migration between Ghana and Europe.

In Section 4.2 we discuss the literature on family systems in Chana, and the literature on transnational family life between Ghana and Europe with specific reference to the Netherlands and the UK. We identify prevailing Ghanaian family systems and the variety of living arrangements that exist. The importance of extended family relations is stressed, but also the prevalence of child fostering and multilocal residence between spouses. These family practices provide a contextual background to support the interpretation of the results of our analyses, as presented in the subsequent Sections $4.3,4.4$, and 4.5. Each of these sections focuses on a different element of family life in relation to international migration.

In Section 4.3 we examine the family arrangements of Ghanaian households and their relationships with migrants overseas. We show that households in Ghana are involved in multiple transnational relationships, with both nuclear and extended family members. We used the data from the household survey (see Chapter 3) to identify the prevailing family arrangements in the two Ghanaian urban areas that we surveyed, Accra and Kumasi, as well as the functioning of family life across borders. When examining family practices across borders, we notice the importance of remittances that are being sent to the households from migrants abroad, and interestingly, we also find evidence of reverse remittances, that is flows from household in Ghana to their migrants abroad.

In Section 4.4 we change our perspective from Ghana to Europe. Using the individual biographic survey (see Chapter 3 ) that was carried out among Ghanaian migrants currently living in the Netherlands and the UK, we examine how nuclear family life takes shape in the context of international migration. We find that transnational nuclear family life is a relatively common phenomenon amongst Ghanaian migrants in these two countries. Additionally, we show that different types of nuclear family arrangements prevail among these Chanaian migrants, and we distinguish between transnational families, unified 
families, and reunified families. We study to what extent migrants in these different types of nuclear family arrangements differ concerning several socio-demographic, socioeconomic and migration-related characteristics. The focus in this section is on nuclear family members, as these are mainly the people who are eligible for family reunification.

In Section 4.5, we delve further in the study of transnational families by first examining where nuclear family members are living at the time that a migrant's first departure to the Netherlands or the UK, and subsequently, whether those who did not migrate together as a family eventually reunified. We look at the reunification of spouses as well as that of children with their parents. Similarly to Section 4.4, we use the individual biographic survey. We find that family separation can be a long-lasting arrangement, if reunification occurs at all. An important element of our analysis is that we trace where reunification takes place. Previous studies on reunification generally focus on the receiving country side, yet the MAFE multi-sited dataset allows us to examine also where families reunify. Distinguishing between reunification in the sending and receiving country, we show that reunification is not limited to the migrant-receiving country, but that reunification to a large extent takes place at origin.

\subsection{Literature revieu ${ }^{l}$}

\subsubsection{Family Systems in Chana - the importance of the extended family}

Before presenting our findings it is important to understand the kinds of family systems that prevail in Ghana, how these are changing and the norms that guide familial relationships. These can be important elements in interpreting the findings that follow. In Ghana, as elsewhere in Africa, 'the family' extends beyond immediate nuclear members to include other relations to whom one has 'extensive reciprocal duties, obligations and responsibilities' (Nukunya, 1992, p. 47). These members include grandparents, uncles, aunts, nieces, nephews and cousins among others. Additionally, polygamous marriages in the form of a male with multiple spouses are socially accepted and comply with traditional customary law although they are officially illegal according to national state law. They are particularly found amongst rural inhabitants and the less educated and are more prevalent in the northern part of the country.

Linked to kinship, family descent systems in Ghana are patrilineal or matrilineal with members tracing their descent through the father or mother's lineage, respectively. The type of descent system one belongs to has implications for inheritance, responsibilities

1 This section has been revised with respect to the original publication 
within the family and relationships with its members. In patrilineal descent systems, the offspring, particularly the male children, are the direct beneficiaries while in a matrilineal situation, the nephew through a man's sister directly inherits from the man to the detriment of the man's own children.

The importance of the extended family system has been significantly affected by modern trends such as urbanization and technological development, though it continues to be important. The effects include a change in the family structure with a tendency towards nuclear family focus, a reduction in family size and the use of paid house helps instead of family members (Oppong, 1974; Ardayfio-Schandorf, 1994). Other functions of the family such as sanctions for socially deviant behaviours have been taken over by the state and other agencies, which have also lessened the influence of the extended family. An example is the Intestate Succession Law (PNDCL 111) of 1985, which gives inheritance rights to the nuclear family members and is designed to attenuate negative effects on the children of a deceased parent (Mensa-Bonsu \& Dowuona-Hammond, 1994).

In spite of all these changes, the extended family system in Ghana continues to play effective support roles on occasions such as a birth of a child, education of its members, marriage, and particularly in times of crisis such as ill-health and death. And importantly, in the context of this chapter, the extended family also plays a role in sponsoring foreign travels. Additionally, multilocal residence is still widely practiced, both in urban as well as in rural areas. According to the 2008 DHS survey, child fostering occurs almost equally between rural and urban areas (19 and 18 per cent, respectively), and non-residential marriages are even more frequent among urban households $(28$ per cent of married women have their husband staying elsewhere, compared to 22 per cent for rural households) (DHS, 2008, own calculations).

\subsubsection{Marital Relationships in Ghana}

The extended family role in the institution of marriage in Ghana cannot be overemphasized particularly because marriage is perceived to be between the two families of the couple involved. The extended family of the woman plays a key role in deciding whether to accept the offer of marriage made by the man. Furthermore the extended family mediates in marital problems and is usually resorted to rather than going through the official legal system. In recent times, however, the role of the extended family in finding a marriage partner has reduced. While in public discourse this reduced role has been said to contribute to an increase in divorce rates in Ghana, others argue that divorce has always been prevalent in Ghanaian society, especially among Akans (Bleek, 1987; Fortes, 1950; Takyi \& Gyimah, 2007) who comprise the largest ethnic group in Ghana (Ghana Statistical Service (GSS), 2012). 
According to some, matrilineal kinship ties influence the instability of marriages, as matrilineal ties provide greater independence for women (Takyi \& Broughton, 2006; Takyi \& Gyimah, 2007). Matrilineal (Akan) women are believed to enjoy greater autonomy than their patrilineal counterparts. Greater autonomy for women in turn is often associated to marital instability, as these women are more able to establish independent households. Several studies point to the fact that the independence of Chanaian women is decreasing due to processes of modernity (Boni, 2001). According to Oppong, Okali and Houghton (1975), modern developments of the twentieth century have enhanced the position of the men and decreased women's independence and power. Yet matrilineal (Akan) women are still believed to enjoy greater autonomy than their patrilineal counterparts (Boni, 2001).

Regardless of the lineage ties, the extended family plays are large role in couples' relationships. A marriage is not considered to be an affair between two spouses, but rather as an affair between two families (Awusabo-Asare, 1988; Takyi \& Dodoo, 2005; Takyi \& Gyimah, 2007). The woman's family decides whether or not the men's marriage offer is accepted, although the role of the family in finding a suitable marriage partner has reduced in recent times. Nonetheless, extended family members are generally still involved when it comes to resolving marital problems (Takyi \& Gyimah, 2007). Even though some scholars assert that Western notions about family life are gaining prominence in Chana, such as the superiority of the nuclear family, the necessity of proximity among nuclear family members, a reduction in family size, or the use of paid house helps (Ardayfio-Schandorf, 1994; Asima, 2010; Fair, 2004; Oppong, 1974), the extended family systems remains important, particularly considering familial life events such as the birth of a child, marriage, or in times of ill-health or death.

Multilocal residence is quite common for Chanaian couples (Clark, 1994; Coe, 2011; Fortes, 1950; Manuh, 1999; Oppong, 1970). Traditionally, it was common for men and women to live apart, each spouse with his or her family (Fortes, 1950). Such multilocal residence was practiced in both matrilineal and patrilineal descent groups (Oppong, 1970). Customarily, husbands and wives also did not jointly possess land, as both accessed land through their respective lineages (Coe, 2011). Even today, couples generally do not pool their resources, and joint bank accounts are a rarity in Chana, where men and women keep their incomes separated (Manuh, 1999, 2001; Wong, 2006). Keeping separate accounts also facilitates fulfilling financial obligation towards their own families. In the current context of international migration, it is important to consider the commonly practiced multilocal residence in Ghana because it may contribute to international migration having different effects on marital relationships and transnational family life than in contexts where proximity is viewed as a necessity for family life. 


\subsubsection{The Child in the Ghanaian Family: Fostering and Social Parenthood}

The birth of the child is seen as a communal affair. The upbringing, socialization process and rites of passage of a child are seen as the responsibility of the extended family. This belief, though losing currency in recent times, accounts for the practices of child fostering and social parenthood. Fostering involves the giving of children to other relatives apart from their biological parents to be raised. In this regard, relatives from both maternal and paternal sides are the likely foster parents who have a claim to the child or children involved. Fostering can be practiced due to crises such as death of a parent or voluntarily with a specific purpose, such as giving a rural child to an urban family member to further educational or apprenticeship possibilities or to an elderly family member for companionship and labour (Ardayfio-Schandorf \& Amissah, 1996; Goody, 1982). In contrast to Western societies, where child fosterage tends to occur in response to an extraordinary familial crisis, the care of children by relatives and nonrelatives is widespread and is not stigmatized in many parts of West Africa, including Ghana (Alber, 2003; Bledsoe, 1990,1993; Goody, 1982).

It is important to take these family norms into account when interpreting our findings. For example, the fact that divorce is quite common in Ghanaian society means we need to be cautious in associating migration with divorce. Likewise, the common practice of fostering children may facilitate parents' decisions to migrate, as they can ask someone at home to take care of their children while they migrate to Europe - a receiving context that is restrictive with regards to family migration for many potential Ghanaian migrants. At the same time, however, international migration presents quite different conditions than the traditional child fostering situations. Fostering during international migration, in contrast to traditional fostering, involves continued involvement of the migrant parent and economic opportunities abroad create a different set of expectations on the migrant parent to remit and on the caregiver to provide top quality care giving (Dankyi, 2012; Mazzucato, 2011), than is typical of traditional fostering. It is therefore important in studies of the effects of migration on family life to be able to compare those families with migration experience to those without. The MAFE dataset provides this kind of comparative context.

\subsubsection{Ghanaian Transnational Families in the Netherlands and the UK}

There were 21,376 Ghanaians registered in the Netherlands in 2011 (CBS, 2011), but because there are also large numbers of undocumented migrants, this number is underestimated (Mazzucato, 2008a). The percentage of registered women is almost equal. Of these Ghanaians, $62 \%$ are first-generation immigrants. The other $38 \%$ was born in the Netherlands and therefore belongs to the so-called second-generation. The division between men and women is, and has been, almost equal. Since these official statistics 
exclude undocumented migrants, these figures are likely to be an underestimation. In 2000 , Ghanaian migrants were estimated to be at least double those of official figures (Mazzucato, 2008a). The Ghanaian population in the Netherlands is young, with $37 \%$ being younger than 20 years old. $60 \%$ of the population is between $20-60$ years of age and only $3 \%$ is 60 years or older (Amsterdams Centrum Buitenlanders (ACB), 2011).

Migration from Ghana to the Netherlands is a quite recent phenomenon, mostly situated in the last decades of the 2oth century. As described by Schans, Mazzucato, Schoumaker and Flahaux (2013), Ghanaian migrants to the Netherlands are essentially economic migrants. They started arriving in the 1980 s when the economies of Ghana as well as of Nigeria, where many were working, were experiencing an economic downturn. From the ' 90 's onwards, chain migration and family reunification become the most important factors for migration to the Netherlands (Mazzucato, 2008a).

In 2010, around 84,000 Ghanaians were registered as living in the UK and as such the UK has the largest population of Ghanaian migrants in Europe. Ghanaian migration to the UK has a longer history than Ghanaian migration to the Netherlands and other European countries. Colonial history, the use of English as the official language and in the Ghanaian educational system, and the need for medical staff in the UK has facilitated the migration of many students and professional workers such as nurses and doctors. Even though immigration controls tightened for African migrants (as opposed to more liberal approaches towards migrants from Central and Eastern Europe during the 1990s), Ghanaian migration continued to grow (Schans et al., 2013).

Family migration policies have become stricter in the UK as well, particularly for non-EU citizens, resulting in a decrease of family migration to the UK (Sibley, Fenelon \& Mole, 2012). Consequently, Ghanaian migrants in the UK have experienced downward mobility both economically and socially. Asima (2010) reported that labour market outcomes have been relatively better for Ghanaian women than for men. Additionally, a recent study on the labour market outcomes of Ghanaian migrants reported a more optimistic scenario. Ghanaians in the UK have acquired highly skilled occupations, and, similar to Asima's (2010) study, women in particular have experience occupational mobility (Black et al., 2014). More information on the general characteristics of Ghanaian migration to the two European countries can be found in Schans et al. (2013).

An important finding from Schans et al. (2013), considering Ghanaian family life in the context of international migration, is the evidence of transnational lifestyles among Ghanaian migrants. Ghanaian migrants frequently return to Ghana for both longer stays as well as shorter visits, and maintaining familial relationships back home can be facilitated through these visits. Importantly, opportunities for transnational lifestyles are not equally distributed among migrants, and these opportunities are closely linked to the financial situation and educational level of the migrant. 
Very little quantitative data however exist on (transnational) family life both in the Netherlands and the UK. There are no figures on the number of people who have nuclear family members in the sending country or even third countries. The MAFE data make it possible to give a more complete picture of the various family arrangements amongst migrants and family members both in Europe and back home in Ghana.

\subsubsection{Family Reunification between Ghana and Europe}

Family-related migration has become one of the main legal means for people to gain admission to Europe. Yet, in countries such as the Netherlands and the UK family-related modes of migration are more and more subject to restrictions (Kraler, 2010). Family related forms of migration gained importance after the 1973 oil crisis, when labour recruitment in European countries was brought to a halt and increased restrictions were placed on labour migration. However, after an initial relaxation of family migration criteria (for example, permitting partnerships and same-sex couples to apply for family formation), new family reunification restrictions have been imposed in the last decades including higher income and language requirements for new migrants.

Two main types of family migration can be distinguished: (1) Family reunification, in which pre-existing family members join migrants in the receiving country and (2) family formation, in which a new migrant joins a settled migrant to form a new family (marriage migration). In general, family-related admission is limited to nuclear family members: spouses, and dependent children below a certain age. However, differences in criteria exist between countries, but admission can also change within countries over time. For example, whereas in the UK a potential spouse needs to be 18 years old, in the Netherlands this threshold was raised to 21 in 2005 through the Integration Abroad Act.

Assumptions underlying state policies do not always recognize the complex reality of family migration. For example, as described in Section 4.2.1 above, extended family members may be just as important as nuclear family. Yet in the Netherlands only spouses and children can qualify for family reunification and in the UK, although elderly parents and other extended family members might be granted family reunification, criteria are stricter than for nuclear family and based on dependency on the sponsor.

Family reunification has become a major concern for policy makers as it is viewed as the primary pathway for migrants to enter Europe. This is reflected in the issues that Ghanaian migrants experience during their stay in the Netherlands. In a study on Ghanaian migrants from 2001 (Ministerie van Binnenlandse Zaken en Koninkrijksrelaties, 2001) respondents state that difficulties with family formation and reunification procedures and the related difficulties in having their documents verified and legalized are one of the main problems they face in the Netherlands. Since documents are often not accepted there is a feeling amongst Ghanaian migrants that the Dutch government mistrusts 
them and many spend a great deal of their time and money on legal issues related to residence and work permits and family reunification (Mazzucato, 2008a).

Additionally, in Dutch political debates, the migrant family is seen as a potential barrier to integration. Compared to other EU countries, family migration policies in the Netherlands are among the most stringent (Bonjour, 2008). In particular, these policies have become stricter since the 1990s, and especially the period between 2002 and 2006 has been characterized by restrictive reforms (Bonjour, 2008; De Hart, Strik \& Pankratz, 2012). Since 2006, family members are required to take a computerised test on language proficiency and knowledge of Dutch society at the Dutch embassy/consulate in their sending country as part of the visa application for family migration in line with the Integration Abroad Act (Bonjour, 2008). Combined with other recent requirements, such a high-income requirement ( $120 \%$ of the minimum wage) for the migrant, family reunification and formation have become increasingly difficult in the Netherlands. ${ }^{2}$

In the UK, family migration policies have been restrictive during the 1980s and 1990s (Bhabha \& Shutter, 1995) but experienced a period of relative liberalization in the late 1990s. More recently, instead, the UK has become stricter again. Debates on family migration currently focus on the abuse of the system, particularly through 'scam marriages' and policies have been implemented to impede such marriages (for example through the Immigration and Asylum Act 1999). Furthermore, since 2010, a pre-entry test has been instituted for family migrants (Kraler, 2014). ${ }^{3}$

In general, nation-states tie family reunification rights to a series of conditions, most importantly the legal status of the sponsor and their ability to provide secure income and housing. As such, family migration polices are socially selective, particularly excluding more vulnerable groups from the right to family reunion and formation (Kraler $\&$ Kofman, 2009). Moreover, the consequences of requirements are highly gendered. Kraler (2010) shows that in all European countries covered by his study, it was more difficult for women to meet family migration requirements such as the income criteria than for men.

\footnotetext{
2 The Netherlands was the first country to introduce a pre-entry integration test (i.e. the Integration Abroad Act, 2005). Additionally, the income requirement (which was $70 \%$ net of the social welfare level in 1993, and rose to 120\% in 2004) and relatively high cost for residence permits, spurred significant debate both within the Netherlands and internationally. For a detailed overview of the changes in Dutch family migration policies see e.g. Bonjour (2008), Groenendijk, Fernhout, Van Dam, Van Oers and Strik (2007), De Hart et al. (2012), and Strik et al. (2013)).

3 For a detailed overview of the changes in family migration policies in the UK see e.g. Kofman et al. (2008), Sibley et al. (2012) and Strik et al. (2013)).
} 


\subsection{Ghanaian hausehalds o their migrant family members}

The first part of our analysis focuses on the prevalence and composition of transnational families from the perspective of the migrant-sending country, Ghana. We explore the extent to which households in Ghana are transnational by looking at which family members are currently living abroad and where they reside. Furthermore, we examine which type of transnational practices are common (sending remittances, paying visits, being in contact), and which of the households' contacts (nuclear family members, extended family, and non-kin) are involved in transnational relationships. We will see that extended family members and also non-kin relations play an important role, highlighting the importance of looking beyond the nuclear family.

Section 4.3.1 describes the prevalence of Ghanaian households with migratory contacts, the relationship between the migrant abroad and the household head, and the whereabouts of these migrants. In Section 4.3.2 we discuss the functioning of these transnational families by looking at the support migrants received from the household, as well as the contribution migrants make to the households, in the form of monetary and in-kind remittances. Additionally, we present the different modes and frequency of contact between Chanaian households and their migrant household members.

\subsubsection{Ghanaian families: household living arrangements and migratory contacts}

When examining Ghanaian families, it is important to keep in mind, as discussed in Section 4.2, that family practices in Ghana can be quite different from the Western nuclear family model that presumes the primacy of geographic proximity. Ghanaian families extend beyond the nuclear family and they are often characterized by multilocal residence. The MAFE project employed a classical definition of the household: a group of individuals who live together and share partly or totally their resources to satisfy their essential needs (housing, eating). But to further capture the complexity of Ghanaian family life, the MAFE household survey includes not only household members, but also individuals that live outside the household, both within Chana as well as abroad, whom the household head considers to be part of their household. Migratory contacts are people who are living abroad and are either children/spouses of the head, partner(s) of a member of the household, or relatives of the household head or of his/her partner who have been in regular contact with the household over the past 12 months (for further details about the definitions of households and their migratory contacts, see Chapter 3, Box 3.1). We examine different categories of household members and their migratory contacts: the household head, his/her nuclear family members (spouse and children), 
his/her siblings, other relatives (e.g. grandparents, uncles, aunts, nieces, nephews), and non-kin.

In total, 1,246 Ghanaian household heads living in Kumasi and Accra were interviewed. Almost half of these household heads declared having at least one migratory contact (46\%, not shown). This high proportion of households with contacts abroad shows the high pervasiveness of households with migratory contacts in Ghana (see also Mazzucato et al., 2014a; Schans et al., 2013). Moreover, these households with such contacts are, on average, in touch with more than one migrant.

Most household heads (71\%) are currently married or in a consensual union and have at least one biological child (80\%), including also adult children (not shown). Further highlighting the transnationality of Ghanaian households, $10 \%$ of household heads had a spouse that lived abroad at the time of survey, and $12 \%$ had at least one biological son or daughter living abroad (Table 4.1). Many of these household heads also have multiple children living abroad (1.9 on average, not shown). ${ }^{4}$ Household heads also had contacts with extended family members and non-kin relations abroad. One third of the heads declared to have at least one such contact. The migratory contacts outside the nuclear family were mostly former household members, although some of these contacts were also with individuals that were never part of the household, but with whom regular contact exists. This stresses the importance of looking beyond the nuclear family when considering the contacts that households have with people living abroad.

Table 4.2 presents an overview of the whereabouts of migrant spouses, migrant children, and other migratory contacts. When looking at the destinations of these migratory contacts, we distinguish between four categories: Europe, North America, Africa, and other countries. Schans et al. (2013) already revealed that Europe is by far the most popular destination for Ghanaian migrants since the 1990s. We find this to be true for spouses, children and other migratory contacts alike. North America is the second most popular destination while African countries and other countries (such as Asia or Middle East) are by far less popular among these migratory contacts (see also Schans et al., 2013).

Migration within Africa is an important phenomenon in Ghana (GSS, 2012, p. 38). The fact that our figures show such a prevalence of European and North American contacts most likely reflects the fact that our survey was conducted in the two largest urban centres in Ghana, Accra and Kumasi, from which many migrants depart when migrating to the Global North.

4 Of these households with children living abroad, only $0.5 \%$ (13) household heads have children under-18 that live abroad. These 13 households have in total 19 children living abroad. Due to this small number, we do not look at this category separately. 
In summary it is important to take the often-complex nature of Ghanaian families into account when studying international migration. The family goes beyond nuclear family ties; relationships exist with other relatives as well as non-kin abroad. We have shown that a large share of households maintains regular contact with migrants abroad. In the next section, we examine the functioning of these families across borders.

Table 4.1. Ghanaian households and their migratory contacts

\begin{tabular}{|c|c|c|c|}
\hline & & $n$ & $\%$ \\
\hline \multirow[t]{3}{*}{ Married household heads that have... } & ...no spouse abroad & 717 & 90 \\
\hline & ...at least 1 spouse abroad & 151 & 10 \\
\hline & Total & 868 & 100 \\
\hline \multirow[t]{3}{*}{ Household heads with children that have... } & ...no children abroad & 853 & 88 \\
\hline & ....at least 1 child abroad & 144 & 12 \\
\hline & Total & 997 & 100 \\
\hline \multirow[t]{4}{*}{ Household heads that have... } & ...no migratory contacts & 596 & 57 \\
\hline & ...nuclear migratory contacts only & 185 & 11 \\
\hline & ...other migratory contacts & 465 & 32 \\
\hline & Total & 1246 & 100 \\
\hline
\end{tabular}

Note: weighted percentages Q unweighted frequencies; Source: MAFE-Ghana, 2009-2010, Household survey

Population: Married Ghanaian household heads ( $n=868)$; Ghanaian household heads with children ( $n=997)$; All Ghanaian household heads $(n=1,246)$

Interpretation: Of all married Chanaian household heads, $10 \%$ have at least one spouse living abroad.

Table 4.2. Whereabouts of household's migratory contacts, by relationship to the household head

\begin{tabular}{|c|c|c|c|c|c|c|}
\hline & \multicolumn{2}{|c|}{ Migrant spouses } & \multicolumn{2}{|c|}{ Migrant children } & \multicolumn{2}{|c|}{ Other migratory contacts } \\
\hline & $n$ & $\%$ & $n$ & $\%$ & $n$ & $\%$ \\
\hline Africa & 15 & 6 & 39 & 11 & 90 & 9 \\
\hline Europe & 62 & 32 & 111 & 41 & 405 & 49 \\
\hline $\mathrm{N}$-America & 57 & 29 & 112 & 40 & 312 & 38 \\
\hline Other & 10 & 5 & 11 & 8 & 35 & 4 \\
\hline Unknown & 2 & 28 & O & O & 6 & $\mathrm{O}$ \\
\hline Total & 146 & 100 & 273 & 100 & 848 & 100 \\
\hline
\end{tabular}

Note: weighted percentages $Q$ unweighted frequencies; For all three categories, the number of migrants is higher than the number of household heads that declared to have migratory contacts in the previous Table 4.1. For spouses, this is due to a small number of household heads with polygamous relationships. For both children and other contacts, the household heads declared on average to have more than one such contact abroad. Source: MAFE-Ghana, 2009-2010, Household survey

Population: Ghanaian household head's migratory contacts ( $n=1272) ; 5$ missing observations are not reported Interpretation: Of all Ghanaian migrant spouses, $6 \%$ lives in Africa. 


\subsubsection{Families functioning across borders: support, remittances and visits}

The migratory contacts we identified in the previous section can be engaged with the household in Ghana in various ways: through financial remittances, home visits, and virtual communication. In this section we address the contributions migrants make to households in Ghana. There are two points made here: 1) contributions from migrants to households in Ghana are not exclusively from nuclear family, and/or from kin members only but encompass a wider range of relationships, hereby again emphasizing the importance of challenging western notions of the family in an African migration context; and 2) it is important to include the ways and frequency with which migrants stay in touch with their households in the sending country. It is through such contacts that migrants and their households can influence each other in non-material ways, such as via ideas, norms and ways of doing things, which are often termed 'social remittances' (Levitt, 1998).

At the same time, it is important to pay attention to what families do for migrants. Remittance literature tends to emphasize the remittances that migrants send home. Yet equally important are the reverse remittances in the form of 'help' that migrants receive from their families back home especially in the first phase of their migration (Mazzucato, 2009, 2011). Below, we examine one particular type of 'help' migrants receive from their households in the sending country, that is, the assistance they receive in making their trip abroad (Households contributing to migrant's departure(s)). Next, we examine the financial contributions migrants make to the household in the form of remittances (Economic remittances). We also assess to what extent remittance sending (material and non- material) is related to the support migrants received from the household for their migration. Finally, we look into the non-material ways households and migrants maintain contact (Contact between Ghanaian households and migrants).

\section{Households contributing to migrant's departure(s)}

Migrants often received some form of support from their households in Accra and Kumasi for their migration trip. Support can be provided in different ways. Households may, for example, provide the migrant with assistance with preparations for the trip, or by paying for the trip, or both. In this section we study the prevalence of support migrant household members received.

Receiving support from family members seems not to be common practice (for definitions of receiving support and sending remittances, please see Chapter 3, Box 3.2). Looking at all migratory contacts, only $19 \%$ received some form of support (see Figure 4.1). Theories of remittance behaviour that conceptualize the sending of remittances as a form of debt repayment for the initial investment made in his or her trip, do not seem to explain what we observe in Ghana (Stark \& Lucas, 1988). 
A difference between male and female migrants exists when it comes to receiving support. Of all male migrants, $16 \%$ received support, compared to $23 \%$ of all female migrants (not shown in Figure 4.1). This shows that even though in general, most migrants do not receive support from their households, being a female migrant increases the chances of having received some form of assistance with their migration trip.

Different types of migratory contacts also have different likelihoods of receiving support for their migration trip. We distinguish between household head's spouses, children (all ages), siblings, other relatives, and non-kin (this latter category is small, and should thus be interpreted with caution). Figure 4.1 shows that children are most likely to be supported (44\%) followed by spouses (29\%). While in general support for migratory trips from the migrants' origin households is low, those that receive such support are overwhelmingly from the nuclear family. However, extended family members are not necessarily excluded from support. Of all siblings, 10\% received support and of all other relatives, $11 \%$ received support to migrate.

Figure 4.1. Household's migratory contacts who received support from the household

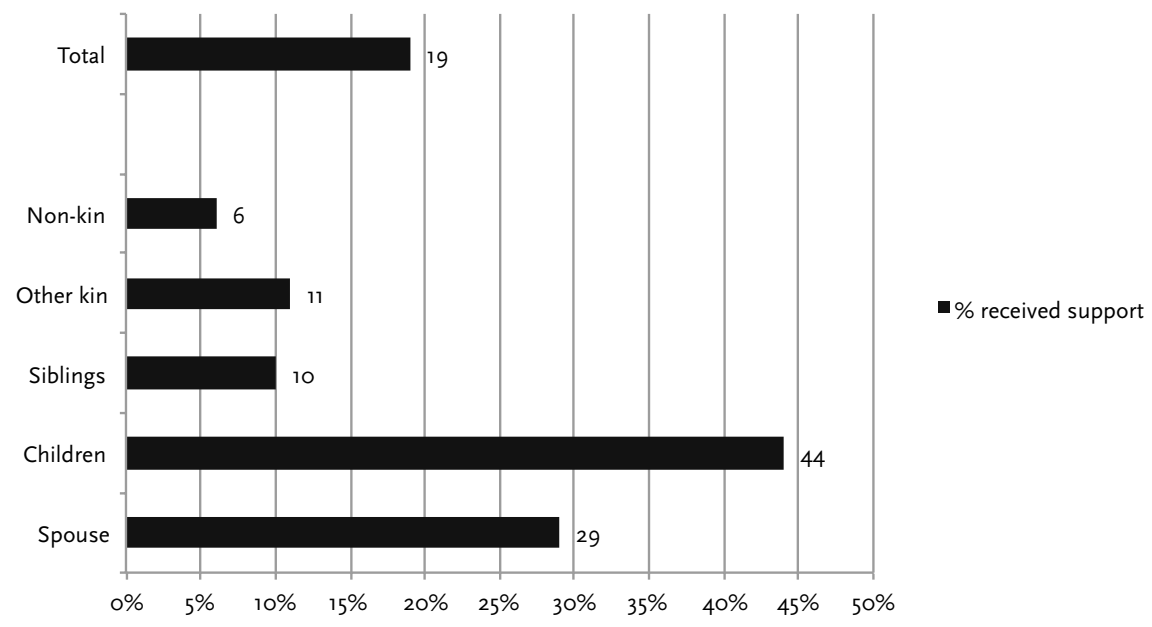

Note: weighted percentages; Source: MAFE-Ghana, 2009-2010; Household survey

Population: Ghanaian household head's migratory contacts ( $n=1272) ; 5$ missing observations are not reported Interpretation: Of all migrant spouses, $29 \%$ received support for their migration trip.

Statistical significance: Receiving support differs significantly by the type of relationship to the household head ( $p<0.000$, Design-based F-test) 


\section{Economic Remittances}

While remittances are normally discussed in relation to the sending country development, they are also a way that families enact family life across borders. Remittances are used to fulfil gendered kinship obligations (Wong, 2006) and intergenerational reciprocity (Mazzucato, 2008c). Mazzucato, Van der Boom and Nsowah-Nuamah (2008), in analysing nationally representative data, found that in Chana most senders of remittances are children and siblings of the household head. However, those who remitted the greatest amounts of money were spouses of the household head. Remitters from outside Africa donated the largest yearly average amount. Furthermore, Black et al. (2013) showed that a high proportion of Ghanaian migrants in the Netherlands and the UK send remittances (around two-thirds), and remittance-sending behaviour is closely linked to the duration of stay in the receiving country, educational level, and occupational status.

Here we focus more generally on all migrants that have contact with households in Ghana. In general, we find that sending remittances is more common for migrants than receiving support. A little more than half of all migrants sent monetary remittances to the household in the past 12 months (see Figure 4.2). Importantly, and contrary to some of the literature on gender and migration that reports that women are more likely to send remittances back home, we find no differences in gender with regards to remittancessending behaviour (not shown; see also Black et al., 2013). Clear differences emerge considering remittance-sending behaviour when looking at the type of relationship (Figure 4.2). Spouses are the most likely to remit, followed by children. Even though nuclear family members are the most likely remitters, the importance of remittances from extended family members should not be underestimated. Almost half of all siblings abroad remitted and just over half of all other relatives did so.

Sending monetary transfers is not the only form of remittances. Migrants also send remittances in the form of goods, so-called 'in-kind remittances' (not shown). In the sample, in-kind remittances are sent by a little less than half of all migrants (41\%). Female migrants are more inclined to remit in-kind than their male counterparts: $49 \%$ and $37 \%$, respectively. 5 Taking these two kinds of remittances, monetary and in-kind together, we find that almost two-thirds of all migrants remitted monetary and/or in kind in the past 12 months.

While the above shows that sending remittances is a common phenomenon, it does not say anything about the magnitude of these remittances. We therefore turn to looking at the share of household expenditures covered by remittances (not shown). Respondents were asked to estimate the share that remittances covered of their household expenditures, such as food, medicine, transport and housing. Of all migratory

5 The difference between men and women in terms of sending in-kind remittances is significant $(p<0.01$, Design-based F-test). 
remittances, $28 \%$ cover a very large to large share of the household expenditures. Spouses and children are most likely to remit large shares of the household expenditures, but remittances from extended family are also often substantial. As for difference by gender, more male migrants accounted for a large share of the household expenditures (35\%) than female migrants (17\%). While men seem mostly to cover either a large or a small share, women tend more to cover a moderate share (34\% for women, and $27 \%$ for men). ${ }^{6}$

\section{Figure 4.2. Household's migratory contacts who sent remittances to the household}

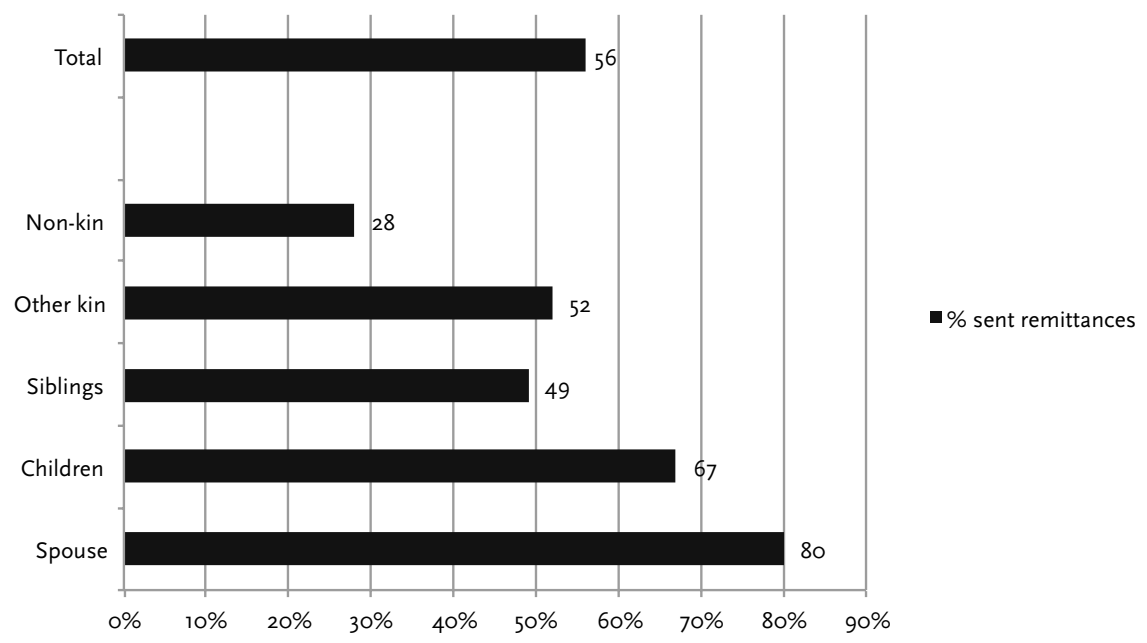

Note: weighted percentages; Source: MAFE-Ghana, 2009-2010, Household survey

Population: Ghanaian household head's migratory contacts ( $n=1272$ ); 5 missing observations are not reported Interpretation: Of all migrant spouses, $80 \%$ sent remittances to the household in the past 12 months.

Statistical significance: Sending remittances differs significantly by the type of relationship to the household head ( $p<0.000$, Design-based F-test)

One of the reasons that migrants remit is as a 'pay back' mechanism for the investments that families make in them to finance their migration trip (Stark and Lucas 1988). We investigate this hypothesis within our sample by looking at whether migrants who received support are also those more likely to send remittances (not shown). Indeed, we find that migrants who received support from their household in Ghana were more likely to send monetary remittances $(65 \%)$ than those who did not receive support $(54 \%){ }^{7}$ Yet there are two important caveats. First, as stated above, more than half of migrants who did not receive support do remit. Secondly, the significant and positive relation

\footnotetext{
6 The difference between the type of relationship to the household head and the share of expenditure covered by remittances is significant $(\mathrm{p}<0.001$, Design-based F-test), and the difference between men and women in terms of the share of expenditures their remittances cover, is significant ( $\mathrm{p}<0.10$, Design-based F-test).

7 The relationship between receiving support and sending monetary remittances is significant $(p<0.05$, Design-based F-test).
} 
between receiving support and remitting only holds for financial remittances and not for in-kind remittances. This indicates that 'pay back' is not the only reason for remitting and that more is involved in explaining remittance sending behaviour than household investments in facilitating migration of a household member (Mazzucato, 2009).

\section{Contact between Ghanaian households and migrants}

Migrants are in contact with their households 'back home' in a variety of ways, in addition to sending monetary or in-kind remittances. We examine here visits migrants make to their households and the means and frequency of contact while they are abroad. Through these contacts, migrants and their households can share information, ideas, norms and ways of doing things that affect the way families function across borders. This non-material exchange is therefore important to take into account when studying the functioning of families across borders.

Visits to the household in Ghana in the past 12 months are relatively common (see Figure 4.3), which is in line with the mobility patterns of Ghanaian migrants (see Schoumaker et al., 2013b), who return relatively frequently to Ghana for longer or shorter visits. Looking closer at the different relationships, we see that the difference between visiting nuclear and extended family members is small.

\section{Figure 4.3. Household's migratory contacts who visited the household}

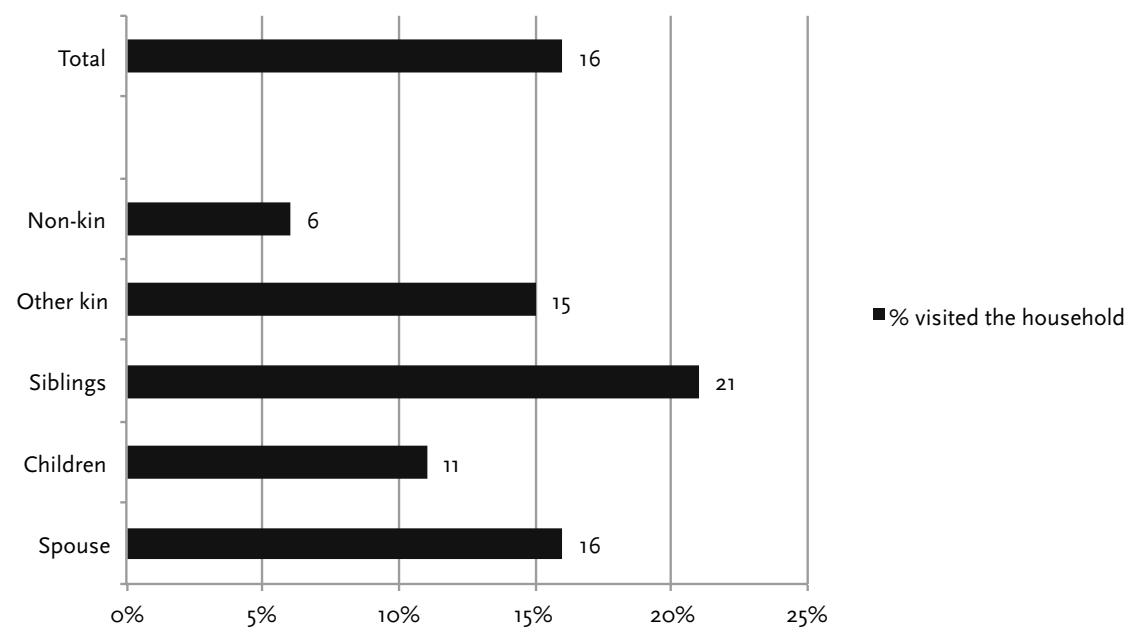

Note: weighted percentages; Source: MAFE-Ghana, 2009-2010, Household survey Population: Ghanaian household head's migratory contacts ( $n=1272)$; 5 missing observations are not reported Interpretation: Of all migrant spouses, $16 \%$ visited the household in the past 12 months.

Statistical significance: There is no significant difference in term of visiting the household by the type of relationship to the household head ( $p>0.10$, Design-based F-test) 
Aside from visits, migrants also maintain contact with their household left-behind in other ways, such as through telephone calls (not shown): only $1 \%$ of all migrants did not have contact with the household in the past 12 months. Contact by means of telephone calls is by far the most popular way of staying in touch. Other means of contact, such as mail or Internet, are less used. This reflects the well-developed mobile telephone infrastructure in Ghana and the relatively less developed Internet infrastructure as well as the fact that most people in Ghana do not own computers nor have access to one. Contact with the household is also frequent (not shown): $40 \%$ of migrants are in contact at least once a week, and $35 \%$ at least once a month. Only $20 \%$ is in contact less than on a monthly basis. There is a difference when examining the frequency of contact when taking into account the relationship to the household head. Almost all migrant spouses and the majority of migrant children are in contact at least once a week with the household Although a little less, extended family members are also in contact on a weekly basis: $27 \%$ of siblings and $40 \%$ of other relatives. ${ }^{8}$

In summary, Section 4.3.2 has shown that despite the fact that most migrants did not receive support in any form for their migration trip, a large majority did send remittances, either monetary or in-kind. This remittance sending behaviour is not at all restricted to nuclear family members. Even though spouses and children seem to be the most likely remittance senders, the majority of siblings and other relatives also remit. In the same vein, while migrant nuclear family members remit the largest share of household expenditures, most extended family members also remit moderate to large shares. Finally, Ghanaian migrants stay in touch with households in the sending country, especially through (cellular) telephones, but also through short return visits.

\subsection{Family life: Ghanaian migrants in Eurape}

In the previous section, we focused on families in large cities in Ghana (i.e. Accra and Kumasi), and their relations to migrants. In this section, we will focus on Ghanaian migrants in Europe (i.e. the Netherlands and the UK). First, we will evaluate the prevalence and composition of transnational families of Ghanaian migrants in Europe, using the European biographic surveys from the Netherlands and the UK. Secondly, we will examine whether transnational families differ from families that live together concerning some key demographic and socio-economic characteristics, as well as characteristics

8 The relationship between the frequency of contact and the type of relationship to the household head is significant $(p<0.05$, Design-based F-test). 
relating to their migration experience. In this section, we will compare the characteristics of the different family arrangements.

There are some important similarities and differences between Ghanaian migrants in the Netherlands and in the UK to keep in mind when reviewing the analysis presented below. Both groups are similar in terms of sex and age but they significantly differ in terms of education. Ghanaian migrants in the UK are more highly educated than those in the Netherlands. Both the UK and the Netherlands practiced active recruitment of nurses and medical personnel in Ghana and other African countries, therefore this difference is more likely to do with the fact that English is the official language of education in Ghana, making it easier for highly skilled migrants to practice their professions in the UK rather than in the Netherlands. There is also some evidence that the Netherlands has stricter rules regarding the recognition of foreign diplomas and certifications (Mazzucato, 2008a). A full overview of demographic, socio-economic and migration characteristics of these two groups is provided in Black et al. (2013).

\subsubsection{Living arrangements of Ghanaian migrants in Europe}

There are different nuclear family configurations that prevail among Ghanaian migrants in the Netherlands and the UK, reflecting the complex nature of transnational nuclear family ties. We use a typology based on the combination of two variables: 1) the whereabouts of the interviewed migrant's children, sub-divided in four categories, and 2) the whereabouts of the interviewed migrant's spouse, again sub-divided in four categories. ${ }^{9}$ For an overview of the distribution of these two variables, see Table A.1 in Appendix $A$. These variables are combined to arrive at the following typology (for details about this typology, please see Table A.2 in Appendix A and Box 3.3 in Chapter 3): 1) no nuclear family, 2) totally unified family (all members have always lived together and are living together in one country at the time of survey), 3) reunified family (at least one member was living in another country than the migrant and has reunified at the time of survey), and 4) partially or totally transnational family (either one or more members are living in another country from the migrant).

In Table A.3, in Appendix A, we present an overview of this typology for all Ghanaian migrants and by survey country. It is important to note that $27 \%$ of the total sample of migrants in the UK and the Netherlands are not in a nuclear family (they have no spouse and children either in the sending or receiving country) (Table A.3). The remainder of the analysis below will focus on migrants who are in a family. Because of the differences

\footnotetext{
9 In this sample of Ghanaian migrants in the Netherlands and the UK, there are 7 polygamous unions in 2008. For each case we selected only one union for analysis. This means that in the case of polygamy consisting of one marriage and one union, we took the marriage into consideration. In the case of polygamous unions, we considered the last relationship. No cases of polygamy with more than one marriage were reported.
} 
between the two survey countries, and in order to better interpret the findings, we focus the analysis of this section on the two countries separately.

In Figure 4.4 we present the distribution of these three family types for migrants in the Netherlands and the UK. Transnational family life is more prevalent among Ghanaians in the Netherlands than among Ghanaians in the UK. In the UK, it is by far more common to be in a totally unified family, which include families that were formed in the receiving country or families that migrated together.

In both countries, the reunified family is the least prevalent type of family arrangement, which reflects the restrictiveness of reunification policies in both countries of the past decades (Kraler, 2010). In the following sections, we examine whether these different types of family arrangements are associated with particular socio-demographic, socio-economic and migration-related characteristics of migrants.

\section{Figure 4.4. Distribution of family arrangement typology of Ghanaian migrants in Europe}

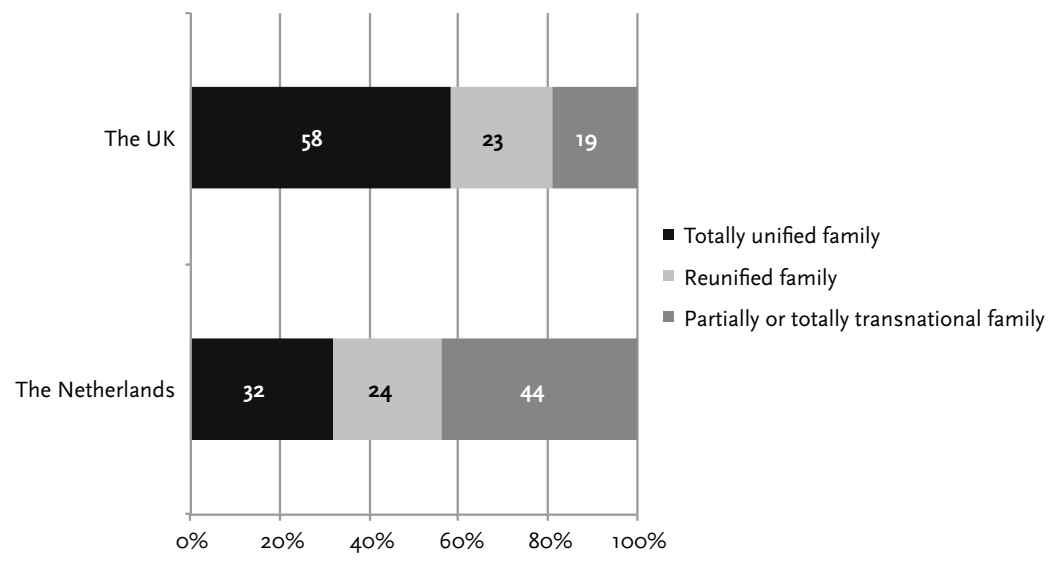

Note: weighted percentages; Source: MAFE-Ghana, 2009-2010, Biographic survey

Population: Ghanaian migrants in the UK and the Netherlands ( $n=410)$;

Interpretation: $58 \%$ of Ghanaian migrants with families in the UK are living in a totally unified family, and $32 \%$ of Ghanaian migrants with families in the Netherlands are living in a totally unified family.

Statistical significance: The distribution of this family arrangement typology differs significantly by country ( $p<0.01$, Design-based F-test)

\subsubsection{Characteristics of Ghanaian transnational families in Europe}

Ghanaian migration is characterized by an almost equal share of women migrating as men (Schans et al., 2013) to Europe and North America. Figure 4.5 shows that both in the UK and in the Netherlands, female migrants are more often in reunified families than men, but these differences are not significant. When it comes to totally unified families and transnational families, there is vey little difference between male and female migrants. 
Figure 4.5. Family arrangement typology, by sex of the migrant

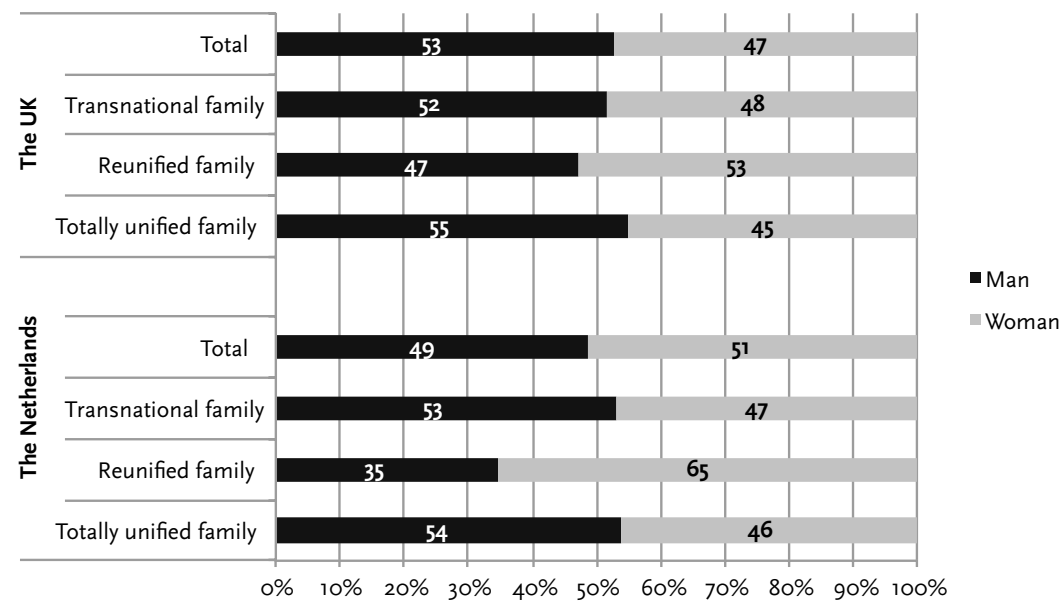

Note: weighted percentages; Source: MAFE-Chana, 2009-2010, Biographic survey Population: Ghanaian migrants in the UK and the Netherlands ( $n=410)$;

Interpretation: $52 \%$ of Ghanaian migrants with transnational families in the UK are male, and $53 \%$ of Ghanaian migrants with transnational families in the Netherlands are male.

Statistical significance: The distribution of this family arrangement typology is not significantly different by sex in either the UK or the Netherlands ( $p>0.10$, Design-based F-test)

Figure 4.6. Family arrangement typology, by average age of the migrant

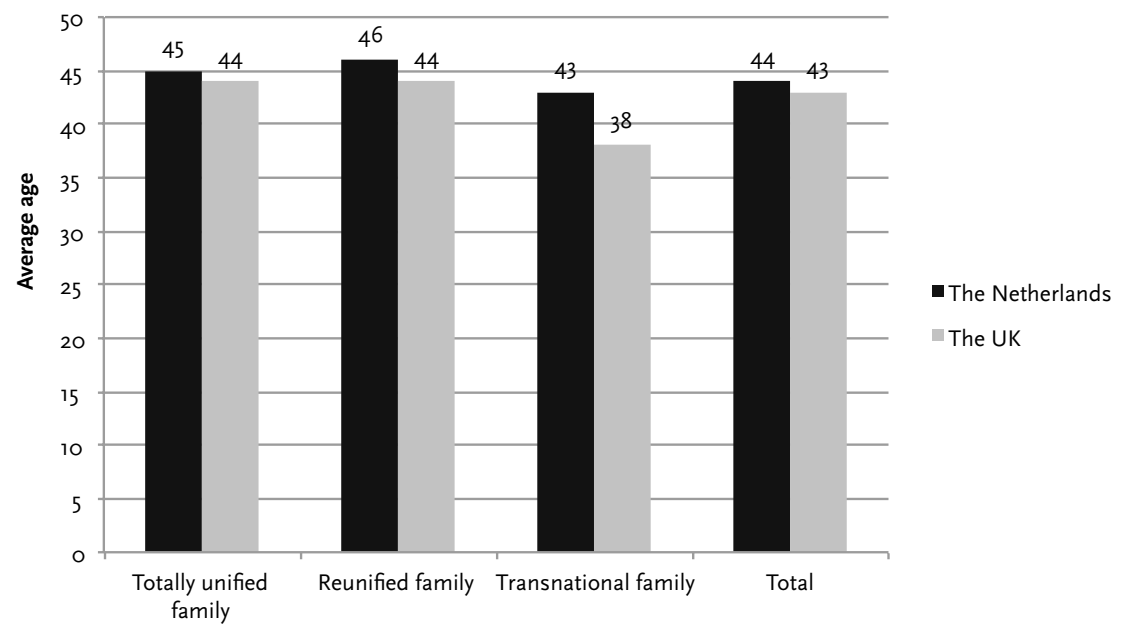

Note: weighted percentages; Source: MAFE-Ghana, 2009-2010, Biographic survey

Population: Ghanaian migrants in the UK and the Netherlands ( $n=410)$;

Interpretation: The average age of Ghanaian migrants with transnational families in the UK is 38 years, and the average age of Chanaian migrants with transnational families in the Netherlands is 43 years.

Statistical significance: The average age between family arrangement typologies is not significantly different in the Netherlands ( $p>0.10$, Design-based F-test), and it is significantly different in the UK ( $p<0.10$, Design-based F-test). 
Figure 4.7. Family arrangement typology, by educational level of the migrant

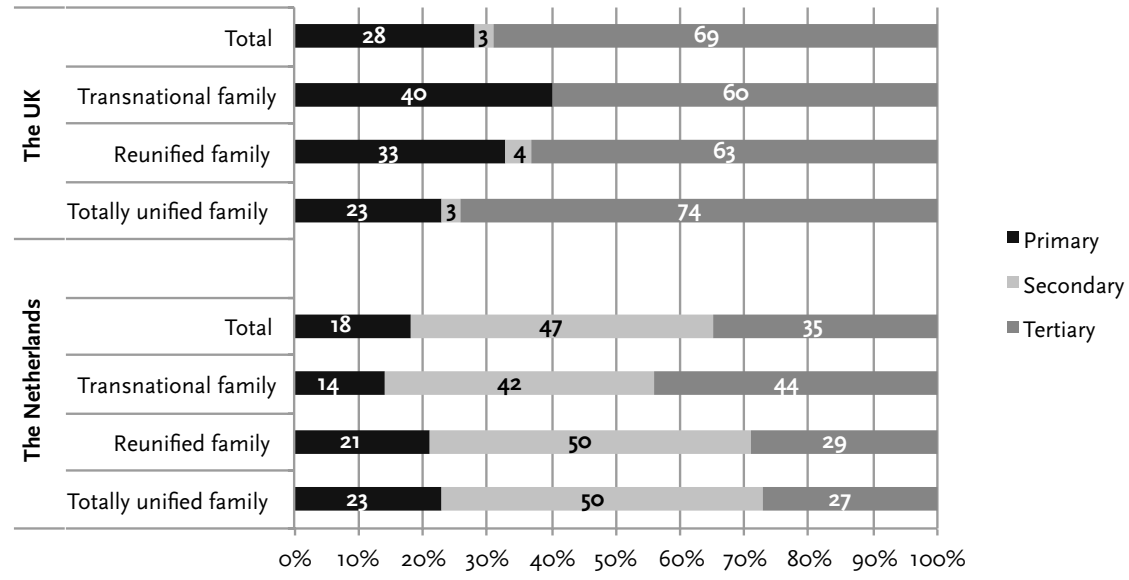

Note: weighted percentages; Source: MAFE-Ghana, 2009-2010, Biographic survey Population: Ghanaian migrants in the UK and the Netherlands ( $n=410)$;

Interpretation: $40 \%$ Ghanaian migrants with transnational families in the UK have primary education, and $14 \%$ of Ghanaian migrants with transnational families in the Netherlands have primary education.

Statistical significance: The distribution of educational between family arrangement typologies is not significantly different in the UK ( $p>0.10$, Design-based F-test). It is significantly different in the Netherlands for tertiary level education ( $p<0.10$, Design-based F-test).

Figure 4.8. Family arrangement typology, by ISEI score of the migrant

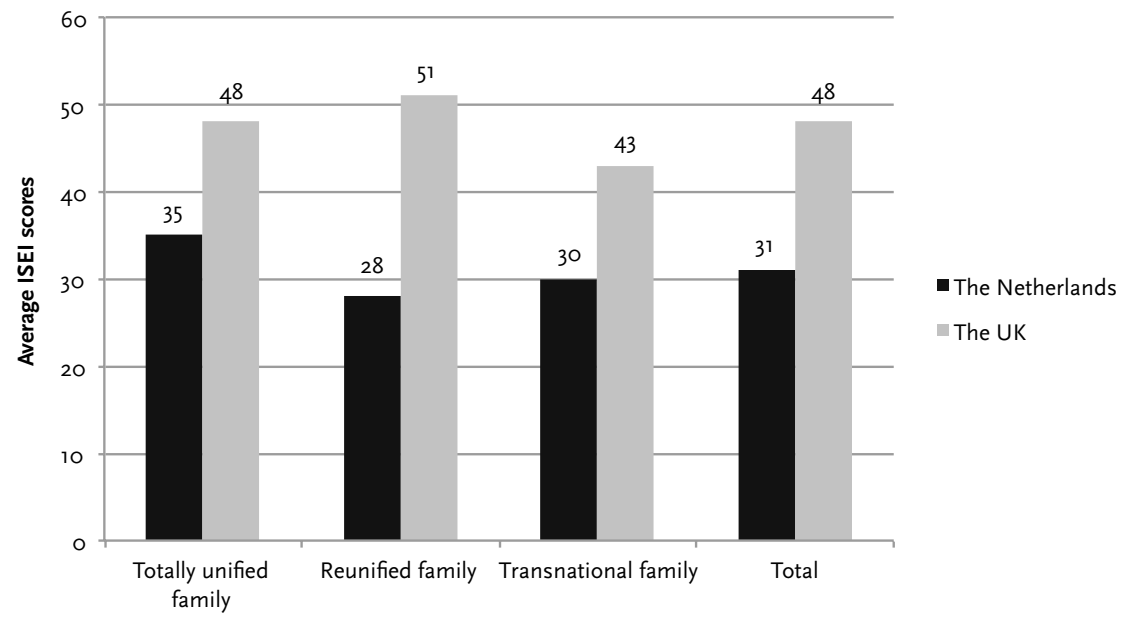

Note: weighted percentages; Source: MAFE-Ghana, 2009-2010, Biographic survey Population: Ghanaian migrants in the UK and the Netherlands ( $n=410)$;

Interpretation: The average ISEI score of Ghanaian migrants with transnational families in the UK is 43, and the average ISEl-score of Ghanaian migrants with transnational families in the Netherlands is 31.

Statistical significance: The average age between family arrangement typologies is not significantly different in the UK ( $p>0.10$, Designbased F-test). It is significantly different in the Netherlands ( $p<0.05$, Design-based F-test). 
In general, migrants in any of the three types of family arrangements are on average older in the Netherlands than in the UK. In both countries, migrants in transnational families are on average younger (Figure 4.6). Migrants in totally unified families instead are less likely to be highly educated in the Netherlands while they are more likely to be highly educated in the UK (Figure 4.7).

In Figure 4.8 shows the occupational status of Ghanaian migrants in the two receiving countries using the ISEI-index. ISEI is a continuous indicator of occupational status, with index scores derived from education and income, and with higher scores referring to higher occupational status. Among migrants in the Netherlands, the range of ISEI scores lies between 16 and 71 , and in the UK between 16 and 76 . While this range is similar in the two countries, migrants in the Netherlands have, on average, much lower ISEI scores compared to migrants in the UK (see also Castagnone, Mezger, Schoumaker, Nazio \& Rakotonarivo, 2013). Furthermore, reunified families have the lowest ISEI score of all three family types in the Netherlands, while they have the highest ISEI score in the UK. The difference between types of families in the Netherlands is statistically significant whereas in the UK it is not.

Migrants were asked to give a subjective evaluation of their wealth status by answering the question, whether they felt that they currently had enough to live on. The response categories were 'Yes, absolutely', 'It depended', or 'No, not at all'. Figure 4.9 below shows the differences between families concerning their subjective wealth status. Most migrants in both countries feel they absolutely have enough to live on. For both countries, the differences between family types are small and not significant. Yet interestingly migrants in the UK are on average higher educated and have higher occupational status but they appear to be less satisfied with what they have to live on. This possibly reflects the higher costs of living in the UK with respect to the Netherlands.

Finally, we study variables related to the migration experience: age when entering current country of residence, duration of current stay abroad, and legal status in country of current residence. Migrants in unified families arrived when they were quite young, both in the Netherlands and the UK, especially compared to migrants in the other two family types (Figure 4.10). This might indicate that most migrants in unified families started family formation after entering the receiving country.

In general, migrants have been longer in the UK than in the Netherlands (see Schans et al., 2013). And if we look at the differences between family types, we see that those in unified families have, on average, the longest stay compared to the other family types (Figure 4.11). Transnational families are those that are for the shortest amount of time in the current receiving country. This could reflect that migrants in transnational family arrangement have not yet had the opportunity to reunite or possibly do not have the desire to become reunified, or to return to the sending country. However, increasingly 
restrictive migration policies in both countries could also be driving this result.

We investigate migrants' legal status by distinguishing between 1) migrants who do not need a permit (e.g. due to citizenship), or who have a longer-term permit (such as a residence permit), 2) migrants who have a temporary permit, such as a visa, and 3 ) migrants who have no residence permit at all. In both countries, the majority of migrants do not need a residence permit or they have a long-term permit (Figure 4.12). Similarly, we see in both countries that there is a difference between family types, and that migrants in transnational families are more likely to have no residence permit. In the Netherlands, almost one-third of those in a transnational family are without a residence permit. As was also shown by Schans et al. (2013), more migrants in the Netherlands lack a permit compared to the UK. On the other hand, we see that in the UK it is more common to have a temporary permit, such as a visa.

Figure 4.9. Family arrangement typology, by subjective wealth status of the migrant

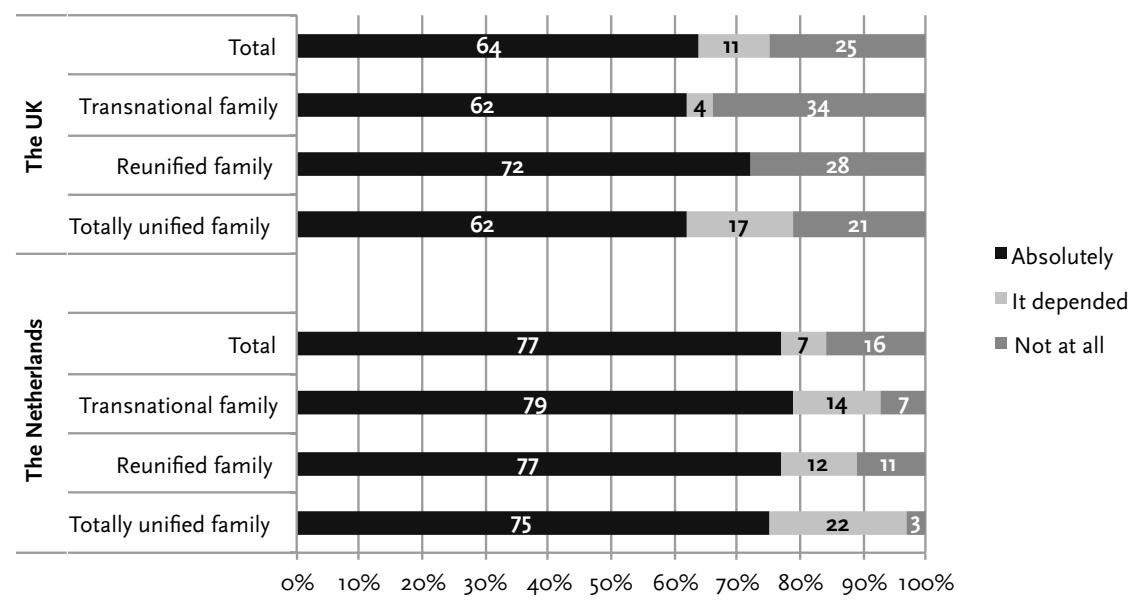

Note: weighted percentages; Source: MAFE-Ghana, 2009-2010, Biographic survey Population: Ghanaian migrants in the UK and the Netherlands ( $n=410)$;

Interpretation: $62 \%$ of Ghanaian migrants with transnational families in the UK feel they have absolutely enough to live on, and $79 \%$ of Chanaian migrants with transnational families in the Netherlands feel they have absolutely enough to live on.

Statistical significance: The distribution of subjective wealth status between family arrangement typologies is not significantly different in the Netherlands ( $p>0.10$, Design-based F-test). It is significantly different in the UK for those indicating that they have not at all enough to live on ( $p<0.10$, Design-based F-test). 


\section{Figure 4.10. Family arrangement typology, by age at arrival in Europe}

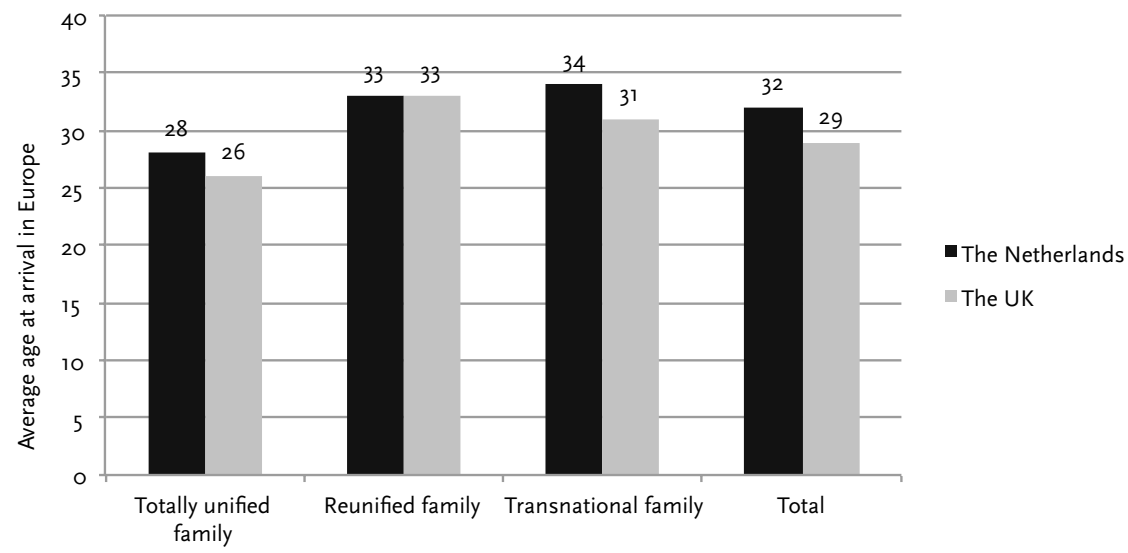

Note: weighted percentages; Source: MAFE-Ghana, 2009-2010, Biographic survey Population: Ghanaian migrants in the UK and the Netherlands ( $n=410)$; Interpretation: The average age at arrival in Europe of Ghanaian migrants with transnational families in the UK is 31, and the average age at arrival in Europe of Ghanaian migrants with transnational families in the Netherlands is 34.

Statistical significance: The average age at arrival in Europe between family arrangement typologies differs significantly in both the UK and the Netherlands ( $p<0.01$, Design-based F-test).

\section{Figure 4.11. Family arrangement typology, by duration of stay in Europe}

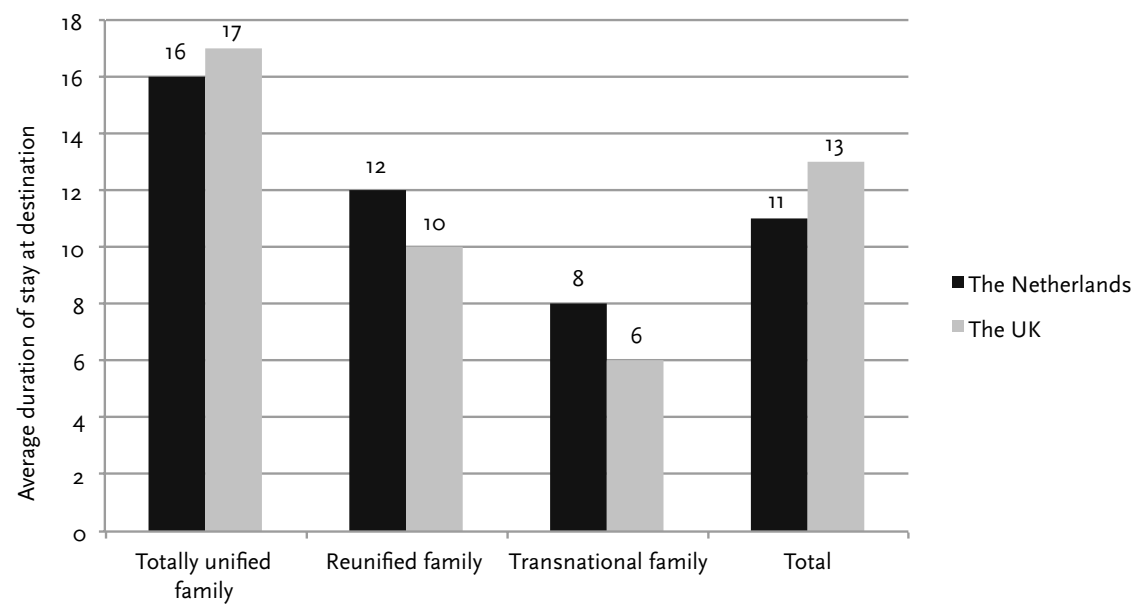

Note: weighted percentages; Source: MAFE-Chana, 2009-2010, Biographic survey Population: Ghanaian migrants in the UK and the Netherlands ( $n=410)$;

Interpretation: The average duration of stay in Europe of Ghanaian migrants with transnational families in the UK is 6 , and the average duration of stay in Europe of Ghanaian migrants with transnational families in the Netherlands is 8.

Statistical significance: The average duration of stay in Europe between family arrangement typologies differs significantly in both the $U K$ and the Netherlands ( $p<0.01$, Design-based F-test). 
Figure 4.12. Family arrangement typology, by legal status of the migrant

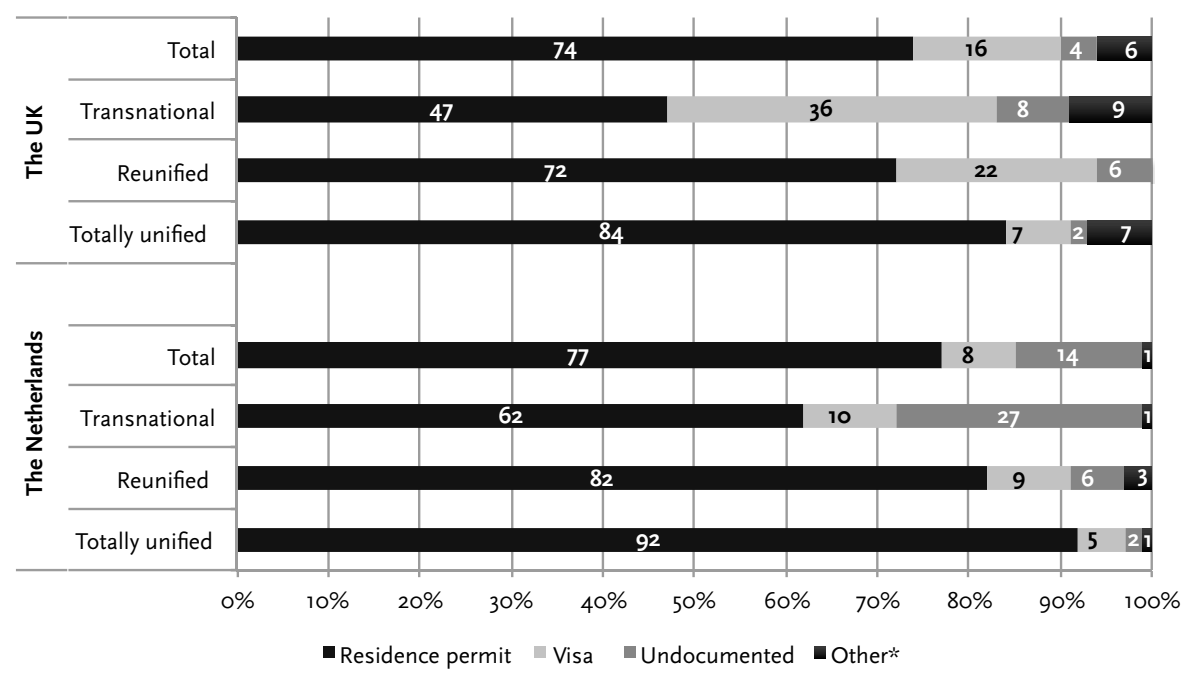

* The category "other" includes missing values: in the Netherlands, 1 "other" + 2 "missings", in the UK, 3 "other" + 3 "missings". Note: weighted percentages; Source: MAFE-Ghana, 2009-2010, Biographic survey

Population: Chanaian migrants in the UK and the Netherlands ( $n=410)$;

Interpretation: $47 \%$ of Ghanaian migrants with transnational families in the UK have a residence permit, and $62 \%$ of Ghanaian migrants with transnational families in the Netherlands have a residence permit.

Statistical significance: The distribution of legal status between family arrangement typologies is not significantly different in the Netherlands and the UK for residence permit ( $p>0.10$, Design-based F-test). It is significantly different in the UK for having a visa $(p<0.05$, Design-based F-test), and it is significantly different in the Netherlands for undocumented.

In sum, Ghanaian migrants in the Netherlands and in the UK showed different trends in family types. In the Netherlands, an undocumented status is strongly related to being in a transnational family, while this association is not significant in the UK, although this latter result may be due to a small sample size (in the UK, we have only few migrants with undocumented status) and therefore should be interpreted with caution. Additionally, in the Netherlands, transnational family life is associated with a higher education, while we see the opposite relationship for the UK. Although our data cannot fully explain the differences between these two countries, based on our findings we expect that migrants in the Netherlands are less inclined to bring their families over due to the difficulties children might have in school - not speaking the Dutch language -, the fact that it is more difficult to have one's educational credentials acknowledged in the Netherlands than in the UK (Mazzucato, 2008a), and the difficulty with which family formation and reunification requirements can be met in the Netherlands. 


\subsection{Transnatianal families and reunification}

In this section, we take a closer look at the relationship between international migration and living arrangements between spouses and parents and children, from the perspective of Ghanaians who have migrated to the Netherlands or the UK. We examine the living arrangements of these families, and the prevalence of transnational arrangements. Next, we study to what extent these transnational families reunify, looking at couples and parent-child dyads separately.

\subsubsection{Marriages}

At the time when Ghanaian migrants were preparing to depart to either the Netherlands or the $\mathrm{UK}, 1^{\circ}$ a little less than half were married, with little difference between migrants in the Netherlands and migrants in the UK (Figure 4.13). In total, about one quarter of migrants were in a consensual union, but that relationship status is much more common in the UK. For migrants in the Netherlands, divorce rates are higher.

Figure 4.13. Marital status at the time of 1st migration to current destination

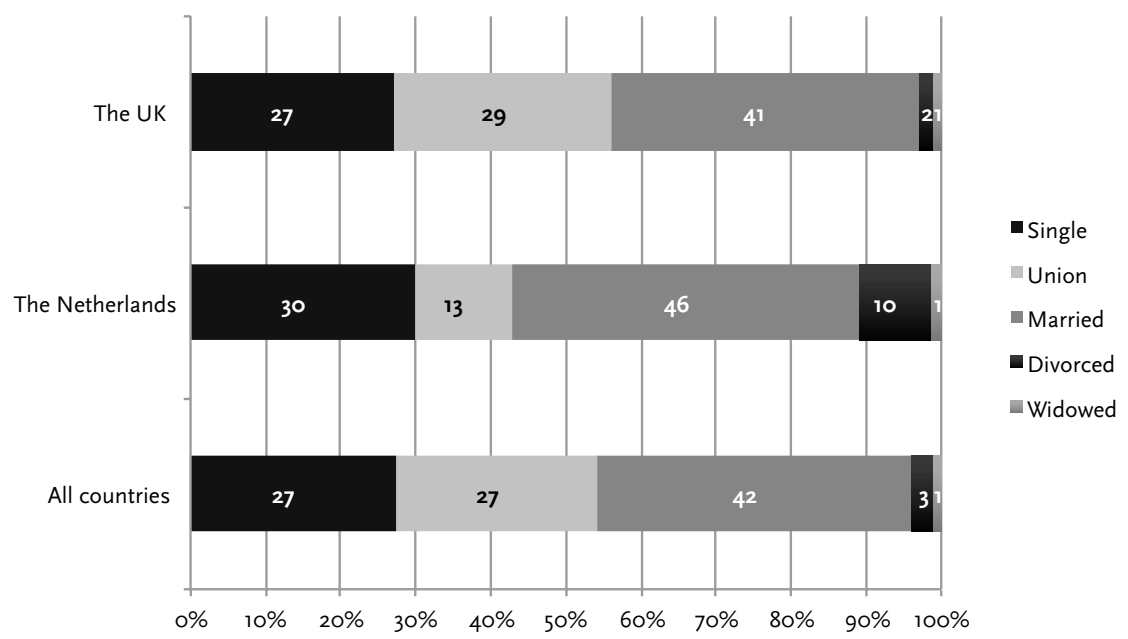

Note: weighted percentages; Source: MAFE-Ghana, 2009-2010, Biographic survey Population: Ghanaian migrants in the UK and the Netherlands ( $n=410)$;

Interpretation: $27 \%$ of Ghanaian migrants in the UK were single at the time of their 1st migration to the current receiving country, and $30 \%$ of Chanaian migrants in the Netherlands were single at the time of their 1st migration to the current receiving country. Statistical significance: The distribution of legal status between family arrangement typologies is significantly different between the Netherlands and the UK ( $p<0.01$, Design-based F-test).

10 In the case of polygamous marriages we included first marriages in the category 'marriage'. When the first relationship is a union, and the second a marriage, we include the marriage. In the case of polygamous unions (so no marriages), we include the first union in the category 'union'. 
Figure 4.14. Living arrangements of married spouses at the time of their 1st migration to current destination

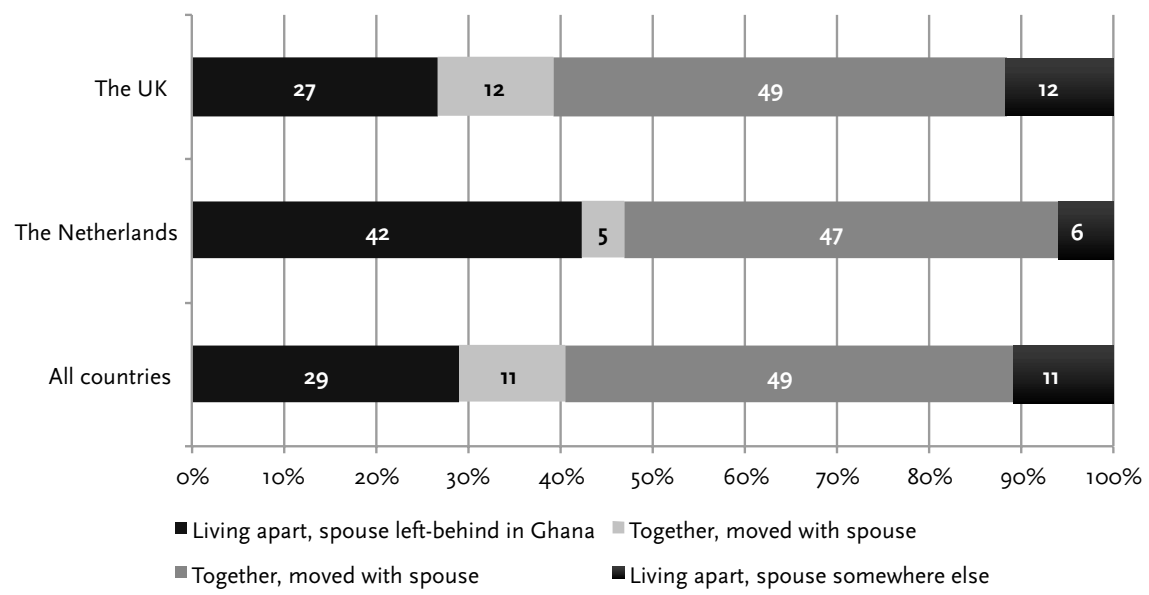

Note: weighted percentages; Source: MAFE-Ghana, 2009-2010, Biographic survey Population: Married Ghanaian migrants in the UK and the Netherlands ( $n=172)$;

Interpretation: $27 \%$ of Ghanaian migrants in the UK were living apart, with their spouse left-behind in Ghana, at the time of their $15 t$ migration to the current receiving country, and $42 \%$ of Ghanaian migrants in the Netherlands were living apart, with their spouse left-behind in Ghana, at the time of their 1st migration to the current receiving country.

Statistical significance: The distribution of living arrangements is significantly different between the Netherlands and the UK ( $p<0.10$, Design-based F-test).

Of those who were married at the time they left Ghana for the Netherlands or the UK, almost half had spouses already in the receiving country, with hardly a difference between countries (Figure 4.14). Migrating together is not very common for these Ghanaian migrants in general, but it is more common in the UK than in the Netherlands. In the Netherlands, it is much more common for migrants to arrive having left their spouses in Ghana.

These processes are highly gendered, as there are significant differences between the sexes and between countries (Figure 4.15)." Migrating and leaving one's spouse behind is more common among male migrants. This difference is especially prevalent in the Netherlands, where $70 \%$ of the male migrants left their wives behind, compared to $30 \%$ of the female migrants. At the same time, reunifying with one's spouse in the receiving country is more common for female migrants: $78 \%$ of the female migrants in the Netherlands migrated to reunify with their husbands in the receiving country, and $70 \%$ in the UK.

\footnotetext{
11 These findings seem to point to interesting differences between both gender and between countries, but the UK results especially should be read with caution due to small sample size.
} 
Figure 4.15. Living arrangements of married spouses at the time of their 1st migration to current destination, by sex of the migrant

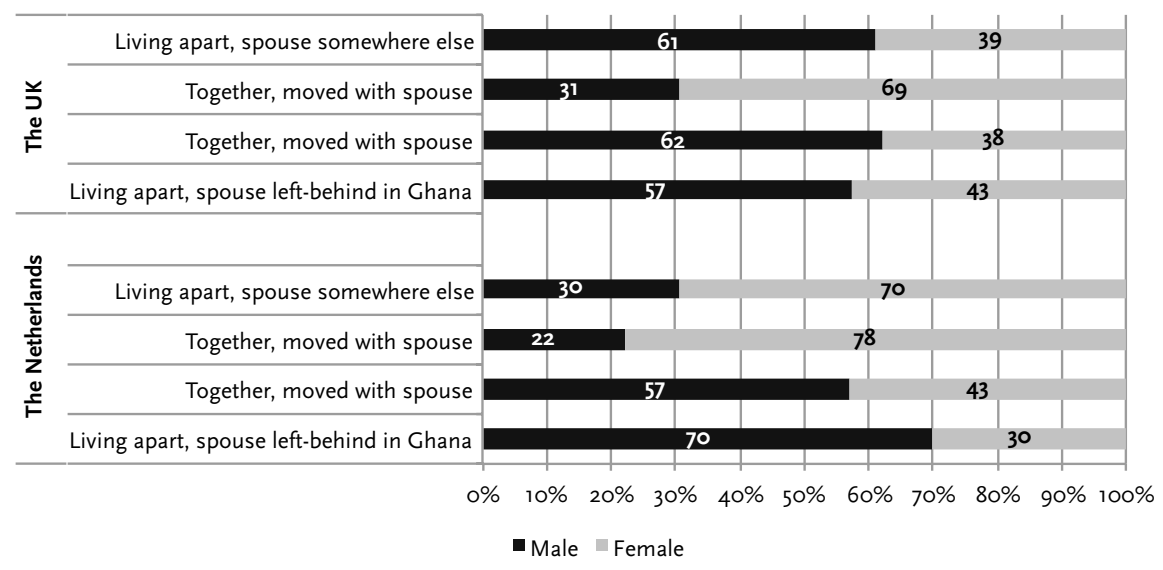

Note: weighted percentages; Source: MAFE-Ghana, 2009-2010, Biographic survey Population: Married Chanaian migrants in the UK and the Netherlands ( $n=172)$;

Interpretation: 57\% of Chanaian migrants in the UK that were living apart, with their spouse left-behind in Ghana, at the time of their $15 t$ migration to the current receiving country were male, and $70 \%$ of Chanaian migrants in the Netherlands that were living apart, with their spouse left-behind in Chana, at the time of their 1st migration to the current receiving country were male.

Statistical significance: The difference between these living arrangements by sex is significantly different in the Netherlands $(p<0.01$, Design-based F-test), but not in the UK ( $p>0.10$, Design-based F-test).

\subsubsection{Couples: time to reunification}

Figure 4.14 shows that $40 \%$ of migrants were living separated from each other at the time of their first migration to the Netherlands and the UK (bar 'All countries' in Figure 4.14). Here we look at how much time these couples spent living apart, and how many of these couples end up reunifying in the receiving country. In Box 4.1 we provide a methodological note on methods and samples used. Figure 4.16 shows the time to reunification in the current receiving country, the Netherlands or the UK. Almost half of the couples reunified in Europe after 5 years of separation. And after 10 years, we see that in total $66 \%$ reunified. Figure 4.17 examines the same probabilities, but distinguishes by sex of the migrant. There appear no significant gender differences; both men and women follow similar patterns of reunification in the receiving country.

In Figure 4.18 we see the difference between Chanaian migrants who reunify in the receiving country and those who reunify in the sending country. After 10 years, $25 \%$ of Chanaian migrants reunified in the receiving country, while $52 \%$ reunified in Chana. This shows that reunification in the receiving country might not always be the preferred or feasible option, and reunification can also occur through the migrant returning home. 


\section{Box 4.1. Examining couples' reunification}

Kaplan-Meier survival functions are used to examine spousal separation from the perspective of migrants in the Netherlands and the UK, seeing to what extent Ghanaian migrants are reunified with their spouse in Europe, and how long they stay separated from their spouses. All Kaplan-Meier estimates are shown using sampling weights. Using the Kaplan-Meier survival estimates to examine the proportion reunified, we show plots that consist of a series of horizontal steps of decreasing magnitude, representing the proportion separated. This proportion decreases as time passes, since more migrants reunify.

In order to carry out this analysis, we defined our sample by looking at who is 'at risk' of reunification. For the first two Figures (4.16 and 4.17), the analysis was restricted to Ghanaians currently living in Europe, who, at the time they started their current migration, were married and had their spouse living in Ghana or in another country $(n=82)$. The event is defined as reunification, when couples start living together in the current receiving country. The plot below shows the total proportion of reunified migrants after a 10-year period. In total, 25 couples reunified within this time period (17 male migrants and 8 female migrants). When individuals have not reunified before the occurrence of the year of survey (2008) or when they divorce or become widowed, they are no longer considered in the analysis.

While the above Figures concentrate on reunification in the receiving country, we also investigate whether reunification takes place in the sending country (Figure 4.18). To examine this, we add to our sample, those migrants who have returned to Ghana and who, at the time they started their first migration to the UK or the Netherlands, were married and had their spouse living in Ghana or in another country $(n=21$, increasing the total sample for Figure 12.18 to $n=103$ ). The event is defined as reunification, when couples start to live together at either the receiving country or the sending origin. For each situation, we estimated a separate survival function, using a competing risks approach. When we examine reunification in the sending country, reunification in the receiving country is censored, and vice versa. 


\section{Figure 4.16. Time to reunification between Ghanaian couples}

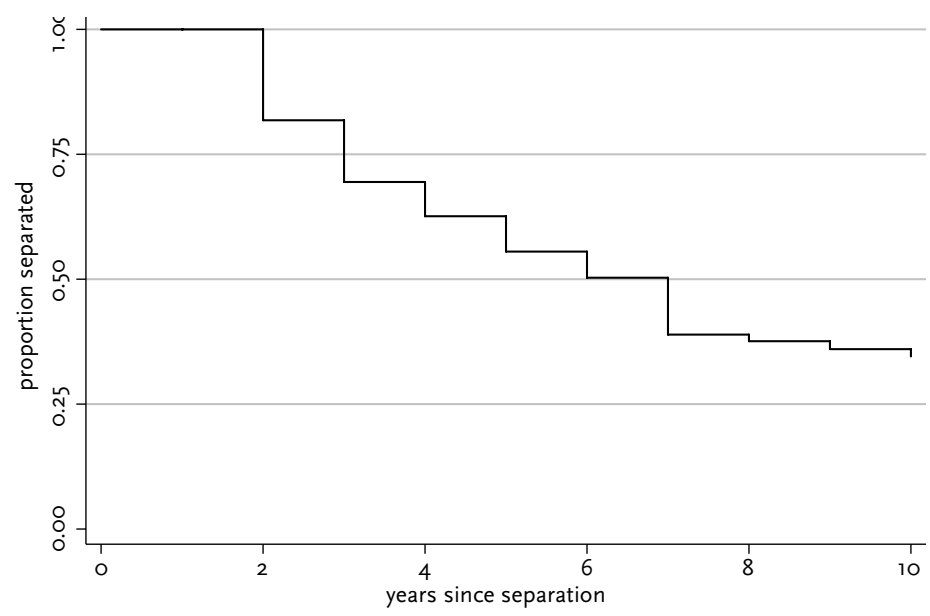

Note: weighted percentages; Source: MAFE-Chana, 2009-2010, Biographic survey

Population: Ghanaian migrants currently living in Europe, who, at the time they started their current migration, were married and had their spouse living in Ghana $(n=82)$;

Interpretation: $44 \%$ of the couples reunified in Europe after 5 years of separation. And after 10 years, we see that in total $66 \%$ reunified.

\section{Figure 4.17. Time to reunification between Ghanaian couples by sex of the migrant}

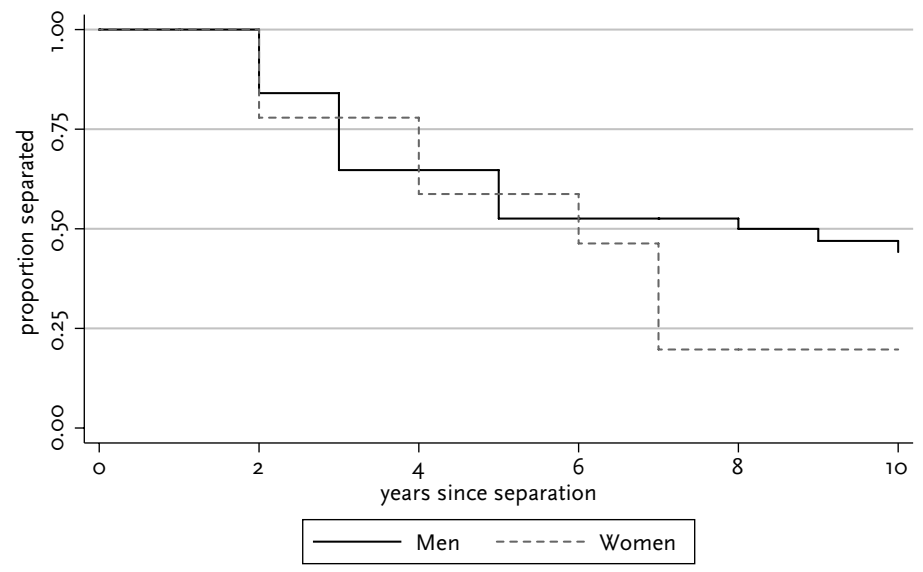

Note: weighted percentages; Source: MAFE-Chana, 2009-2010, Biographic survey

Population: Ghanaian migrants currently living in Europe, who, at the time they started their current migration, were married and had their spouse living in Ghana $(n=82)$;

Interpretation: $47 \%$ of the male migrants reunified in Europe after 5 years of separation, and $41 \%$ of the female migrants did so.

Statistical significance: The difference between reunification and sex of the migrant is not significant ( $p>0.10, \log$ rank test). 


\section{Figure 4.18. Time to reunification between Ghanaian couples:}

origin and destination reunification

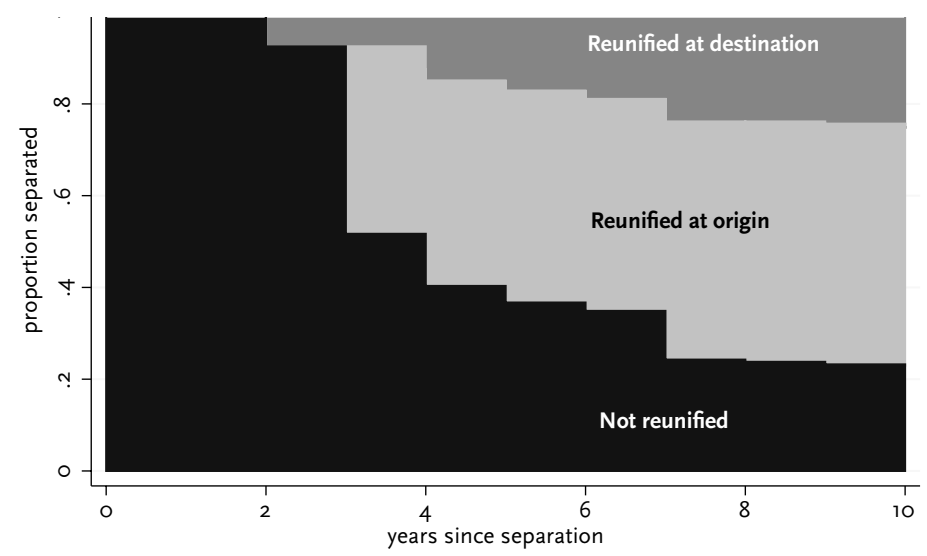

Note: weighted percentages; Source: MAFE-Ghana, 2009-2010, Biographic survey

Population: Chanaian migrants currently living in Europe, who, at the time they started their current migration, were married and had their spouse living in Ghana + those migrants who have returned to Ghana and who, at the time they started their first migration to the UK or the Netherlands, were married and had their spouse living in Ghana $(n=103)$;

Interpretation: $46 \%$ of Chanaian migrants reunified at origin after 5 years of separation, and $17 \%$ of Chanaian migrants reunified in the receiving country.

These findings reveal that transnational marriages can be a long-lasting arrangement, which may be a consequence of stricter policies that make it difficult for couples to reunify, or because of cultural practices in Ghana, where multilocal residence among spouses is common, making geographical separation a preferred option over reunification (Caarls \& Mazzucato, in press).

\subsubsection{Children}

Similarly, we examine parent-child separations and reunifications. Since children need to be 18 years or younger to be eligible for family reunification, we focus on parents with children 0-18 at the time of their first migration. ${ }^{2}$ First, we look at how many parents had children at the time of their first migration to the current receiving country, either the Netherlands or the UK (Figure 4.19).

12 This means that migrants with no children and migrants with only children over-18 are excluded here. Migrants with at least 1 child under-18 are included. 


\section{Figure 4.19. Parental status at the time of 1st migration to current destination}

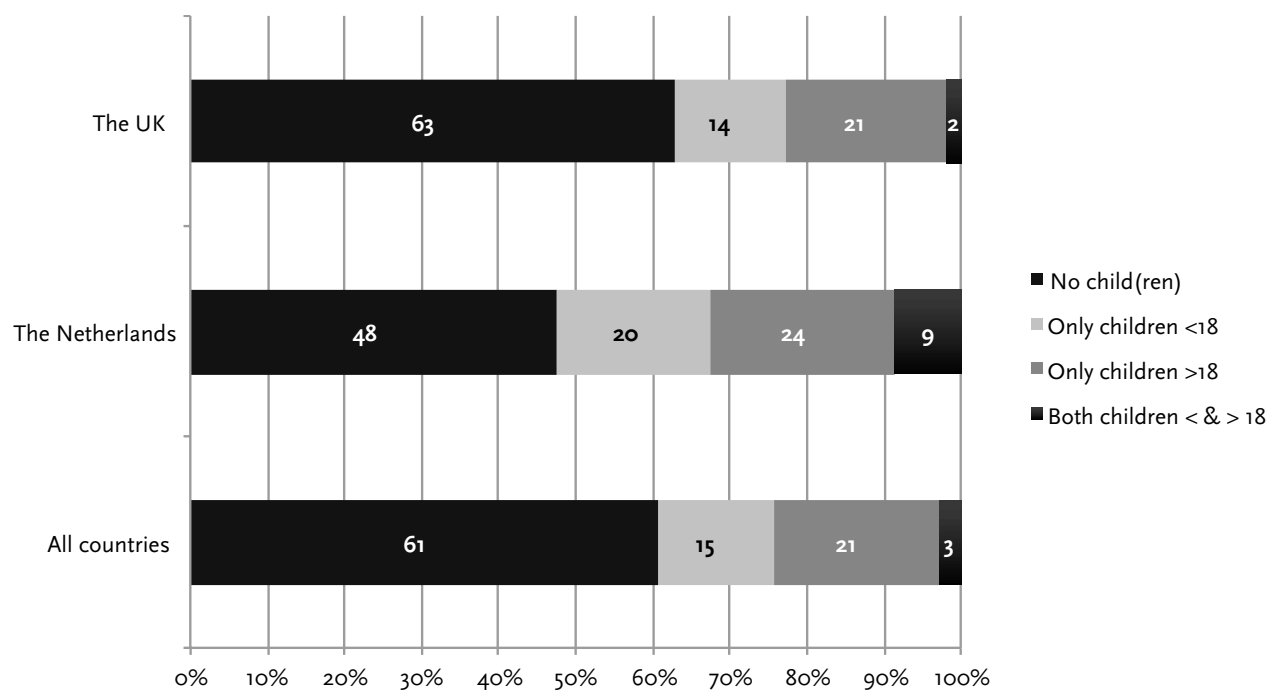

Note: weighted percentages; Source: MAFE-Ghana, 2009-2010, Biographic survey Population: Ghanaian migrants in the UK and the Netherlands ( $n=410)$;

Interpretation: $63 \%$ of Chanaian migrants in the UK had no children at the time of their 1st migration to the current receiving country, and $48 \%$ of Chanaian migrants in the Netherlands had no children at the time of their 1st migration to the current receiving country. Statistical significance: The distribution of parental status is significantly different between the Netherlands and the UK $(p<0.01$, Design-based F-test).

On average, most migrants migrated to their current receiving country without having children. This holds especially true for migrants currently in the UK, where two-thirds of the migrants migrated when they did not have any children, but also in the Netherlands, almost half of the migrants did not have children when they migrated. Looking at the sub-set of migrants who moved to their current receiving country when they had at least one child under 18 years of age, $76 \%$ left all of their children in Ghana (not shown).

\subsubsection{Children: time to reunification}

In this section, we examine the time parents and children spent living apart, and the proportion of parent-child dyads that reunify in the receiving country. Kaplan-Meier survival functions are used to examine parent-child separation from the perspective of migrants in the Netherlands and the UK, seeing to what extent Ghanaian migrants reunify with their child in Europe, and how long they stay separated from their children. We use the same method, Kaplan-Meier survival functions, as explained in Box 4.1. For a methodological note on the specific parent-child sample used, please see Box 4.2. 


\section{Box 4.2. Examining reunification between parent-child dyads}

Kaplan-Meier survival functions are used to examine parent-child separation from the perspective of migrants in the Netherlands and the UK, seeing to what extent Ghanaian migrants reunify with their child (always referring to biological children under-18at the time of survey) in Europe, and how long they stay separated from their children.

The analysis was restricted to Ghanaians currently living in Europe, who, at the time they started their current migration, left their children behind in Ghana. The sample was further restricted in those children who were under-18 at the time the migration started. Each parent-child dyad is one observation $(n=226)$. The event is defined as parent-child reunification in the receiving country ( $n=41$ reunified dyads), with parent-child dyads living together in the current receiving country. When parents have not reunified with their children before the occurrence of the year of survey (2008), when the child has deceased, or when the child reaches the age of 18 , they are treated as censored. Similar to the plots on couple reunification presented above, we show in the plots below the total proportion of reunified migrants after a 10-year period of separation.

When we examine reunification in both the sending and receiving country, we examined these competing 'risks', by including returned migrants from the two survey countries.

\section{Figure 4.20. Time to reunification between Ghanaian parent-child dyads}

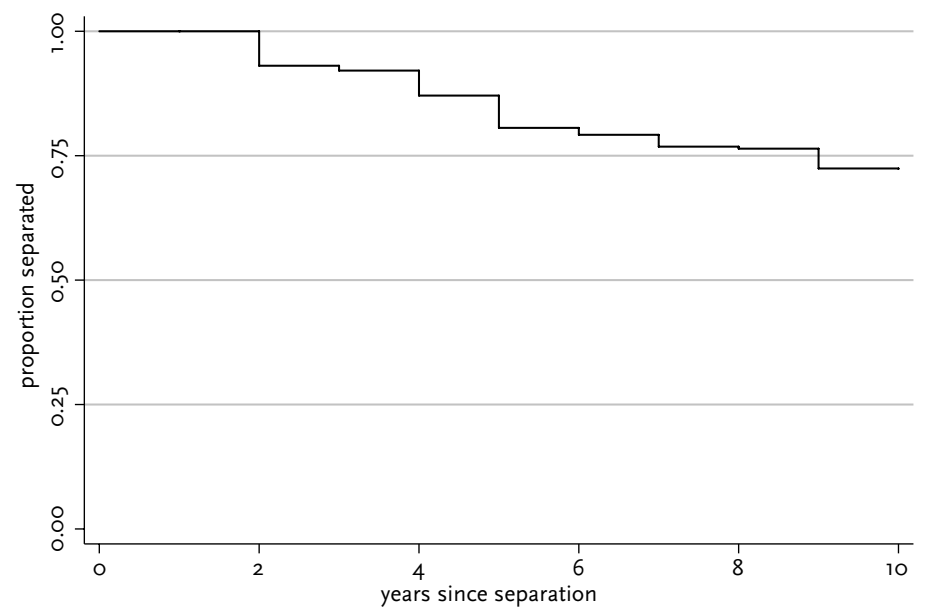

Note: weighted percentages; Source: MAFE-Ghana, 2009-2010, Biographic survey

Population: Ghanaian migrants currently living in Europe, who, at the time they started their current migration, had their child under-18 living in Ghana $(n=226)$;

Interpretation: $19 \%$ of the parent-child dyads reunified in Europe after 5 years of separation. And after 10 years, we see that in total $28 \%$ reunified. 
Figure 4.21. Time to reunification between Ghanaian parent-child dyads by sex of the migrant

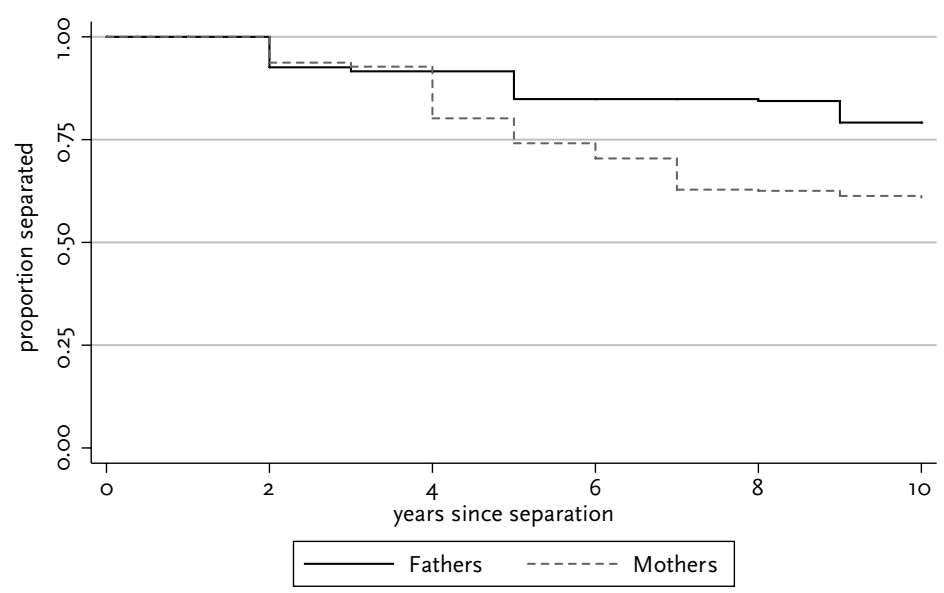

Note: weighted percentages; Source: MAFE-Ghana, 2009-2010, Biographic survey

Population: Ghanaian migrants currently living in Europe, who, at the time they started their current migration, had their child under-18 living in Ghana $(n=226)$;

Interpretation: $15 \%$ of the migrant fathers reunified in Europe after 5 years of separation, and $26 \%$ of the migrant mothers did so. Statistical significance: The difference between reunification and sex of the migrant is not significant ( $p>0.10, \log$ rank test).

Figure 4.22. Time to reunification between Ghanaian parent-child dyads: origin and destination reunification

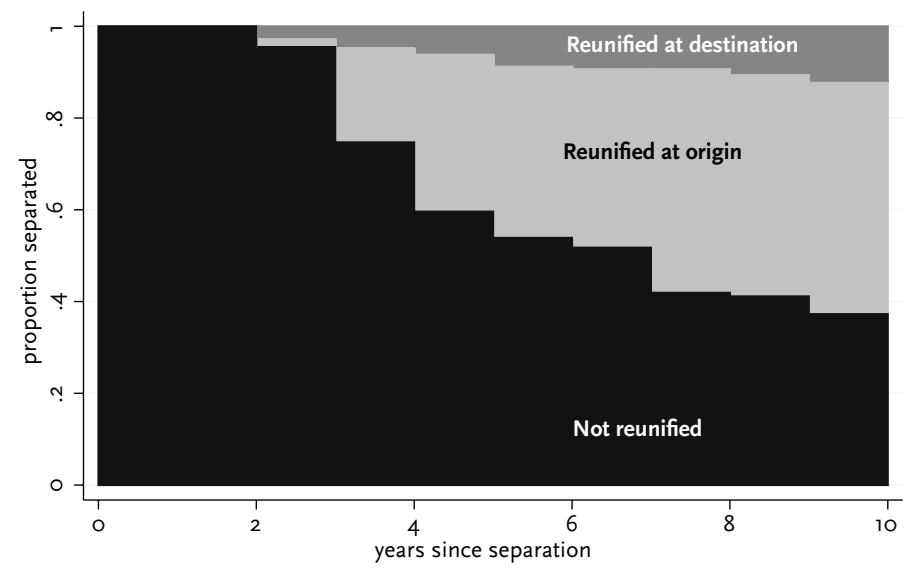

Note: weighted percentages; Source: MAFE-Ghana, 2009-2010, Biographic survey

Population: Ghanaian migrants currently living in Europe, who, at the time they started their current migration, had their child under-18 living in Ghana + those migrants who have returned to Ghana and who, at the time they started their first migration to the UK or the Netherlands, had their child under-18 living in Ghana $(n=299)$;

Interpretation: $37 \%$ of the migrant parents reunified in Europe after 5 years of separation, and $9 \%$ of the migrant parents reunified in the receiving country. 
Figure 4.20 shows the time to reunification in the current receiving country for Ghanaian immigrants in Europe (the Netherlands and the UK) with their left-behind children in Ghana, who were under-18 at the time of the migrant's departure. After 5 years, $19 \%$ reunified with their child, and after 10 years, this increased to $28 \%$. Figure 4.21 shows the difference in reunification between migrant fathers and mothers. Migrant mothers were somewhat more likely to reunite with children compared to fathers, but this difference is not significant.

Again, reunification can take place both in the sending and receiving country. So also for parent-child dyads we examined these competing 'risks', by including returned migrants from the two survey countries, the Netherlands and the UK, see Figure 4.22. We see that, after 10 years, $12 \%$ of migrant parents reunified with their child in the receiving country, compared to $50 \%$ that reunified in the sending country.

Also here, transnational living arrangements are quite prevalent, even more so for parent-child dyads than for couples, and these arrangements are long lasting. The reason for parents to leave their children behind reflects the difficulties that some parents have in meeting the legal requirements for reunification with their children but also that for some parents the Ghanaian educational system is preferred and, additionally, keeping their children in Ghana is a way for having their children grow up in a more culturally appropriate way (Bledsoe \& Sow, 2011; Mazzucato \& Cebotari, 2012).

\subsection{Canclusian d discussian}

The extended family and geographic dispersal of family members that characterize the organization of Chanaian family systems are important elements to take into consideration when interpreting the trends with respect to families and international migration presented in this chapter. Even though there are changes in the roles of the extended family due to modernization processes, the extended family continues to play an important role in marriages, child rearing and in the rights and responsibilities that govern familial relationships. Ghanaian families are also characterized by geographic dispersal. Even at the nuclear family level, it is common for family members to live dispersed due to high levels of internal migration and also to the practices of child fostering and social parenthood where children are placed outside the household to be raised by extended family members.

With this background in mind, family structures under conditions of international migration can be seen as a continuation of certain characteristics of Ghanaian family systems while at the same time presenting new dimensions particular to the international 
context. In the urban contexts surveyed in Ghana, almost half of the households had at least one household member overseas which can be seen as a continuation of multilocal families as already practiced in Ghana. These migratory contacts were for a large part from the extended family, attesting to the importance of extended family members in understanding relationships between migrants and households back home. Nuclear family members were particularly important in terms of receiving support for their migratory trips yet, importantly, more migrants than only those supported actually sent remittances to the household. This indicates that 'pay back' is neither the only nor the main reason for remitting as has been stipulated by some migration studies. Most migrants migrated without help from their households and they send remittances irrespective of whether they received help to migrate. Transnational family life, therefore, takes place within a diversity of relationships within the extended family.

International migration can impact the forms that families take. In European countries, nuclear families can reunite in the receiving country. But at times, either due to restrictive policies or by choice, nuclear family members of migrants live in the country of origin or in a third country. Finally, nuclear families may migrate together or be formed in the receiving country. In a second part of our analysis we focused on the forms that migrants' nuclear family take. We investigated if, when and where families live geographically separate from each other and reunify. There are several salient findings in this regard. First, many migrants were not married nor had children and therefore do not fall under the category of 'reunifiable' families. This is important because both at the European level as well as in the Netherlands and the UK public and policy discourses center around the idea that family reunification is the way for most migrants to enter European countries. Yet of all Ghanaians who migrated to the Netherlands and the UK, $27 \%$ were not married and had no children (or no children under-18), and therefore do not fall under the category of migrants who can potentially move as a family or reunify after one member migrates.

Second, the receiving country makes a difference for family life. Being in a transnational family is more common amongst Ghanaians in the Netherlands than in the UK. In the UK, being in a transnational family is related to lower levels of education relative to migrants who live with their families in the UK and having arrived recently. In the Netherlands, migrants in transnational families have higher educational attainment relative to migrants who live with their family in the Netherlands and have also arrived more recently.

These findings point to two contending explanations as to why migrants live in transnational families. For some migrants, living in a transnational family arrangement may be the preferred choice. In general, Ghanaian migrants in the UK are more highly skilled and occupy professions with higher status than in the Netherlands making it 
possible for them to support a family in the UK. Furthermore, the UK and Ghanaian educational systems share the same language, making it easier for Ghanaian children to transition from Ghanaian to British schools. These conditions favour migrating together as a family or to reunify in the UK. In the Netherlands, instead, where Ghanaian migrants are on average less educated than their UK counterparts and have lower occupational status, and where the school system is in Dutch, Ghanaian parents may prefer to keep their children in Ghana in order for them to complete their secondary education, thus operating as transnational families. This explanation highlights that in some cases living in transnational families may be the preferred choice for migrants given the context of their migration.

A second explanation for transnational family forms is that families are constrained by policies in the receiving countries. In both the UK and the Netherlands the past decade has been one of increasing restrictions in the form of more and higher criteria required for family reunification. In both countries, we see that migrants in transnational families have arrived within the past decade. While the relatively shorter time that they have been in the country may not have given them the chance yet to settle and reunify, it could also be a reflection of increasing restrictions imposed in both the Netherlands and the UK. Rights to family reunification are tied to a series of conditions, most importantly the legal status of the sponsor and their ability to provide secure income and housing. In fact, in both countries we see a relation between legal status and family types, with those who are undocumented or with a visa (short term permit) being mainly in transnational families. This implies that family migration polices are socially selective, particularly excluding more vulnerable groups from the right to family reunification. This explanation highlights that for some migrants, especially the most newly arrived and more vulnerable, being in a transnational family may not be a choice but the result of stringent policy. Gaining a greater understanding when transnational family formations are a preferred choice (driven by individual characteristics) and when instead they are imposed (due to stringent policy) is a fruitful avenue for future research.

Finally, focusing on those that do reunify, our multi-sited data collection allows us to look at where families reunify. This is a new area that the MAFE project has investigated as most research on reunification only focuses on the receiving country side. Importantly we show that reunification between migrants and their spouses and/or children happens to a large extent also in the migrant-sending country. 


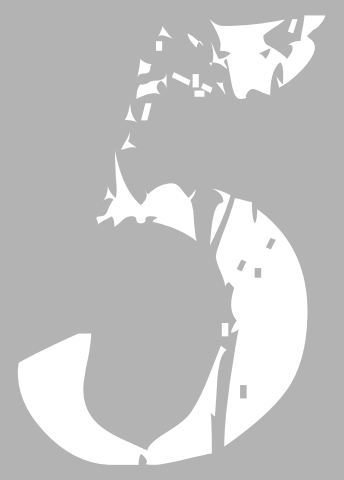

RELATIONAL TRATECTORTES

AND LIVING
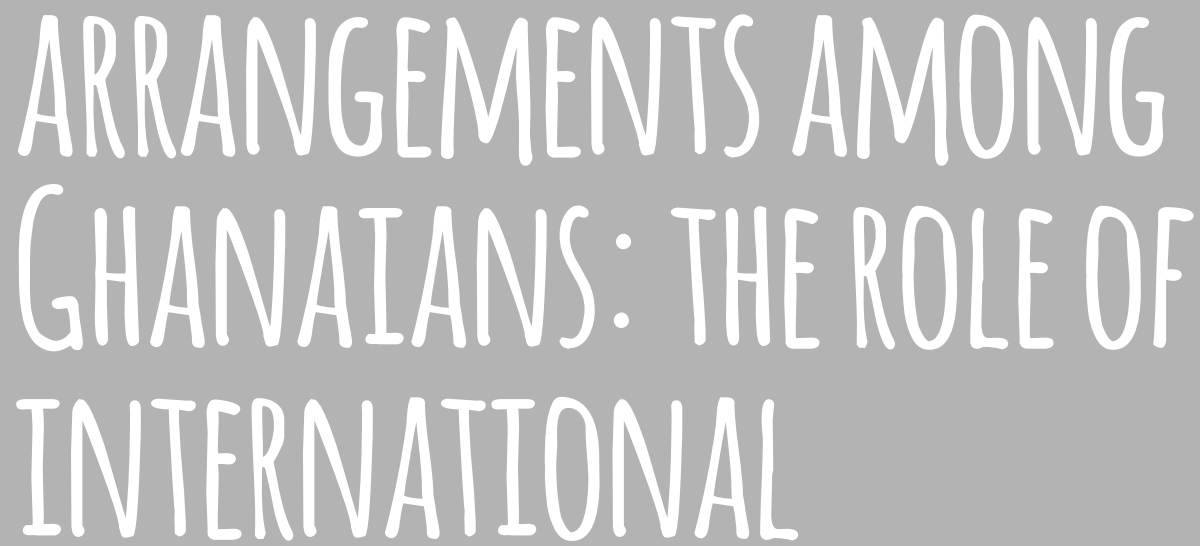

MIGRATION*

* A slightly different version of this Chapter has been submitted as: Caarls, K. \& De Valk, H. (2014). 'Relational trajectories and living arrangements among Ghanaians: the role of international migration' to an international peer-reviewed journal. Tables and figures are re-numbered in order to fit the thesis format. 


\section{I Intraductian}

Migration patterns between Africa and Europe have intensified over recent decades. While a large body of research has addressed the socioeconomic consequences of migration for individuals (e.g., De Haas, 2005; Maimbo \& Ratha, 2005; Orozco, 2002; Portes, Guarnizo \& Haller, 2002), the outcomes for family life are yet to be fully understood. Migrants' relationship status is often simply classified as either single or married. However, these categories do not fully capture people's unions, particularly for international migrants. First, migrants' classification as either single or married reflects a narrow conceptualization of relational status (Roseneil, 2006). To understand migrants' relational trajectories, we should consider couples' living arrangements. Not only unmarried unions but specifically non-residential relationships should be included because couples do not always share a home (Antoine et al., 2009). Questions about how couples' living arrangements may vary as a consequence of migration or how these living arrangements might be shaped by the context in the sending or receiving country are still unanswered. Relational trajectories can also be influenced through exposure to the sociocultural practices of the origin country. Furthermore, regulations concerning legal documents and family reunification policies play a crucial role in shaping these trajectories in the receiving country.

Second, a classification as married or single does not pay sufficient attention to the reality that migrants might bring a spouse either through family reunification or as part of family formation. Spousal migration is often viewed with apprehension. It is often associated with dependent and subordinate spouses who are mostly female and often do not participate in the labour market; spousal migration can also be regarded as leading to a situation where forced, arranged and fraudulent marriages take place (Kofman et al., 2013). Additionally, family migration, and spousal migration in particular, has become one of the main routes of legal entry into Europe and the United States (OECD, 2014). Because of these concerns, there is an increased focus in many nation-states on how to manage spousal migration. However, despite this focus, there is still limited knowledge about the dynamic nature of and variation in migrants' relationship trajectories.

The majority of research on international migration and family life focuses on migratory flows between Latin America or Asia and the US (e.g., Constable, 2003; Frank \& Wildsmith, 2005; Hill, 2004; Landale \& Ogena, 1995). Studies on migrants in Europe predominantly focus on the integration of the 'guest worker' generation (Glick, 2010). However, 'new' migrant groups, mostly those who migrated between Sub-Saharan Africa and Europe, remain largely understudied despite their increasing numerical significance. Studying the relational trajectories of these African migrants can be beneficial for an understanding of familial relations in the context of international 
migration. These migrants typically come from origin contexts where norms surrounding living arrangements are very different compared with norms in countries where guest workers have migrated to, such as norms about spouses living geographically separate. In addition, these migrants have different socioeconomic backgrounds and face a different receiving context compared with guest workers who arrived during the 1970 s and 1980 s (Mazzucato \& Schans, 2011).

In this paper, we simultaneously explore the relational trajectories and living arrangements of Ghanaians. Furthermore, we question to what extent international migration shapes relational trajectories, and how these might differ between men and women. Examining the Ghanaian case is particularly interesting for studying the effect of migration on relational trajectories. First, Chana has a long history of both internal and international migration (Anarfi et al., 2003; Reed, Andrzejewski \& White et al., 2010; Twum-Baah, 2005). Second, the Ghanaian case allows us to unravel the relationship between the effects of existing sociocultural practices in the country of origin on the one hand, and the effect of international migration on the other hand. Previous studies (e.g., Mazzucato \& Schans, 2011; Caarls, Schans, Mazzucato, Quartey \& Tagoe, in press) have argued that transnational relationships can be relatively straightforward for migrants from Chana, as such relationships are seen as a continuation of the individuals' previous lifestyle of living apart together. Or, for those who did not experience this practice first hand, they are part of a culture where norms about living arrangements include multilocal residences. The fact that multilocal residence is commonly practiced in Chana both historically as well as today allows us to compare the relational trajectories of individuals with and without this experience. Third, Ghanaian migration has traditionally included substantial shares of women. This specific feature enables an exploration of how relationship histories and migration evolve differently across life for men and women.

To capture the many ways in which couples' relational trajectories can be affected by international migration, we require full information on the relational trajectories of both migrants and non-migrants. Until recently, few large-scale datasets were available that allowed for such a comparison. The unique dataset collected in the Migration between Africa and Europe (MAFE) Ghana project allows this type of analysis. Using a biographical life history survey, this paper uses data from the MAFE-Chana project, which sampled current migrants in Europe and returnees and non-migrants in Chana.

We adopt a life course approach when studying the relational trajectories. This approach explicitly addresses the sequencing and timing of events and how such events are related to changes in context (Elder, 1985; Kulu \& Milewski, 2007). While the majority of migration studies concentrate on a specific point in time, a full comprehension of migrants' (family) behaviours requires an approach that addresses the dynamic nature of migrants' lives (Wingens et al., 2011). Thus, we contribute to the literature by studying 
relational trajectories over time. Additionally, by recognizing the gendered nature of migration experiences (e.g., Gallo, 2006; Hill, 2004; Jolly \& Reeves, 2005), we specifically investigate whether migrant men and women have different relational trajectories.

\subsection{Relatianships d migratian in Ghana}

Scholarly work on transnational families has resulted in questions about common notions about family life, such as Western norms that stress the need for geographic proximity as a condition to practicing familyhood (Mazzucato, 2013). Although international migration often results in 'scattered families', such families still experience a sense of belonging and familyhood (Coe, 2014; Bryceson \& Vuorela, 2002). Additionally, in Ghana, as in many countries in the region, couples do not necessarily co-reside. Men and women have traditionally lived apart, typically with each spouse living with his or her own family, which stresses the importance of lineage ties over conjugal bonds (Clark, 1994; Manuh, 1999; Oppong, 1970). This practice of non-residential relationships is not necessarily a remnant of the past. Even today, many couples continue to live apart together in Ghana (Coe, 2011, 2014).'

When considering conjugal life in Ghana, it is important to consider gender norms, which shape the context in which these relationships take place. Many studies have noted the independence of Ghanaian women from both matrilineal and patrilineal lineages (Manuh, 1999; Oppong, 1970). Women who work outside the household are not uncommon in Ghana. The combination of this independence and the common practice of multilocal residence have resulted in relationships that are not necessarily egalitarian but that can be characterized by a great degree of autonomy for both spouses (Coe, 2011). This autonomy shapes a context in which geographic separation is not only frequently practiced but is also not necessarily problematic.

In addition to this context of union formation, Ghana is also characterized by substantial internal and international migration. Although both migration streams are significant, we focus on international migration here. While Ghana became a netemigration country beginning in the 1960s, migration flows notably increased in the $1980 \mathrm{~s}$ (Anarfi et al., 2003). Since then, migration to Europe and North America has continued to expand, with Ghanaians becoming part of the so-called 'new African diasporas' in the 1990 (Koser, 2003). While reliable data are lacking, Twum-Baah (2005) estimated

1 We use the terms 'LAT relationships' and 'non-residential relationships' interchangeably. The practice of 'multilocal residence' also refers to this type of relationship. 
that approximately 1.5 million Ghanaians lived overseas in 2003. Consequently, many Ghanaian families are transnational, and almost half of Ghanaian urban households have a household member residing overseas (Caarls et al., in press). Ghanaian migrants extensively engage in transnational practices through monetary and social remittances as well as through investments at origin (Orozco, 2005).

The reputedly greater independence of Ghanaian women compared with women from more patriarchal neighbouring countries (Oppong, 1970), in addition to the feminization of the Ghanaian migration flow (Anarfi et al., 2003), makes the study of the role of gender in shaping relational trajectories in the context of migration extremely relevant. Previous work has shown that which partner migrates matters: the probability of divorce has been found to be larger for Ghanaian couples when the wife migrated independently than when the husband migrated independently (Caarls \& Mazzucato, in press). Similarly, relational trajectories might also differ for couples where the man moves versus couples where the migrant is female. Furthermore, couples with previous experience with multilocal residence might be affected differently than those who do not have such experience. For example, couples who were engaged in a non-residential relationship prior to their migration might be more likely to continue their LAT relationship across borders.

\subsection{Riving apart tagether acrass learders}

Given the multilocal tradition, Ghanaian couples do not necessarily live together in Ghana. In addition to this practice in the country itself, an increasing body of literature has addressed the phenomenon of couples living apart together across borders, often referred to as transnational couples. Existing studies using qualitative research methods have shown that maintaining a relationship across borders requires extensive effort by both the migrant and the left-behind spouse (Gallo, 2006; Hondagneu-Sotelo, 1994; Pribilsky, 2004). Although transnational relationships are predominantly considered problematic or as second-best options, some scholars stress that couples can manage long-distance separations quite well and for long durations (Kanaiaupuni, 2000; Landolt \& Wei Da, 2005; Pribilsky, 2004).

However, we still know little about the prevalence of transnational families, and transnational couples have only recently been studied using a more quantitative research approach. The few existing studies have all noted that LATAB could be a long-term arrangement, particularly for West Africans (González-Ferrer, 2011; Baizan et al., 2014; Beauchemin et al., 2014). In addition, not all transnational couples desire to reunify 
(Landolt \& Wei Da, 2005). The long duration of LATAB arrangements might be the result of several factors. As for the receiving context, more stringent immigration policies as well as stricter regulations concerning family reunification might hinder processes of reunification both in terms of reunification in the sending and the receiving country (González-Ferrer, 2011; Baizan et al., 2014). For Senegalese migrants in Europe, those with lower social and economic status were reported to be more likely to stay separated (Baizan et al., 2014). However, existing social-cultural practices in the origin context might make West Africans more inclined to endure long-term relationships across borders than migrants coming from countries where such practices are less common.

\subsection{Relatianal trajectaries: a life caurse appraach}

The life course approach has been applied extensively in family sociology, including in studies on union and family formation and the transition to adulthood in general. Scholars have acknowledged the importance of studying transitions and experiences throughout the life course, not only as separate events but also as a sequence of events that evolve over life. Studying not only the occurrence but more specifically the sequence of events allows for a better understanding how lives evolve by recognizing that events over the life course are linked, influenced by significant others, and take place in a specific historical, geographic and institutional context (Billari \& Piccarreta, 2005; Giele \& Elder, 1998). A life course approach thus considers both agency of the individual and the structural situation over time (Elder, 1985; Giele \& Elder, 1998; Kohli, 2007; Mayer, 2000; Wingens et al., 2011).

Although the link to migration decisions seems obvious, the life course approach has been rather scarcely applied in migration studies. Most migration studies focus on one specific point in time, such as the situation of migrants after migration. Additionally, migration studies are largely dominated by studies on migrant integration that examine migrants' socioeconomic situation in the receiving society. However, understanding migrants' behaviours, which are embedded in and shaped by their societal structures, necessitates an approach that explicitly addresses the dynamic nature of human life (Kulu \& Milewski, 2007; Wingens et al., 2011).

In addition, for the current study, where we aim to link migration and living arrangement decisions, a more integrated perspective on the linkages between these choices seems useful. Non-residential relationships can occur at multiple moments: 
prior to migration, as a consequence of migration or as a living arrangement in the receiving country after migration. Moreover, non-residential relationships are an accepted part of Ghanaian society. In addition to revealing the dynamic nature of relationships by examining the relational trajectories of Ghanaian couples over time, we further aim to explore the role of international migration on these trajectories. Considering the fact that gender shapes both migration experiences and relationship trajectories, we also scrutinize the role of gender and in particular the interplay between gender and migration.

\subsection{Data d methads}

The MAFE-Ghana survey, which was carried out in 2009-2010 among Ghanaians in Ghana, the United Kingdom (UK), and the Netherlands, provides the data for our study. This survey collected retrospective information on different life domains, such as housing, education, migration, and marital status, on an annual basis. Respondents between the ages of 25 and 75 years old and who were born in Ghana were sampled. Current migrants were interviewed in the Netherlands and the UK, and non-migrants, migrant spouses and returnees were interviewed in Ghana. The collection of the survey data took place in urban areas both in Ghana (Accra and Kumasi) and in Europe (Amsterdam, The Hague, and Almere for the Netherlands and London for the UK). In Ghana, 1,246 respondents were surveyed, and 273 and 149 migrants were surveyed in the Netherlands and the UK, respectively. These three datasets yielded a complete dataset of 1,665 respondents (for more details about the data collection, please see Beauchemin, 2012; Schoumaker \& Diagne 2010).

\section{Analytical sample}

To study the relational trajectories of Ghanaians with and without international migration experience, we analyse the relationship histories of individuals between the ages of 21 and 35 years. Retrospective information was used to capture these transitions, which were reported on an annual basis. All of the respondents had to be observed over an identical period to describe and analyse their relational trajectories (Robette \& Thibault, 2008) because we only wished to examine complete trajectories.

The age bracket 21-35 captures Ghanaians in their young adulthood, and Ghanaians on average entered their first marriage within this age bracket (21.1 for females and 25.4 for males (GSS, Ghana Health Service (GHS) and ICF Macro, 2009)). We further expect both migration and relational trajectories to differ substantially after age 35. At age 35, the likelihood of different previous relationships, partners and children increases, and such 
differences may have different implications for migration decisions than is the case for those who are making these transitions to adulthood for the first time. Based on these considerations, we opted to analyse respondents when they were aged 21 to 35 , and we restricted our sample to respondents for whom we had information about the entire 15year period we were interested in.

Polygamous couples, couples whose relationship ended because of the death of a spouse, and couples for whom the spouse was the migrant (and the respondent did not experience migration) within our observation period were excluded because the size of these groups was insufficient to enable a specific analysis. Thus, from our initial sample of 1,107 respondents with a sequence length of 15 years, we dropped 239 (21.6\%) individuals. In total, 46 (4.2\%) respondents were involved in a polygamous relationship, $114(10.3 \%)$ were widowed, and 83 (7.5\%) respondents did not experience migration. These restrictions resulted in a total sample size of 886 respondents to be analysed here.

\section{Estimation strategy}

To examine relational trajectories over time, we applied sequence analysis (Abbott \& Tsay, 2000; Robette \& Thibault, 2008). A trajectory is an ordered list of states, where states refer to values of a categorical variable that describe the status of an individual or a couple at a given point in time. This categorical variable can take a finite set of possible values. In this paper, we studied relational trajectories and identified 6 possible states that our respondents could experience over the course of the 15 -year period of observation.

There were several parts to the analysis. First, we described the relational trajectories of Ghanaian couples and explored which trajectories were most prevalent. Second, we applied Optimal Matching (OM) to identify clusters of similar trajectories (Abbott \& Tsay, 2000). OM matches sequences that are considered the most similar, where similarity is calculated by considering the 'costs' of matching sequences. We opted for a cost matrix that is based on the transition rates (for more detail, see, e.g., Abbott \& Tsay, 2000; Anyadike-Danes \& McVicar, 2010; Brzinsky-Fay \& Kohler, 2010; Robette \& Thibault, 2008). Transition rates refer to the probability of moving from one state to another between each pair of states (e.g., the probability of moving from $S$ to UT, from $S$ to MT, or from MT to S).

We applied the Partitioning Around Medoids (PAM) algorithm to identify clusters, and we carried out a visual inspection of the clusters combined with reported Average Silhouette Width (ASW) to decide on the optimal number of clusters (Kaufman \& Rousseeuw, 1990; Kleinepier, De Valk \& Van Gaalen, 2014). The TraMineR and WeightedCluster packages in R were used for the calculations (Gabadinho, Ritschard, Müller \& Studer, 2011; Studer, 2013). 
After identifying the optimal number of clusters based on the criteria stated above, we used these clusters to examine whether they differed between migrants and nonmigrants as well as between men and women. Finally, we used multinomial logit models with the clusters derived from $\mathrm{OM}$ as the dependent variable to estimate which factors are associated with which typology.

\section{Measures of variables}

To analyse relational trajectories, we combined two variables. The first variable measures relationship status and distinguishes between four possible states: single, in an unmarried union, in a married union, and separated (either through separation or divorce). We used self-defined measures of marital status; 'married' can imply customary, religious, or civil marriages or a combination of these. Similarly, separation and divorce are also self-reported. The second variable captures a couple's living arrangement, i.e., whether the spouses live in the same household. Integrating these two variables resulted in six different states, which will serve as inputs for our sequential analyses: 1) being single (S), 2) being in a union and living together (UT), 3) being in a union and living apart (UA), 4) being married and living together (MT), 5) being married and living apart (MA), and 6) being out of a relationship (D).

In Table 5.1, an overview of the independent variables used in our analytical sample is presented for the full sample as well as for those with and without migration experience separately. Our main variable of interest is the migration experience. We used a dichotomous variable that captures whether the respondent migrated internationally when he or she was between 21 and 35 years of age. While the MAFE survey recorded both long and short stays outside of Ghana, when we refer to a migration experience in this paper, we refer to long stays, i.e., a period abroad that lasted for at least one year. We have information on all international moves and the year they occurred, which allows for distinctions between not only the occurrence but also the ordering of events, which is crucial for sequence analyses.

Additionally, we controlled for several sociodemographic and socioeconomic variables that are known to influence relationships and living arrangements in Ghana (see, e.g., Amoateng \& Heaton, 1989; Awusabo-Asare, 1988; Reed et al., 2010; Takyi, 2001; Takyi \& Gyimah, 2007). First, we consider the respondents' sex ( $1=$ men, $2=$ women). The educational level of the respondent was included by measuring the highest level attained at age 35, with $1=$ no schooling/primary level, $2=$ secondary level, and $3=$ tertiary level. We further included the total number of children the respondent had at age 35 (range $0-8$ ), and whether the respondent belongs to the matrilineal lineage group Akan $(\mathrm{o}=n o, 1=$ yes). Respondent's birth cohort was distinguished by 3 categories: $1=$ $<=1950,2=$ between 1951 and 1960 , and $3=>=1961$. 
Table 5.1. Overview of independent variables

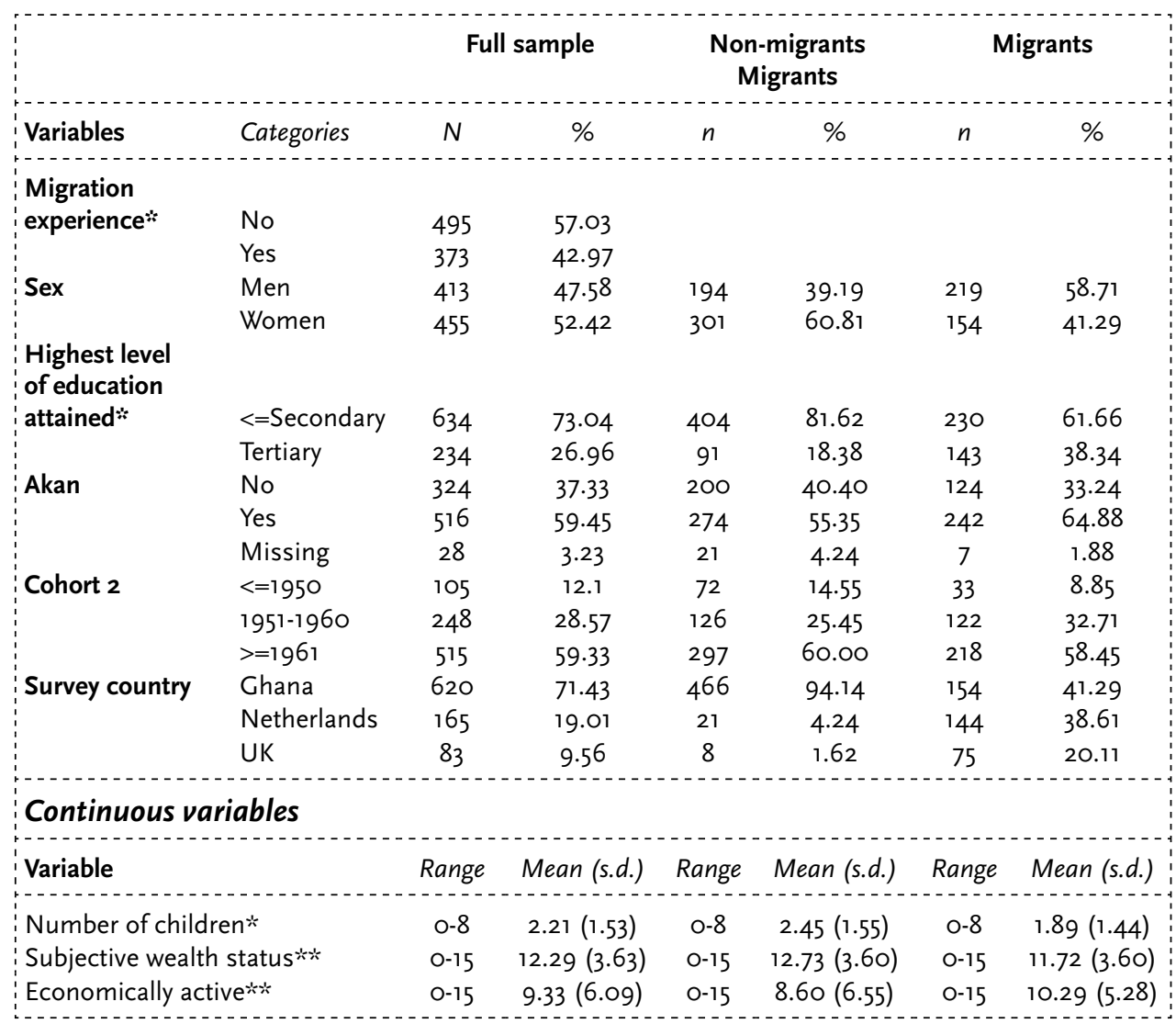

Source: MAFE-Ghana data, 2009-2010

Notes: * Referring to the period of observation, i.e., between $21-35$ years of age $* *$ Referring to the number of years the respondents have experienced episodes of being satisfied with their financial situation/being economically active.

Subjective wealth status captured retrospective information about the subjective wealth status of the respondent for each year. It is difficult to reliably capture respondents' objective income with a retrospective survey; therefore, we use the respondents' replies concerning their subjective wealth status. The following question was asked: 'Would you say that during this period you had enough to live on?' This question resulted in three response categories: $1=$ absolutely, $2=$ it depended, and $3=$ not at all. For our multinomial analyses, we recorded the number of years that the respondent indicated to be absolutely satisfied between ages 21 and 35 , thus creating a continuous variable where higher scores indicate more periods of being financially satisfied. In a similar vein, we created the variable economically active, which refers to the number of years that the respondent was economically active. To further examine the role of gender and to analyse the gendered 
nature of migration, we included an interaction term between gender and migration experience.

\subsection{Findings}

Using respondents' retrospective information for a 15-year period, starting from when they were 21 years of age, we measured transitions on a yearly basis. Because each trajectory consists of 15 states, we could theoretically identify 615 different trajectories. We identified 480 different sequences in our sample, and 384 (44.2\%) are distinct sequences. Next, we examined the diversity of states in our sample at each given age. We compare these transversal state distributions between migrants and non-migrants, men and women, and a combination of migration experience and gender.

We examined the sequencing of states by looking at the most common trajectories for migrants and non-migrants (Table 5.2). Both migrants and non-migrants moved most often from a single status to a non-residential marriage, although this trajectory occurred more frequently among migrants (S-MA, $25.4 \%$ for migrants and $18.8 \%$ for non-migrants). The second most popular trajectory for non-migrants was to already be married and living apart at age 21 and remaining so at least until age 35 (MA, 15.8\%). Migrants, on the other hand, were more likely to move from being single to a co-residential marriage and then to a non-residential marriage (S-MT-MA, 23.2\%). This result indicates that migrants on average entered into marriage at a later age compared with non-migrants. It also shows that for a large share of migrants, a co-residential marriage was followed by a non-residential marriage. This pattern also occurred among non-migrants, although to a much lesser extent (15.2\%). The prevalence of non-residential marriages among both migrants and non-migrants exemplifies that this type of arrangement is not necessarily the outcome of international migration. In terms of the 10 most common trajectories, migrants were also more often engaged in unmarried unions: $17.3 \%$ compared with $11.4 \%$ for non-migrants. 
Table 5.2. 10 most common successions of states by migration experience

\begin{tabular}{|c|c|c|c|c|c|}
\hline \multicolumn{4}{|c|}{ Migrants } & \multicolumn{2}{|c|}{ Non-migrants } \\
\hline States* & $n$ & $\%$ & States & $n$ & $\%$ \\
\hline S-MA & 47 & 25.4 & S-MA & 63 & 18.8 \\
\hline S-MT-MA & 43 & 23.2 & MA & 53 & 15.8 \\
\hline MA & 20 & 10.8 & S-MT-MA & 51 & 15.2 \\
\hline$S$ & 18 & 9.7 & S-MT & 43 & 12.8 \\
\hline MT-MA & 17 & 9.2 & MT-MA & 38 & 11.3 \\
\hline S-UT-D & 9 & 4.9 & $\mathrm{~S}$ & 32 & 9.5 \\
\hline S-UT-D-MT & 9 & 4.9 & MT & 18 & 5.4 \\
\hline S-MT & 8 & $4 \cdot 3$ & S-UT & 13 & 3.9 \\
\hline UT-D-MT-MA & 8 & $4 \cdot 3$ & S-UT-D-MT & 13 & 3.9 \\
\hline UT-D-MA & 6 & 3.2 & S-UT-D & 12 & 3.6 \\
\hline Total & 185 & 100.0 & & 336 & 100.0 \\
\hline
\end{tabular}

Source: MAFE-Ghana data, 2009-2010

Notes: * $S=$ being single, UT = being in an unmarried union and living together, UA = being in an unmarried union and living apart, $M T=$ being married and living together, $M A=$ being married and living apart, $D=$ being out of a relationship (either through divorce (in case of married union) or separation (in case of unmarried union)).

In Figure 5.1, we examined the distribution of states for migrants and non-migrants between ages 21 and 35. First, we see that the share of singles at age 21 is slightly over $50 \%$ for both groups. Second, we find that those with migration experience are more often in an unmarried union compared with their non-migrant counterparts. Nonmigrants are more frequently in a married union. Non-residential marriages appear to be a significant relationship type for both migrants and non-migrants. Migrants have more often experienced separation (either through divorce or separation from an unmarried union) than their non-migrant counterparts.

In Figure 5.2, we examined transversal state distributions for males and females separately to discern gender differences. In line with previous studies (GSS, GHS and ICF Macro, 2009; World Bank, 2008), we note that men are not only more likely to be single at age 21 but are also more likely to remain single over time. This result indicates that males enter into marriage at later ages than their female counterparts. LAT relationships are more common among women than men. 
Figure 5.1. State distributions for migrants and non-migrants

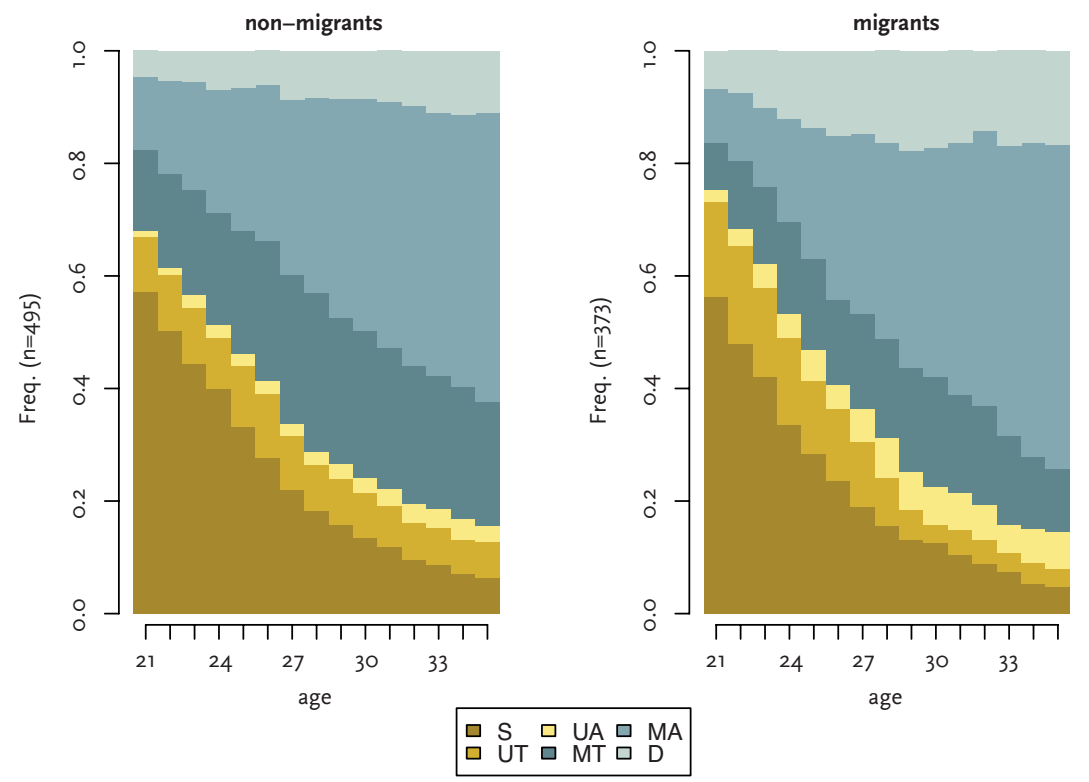

Source: MAFE-Ghana data, 2009-2010

Figure 5.2. State distributions for men and women

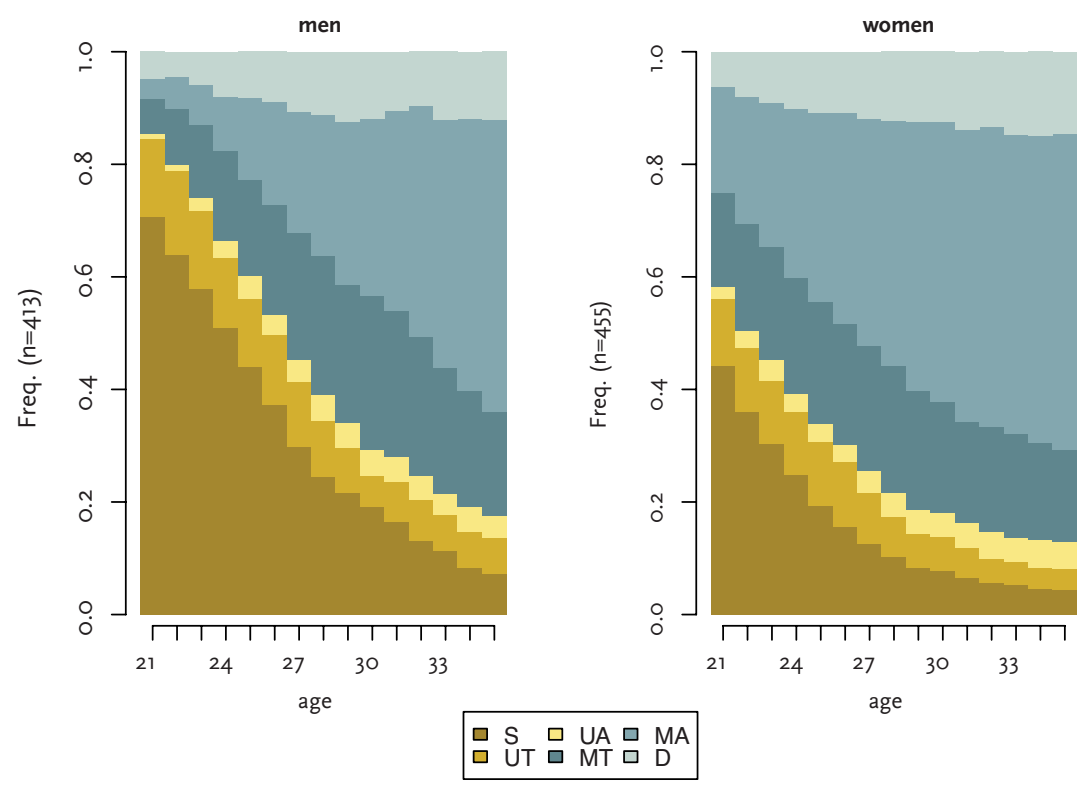

Source: MAFE-Ghana data, 2009-2010 
To examine the interplay between migration and gender, we plotted the state distributions for migrant men and women as well as for non-migrant men and women in Figure 5.3. While men are more likely to be single than women in general (see Figure 5.2), nonmigrant men are particularly more likely to be single than non-migrant women. Migrant men are more often in an unmarried union compared with non-migrant men. However, non-migrant men are more likely to be involved in co-residential marriages than migrant men. Similarly, non-migrant women are more frequently engaged in co-residential marriages than migrant women. In line with Figure 5.1, we see that both migrant men and women are more likely to be divorced or separated. Being married and living apart is much more common for women, but for migrant women in particular.

\section{Figure 5.3. State distributions for (non-) migrant men and (non-) migrant women}
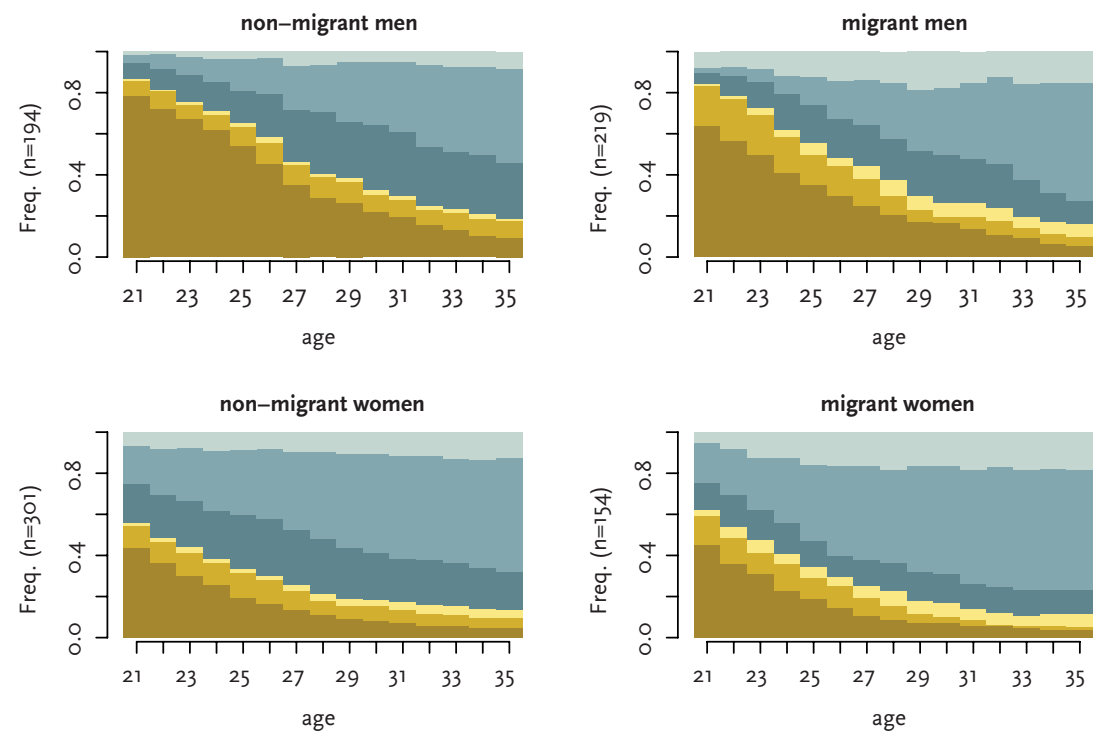

$\begin{array}{lllll}\square & S & \text { UA } & \square & \text { MA } \\ \square & \text { UT } & \square & \text { MT } & \square\end{array}$

Source: MAFE-Ghana data, 2009-2010

We applied optimal matching techniques to explore which relational trajectories are most similar. We identified 4 clusters (ASW 0.43) that represent 4 different types of relational trajectories for young Ghanaian adults (Figure 5.4). The first cluster refers to young adults who follow a trajectory that is predominated by co-residential marriages that came about in their early 20s. We labelled this trajectory 'co-residential marriages', and $25.0 \%$ of Ghanaians in our sample belonged to this type. A second type of relational trajectory is composed of Ghanaians that were mostly single until age 35 or those who 
entered into relationships later in life (mostly in their early 30s). We refer to this cluster as 'singles', and it represents $17.7 \%$ of our sample.

The third cluster is the most heterogeneous cluster. It captures trajectories that are characterized by unmarried unions as well as relationships that are characterized by separation, either through separation from an unmarried union or divorce. $20.1 \%$ of our sample belongs to this cluster, which we named 'mixed trajectories'. Finally, in the fourth cluster, we included trajectories with non-residential marriages. Almost all of the respondents in this cluster experienced non-residential marriages, and some did so over the entire period of observation. This cluster is labelled 'non-residential marriages', and with $37.2 \%$ of our sample belonging to this category, this cluster represents the most common trajectory.

\section{Figure 5.4. Four relational trajectories clusters identified through OM}

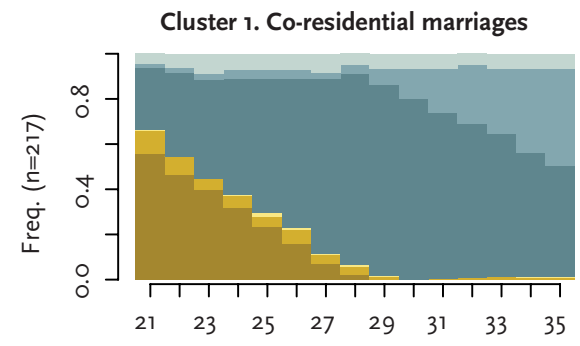

Cluster 3. Mixed trajectories

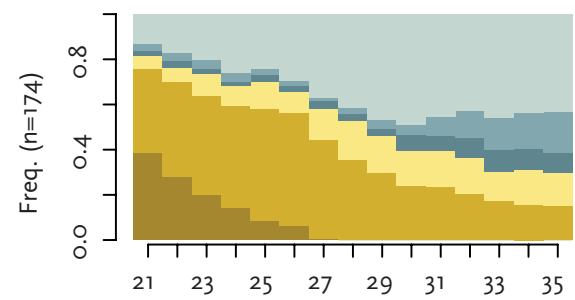

Cluster 2. Singles

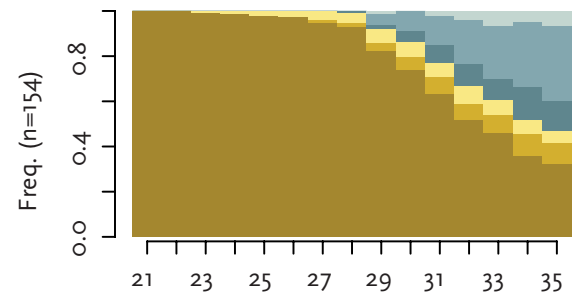

Cluster 4. Non-residential marriages

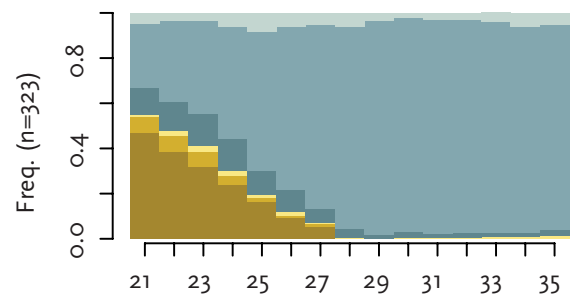

$\begin{array}{lll}\square & S & \text { UA } \\ \square & \text { UT } & \text { MA } \\ \text { MT } & \text { D }\end{array}$

Source: MAFE-Ghana data, 2009-2010

Using the four-cluster solution from $\mathrm{OM}$ as the dependent variable, we estimated multinomial logit models to examine which factors are associated with which types of trajectories (Table 5.3). We used the cluster co-residential marriages as the reference category. The coefficients on the explanatory variables should be interpreted as the likelihood of belonging to that cluster vis-à-vis the cluster co-residential marriages. 


\section{Table 5.3. Multinomial models of the four relational trajectory clusters}

\begin{tabular}{|c|c|c|c|c|c|c|}
\hline \multicolumn{7}{|c|}{ Cluster 1: Co-residential marriages (ref.) } \\
\hline \multicolumn{7}{|l|}{ Cluster 2: Singles } \\
\hline & \multicolumn{2}{|l|}{ Model १A } & \multicolumn{2}{|l|}{ Model 1 B } & \multicolumn{2}{|l|}{ Model $1 \mathrm{C}$} \\
\hline & RRR & S.E. & RRR & S.E. & RRR & S.E. \\
\hline Migration experience (No = ref.) & 1.251 & 0.336 & 0.914 & 0.277 & 0.750 & 0.260 \\
\hline Sex (Male = ref.) & & & & 0.205 & 0.656 & 0.208 \\
\hline Education (<=secondary = ref.) & & & 1.359 & 0.377 & 1.355 & 0.376 \\
\hline Number of children & & & $0.374 * * *$ & 0.041 & $0.376 * * * *$ & 0.041 \\
\hline Akan (No = ref.) & & & 1.070 & 0.274 & 1.065 & 0.274 \\
\hline \multicolumn{7}{|l|}{ Cohort $(<=1950=$ ref. $)$} \\
\hline $1951-1960$ & & & $0.438 * *$ & 0.173 & $0.442 * * ;$ & 0.175 \\
\hline$>=1961$ & & & $0.553 *$ & 0.201 & 0.569 & 0.208 \\
\hline Financially satisfied & & & $0.966 *$ & 0.020 & $0.965 *$ & 0.020 \\
\hline Economically active & & & $0.924 * *$ & 0.032 & $0.922 * *$ & 0.032 \\
\hline Sex\#\#Migration experience & & & & 1.875 & 1.875 & 1.004 \\
\hline \multicolumn{7}{|l|}{ Cluster 3: Mixed } \\
\hline & \multicolumn{2}{|l|}{ Model $2 \mathrm{~A}$} & \multicolumn{2}{|l|}{ Model 2B } & \multicolumn{2}{|l|}{ Model $2 \mathrm{C}$} \\
\hline Migration experience (No = ref.) & $2.153^{* * * * *}$ & 0.554 & $2.439 * * * *$ & 0.695 & $2.588 * * * *$ & 0.926 \\
\hline Sex (Male = ref.) & & & $1.520 \%$ & 0.350 & 1.669 & 0.540 \\
\hline Education (<=secondary = ref.) & & & 1.112 & 0.297 & 1.109 & 0.296 \\
\hline Number of children & & & $0.692 * * * *$ & 0.060 & $0.694^{* * * *}$ & 0.060 \\
\hline Akan (No = ref.) & & & $0.691 *$ & 0.159 & 0.697 & 0.161 \\
\hline \multicolumn{7}{|l|}{ Cohort $(<=1950=$ ref. $)$} \\
\hline $1951-1960$ & & & 0.638 & 0.277 & 0.636 & 0.276 \\
\hline$>=1961$ & & & 1.817 & 0.721 & 1.803 & 0.717 \\
\hline Financially satisfied & & & 0.996 & 0.034 & 0.995 & 0.035 \\
\hline Economically active & & & $0.938 * * *$ & 0.017 & $0.938 * * * *$ & 0.017 \\
\hline Sex\#\#Migration experience & & & 1.038 & 0.495 & 1.038 & 0.495 \\
\hline \multicolumn{7}{|l|}{ Cluster 4: Non-residential marriages } \\
\hline & \multicolumn{2}{|l|}{ Model $3 \mathrm{~A}$} & \multicolumn{2}{|l|}{ Model 3B } & \multicolumn{2}{|l|}{ Model ${ }_{3} \mathrm{C}$} \\
\hline Migration experience (No = ref.) & $1.632 * *$ & 0.364 & $2.095 * * * *$ & 0.499 & 1.382 & 0.409 \\
\hline Sex (Male = ref.) & & & $2.204^{* * * k}$ & 0.431 & $1.525^{*}$ & 0.380 \\
\hline Education (<=secondary = ref.) & & & 0.952 & 0.221 & 0.946 & 0.220 \\
\hline Number of children & & & $1.209 * * * *$ & 0.083 & $1.219 * * * *$ & 0.084 \\
\hline Akan (No = ref.) & & & 1.028 & 0.203 & 1.034 & 0.204 \\
\hline \multicolumn{7}{|l|}{ Cohort $(<=1950=$ ref. $)$} \\
\hline $1951-1960$ & & & 0.781 & 0.250 & 0.802 & 0.258 \\
\hline$>=1961$ & & & 1.000 & 0.305 & 1.051 & 0.322 \\
\hline Financially satisfied & & & 1.004 & 0.016 & $0.951 *$ & 0.028 \\
\hline Economically active & & & $0.953 *$ & 0.028 & 1.004 & 0.016 \\
\hline Sex\#\#Migration experience & & & $2.473^{* * *}$ & O.999 & $2.473 * *$ & 0.999 \\
\hline \multicolumn{7}{|l|}{ Model statistics } \\
\hline Observations & 868 & & 840 & & 840 & \\
\hline Log likelihood & -1153.759 & & -964.78377 & & -961.2676 & \\
\hline DF & 9 & & 33 & & 36 & \\
\hline Chi2 & 24.62 & & 326.89 & & 333.93 & \\
\hline Pseudo R-squared & 0.0106 & & 0.1449 & & 0.148 & \\
\hline
\end{tabular}

Source: MAFE-Ghana data, 2009-2010; Note: All models controlled for survey country; *** $p<0.01, * * p<0.05, * p<0.10$ 
First, we compare the likelihood of being part of a cluster predominated by singlehood to the cluster of co-residential marriages in Model 1. Our key variable of interest, whether the respondent experienced migration during the ages 21 to 35 , is not significantly related to singlehood. Additionally, the likelihood of being single does not significantly differ between men and women. In Model ${ }_{1} C$, we tested whether the effect of migration differed for men and women by including an interaction effect of migration experience and sex, but this test also yielded no significant results.

Migrants are more likely to be in mixed trajectories compared with co-residential marriages, and this effect remains after controlling for the other characteristics (Model 2). There are no significant differences between men and women. In Model 3, we examined the probability of being in the non-residential marriages cluster versus the co-residential marriages cluster. Being a migrant increases the likelihood of being in a non-residential marriage (Models $2 \mathrm{~A}$ and $2 \mathrm{~B}$ ), although the interaction effect shows that this result only holds for female migrants (Model $2 \mathrm{C}$ ).

As for our control variables, we found that educational attainment is not related to any of the three clusters. Larger family size is negatively related to the singles cluster and the mixed cluster, but it is positively related to being in a non-residential marriage. Although previous scholars indicated that being part of matrilineal descent groups increases the probability of divorce, we did not find an effect of matrilineage (i.e., Akan) for any of the clusters. Respondents from older birth cohorts (born before 1950) are more likely to be part of the singles cluster. No cohort effects were found for the other two clusters. Subjective wealth status is negatively related to singlehood, meaning that singles perceive that they are more likely to have experienced periods where they were unhappy with their financial situation. They are also more likely to have experienced periods of unemployment. Those in the mixed cluster and those with non-residential marriages were also more likely to be unemployed compared with those respondents who were predominantly engaged in co-residential marriages.

\subsection{Canclusian d discussian}

In this paper, we studied the relational trajectories of Ghanaians in young adulthood. We concentrated on relational histories, and how the relational histories developed over time. Considering the practice of multilocal residence, we examined relationship status and living arrangements simultaneously. In addition to the widespread prevalence of multilocal residence, Ghanaians are very mobile in terms of international migration. The aim of this paper was to gain insight into the link between Ghanaian couples' relational 
trajectories and international migration. Our contribution to the literature is twofold: first, we aim to contribute to studies on migration that typically study migrants' behaviour at a specific point in time through exploring Ghanaian relationships over time using a dynamic life course perspective (Wingens et al., 2011). Second, we contextualize our study of relational trajectories by considering the practice of non-residential relationships. This study therefore provides insight into the prevalence of this practice in Ghana and how it is related to migration by comparing Ghanaians with and without international migration experience. Additionally, we explore the role of gender on these trajectories by considering the gendered nature of both migration and relationship histories (e.g., Gallo, 2006; Hill, 2004; Jolly \& Reeves, 2005).

We found that the relational trajectories of Ghanaian couples are diverse. We further noted that non-residential unions, both married and unmarried, are commonplace among Ghanaians with and without migration experience, which demonstrates that this type of arrangement is not necessarily caused by international migration. The frequent sequencing of co-residential to non-residential marriage might be illustrative of the high mobility of Ghanaians, both in terms of internal and international migration (Anarfi et al., 2003; Reed et al., 2010; Twum-Baah, 2005).

Next, we identified a typology of relational trajectories that consists of four categories that can be typified as predominantly composed of: 1) co-residential marriages, 2) singles, 3) mixed trajectories, and 4) non-residential marriages. The mixed trajectories cluster is the most heterogeneous. It mainly captures unmarried unions and respondents who were divorced or separated. We used multinomial logistic regression to assess which factors are associated with the four types of relational trajectories.

First, we found no relationship between being in the cluster that is predominated by singlehood and having experience with international migration. However, migrants are more likely to be involved in non-residential marriages, and this result holds in particular for female migrants. This result might be related to the fact that female migration is a significant phenomenon in Ghana and that women tend to migrate without their husbands. About half of the migrants are females, and when considering only migration to neighbouring countries, females constitute more than half of all migrants (Anarfi et al., 2003). Additionally, there are a high number of female-headed households in Ghana since the 1970s (Manuh, 1997; Takyi, 2001; Takyi \& Gyimah, 2007). The increase in female-headed households has been attributed to the high degree of autonomy of Ghanaian women, the high mobility of Ghanaian men, both internally and internationally, an increase in divorces, and pre-marital childbearing (Coe, 2011; Manuh, 1999; Oppong, 1970). Additionally, large-scale economic restructuring programs such as the Structural Adjustment Programs (SAPs) have also been attributed to the increase in female-headed households (Manuh, 1997; Mikell, 1992, 1997). 
Migration experience is also positively associated with the mixed trajectories cluster. Two types of relational trajectories are central in this cluster: trajectories characterized by divorce and trajectories characterized by unmarried unions. Although information about union instability and divorce prevalence in Ghana is scarce, several studies have pointed to high divorce rates in general (Takyi \& Gyimah, 2007; Tabutin \& Schoumaker, 2004). Additionally, migrants are said to be even more likely to experience divorce or separation due to more unstable relationships as a consequence of international migration. As previous studies have also shown, experience with international migration can under certain conditions result in a greater likelihood of union dissolution (e.g., Andersson \& Scott, 2010; Caarls \& Mazzucato, in press; Frank \& Wildsmith, 2005; Hill, 2004; Landale \& Ogena, 1995). Migration experience is also associated with a greater likelihood of being in an unmarried union, which corroborates previous studies (e.g., Landale, 1994).

We control for several variables that have been associated with shaping relational trajectories in the Ghanaian context (see e.g., Amoateng \& Heaton, 1989; AwusaboAsare, 1988; Reed et al., 2010; Takyi, 2001; Takyi \& Gyimah, 2007). Lineage type does not seem to play a role in shaping these relational trajectories, which contrasts with previous findings where matrilineal kinship ties have been attributed to greater marital instability (Takyi \& Gyimah, 2007), although others have found no relationship between matrilineage and divorce (Caarls \& Mazzucato, in press). Larger family size is related to non-residential marriages. Larger families require more support from extended families, and additionally, having children fosters closer connections with the lineage, resulting in weaker conjugal bonds, which could be related to non-residential relationships (Coe, 2011; Oppong, 1970). Those in the mixed and the singles clusters are more likely to have smaller family sizes, which is not surprising given the prevailing relationship status in each of these clusters (single, separated, unmarried unions).

Non-residential marriages are prevalent among all layers of society, and this practice is common historically as well as today (Coe, 2011). Nonetheless, respondents in this cluster are more likely to have experienced more periods of unemployment than those in co-residential marriages. Being part of the singles cluster is related to belonging to the older age group. This result might indicate an association with the macroeconomic situation in Ghana. Beginning in 1965, Ghana suffered from a major economic crisis. Subsequent economic restructuring programs were implemented during a period when this cohort was between approximately 21 and 35 years of age. The economic transformations that took place during that period are alleged to have had severe implications for family processes (Mikell, 1992, 1997). Additionally, respondents belonging to this cluster are the mostly economically inactive and the most unsatisfied with their financial situation. Considering this result and the fact that these respondents were of marital age when the first economic crisis hit Ghana, they were plausibly less 
attractive in the marriage market, and as such, their likelihood of being single increased.

This study also raises interesting questions that future studies on the interrelatedness of migration and family formation should address. While our small sample size prevented the possibility of separate analyses for men and women, future research could carry this study further by scrutinizing these differences. Additionally, our aim here was to compare migrants and non-migrants, which led to a limitation based on the migration-specific characteristics of the individual. However, another attractive avenue for future studies would be to investigate whether certain migration characteristics, such as the period of migration, the receiving country, and the duration of migration, shape relational trajectories. In addition to adopting a dynamic perspective of relational trajectories, we incorporated both co-residential and non-residential living arrangements in our study, which advances previous studies that assumed close physical proximity in studying relationships. However, we were not able to simultaneously disentangle living apart together nationally and internationally and to explore the relationship between migration and relational trajectories. While we opted for the latter, we strongly encourage subsequent studies on this topic to probe the different and similar mechanisms behind living apart together nationally versus internationally.

Despite these limitations, this study is among the few that have examined the linkages between union formation, living arrangements and international migration. The MAFE-Ghana project enabled us to do so by offering detailed retrospective information on the relationships and living arrangements of migrants and non-migrants. This comparison between migrants and non-migrants showed that international migration shapes relational trajectories to some extent, but it also revealed that some types of living arrangements are related to sociocultural practices at the place of origin, which emphasizes the importance of taking the origin context into account when studying processes related to international migration. 


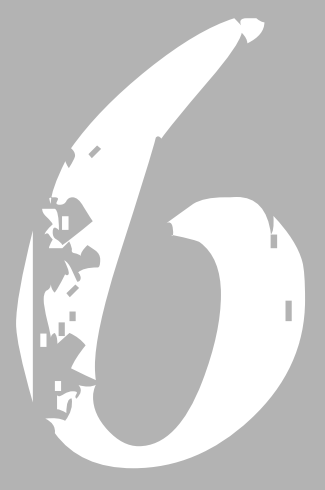

TRANSNATIONAL
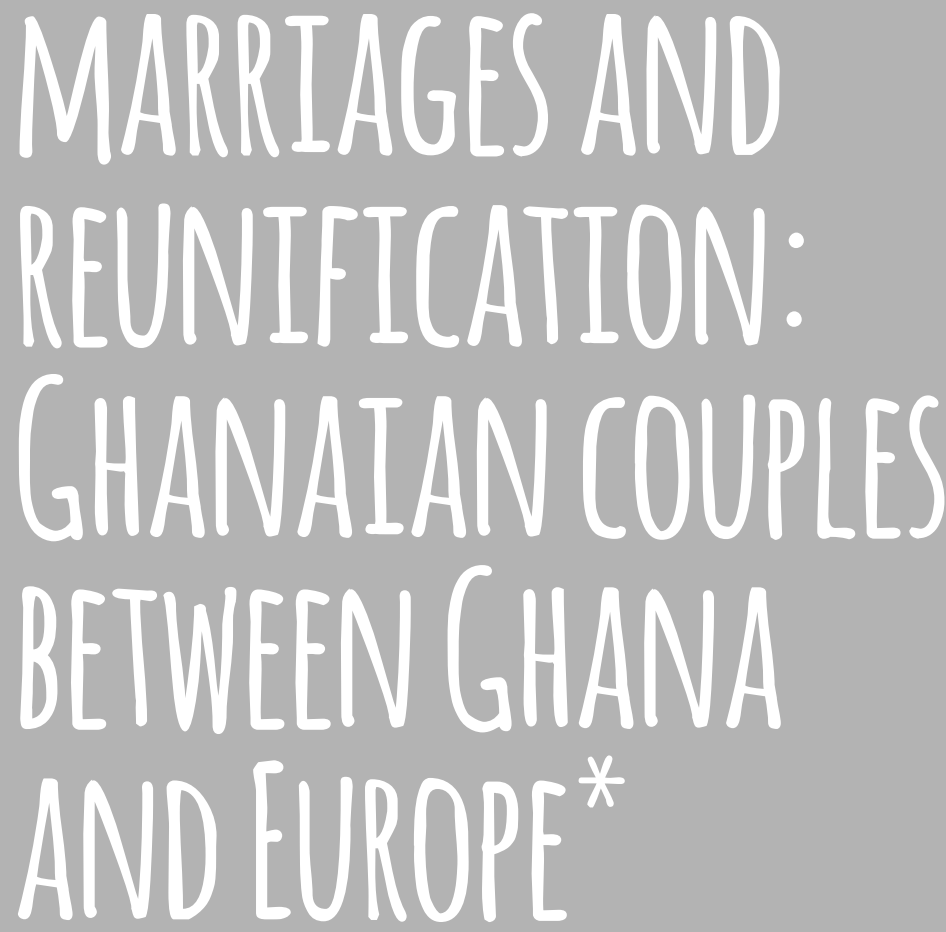

*A slightly different version of this Chapter has been submitted as: Caarls, K. \& Mazzucato, V. (2014). 'Transnational marriages and reunification: Ghanaian couples between Chana and Europe' to an international peer-reviewed journal. Tables and figures are re-numbered in order to fit the thesis format. 


\section{I Intraductian}

In the context of international migration, transnational relationships in which couples living apart together across borders are common because of limited possibilities of migrating together. In recent decades, migration laws in Europe have become stricter, creating barriers to entry and limited possibilities for family reunification (Kraler, 2010; Leerkes \& Kulu-Glasgow, 2011). These limitations apply especially to couples coming from developing countries. As a result, transnational relationships are gaining prominence (Kofman, Kraler, Kohli \& Schmoll, 2011). At the same time, living transnationally might be a choice for some couples, such as when geographical separation is a continuation of previous spousal living arrangements. This choice may particularly be the case where marital relationships have an independent and fluid character, as has been documented in some parts of Africa.

This paper investigates couples' transnational living arrangements and to what extent couples reunify or remain transnational. Generally, studies that address couples and migration do not explicitly consider the variety of living arrangements that may result from migration. Studies often focus on couples who migrate either jointly or successively (e.g., Hondagneu-Sotelo, 1994; González-Ferrer, 2007), and these studies concentrate on the labour market outcomes of either or both partners (Boyle, Feng \& Gayle, 2009; Wagner \& Mulder, 1993). Moreover, it is generally assumed that couples have been living together before migration and that all couples aspire to reunify (Landolt \& Wei Da, 2005). Questions regarding how these living arrangements might be shaped by the situation in the sending or receiving country are often left unanswered.

We study transnational relationships of Chanaian migrants. Although family separations because of international migration have increasingly received scholarly attention, these studies mostly focus on migration from Latin America or Asia (Mazzucato \& Schans, 2011). Migration between Sub-Saharan Africa and Europe has received scant attention, even though migrants from Sub-Saharan Africa constitute one of the largest migrant populations of Europe. Moreover, Ghanaian couples are particularly interesting to study because multilocal residence is a common practice among Ghanaian couples irrespective of migration, which may facilitate people's decisions regarding LATAB relationships (Oppong, 1983).

We examine the prevalence of transnational couples and to what extent they reunify. Through this study, we explore whether these living arrangements are the consequence of migrants' choice or whether socio-economic or policy-related characteristics in the receiving country shape migrants' spousal living arrangements. We adopt a historical perspective, using biographic life history data from the MAFE-Ghana project. We examine Ghanaian couples $(N=291)$ who have experienced, or are experiencing, a period of 
transnationality. We also estimate discrete-time logistic event history models to estimate the probability of reunification in the receiving country, which is either the Netherlands or the UK. We include individual, couple and context characteristics that influence couples' probability of reunifying in the receiving country. We include information regarding couples' living arrangements before migration to study the role of the sending country context. Additionally, we explore the role of the receiving country context by comparing couples who migrated to either the UK or the Netherlands, and investigate whether their legal status and the period of migration affect the probability of reunification.

\subsection{The sending cauntry cantext}

Norms regarding conjugal life in Ghana

Family norms in migrants' origin countries are important for understanding choices around transnational family life. These context-specific norms are not usually considered in demographic studies concerning couple migration (Mazzucato \& Schans, 2011; Zentgraf \& Chinchilla, 2012). Consequently, transnational family life is usually seen as stressful, problematic, and a 'second-best' option whereas this is not always the case. As Dreby and Adkins (2010) show, transnational families are either discussed as households that, despite the different constraints they face, continue to function as cooperative units or as households where geographical separation creates or exacerbates conflict.

In conjugal life in Ghana, spousal geographic separation, as in many parts of West Africa, is common (Coe, 2011; Oppong, 1983). Marriages are often arrangements between families, serving to create and maintain alliances between them. In these cases, geographical distance between spouses can be the rule rather than the exception, and too much intimacy between a husband and wife might reduce the loyalty to the respective families of the spouses (Oppong, 1983). Despite the lack of co-presence, husbands and wives share productive and reproductive obligations and responsibilities (Fortes, 1950).

Marriages in Ghana are not necessarily formally arranged; they tend to have a fluid character. Divorce occurs relatively easily and frequently (Clark, 1994). According to Takyi and Gyimah (2007), divorce is even more prevalent among Ghanaians from matrilineal lineages, such as the Akan (Takyi \& Gyimah, 2007). The high prevalence of divorce might be the result of external factors such as the spread of Western norms concerning individualism or a consequence of the informal and fluid character of marriages combined with the importance of lineage ties (Bleek, 1987; Oppong, 1980). Others attribute these higher levels of divorce to the reputed independence and autonomy of Ghanaian women both from patrilineal and matrilineal descent (Clark, 1994; Oppong, 1970). 
The practice of living apart together is, of course, not an exclusively African phenomenon. Demographers also have studied non-residential relationships among predominantly Western populations in Western countries. Previously, individuals were narrowly conceptualized as either single, in a cohabiting union or married, thereby assuming that partnership and co-residence coincide (Roseneil, 2006). However, emerging studies have identified increasing social acceptance of these LAT relationships (Duncan \& Phillips, 2011; Latten \& Mulder, 2013; Levin, 2004).'

Explanations for why people are involved in LAT relationships differ considerably between African and Western contexts. Non-residential relationships in many parts of Africa are generally ascribed to loyalty towards the wider family. In contrast, research on this type of relationship in Western countries generally identifies different reasons, such as the need for autonomy of both spouses. Although motivations for being in LAT relationships vary between countries and over the course of a person's life, they tend to occur more frequently among the young, the higher educated, or the divorced (Strohm, Seltzer, Cochran \& Mays, 2009). These studies distinguish between LAT relationships that exist because of economic constraints and those that exist because both partners choose this particular lifestyle (Levin, 2004).

Both studies on African and Western non-residential relationships focus primarily on relationships occurring inside nation-state borders, thus omitting cases of LATAB couples. Origin-context familial norms might encourage transnational relationships for Chanaian migrants because multilocal residence is a socially accepted and widespread practice among couples. However, motivations to live apart together across borders might also align with motivations found among LAT couples in a Western context.

\subsection{Riving apart tagether acrass learders}

Few studies have explicitly incorporated the family and family separation when distinguishing between different types of migrants. Previous migration scholars have used different typologies to classify migration that were based on labour outcomes, the duration of migration, legal status, or other factors (e.g., Cohen, 1996; King, 2002; Portes \& Rumbaut, 1990). Hondagneu-Sotelo (1994), one of the first scholars to unravel how men and women create and recreate family life in the context of international migration, placed transnational family life at the forefront of her study. She differentiated between

\footnotetext{
1 We use the terms 'LAT relationships' and 'non-residential relationships' interchangeably. Additionally, we refer to multilocal practices when discussing LAT relationships.
} 
three types of migration: 1) independent migration, referring to unmarried migrant men or women who migrate independently; 2) family unit migration, which captures intact families who migrate as a whole; and 3) family stage migration, referring to cases where the husband migrates and his wife and children follow later. These typologies determine how family life across borders functions and what type of transnational ties and practices are maintained.

Hondagneu-Sotelo's category of family stage migration encompasses the reunification of families, at some point, in the receiving country. This consideration corresponds to the common assumption that transnational families are a temporary phenomenon, with the implicit belief that 1) migrants desire to reunify with their family and 2) this desire is always directed towards the receiving country (Landolt \& Wei Da, 2005; Mazzucato et al., 2014a). However, for some migrants, living transnationally might be favoured over reunification because of constraining circumstances or choices. As Levitt (2001a) noted, transnational lifestyles are no longer exceptional but a common way of life. Moreover, many migrants also return to their origin country, where they reunify with their family. Consequently, families may stay separated for extended periods of time, may not reunify at all, or may reunify in the origin country.

Considering these aspects, two additions can be made to Hondagneu-Sotelo's (1994) typology. First, with female migration increasing, family stage migration can also refer to women who migrate while leaving a husband and/or children behind. Second, recognizing transnationalism as a lifestyle, a fourth category can be added: 4) families living apart together across borders. This category refers to transnational family life that is characterized by long-term separations or transnational families for whom reunification is not the goal. Furthermore, reunification in the origin country could be an additional category, which is beyond the scope of this paper, but a category that is starting to be addressed (Baizan et al., 2014; Caarls et al., in press).

Little is known about the reunification behaviour of LATAB couples. Information regarding the prevalence of transnational couples is rare, and we have limited knowledge regarding the factors that influence the decision to either stay separated or reunite. Comparing spousal reunification patterns of immigrants in Spain, González-Ferrer (2011) found that immigrants from African countries are most likely to stay separate compared with immigrants from other EU countries. In addition, African migrants take the longest time to reunify. This length of time could be a result of stricter rules that apply to this particular group of migrants. This length of time could also be related to cultural practices, such as the frequent occurrence of non-residential relationships among West Africans that makes African migrants more inclined towards LATAB relationships (Bledsoe \& Sow, 2011; Coe, 2011).

Baizan et al. (2014) have found that LATAB relationships are a significant 
phenomenon for Senegalese male migrants in Europe; these relationships are characterized by long-term separations. Reunification in the receiving country is most likely for the most 'integrated' migrants, which the authors defined as migrants who have enough resources, tertiary education and a high socio-economic status.

Characteristics of family members 'back home' also seem to have an effect on reunification. Baizan et al. (2014) found that Senegalese migrants with partners in the origin country, who have the potential to adapt to the labour market circumstances in Europe, are more likely to reunify, while having children did not increase the likelihood of reunification in the receiving country. Children increase the costs of family life and thus, motivate migrants to stay abroad generating income. Kanaiaupuni (2000) found that the non-migrant wives of Mexican migrants in the U.S. are central to the initiation and perpetuation of transnational households.

\subsection{The receiving cantext}

\section{International migration and changing gender norms}

Both family separation and reunification are gendered processes. The impact of international migration on gender roles has been investigated by transnational family studies, generally focusing on the dynamics in transnational relationships (e.g., Gallo, 2006; Hondagneu-Sotelo, 1994; Kanaiaupuni, 2000; Pribilsky, 2004). Studies have shown that gender norms affect not only women's migration experience but also women's transnational practices (Hondagneu-Sotelo, 1994; Landolt \& Wei Da, 2005; Parreñas, 2001; Wong, 2006). Wong (2006), for example, studying remittance behaviour of Ghanaian women, revealed that women continue to fulfil their gendered obligations to their extended kin by investing remittances predominantly in transnational household reproduction. Being able to remit empowers these women, providing them with decisionmaking authority. At the same time, obligations to remit can burden these women, making the socioeconomic reality of life abroad increasingly difficult.

The context of international migration can introduce important changes in gendered household roles. One change that has been documented is the pooling of resources, such as joint bank accounts, because of a difficult socio-economic situation in the receiving country. This pooling of resources is different from the way couples in Ghana usually organize their resources, where men and women tend to keep their resources separate (Manuh, 1999; Wong, 2006). This pooling of resources can have several consequences. Women lose the opportunity to independently make decisions regarding their incomes, men are no longer able to assume their role as the main breadwinner, and conjugal 
bonds are prioritized over lineage obligations (Wong, 2006). These changes in gender roles can cause tensions in transnational families.

With the feminization of migration, women are increasingly migrating internationally, with and without their husbands. Previous studies have shown that the way transnational families function differs between situations of independent female migration compared with situations of independent male migration. For example, Ghanaian transnational couples have a higher likelihood of divorce when the wife migrates independently compared with couples without a migration experience and compared with transnational couples where the husband migrates independently (Caarls \& Mazzucato, in press).

Although most studies concentrate on migrant women's experiences, few have specifically addressed men's experiences. Gender norms influence both men's and women's migration experiences, and these experiences can be empowering, disempowering, or both (Gallo, 2006; Hirsch, 2003; Zontini, 2010; Wong, 2006). Because of changing gender norms in response to migration, men can also feel diminished, undervalued and their masculinity threatened (Charsley, 2005; Gallo, 2006; George, 2000; Manuh, 1999).

Despite these reported differences between men and women, González-Ferrer's (2011) study on reunification in Spain found no significant differences between the probability of reunification behaviour of male and female pioneer migrants. This similarity might be related to the fact that women pioneer migrants are in more egalitarian relationships compared with women who do not migrate or who follow their husbands. Thus, female pioneer migrants might be equally likely to reunify as their male counterparts. However, differences were found in the pace of reunification: women reunify sooner with their husbands in the receiving country than men reunify with their wives (González-Ferrer, 2011).

\section{Migration policies}

In order to investigate the role of receiving country context, we compare Ghanaian migrants living in two receiving countries: the Netherlands and the UK. Both countries have been among the primary destinations of Ghanaian migrants since the $1990 \mathrm{~s}$ (Akyeampong, 2000).

One particular aspect of the receiving country context that influences the decision to reunite or live transnationally is migration policies. Little empirical research has been conducted on the relationship between family reunification policies and the actual family reunification behaviour of migrants (Strik et al., 2013). In 2003, the European Council passed the Right to Family Reunification Directive (European Council, 2003). Although in this directive the right of family reunification for third country nationals is acknowledged, family reunification has become increasingly difficult, if not impossible, 
in most member states (Bernhard, Goldring \& Landolt, 2005) including the Netherlands and the UK. The Netherlands adopted this Family Reunification Directive, but the UK did not (Strik et al., 2013). Nonetheless, the Netherlands had stricter policies compared with the UK, especially in the years prior to 2012. For example, between 2004 and 2010, migrants wishing to bring their spouse were subject to exceptionally stringent income requirements (i.e., sponsors needed to earn $120 \%$ of the minimum wage) (see De Hart et al., 2012; Sibley et al., 2012).

Several studies emphasize that female migrants experience greater difficulties in the process of reunification (Kraler, 2010; Van Walsum, 2006). Although migration policies are considered to be gender-neutral, some have argued they are highly gendered, particularly regarding the treatment of migrant women (Morris, 2014). Migrant women more often work in feminized domains of the labour market, such as domestic or care work, and these domains are typically more precarious, under-regulated, low-status and low-paid (Lutz, 2010). Consequently, it is often more difficult for female migrants to meet the income requirements for family reunification policies (Kraler, 2010; Van Walsum, 2006).

However, migrants do not only reunify through family reunification policies. An important distinction must be made between de jure reunification and de facto reunification (Baizan et al., 2014; González-Ferrer, 2011). De facto reunification refers to reunification by any means available, even through irregular migration. Few studies have examined de facto reunification. For immigrants in Spain, surprisingly, legal status did not result in a higher probability of reunification in Europe, which might be an indication that many migrants are able to circumvent the legal route (González-Ferrer, 2011). Similarly, for Senegalese migrants in Spain, Italy or France, legal status did not affect the likelihood of reunification (Baizan et al., 2014). This paper will investigate to what extent having legal status encourages reunification for Ghanaian migrants in the Netherlands and the UK.

\subsection{Ghanaian migratian}

Historical ties between the UK and Ghana have resulted in a longer history of migration compared with the Netherlands. The Ghanaian migrant population is also larger in the UK. Estimates show that in 2003, 35,474 Chanaians lived in the Netherlands compared with 109,382 in the UK (Twum-Baah, 2005). In general, Ghanaians in the UK are more often higher educated than in the Netherlands. Migrants in the UK are more often students or high-skilled professionals, such as nurses and doctors (Schans et al., 2013).

What little is known about the reunification behaviour of African migrants comes 
from two countries: Senegal and Congo (Baizan et al., 2014; Beauchemin et al., 2014). ${ }^{2}$ Ghanaian migration differs in several respects from these two migration flows. The composition of Ghanaian migration differs, with Ghanaian migrants being, on average, higher educated and older (Mazzucato et al., 2014a). Furthermore, Ghanaian migration involves an increased feminization of migration (Anarfi et al., 2003; Wong, 2006). Most importantly, norms surrounding family life vary. Although many West African countries can be characterized as being more patriarchal with strict hierarchical gender structures (Beauchemin, Caarls \& Mazzucato, 2013), in Ghana, women have historically experienced greater independence (Oppong, 1970).

Ghanaian migrants are also reputed to have a "profound transnational engagement", being connected to both the receiving country and Ghana (Wong, 2006, p. 359). Ghanaian migrants are extensively involved in supporting their families back home, participating in hometown organizations, transnational political organizations, and buying property and houses in Ghana (Caarls et al., in press; Mazzucato, 2008a; Orozco, 2005). However, transnational practices, such as long-distance communication and travel, are shaped by the policies of nation-states (Mazzucato et al., 2004). Although globalization is often heralded for easing long-distance communication and travel, this improvement does not apply equally to all migrants. Especially for poorer and undocumented migrants, maintaining familial relationships over long distances may be problematic (Poeze \& Mazzucato, 2012). Considering these characteristics of Ghanaian migration, the Ghanaian case may provide new insights in the factors that affect reunification or separation of couples across borders.

\subsection{Data d methads}

We used a longitudinal dataset that was collected in 2009-2010 as part of the MAFEGhana project. For this paper, we used the biographic surveys that were collected from Ghanaians in the UK and the Netherlands. The surveys were conducted in the urban areas of the Netherlands (Amsterdam, The Hague, and Almere) and the UK (London), focusing on major cities where Ghanaian migrants live. We interviewed current migrants and asked them identical biographical questions retrospectively, for each year since birth until the year of the survey. Questions focused on domains such as housing, education, marital status and migration experience.

No suitable sampling frame was available in the Netherlands and the UK; therefore,

2 With the exception of González-Ferrer (2011), who examines other African migration flows (see p. 201 for an overview) 
quota sampling was used. In both countries, quotas were set by age and gender to reflect the characteristics of the migrant populations in the respective countries. Respondents were eligible if they were between 25 and 75 years old and born in Ghana. To ensure a variety of types of respondents, different recruitment methods and types of recruiters were employed. In total, 422 Ghanaian migrants were surveyed in Europe, 273 in the Netherlands and 149 in the UK (for more details about the data collection, please see Beauchemin, 2012; Schoumaker \& Diagne, 2010).

\section{Analytical Sample}

To answer questions regarding a couple's probability of reunification, a specific analytical sample was created, consisting of couples who experienced a period of living-together transnationally for at least 1 year. Having a sub-sample of these 'transnational couples' allows for comparing couples who did not reunify with couples who reunified in the receiving country.

First, respondents needed to be in or have been in a relationship, either a consensual union or marriage, for at least one year. ${ }^{3}$ Second, we selected couples who were LATAB for at least one year. Third, from these LATAB couples, we selected LATAB couples where the respondent was the pioneer. This selection means we omitted cases where the respondent was the spouse who joined the pioneer migrant in the receiving country. We omitted these cases because of the way the questionnaire was administered; we did not collect all of the same information when the pioneer migrant was the spouse as when he/she was the respondent. Data include detailed retrospective information regarding all the modules, including remittance-sending behaviour, whether short return visits took place, and whether the respondent possessed a residence permit/visa. Data also include basic socio-demographic information, referring to the situation at the time the marriage started, and retrospective information concerning migration histories.

Our analytical sample thus includes 291 couples who experienced a LATAB period. ${ }^{4}$ To estimate the probability of reunification, we considered couples from the year they started their LATAB period until reunification occurred, or when observations are censored. Observations are censored at the time of survey, when the relationship dissolved because of the death of a spouse or divorce, or when the migrant returned to Ghana. We constructed a couple-year-file consisting of 927 couple-years. Table 6.1 shows the number of respondents reunified in the receiving country as well as the number of respondents censored, presented both by receiving country and by sex.

\footnotetext{
3 Respondents who were involved in polygamous relationships $(n=14)$ were not included (analyses (not shown) including these respondents did not result in substantially different results). We also excluded couples who had incomplete information concerning start and end years of their union formation and migration periods $(n=13)$.

4 Respondents could be involved in more than one relationship successively; the sample consists of 232 respondents.
} 
Table 6.1. Prevalence of reunification in the receiving country

\begin{tabular}{|c|c|c|c|c|c|c|c|c|c|c|}
\hline & & & \multicolumn{4}{|c|}{ By receiving country } & \multicolumn{4}{|c|}{ By sex } \\
\hline & \multicolumn{2}{|c|}{ Full sample } & \multicolumn{2}{|c|}{$\begin{array}{l}\text { Netherlands } \\
\text { Nand }\end{array}$} & \multicolumn{2}{|c|}{ UK } & \multicolumn{2}{|c|}{ Male } & \multicolumn{2}{|c|}{ Female } \\
\hline & $n$ & $\%$ & $n$ & $\%$ & $n$ & $\%$ & $n$ & $\%$ & $n$ & $\%$ \\
\hline $\begin{array}{l}\text { Reunified in the receiving country } \\
\text { Not reunified in the receiving } \\
\text { country: }\end{array}$ & 31 & 10.7 & 15 & 9.0 & 16 & 12.8 & 20 & 10.7 & 11 & 10.5 \\
\hline Still LATAB & 201 & 69.1 & 123 & 74.1 & 78 & 62.4 & 127 & 68.3 & 74 & 70.5 \\
\hline Divorced/Separated/Widowed & 55 & 18.9 & 28 & 16.9 & 27 & 21.6 & 37 & 19.9 & 18 & 17.1 \\
\hline Returned to Ghana & 4 & 1.4 & - & - & 4 & 3.2 & 2 & 1.1 & 2 & 1.9 \\
\hline Total & 291 & 100.0 & 166 & 100.0 & 125 & 100 & 186 & 100 & 105 & 100 \\
\hline
\end{tabular}

Source: MAFE-Ghana data, 2009-2010

\section{Estimation strategy}

We first examined the extent to which couples reunify after a period of transnational separation using Kaplan-Meier estimates. Next, we estimated the probability of reunification in the receiving country with a discrete-time logistic event-history model (Singer \& Willett, 2003). When estimating the models, we included both time-constant and time-varying covariates. All time-varying variables were lagged one year, following standard event-history procedures, which rest on the assumption that changes in the covariates in the previous year will affect the probability of reunification in the current year (Singer \& Willett, 2003).

To examine the factors that determine reunification in the receiving country, we first included basic socio-demographic information for respondents and their spouse. Table 6.2 presents descriptive statistics for all the variables used. For the time-varying variables, information is presented regarding the year that the LATAB period started. 
Table 6.2. Overview of the independent variables

\begin{tabular}{|c|c|c|c|c|c|c|c|c|c|c|}
\hline & \multicolumn{2}{|c|}{ Full sample } & \multicolumn{2}{|c|}{ UK } & \multicolumn{2}{|c|}{ NL } & \multicolumn{2}{|c|}{ Men } & \multicolumn{2}{|c|}{ Women } \\
\hline & $n$ & $\%$ & $n$ & $\%$ & $n$ & $\%$ & $n$ & $\%$ & $n$ & $\%$ \\
\hline \multicolumn{11}{|l|}{ Socio-demographic variables } \\
\hline \multicolumn{11}{|l|}{ Sex } \\
\hline Male & 186 & 63.9 & 72 & 57.6 & 114 & 68.7 & - & - & - & - \\
\hline Female & 105 & 36.1 & 53 & 42.4 & 52 & 31.3 & - & - & - & - \\
\hline \multicolumn{11}{|l|}{ Respondents' education } \\
\hline Secondary or less & 148 & 50.9 & 59 & 47.2 & 89 & 53.61 & 97 & 52.2 & 51 & 48.6 \\
\hline Tertiary & 143 & 49.1 & 66 & 52.8 & 77 & 46.39 & 89 & 47.9 & 54 & 51.4 \\
\hline \multicolumn{11}{|l|}{ Spouse's education } \\
\hline Secondary or less & 157 & 54.0 & 46 & 36.8 & 111 & 66.9 & 110 & 59.1 & 47 & 44.8 \\
\hline Tertiary & 129 & 44.3 & 75 & 60.0 & 54 & 32.5 & 72 & 38.7 & 57 & 54.3 \\
\hline Missing & 5 & 1.7 & 4 & 3.2 & 1 & 0.6 & 4 & 2.2 & 1 & 1.0 \\
\hline \multicolumn{11}{|l|}{ Subjective wealth status* } \\
\hline Depended/Not at all (ref.) & 85 & 29.2 & 41 & 32.8 & 44 & 26.5 & 50 & 26.9 & 35 & 33.3 \\
\hline Absolutely & 201 & 69.1 & 82 & 65.6 & 119 & 71.7 & 133 & 71.5 & 68 & 64.8 \\
\hline Missing & 5 & 1.7 & 2 & 1.6 & 3 & 1.8 & 3 & 1.6 & 2 & 1.9 \\
\hline \multicolumn{11}{|l|}{ Multilocal residence } \\
\hline No & 110 & 37.8 & 45 & 36.0 & 65 & 39.2 & 72 & 38.7 & 38 & 36.2 \\
\hline Yes & 181 & 62.2 & 80 & 64.0 & 101 & 60.8 & 114 & 61.3 & 67 & 63.8 \\
\hline \multicolumn{11}{|l|}{ Couple's characteristics } \\
\hline \multicolumn{11}{|l|}{ Marital status* } \\
\hline Unmarried & 130 & 44.7 & 62 & 49.6 & 68 & 41.0 & 89 & 47.9 & 41 & 39.1 \\
\hline Married & 161 & $55 \cdot 3$ & 63 & 50.4 & 98 & 59.0 & 97 & 52.2 & 64 & 61.0 \\
\hline \multicolumn{11}{|l|}{ Children* } \\
\hline No children & 155 & 53.3 & 67 & 53.6 & 88 & 53.0 & 97 & 52.2 & 58 & 55.2 \\
\hline At least one child in Chana & 53 & 18.2 & 19 & 15.2 & 34 & 20.5 & 37 & 19.9 & 16 & 15.2 \\
\hline All children receiving country & 83 & 28.5 & 39 & 31.2 & 44 & 26.5 & 52 & 28.0 & 31 & 29.5 \\
\hline \multicolumn{11}{|c|}{ Receiving country characteristics } \\
\hline \multicolumn{11}{|l|}{ Receiving country } \\
\hline UK & 125 & 43.0 & - & - & - & - & 72 & 38.7 & 53 & 50.5 \\
\hline The Netherlands & 166 & 57.0 & - & - & - & - & 114 & 61.3 & 52 & 49.5 \\
\hline \multicolumn{11}{|l|}{ Period* } \\
\hline 2003 & 96 & 33.0 & 41 & 32.8 & 55 & 33.1 & 65 & 35.0 & 31 & 29.5 \\
\hline 2004 & 195 & 67.0 & 84 & 67.2 & 111 & 66.9 & 121 & 65.1 & 74 & 70.5 \\
\hline \multicolumn{11}{|l|}{ Legal status* } \\
\hline Undocumented & 30 & 10.3 & 6 & 4.8 & 24 & 14.5 & 23 & 12.4 & 7 & 6.7 \\
\hline Documented & 257 & 88.3 & 116 & 92.8 & 141 & 84.9 & 162 & 87.1 & 95 & 90.5 \\
\hline Missing & 4 & 1.4 & 3 & 2.4 & 1 & 0.6 & 1 & 0.5 & 3 & 2.9 \\
\hline \multicolumn{11}{|l|}{ Short return visits } \\
\hline No & 198 & 68.0 & 79 & 63.2 & 119 & 71.7 & 125 & 67.2 & 73 & 69.5 \\
\hline \multirow[t]{2}{*}{ Yes } & 93 & 32.0 & 46 & 36.8 & 47 & 28.3 & 61 & 32.8 & 32 & 30.5 \\
\hline & Mean & S.E. & Mean & S.E. & Mean & S.E. & Mean & S.E. & Mean & S.E. \\
\hline Duration of LATAB+ & 5.42 & 5.95 & 5.47 & 6.54 & 5.38 & 5.48 & 5.00 & 5.30 & 6.12 & 6.85 \\
\hline Duration of the union++ & 9.62 & 7.83 & 9.72 & 8.82 & 9.55 & 7.04 & 9.14 & 7.30 & 10.43 & 8.60 \\
\hline
\end{tabular}

Source: MAFE-Ghana data, 2009-2010

Notes: *Time-varying variable. Information for all time-varying variables is presented in this Table for the year the LATAB period started; + range $=1$ to $31 ;++$ range $=1$ to 47 . 
Duration of $L A T A B$ was captured in the models using the years of separation and a squared term of the years of separation. These variables fit the data best, and they reflect that reunification is more likely at first, but after a certain period of time, the transnational arrangement may become more stable, and reunification becomes less likely.

Sex refers to the sex of the respondent, with $1=$ male and $2=$ female. For education, we included time-constant variables for both the respondent and the spouse. The respondent's educational level refers to the highest level attained during the LATAB period, with $O=$ secondary schooling or less and $1=$ tertiary schooling. The spouse's educational level was measured at the time the marriage started, using the same values as the variable capturing respondent's education. It is difficult to reliably capture respondents' objective income with a retrospective survey; therefore, we use the respondents' replies concerning their subjective wealth-status. This variable is timevarying and indicates the subjective wealth-status of the respondent for each year. The following question was asked: 'Would you say that during this period you had enough to live on?' We used two response categories: $\mathrm{O}=$ it depended/not at all and $1=$ absolutely. Multilocal residence before migration is a dichotomous variable indicating whether the respondent experienced multilocal residence in Ghana prior to the separation because of migration: $\mathrm{O}=$ no experience with multilocal residence and $1=$ experience with multilocal residence. If couples started their marriage/relationship while being geographically separated because of migration, they were categorized as having multilocal residence before migration.

Information regarding the couple includes a variable stating the marital status of the couple. 'Marriage' is a self-reported status; no distinction was made in the questionnaire between customary, religious, or civic marriages, as respondents would report being married in each case. This variable is time-varying and can take the value $1=$ unmarried and $2=$ married. Having at least one child is a time-varying variable that indicates whether the couple has $\mathrm{O}=$ no children, $1=$ at least 1 child in Ghana, and $2=$ all children in the receiving country. The duration of the union is a continuous time-varying variable referring to the number of years the relationship has lasted.

Finally, we examined several receiving country characteristics. A dichotomous variable captures the receiving country: $1=$ the UK and $2=$ the Netherlands. To capture transnational practices, we considered whether the respondent was able to make short return visits (visits back to Ghana while abroad that lasted less than a year) during the LATAB period: $\mathrm{O}=$ no and $1=$ yes. ${ }^{5} \mathrm{~A}$ dichotomous variable captured the documented

\footnotetext{
5 Sending remittances is another example of a transnational practice that could affect the probability of reunification. We estimated whether sending remittances has a significant influence on the probability of reunification, but the results of this variable were not significant (available in Appendix B). Corresponding to our relatively small sample size, we intended to estimate a parsimonious model to not overestimate our model. Therefore, we decided to exclude the remittance variable. Similarly, we also excluded age of the respondent and reasons for migration, both of which yielded no significant results.
} 
status of the respondent, with $\mathrm{O}=$ undocumented and $1=$ documented. ${ }^{6}$ We investigated whether there is a difference in reunification behaviour for the period before and after 2003, when the Family Reunification Directive was passed (European Council, 2003). Several scholars have shown that family reunification has become more strenuous in most member states, including the Netherlands and the UK (Bernhard et al., 2005). This effect was measured using a time-varying variable referring to $\mathrm{O}=$ the period until 2003 and $1=$ the period from 2004 forward.

\subsection{Findings}

\section{Descriptive findings}

Previous studies have already identified the prevalence of transnational ties among Ghanaians, both migrants and non-migrants (Caarls et al., in press; Mazzucato, 2008a; Orozco, 2005; Wong, 2006). These ties are also reflected in our study. To have experienced a LATAB period was quite common among Ghanaian migrants in the Netherlands and the UK. Of the 422 migrants surveyed in these countries, 389 were in at least one relationship (either married or in a union). Of these 389 migrants, $88.2 \%(n=343)$ experienced at least one period of LATAB compared with $11.8 \%$ who did not. Moreover, these LATAB periods ranged from 1 to 48 years, with an average of 22 years (s.d. 9.97).

In the subsequent analyses, we concentrate on Ghanaian migrants in the Netherlands and the UK who experienced a LATAB period of at least one year. We observed LATAB couples ranging from 1 and 31 years. Kaplan-Meier estimates (Figure 6.1) revealed that just over half of our sample reunified in the receiving country $(55.8 \%)$, and approximately half did not reunify (44.2\%). Those who reunified did so within 13 years since the start of their LATAB. Furthermore, separation can occur for extensive periods of time.

Additionally, we examined to what extent the timing of reunification differed for men and women and by receiving countries. The results are presented in Figures 6.2 and 6.3. In Figure 6.2, we see that after 5 years, $23 \%$ of the couples had reunified in the UK, compared with $16 \%$ of the couples in the Netherlands. The difference between these two countries is significant and continues over time. The difference between men and women is much smaller and not significant (Figure 6.3).

6 Documented status was derived from the respondents' answers concerning their residence permit, and it included the following categories: 'no residence permit needed for this country', 'residence permit', 'visa', and 'other permit'. Undocumented status referred to 'having no permit'. 
Figure 6.1. Kaplan-Meier survival estimate

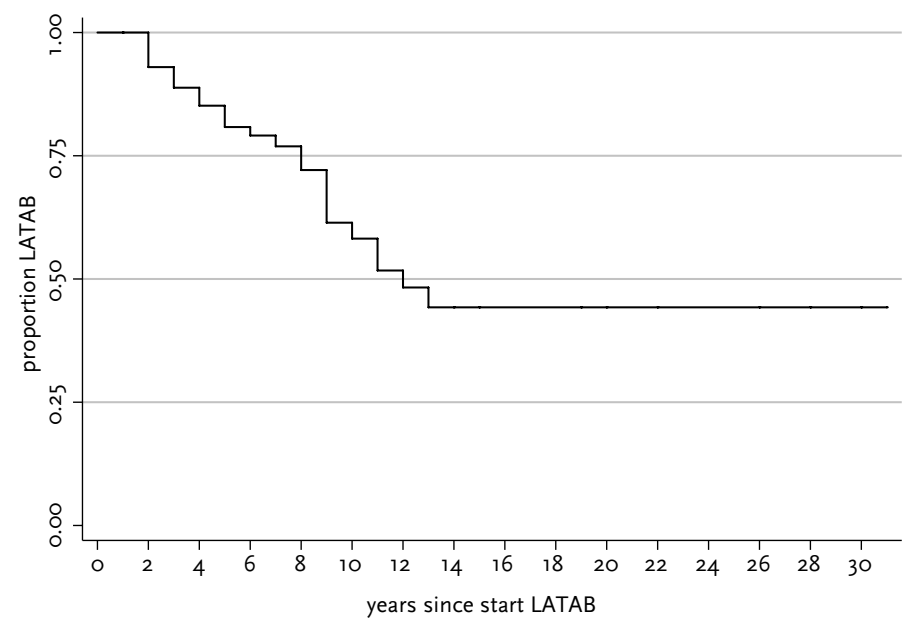

Source: MAFE-Ghana data, 2009-2010

Figure 6.2. Kaplan-Meier survival estimates by destination country

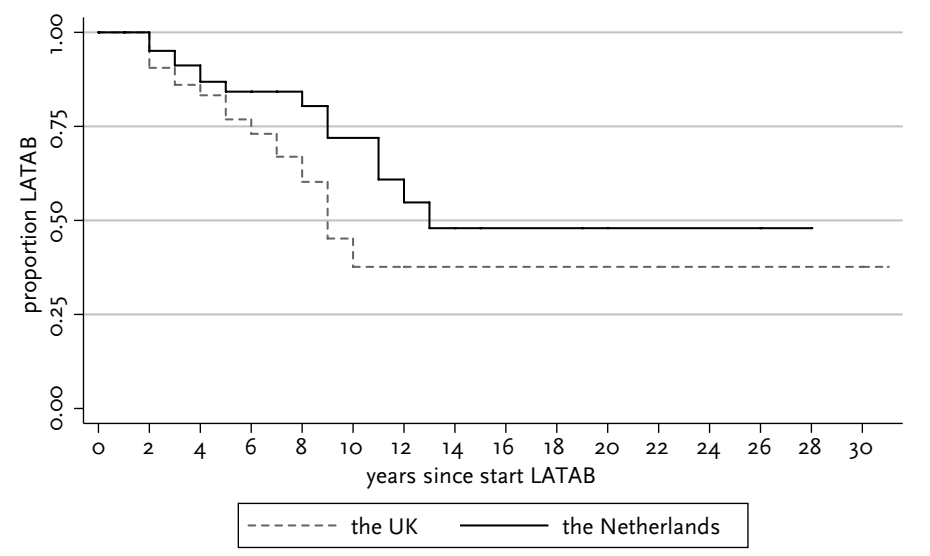

Note: Difference between the UK and the Netherlands statistically significant $(p=0.07)$

Source: MAFE-Ghana data, 2009-2010 
Figure 6.3. Kaplan-Meier survival estimates by sex of the migrant

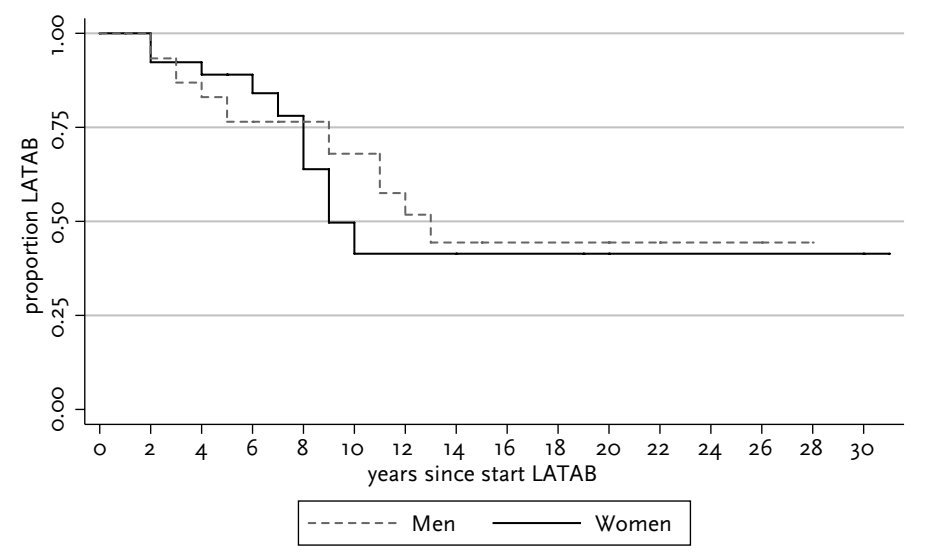

Note: Difference between man and women not statistically significant $(p=0.46)$

Source: MAFE-Ghana data, 2009-2010

Probability of reunification in the receiving country

We estimate discrete-time logistic event-history models using a stepwise approach to determine what factors influence the probability of reunification in the receiving country, with the results presented in Table 6.3. All models controlled for duration, showing that the probability of reunification increases during the first years of separation but decreases as time passes (see the negative sign for duration of LATAB (squared)).

In Model $1 A$, we included gender and the receiving country. There appear no significant differences between male and female migrants regarding their probability to migrate. This effect remains constant for all models, which corresponds to previous findings for African immigrants in Spain (González-Ferrer, 2011). Initially, we find no significant effect of the receiving country, but with the inclusion of education (Model $1 \mathrm{~B}$ ), the effect turns significant and shows that reunification is less likely in the Netherlands. Model $1 \mathrm{~B}$ also shows that migrants with higher levels of education are more likely to reunify. Higher educated migrants are also more likely to be in the UK (Mazzucato et al., 2014a). The significance of the receiving country after including education in Model $1 \mathrm{~B}$ is likely caused by a confounding relationship between education and the receiving country. 
Table 6.3. Estimating the probability of reunification in the receiving country

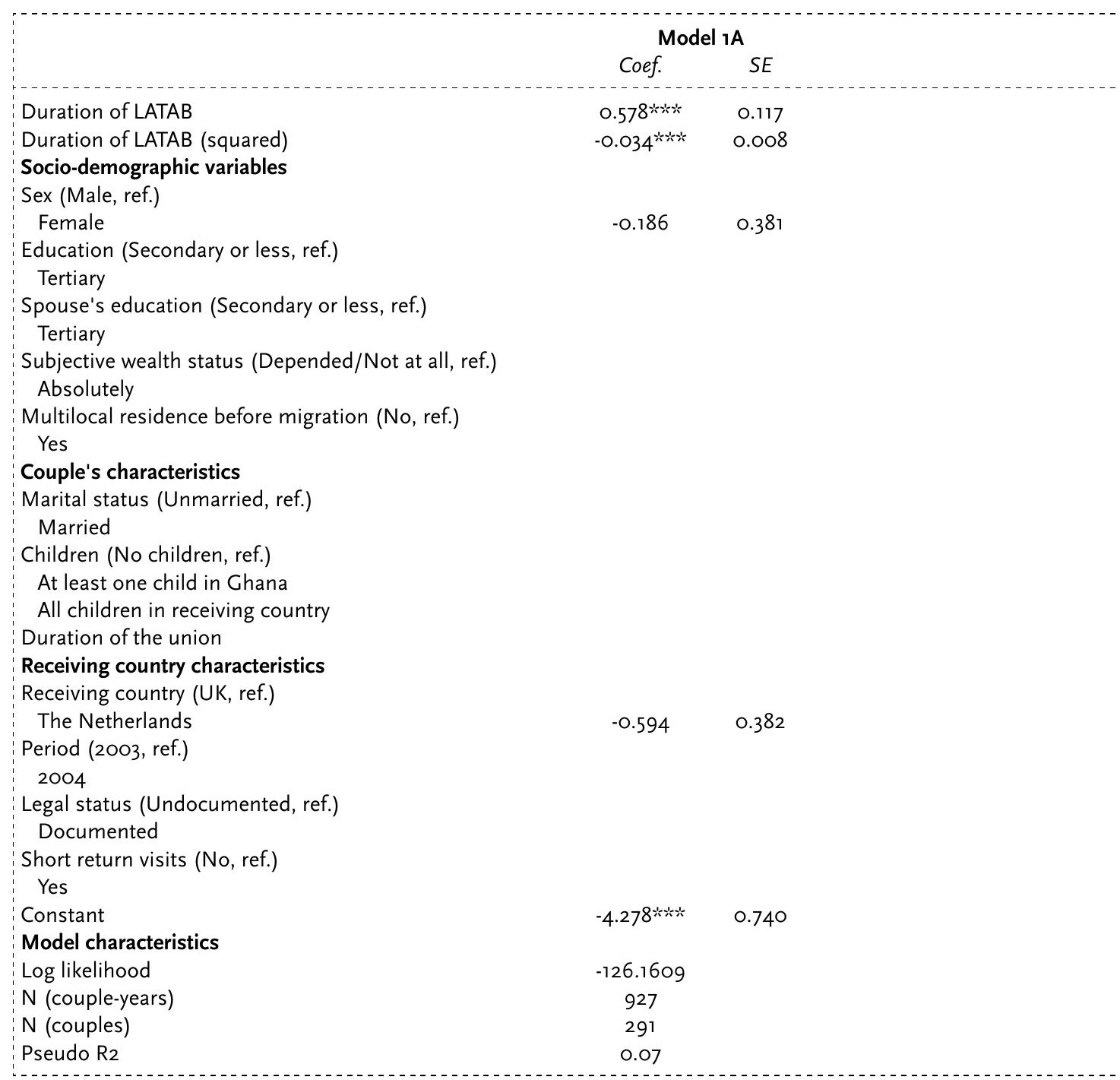

Source: MAFE-Ghana data, 2009-2010

Notes: Robust standard errors reported; ***p<0.01, **p<0.05, *p<0.10 (two-tailed) 


\begin{tabular}{|c|c|c|c|c|c|c|c|}
\hline \multicolumn{2}{|c|}{ Model 1B } & \multicolumn{2}{|c|}{ Model $1 C$} & \multicolumn{2}{|c|}{ Model 1D } & \multicolumn{2}{|c|}{ Model $1 \mathrm{E}$} \\
\hline Coef. & SE & Coef. & SE & Coef. & SE & Coef. & SE \\
\hline $0.561 * * * *$ & 0.123 & $0.630 * * * *$ & 0.133 & $0.685^{* * * *}$ & 0.126 & $0.755^{* * * *}$ & 0.156 \\
\hline$-0.033^{* * * *}$ & 0.008 & $-0.036 * * *$ & 0.009 & $-0.037 k * k *$ & 0.009 & $-0.042 * k *$ & 0.011 \\
\hline-0.278 & 0.404 & -0.237 & 0.451 & -0.206 & 0.471 & 0.068 & 0.483 \\
\hline $0.771^{*}$ & 0.433 & 0.408 & 0.456 & 0.345 & 0.480 & 0.393 & 0.486 \\
\hline \multirow[t]{7}{*}{$-0.797 * * x$} & 0.395 & $-1.104^{* * *}$ & 0.462 & 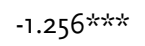 & 0.511 & $-1.131 * *$ & 0.479 \\
\hline & & 0.651 & 0.522 & 0.706 & 0.510 & 0.805 & 0.527 \\
\hline & & $1.724 * 2 * *$ & 0.600 & $1.766 * * * *$ & 0.585 & $1.595^{* *}$ & 0.680 \\
\hline & & & & $0.990 *$ & 0.558 & $1.315 * *$ & 0.591 \\
\hline & & & & $-1.474^{* x * k}$ & 0.541 & $-2.027^{* * * k}$ & 0.610 \\
\hline & & & & $-1.500 * *$ & 0.738 & $-1.998 * *$ & 0.841 \\
\hline & & & & 0.014 & 0.029 & $0.058 *$ & 0.032 \\
\hline \multirow[t]{4}{*}{$-0.897 * * *$} & 0.405 & -1.079 *k火 & 0.445 & $-1.584^{* * * *}$ & 0.597 & $-1.779 * x$ & 0.736 \\
\hline & & & & & & $-1.519 * x+x$ & 0.509 \\
\hline & & & & & & -0.056 & 0.602 \\
\hline & & & & & & $-0.906 * *$ & 0.466 \\
\hline$-4.101 * * *$ & 0.776 & $-5.775^{* * * *}$ & 0.883 & $-5.799 * * *$ & 0.966 & $-5.680 * * * *$ & 1.134 \\
\hline-121.84621 & & -110.03623 & & -104.93205 & & -97.936698 & \\
\hline 917 & & 905 & & 905 & & 868 & \\
\hline 286 & & 281 & & 281 & & 278 & \\
\hline 0.10 & & 0.17 & & 0.20 & & 0.25 & \\
\hline
\end{tabular}


The effect of the respondent's education disappears when we consider multilocal residence prior to migration and subjective wealth (Model ${ }_{1} C$ ); only multilocal residence is significant. Contrary to what we anticipated, having had prior experience with multilocal residence increases the probability of reunification in the receiving country. Education of the spouse (Model $1 \mathrm{~B}$ ) is a strong and significant predictor of the likelihood of reunification and continues to remain so in subsequent models. Migrants with higher educated spouses are more likely to remain LATAB.

Being married increases the probability of reunification compared with couples who are not formally married but in a union (Models $1 D$ and $1 E$ ). Having children makes reunification between partners less likely, regardless of where the children are located, whether with the respondent or in Ghana. The duration of the union is also positively related to the likelihood of reunification (Model $1 \mathrm{E}$ ), meaning that the longer a couple has been together prior to the LATAB, the more probable reunification in the receiving country becomes.

Next to the receiving country, we also examined three other receiving country characteristics. First, we find that reunification has become less likely from 2004 onwards. Second, legal status does not make reunification more probable. Third, short return visits increase the likelihood of staying LATAB.

\subsection{Discussian}

In this paper, we examined Ghanaian migrants' reunification behaviour over time. We first examined the prevalence of Ghanaian couples living transnationally, which $88.2 \%$ of Ghanaian migrants in our sample had experienced at least once, which highlights the significance of this phenomenon. Contrary to common assumptions, these living arrangements across borders are not necessarily short-term. Rather, as our analyses of transnational couples have shown, a significant proportion of migrants are in long-term LATAB relationships.

Focusing on transnational couples, with one spouse living in the Netherlands or the UK and the other spouse remaining in Ghana, we found the same pattern: couples remain separated for extended periods of time. Using Kaplan-Meier estimates, we found that although just over half of the couples reunified either in the Netherlands or in the UK, approximately half did not. This finding demonstrates that LATAB is a substantial phenomenon, and staying separate is an established arrangement for a significant number of migrants.

Because of the significant prevalence of couples living transnationally, we argue that 
it is useful to include this type of arrangement as a separate category when describing migration patterns. Elaborating on Hondagneu-Sotelo's (1994) typology, we suggest including LATAB as a fourth type of migration. This type of migration is characterized by long-term separations where living transnationally as a couple is a stable arrangement. Although we concentrated on couples, including other family members, such as children or elderly parents, could easily extend this category.

Subsequently, we addressed the factors that influence the couples' decision to stay transnational or not. LATAB relationships can be a couples' choice, a consequence of socio-economic circumstances, or a constrained situation due to reunification policies. It is difficult to disentangle these separate influences, yet we made a first attempt in this paper to examine the factors that facilitate and impede a couple's reunification. The educational level of the left-behind spouse proved to be a strong and significant factor: having a higher educated spouse decreases the chance of reunification in the receiving country. This finding signifies the importance of adopting a transnational lens to explicitly incorporate spouses who are left-behind when assessing migration-related processes (Levitt, 2001a; Kanaiaupuni, 2000). Being higher educated might signal more bargaining power for spouses who are left-behind and more prospects in the labour market in the sending country, which would decrease the need and desire to migrate.

This contradicts what Baizan et al. (2014) and Beauchemin et al. (2014) found for Senegalese male migrants, whose probability to reunify in Europe increases with higher educated wives. This might be related to norms in the sending country. Senegal is characterized by strong patriarchal customs, which might make it desirable for higher educated women to leave. In comparison, in Ghana, norms concerning female employment are more favourable (Oppong, 1970). Our finding pertains to both men and women, which can be attributed to more employment opportunities in Ghana for the higher educated compared with Senegal. These opportunities make it more attractive for higher educated spouses to remain in Ghana and for Senegalese spouses to migrate to Europe. Similarly, research on non-residential relationships in a Western context found that LAT relationships are generally associated with higher levels of education (Strohm et al., 2009). Future research should be encouraged to further examine the role of migrant spouse's education. The important role of the left-behind spouse indicates that whether to reunify is not a decision made in isolation by the migrant in the receiving country, but spouses in the sending country are actively engaged in the decision-making process.

We also examined the extent to which the reunification behaviour of Ghanaian migrants is gendered. Because Ghanaian women are reputedly independent and the Ghanaian migration flow constitutes a large number of females (Anarfi et al., 2003; Manuh, 1999; Oppong, 1970; Wong, 2006), it is particularly interesting to examine the gender dimension of their reunification behaviour. However, we found that the probability 
of reunification does not differ between male and female migrants. Although previous studies similarly did not find a difference between men and women (González-Ferrer, 2011), this finding is surprising considering studies that indicate that reunification is more difficult for women (e.g., Kraler, 2010; Van Walsum, 2006). These studies associate the difficulties of female migrants to reunify with the fact that meeting the income requirements is more challenging for women (Kraler, 2010; Kofman et al., 2011). Thus, reunification may be more difficult for poorer women. Separate analyses by gender would be necessary to further scrutinize whether income or other factors affect the reunification behaviour of men and women differently. Our small sample size unfortunately did not allow for these analyses.

In this paper, we considered the role of family norms in the sending country, which could play an important role in shaping reunification decisions. In Chana, the practice of multilocal residence between couples is widespread (Coe, 2011; Manuh, 1999; Oppong, 1970). Thus, non-residential unions are not necessarily considered problematic. Our findings are counterintuitive, showing that having had prior experience with multilocal residence increases the probability of reunification in the receiving country. Future research should further investigate this surprising result.

Previous studies have argued that when the motivation to migrate is to increase income, staying separated would be more lucrative because reunification in the receiving country would increase costs (Baizan et al., 2014). No effects of subjective wealth status were found: feeling well-off does not influence the likelihood of reunification. We did find strong negative effects of having children, indicating that having children significantly reduced the odds of reunification in the receiving country. Interestingly, it does not matter whether the children are with the migrant in the receiving country or whether at least one child is in Chana. Children in the receiving country are also expensive, and partner reunification would further increase the costs. Reunification can be a costly affair (for example, a family reunification procedure in the Netherlands was approximately $€ 1,970$ before 2012 (De Hart et al., 2012)). Not reunifying while there are children in the sending country can also reflect that one of the partners is caring for the children in the sending country, thus discouraging spousal reunification in the receiving country. Marital relationships, which include customary and civil marriages, increase the likelihood of reunification. This could reflect that marriages are often more stable than unions, but this result might also indicate that legal reunification is easier for married couples.

We also investigated the importance of the receiving context. We examined two receiving countries, the UK and the Netherlands, which are among the most popular destinations for Chanaian migrants (Akyeampong, 2000). We found that the probability of reunification is lower for migrants living in the Netherlands. Our data cannot completely uncover the differences between these two receiving contexts, but several factors are 
likely to influence migrants' decision to remain transnational. Dutch migration policies in general have been stricter than those in the UK, and meeting family reunification requirements is more difficult in the Netherlands (De Hart et al., 2012). Additionally, previous research indicated that migrants are reluctant to reunify with their families in the Netherlands because of difficulties at school and in the labour market (Dito et al., in press). These difficulties are more profound in the Netherlands compared with the UK because of not speaking the Dutch language and the problems migrants report with getting their educational credentials recognized in the Netherlands (Mazzucato, 2008a).

Other factors further show the importance of the receiving country context: the period of migration, the documented status of the migrant and the ability to make short return visits to Chana. Migrating after 2004, a period when legislation in most European member states became more restrictive (De Hart et al., 2012; Sibley et al., 2012) decreases the likelihood of reunification. The significant result of this variable could reflect these increasingly difficult circumstances for reunification.

We examined whether the documented status of migrants affected their reunification behaviour. Confirming previous studies (González-Ferrer, 2011; Baizan et al., 2014), legal status did not prove to either facilitate or impede reunification. Most likely, migrants are able to reunify through alternative routes outside the legal framework of family reunification. Although it was not possible to distinguish between de jure and de facto reunification, our findings suggest that both are occurring.

We examined the significance of short return visits to Chana. Extensive transnational ties and activities of migrants facilitate a transnational lifestyle (Grillo \& Mazzucato, 2008). This fact is corroborated by our findings that show that the ability to make short return visits increases the likelihood that couples will live transnationally. This finding might indicate that for some couples, geographical separation is not necessarily problematic and might be a conscious choice.

These four findings taken together lead to two hypotheses regarding the role of family reunification laws in the Global North. First, the period after stricter family reunification legislation was implemented is associated with fewer reunifications, indicating the law's effectiveness; yet legal status of migrants does not seem to make a difference in reunification. This may indicate that the income requirement of family reunification legislation is the higher impediment to reunification. Furthermore, lower income also prevents people from reunifying through informal channels, as this too requires finances. Second, those migrants who engage in short-term visits can be assumed to have legal status and enough income to permit them the travel. Plausibly then, they would meet family reunification legislation requirements. Yet, our findings show that these people are less likely to reunify, indicating a choice not to do so. This attests to the fact that it is more than laws that affect people's decision-making around 
transnational family life and that reunification is not always the preferred option.

Our findings provide several interesting avenues through which research on migrants' reunification behaviour could be advanced. Although our small sample size limited the possibilities to run separate analyses, future studies should further investigate the differences between men and women and between the two countries. Our results revealed that certain receiving context characteristics indicate the success of restrictive policies. However, documented status, an important state-control mechanism, did not influence couples' reunification. Further research could examine the effects of nationstate policies in greater detail. Additionally, we could not assess the role of objective income measures because of the retrospective nature of our data. However, considering increasing income requirements, future research should explore the effect of income. Finally, our study did not include reunification in the sending country. Studying the relative importance of reunification in the receiving country compared with reunification in the sending country can further help to understand migrants' choices and constraints around transnational living (e.g., see Baizan et al., 2014).

Notwithstanding these limitations, our study is among the few that examine the reunification behaviour of migrants, and specifically, that examine this behaviour in two different receiving contexts. The MAFE-Ghana project allowed for this comparison. This comparison emphasizes the importance of including both sending country and receiving country characteristics when investigating migrants' decisions concerning living transnationally or reunifying in the receiving country. 


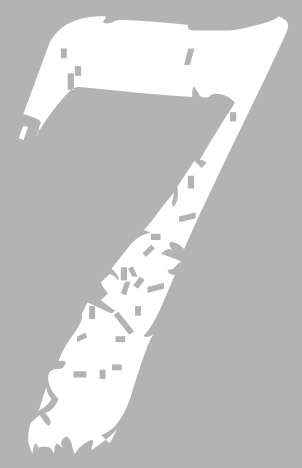

DOES INTERNATIONAL
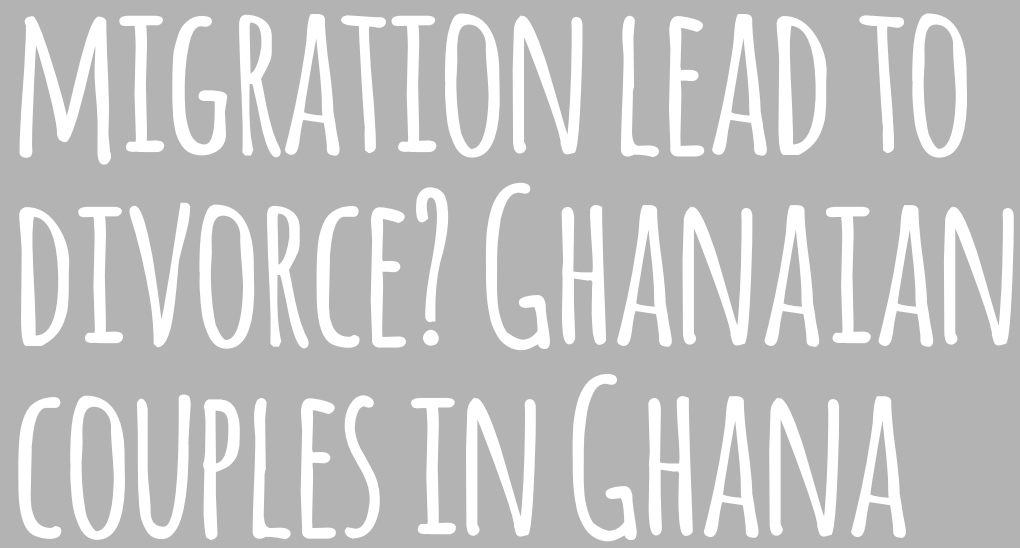

AND ABROAD*

* A slightly different version of this Chapter has been accepted for publication as: Caarls, K. \& Mazzucato, V. (in press). Does International Migration Lead to Divorce? Chanaian Couples in Chana and Abroad. Population. Tables and figures are re-numbered in order to fit the thesis format. 


\subsection{Intraductian}

Socio-demographic studies have found that international migration can result in an increase in divorce (e.g. Andersson \& Scott, 2010; Frank \& Wildsmith, 2005; Hill, 2004; Landale \& Ogena, 1995). Two explanations prevail. First, the act of moving is a stressful life event, resulting in a greater likelihood of divorce (Boyle et al., 2008), and this stress associated with moving might increase when international borders are crossed. Second, migration regimes have become stricter, making it difficult to migrate as a family. Consequently, more families are geographically separated and faced with the challenge of arranging family life transnationally. While living transnationally might be unproblematic for some, for others it could cause marital stress and eventually result in divorce.

Many studies evaluate the extent to which immigrants follow family formation or dissolution patterns that are similar to those of the native counterparts in receiving countries. Yet these studies are inconclusive about whether it is the act of migrating that leads to higher divorce rates because this would require a comparison with divorce rates of non-migrants in the sending country (Clark et al., 2009; Click, 2010). Data for such comparisons are few and far between, as data collection typically takes place in receiving countries (with some exceptions: e.g. Frank \& Wildsmith, 2005; Hill, 2004). The current study compares divorce rates of Ghanaian couples with and without international migration experience. Ghana has high rates of international migration (Twum-Baah, 2005) as well as of divorce (Tabutin \& Schoumaker, 2004). Although these findings could indicate a relationship between divorce and migration, anthropological studies argue that marital relationships in some parts of Africa, and Ghana is no exception, are historically flexible due to the effects of matriliny, the existence of polygyny, and wider socio-political conditions (Boni, 2001; Clark, 1994; Fortes, 1950; Manuh, 1999; Oppong, $1970,1980)$. It is therefore important to compare migrants with their counterparts who stay in the country of origin.

Migration between Africa and Europe includes independent male and female migration (Grillo \& Mazzucato, 2008). Furthermore, increasingly strict migration laws make it difficult for couples to migrate together, and consequently transnational couples, where one partner migrates and the other stays in the country of origin, are increasingly common. The analysis thus also compares transnational couples where husbands or wives migrate. By accounting for such couple configurations, this study pays particular attention to the different effects of male and female migration experiences, as indeed previous studies have found gender differences in the effects of migration, such as changes in gender roles that affect men and women differently (Gallo, 2006; Hill, 2004; Jolly \& Reeves, 2005).

This study also contributes a case of Sub-Saharan Africa migration to scholarly 
literature that has predominantly focused on migration between Latin America or Asia and the U.S., or on former guest workers and migrants from former colonies in Europe (e.g. Constable, 2003; Frank \& Wildsmith, 2005; Glick, 2010; Hill, 2004; Landale \& Ogena, 1995). This has resulted in a knowledge gap concerning 'new' migrant groups, despite the fact that these groups constitute a significant proportion of existing migration systems. Sub-Saharan African migrants face different contexts of migration as a) spousal separation is commonly practiced in many West African countries, and b) family reunification policies of their receiving countries are more restrictive than they were in the 1970 and 1980s, when many guest workers reunited with their families (Mazzucato \& Schans, 2011).

We examine the relationship between migration and divorce by means of discretetime event history analysis, using life histories collected from Ghanaian migrants, returnees, migrant spouses, and non-migrants in 2009-2010. Data from the MAFEGhana dataset are used, with data collected in the Netherlands, the UK, and Ghana. The following section discusses several strands of literature that address migration and divorce, and anthropological literature on marital relationships in Africa and Ghana in particular.

\subsection{Shearetical framewars}

\section{Migration and Divorce}

Much of the sociological and demographic literature on the dissolution of unions has indicated that stressful life events are strong predictors; and one major stressor is moving (Boyle et al., 2008). Studies that examined the relationship between moving and divorce often used traditional models that focus on male pioneers with their so-called 'trailing' wives. This relationship has been explained by indicating that migration typically benefits the career of men and that the labor market status of women is negatively affected by migration, regardless of the women's motherhood, income and occupational status prior to migration (Boyle et al., 2008). Marital stress increases, as does the risk of divorce, as a result of this 'suffering' of women when migrating. These unfavorable effects on women are commonly explained by the fact that family migration is strongly influenced by traditional gender roles that prioritize the male's economic well-being.

However, these traditional demographic studies often did not take international migration into account. Sociological studies on immigrant families instead extensively studied the relationship between family life and migration. Most of these studies explained these relationships using assimilation and acculturation arguments (Glick, 
2010). For example, Bean, Berg, and Van Hook (1996) found that marital disruption behavior of second- and third-generation Mexicans, was similar to that of non-Hispanic Whites in the U.S., which they attributed to processes of assimilation. Similarly, Phillips and Sweeney (2006) found that a migration experience is a strong predictor of marital stability among Mexicans in the U.S., when compared with other immigrant groups or the native population. Yet these findings do not allow conclusions regarding the effect of migration on divorce as they did not compare with the non-migrant population in the sending country, nor did they consider the transnational context of international migration.

\section{Divorce in a Transnational Context}

In the context of international migration, it is not exceptional for couples to opt for a transnational living arrangement, with one of the spouses, typically the husband, migrating while the other remains in the country of origin. Living transnationally can be a preferred option, and family reunification, whether in the receiving or sending country, is not always a feasible or desirable outcome (Baizan, et al., 2011; Mazzucato \& Schans, 2011). Quantitative demographers and family sociologists have given relatively limited attention to this phenomenon, leading to recent calls for more transnational approaches within these quantitative disciplines (Glick, 2010; Mazzucato \& Schans, 2011). Moreover, despite this increase in attention to the relationship between migration and family life, the impact of migration on the probability of divorce has received scant attention (Glick, 2010).

With an increase in the availability of bi-national datasets, with the Mexican Migration Project (MMP) as a well-known and long-running example, more quantitative scholars have taken up the challenges of including a transnational perspective and making comparisons with the non-migrant population when examining the impact of migration. For example, Frank and Wildsmith (2005) concluded that migration as such is not a sufficient causal factor in explaining union dissolution among Mexicans in the US. Rather, extensive periods in the U.S. increase the risk of union dissolution among these Mexican couples. Hill (2004), studying Mexican and Central American women migrating to the U.S., also indicated that the duration of a stay abroad increases the risk of divorce. Hill hypothesized that the risk of divorce is elevated because migrant women are exposed to different normative values concerning divorce in the U.S. Exposure to different normative contexts and its effect on couples' marital stability has also been the topic of several qualitative studies (e.g. Hirsch, 2003; Zontini, 2010).

\section{Divorce and Gender Norms}

The focus of qualitative analyses on marital stability has primarily been on how migration 
impacts ideas about gender norms. Migrants are often confronted with conflicting gender norms from sending and receiving countries as well as the migrant community in the receiving country. These previous studies have indicated that international migration impacts gender relations, revealing that couples' relationships can become stressed, strengthened or altered in the context of migration (Fouron \& Schiller, 2001; Mahler, 2001).

Different gender expectations and attitudes of spouses can be important stress factors and increase the risk of divorce (Boyle et al., 2008; George, 2000; Jolly \& Reeves, 2005; White, 1990). Hirsch (2003) found that after their migration to the U.S., some Mexican migrant women experienced greater freedom from constraining gender norms that were prevalent in their home communities, and those who did were more likely to experience marriage instability. Zontini's (2010) ethnographic work shows that women often change prevailing gender roles in response to migration, for example, by becoming breadwinners. Men can feel marginalized, that their masculinity is threatened, and they do not necessarily recognize the new gender roles, which can lead to spousal conflicts (Charsley, 2005; Gallo, 2006; George, 2000; Manuh, 1999).

Notwithstanding, two gaps remain. First, the abovementioned studies primarily examine either male migration or female migration; however, couples can experience migration in a variety of ways. They can migrate together, simultaneously or successively, or they can become transnational couples, with the wife or husband migrating while the other remains in the country of origin. These experiences might impact marriages differently. Second, migrants from Sub-Saharan Africa have been largely overlooked by these studies. The present study aims to address this gap by examining a Sub-Saharan African migrant group, Ghanaians who migrate internationally.

\section{Migration and Divorce in Ghana}

Studies on divorce in Sub-Saharan Africa are quite limited (Tabutin \& Schoumaker, 2004). The few studies that estimate divorce rates in Ghana have recorded high numbers: Tabutin and Schoumaker (2004) mention that $35 \%$ of women's first marriages end in divorce after 30 years of marriage, and Takyi and Gyimah (2007) estimate that in 2003 , around $25 \%$ of women aged between 15 and 49 years who ever married ended up divorced. Several anthropological studies on marriage instability in Ghana discuss these seemingly high rates and the cultural notions concerning family relationships. These notions are important to consider, as they can shape individuals' decisions concerning marriage and divorce. They might thus explain the relatively high prevalence of divorce.

Norms concerning couples' living arrangements in many West African contexts do not require geographical proximity for family life. In Ghana, multilocal residence is quite common for couples (Clark, 1994; Coe, 2011; Fortes, 1950; Manuh, 1999; Oppong, 1970). 
Traditionally, men and women lived apart in Ghana, each spouse with his or her own family (Fortes, 1950), and this multilocal residence was practiced in both matrilineal and patrilineal descent groups (Oppong, 1970). Spousal separation in such a context might affect marital relationships differently than in contexts where proximity is viewed as a necessity for family life.

Several authors point to external factors as an explanation for the relatively high prevalence of divorce, such as the diffusion of Western norms and values concerning individualism; others point to specific socio-cultural features of Ghana, such as the importance of lineage ties. The latter influence marital relationships in that loyalty to one's lineage causes conjugal bonds to weaken; consequently, divorce occurs relatively easily and frequently (Bleek, 1987; Oppong, 1980; Van der Geest, 1976).

The prevalence of divorce is said to be even higher among Ghanaians with matrilineal kinship ties (Bleek, 1987; Takyi \& Gyimah, 2007) such as with the Akan who constitute the majority of international migrants. Akan women are said to enjoy greater autonomy than their patrilineal counterparts; however, some studies indicate that their independence is decreasing due to processes of modernization. Clark (1994) argues that the difficulties associated with matrilineage lie in that women must manage their marital households in addition to their work. Furthermore, husbands feel greater responsibility toward their own matrilineage, and their interest in their marital household decreases when their wives become more independent.

In general, studies indicate that women in Ghana, from both lineages, are quite independent. According to Oppong (1970), the majority of women in Chana works outside of the household and has done so traditionally. This, combined with the practice of separate residence, has led to relationships that are not necessarily egalitarian, but are characterized by the autonomy of spouses. Women's greater autonomy is, in turn, associated with marital instability, as these women may feel better able to establish independent households and experience fewer moral obligations to remain in a marriage (Boyle et al., 2008).

\section{Ghanaian Couples and International Migration}

Given these anthropological insights, two contesting hypotheses can be formulated. First, in line with sociological and demographic studies, migration is expected to increase divorce rates due to an increase in marital stress caused by migration. Yet, second, taking the Ghanaian context into account, migration is not (or less) expected to influence divorce rates because multilocal residence is relatively common among Ghanaian couples. In addition to these two contesting hypotheses, different outcomes are expected for couples with male, female, and joint migration, since men and women experience migration differently. Additionally, specific migration characteristics are expected to influence the 
divorce rates of migrant couples, such as the duration of time spent apart (more time spent abroad increases the risk of divorce) (e.g. Frank \& Wildsmith, 2005; Hill, 2004), the region of migration (migration to a Western context can create marital tensions, e.g. Charsley, 2005; Gallo, 2006; George, 2000; Manuh, 1999; Zontini, 2010), and whether the couple was already geographically separated at the time the marriage started.

In addition to the role of migration in explaining the probability of divorce, previous studies have identified other important predictors. The effect of the presence of children has been extensively researched, and most studies find that the presence of children discourages divorce (Boyle et al., 2008; Frank \& Wildsmith, 2005; Hill, 2004; White, 1990). Studies on the effect of educational attainment on the risk of divorce have remained inconclusive (Amato, 2010; Takyi \& Gyimah, 2007). Several scholars found that higher levels of education decrease the risk of divorce (Boyle et al., 2008), yet others have pointed to a reversed effect for women's educational attainment (Frank \& Wildsmith, 2005; Kalmijn, De Graaf \& Poortman, 2004). Previous studies have shown that several measures of having a low socio-economic status can result in an increased risk of divorce (White, 1990). Lower ages at marriage are associated with a higher risk of divorce (Boyle et al., 2008; White, 1990). Finally, couples that were in a relationship (either cohabiting or not) prior to their marriage are likely to have more stable relationships (similar to the 'trial marriage' theory) (Kulu \& Boyle, 2010). These variables are controlled for in the analyses.

\subsection{Data d methads}

A longitudinal biographical dataset, collected in 2009-2010 in Ghana, the UK, and the Netherlands as part of the MAFE-Ghana project, was used. The survey was carried out in the urban areas of Ghana (Accra and Kumasi), the Netherlands (Amsterdam, The Hague, and Almere), and the UK (London). Current migrants (in the Netherlands and the UK), non-migrants, returnees, and migrant spouses (in Ghana) were asked identical questions. All, respondents, both in Europe and in Chana, were eligible if they were aged between 25 and 75 years and born in Ghana.

In Ghana, data were collected using stratified random samples of households in the cities of Accra and Kumasi. First, a sampling frame was used to randomly select households, and second, the sampling frame was stratified to oversample households with return migrants. Next, individuals were selected from these households. All return migrants and migrant spouses, if they were currently living in the household, and one randomly selected other eligible member were selected. In total, 1,243 biographic 
questionnaires containing retrospective life histories were collected in Ghana.

In the Netherlands and the UK, no suitable sampling frame was available due to large numbers of undocumented migrants; therefore, quota sampling, setting quotas for age and gender, was used. Different methods of respondent recruitment were used (e.g. some respondents were recruited at the metro station, at the church, at other public places) as well as interviewers from a variety of socio-demographic backgrounds were hired, to increase the likelihood of accessing respondents with different sociodemographic characteristics. In total, 422 Ghanaian migrants were surveyed in Europe ( 273 in the Netherlands and 149 in the UK). The three datasets combined yielded 1,665 respondents. The use of retrospective data allowed for an examination of marriages that were formed over the past 60 years. Because retrospective surveys about peoples' attitudes are unreliable, direct measures of attitudinal variables, such as on gender norms, could not be used. Instead, this study focused on couples' behavior, hereby distinguishing between husbands' and wives' behaviors.

\section{Analytical Samples}

Couples retrospective data were used from the year of a respondent's first marriage until divorce or in case of censoring, either at the time of the survey or the death of a spouse. A sub-sample of couples that were married for at least one year was selected. Information concerning respondents and their spouses is asymmetrical because information on spouses was obtained through respondents. For respondents, detailed retrospective information concerning a wide variety of modules is available (e.g. housing histories, occupational histories, migration histories). For spouses, basic socio-demographic information referring to the situation at the time the marriage started and migration histories were derived through the network module of the questionnaire.

We included migration periods of either spouse that lasted for at least one year. Complete information concerning start and end years of marriage and migration periods was also required. Additionally, polygamous couples, couples for which the spouse was not Ghanaian, and couples for which the wife migrated and her husband followed were excluded because the size of these groups was insufficient to enable specific analysis. These restrictions yielded a dataset of 927 couples, of which 144 divorced during the observation period. The first divorce occurred in 1954, and the last occurred in 2008.

In order to examine the relationship between divorce and migration, we analyzed two models. In the first model, we study to what extent a migration experience affects the probability of divorce, taking the full observation period and the full analytical sample into account. The observation period starts at the time of marriage, and ends when either the marriage ended due to divorce or censoring occurred. In the second model, we examine only those couples that have experienced migration, and observe what 
happens during their migration period. To do so, we exclude couples without migration experience and we additionally changed our observation period. The observation period now starts at the time of the first migration after the couple was formed. We then study whether at the end of the migration period, the couple experienced the event divorce, or not. This means that the end of the observation period coincides with the end of the migration period, or when the event occurred or when censoring occurred. Since all couples without migration experience were excluded from this model, the dataset for model 2 consisted of 442 couples, of which 44 divorced. Due to this small sample size, we controlled for only a limited number of variables (i.e. the educational level of both spouses and the couples' subjective wealth status). This two-spronged approach allows us to study the effect of migration on the risk of divorce (Model 1), and to additionally examine how specific characteristics of the migration experience affect the risk of divorce (Model 2).

\section{The Probability of Divorce}

A discrete-time proportional hazard event-history model was used (Singer \& Willett, 2003) to assess the probability of divorce. Couple-year datasets consisting of 12,481 and 3,775 couple-years were designed, for the first and second model, respectively. Using these datasets, complementary log-log models were used because the underlying survival process is continuous, even though the data were collected on an annual basis (Jenkins, 2005). Duration dependency was assessed in the models using the years of marriage and two polynomials of the years of marriage (a squared and a cubic terms). The inclusion of these three terms fitted the data best. All time-varying variables were lagged one year, following standard event-history procedures, which rest on the assumption that changes in the covariates in the previous year will affect the probability of divorce in the current year (Singer \& Willett, 2003).

\section{Couples' Migration Experience and Control Variables}

Table 7.1 presents all of the variables used for Models 1 with all couples, as well as the variables for Models 2 with only couples with migration experience. For the time-varying variables, descriptive statistics are provided for the beginning of observation period (the year of marriage) and at the end (the year of divorce or the year of survey in the case of censored observations).

In this study we pay particular attention to the gendered effects of migration. We do so by constructing a time-varying variable with information obtained from respondents' and their spouses' migration histories. The resulting variable couples' migration experience consisted of the following time-varying categories: 1 = couple-years without migration experience, 2 = couple-years for which only the husband migrated, 3 =couple-years for which 
only the wife migrated, 4 = couple-years for which both spouses migrated, but the husband preceded the wife, and $5=$ couple-years for which both spouses migrated simultaneously.'

The second model focuses on couples with migration experience only, which allowed the inclusion of migration-specific characteristics. First, two variables identifying the region of migration for the husband and the region of migration for the wife were taken into account. Both variables are time-variant, indicating whether the husband or wife migrated to Europe or North America, or not $(0=n o, 1=y e s)$. Second, the number of years couples spent living geographically separated across borders during their marriage, was included. Third, we included a variable indicating whether the couple was geographically separated across borders at the time the marriage started, referring to whether the couple was living in the same country or not at the time they married $(0=n o, 1=y e s)$.

Marriage cohort refers to the period in which the couple got married, considering the following 5 time periods: $1 \leq 1970,2=1971-1980,3=1981-1990,4=1991-2000$, and $5 \geq 2001$. Husbands' and wife's educational levels are time-varying and indicate the spouses' educational level in four categories, with $\mathrm{O}=$ no education, $1=$ primary education, 2 = secondary education, and 3 = tertiary education.

Respondents' ethnicity is a time-constant variable that refers to whether the respondent is from a matrilineal ethnic group, e.g., Akan, or not. Because religion strongly correlates with ethnicity (Akan are almost exclusively non-Muslims), only ethnicity was taken into account. Since income is difficult to reliably measure with a retrospective survey, we used respondents' subjective wealth-status as a measure for socio-economic status. This variable varies over time and indicates the subjective wealth-status of the respondent for each year. The following question was asked: 'Would you say that during this period you had enough to live on?' This resulted in three response categories, $1=$ absolutely, 2 = it depended, and $3=$ not at all.

Respondent's age at the start of the marriage is added as a time-constant covariate. Union before marriage is a time-constant variable that indicates whether the couple was in a consensual union before they married. Presence of children is a continuous time-varying variable that indicates whether the couple has children together. This variable refers to children born between the two spouses, whether or not during the marriage. In some cases $(n=87)$, children were also born outside of the marriage, with a different spouse; however, controlling for this did not result in a significant effect on the probability of divorce or an improved fit of the models.

\footnotetext{
1 When the respondent returns to the sending country (return migration) this is coded as a 'couple-year without migration experience'.
} 


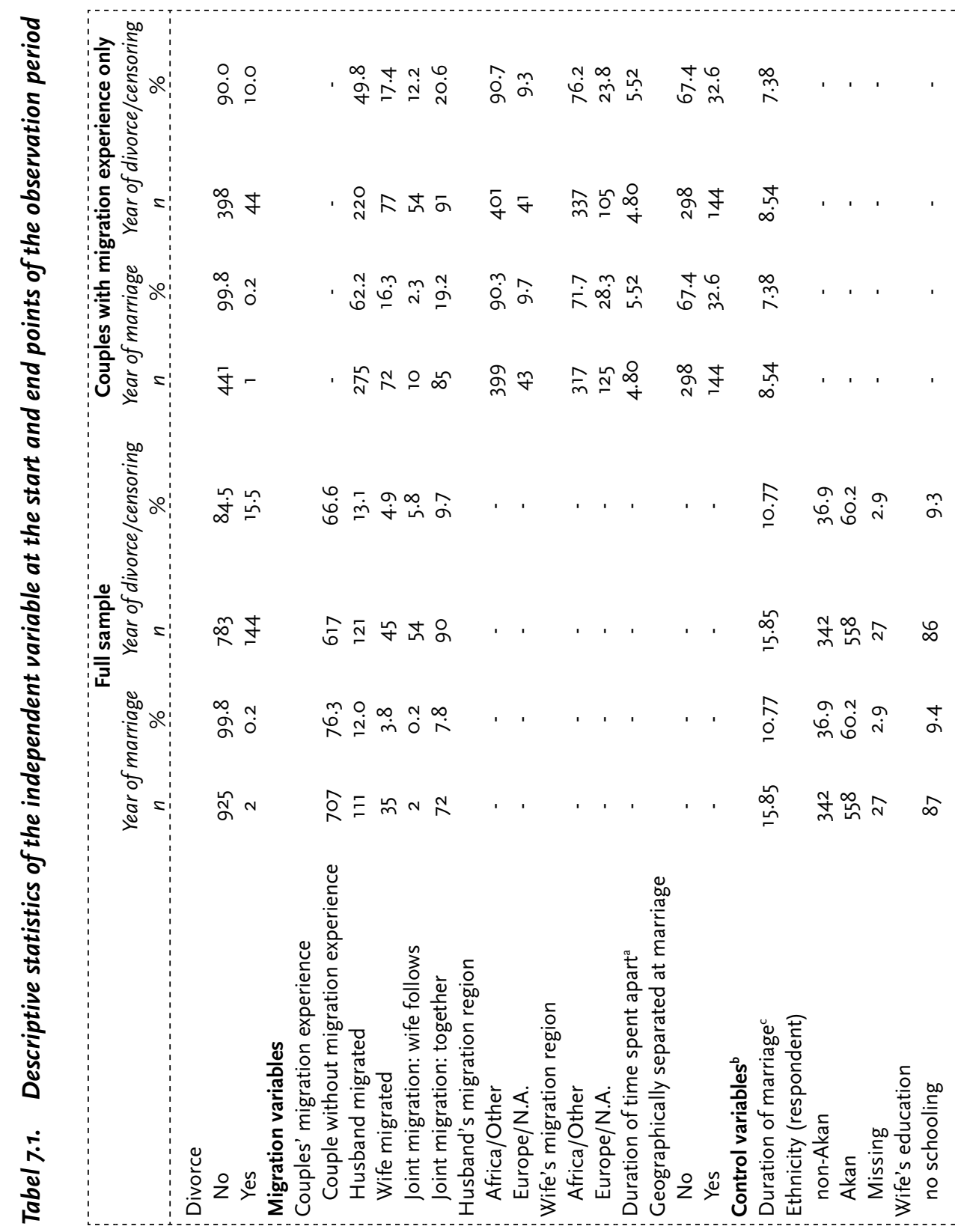




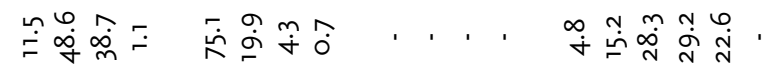

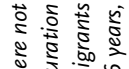

๖

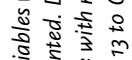

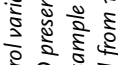

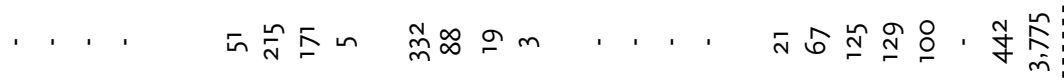

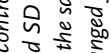

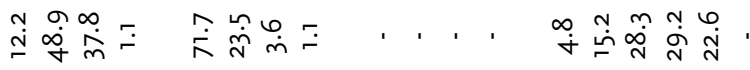

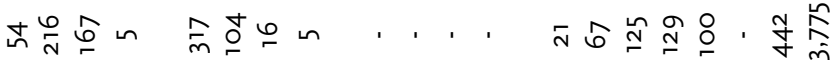

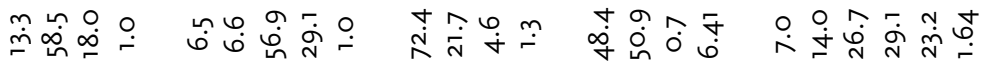

वे वे के

ज迹

ํ.

है के एँ

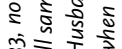

仓े क्षे

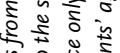

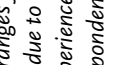

t) $\frac{1}{2}$ के

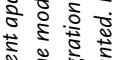

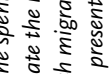

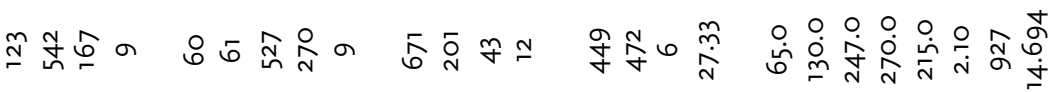

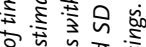

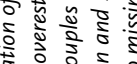

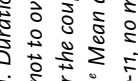

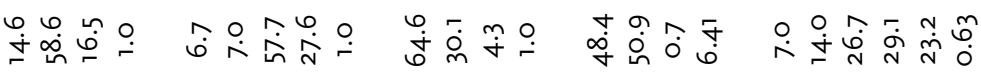

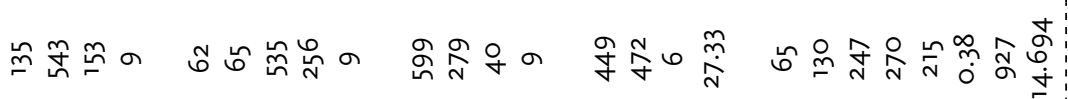

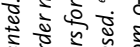

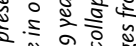

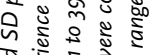

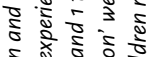

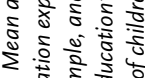

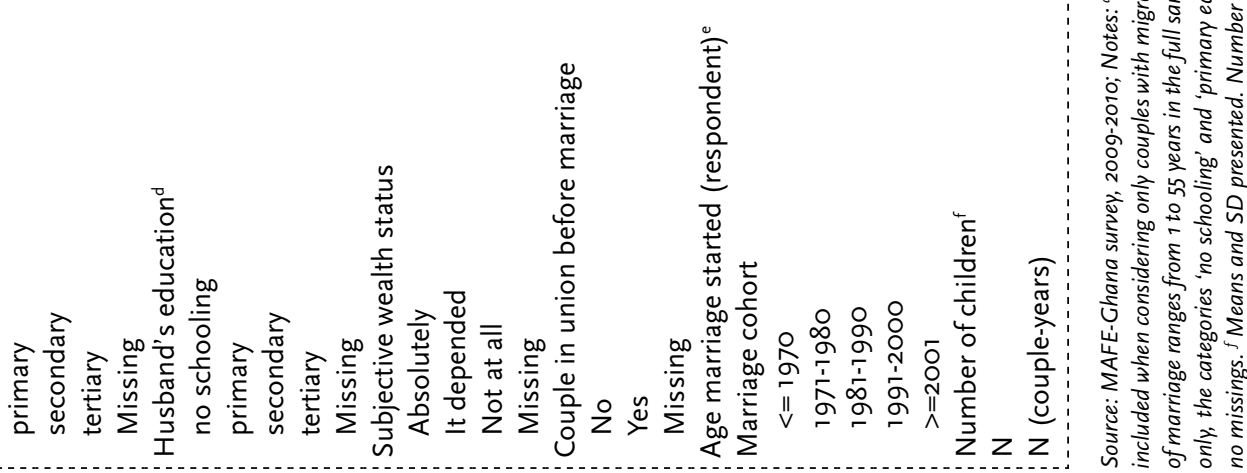




\subsection{Findings}

Cross-tabulations, shown in Table 7.2, revealed that couples without migration experience and couples that experienced joint migration had similar divorce rates $19.8 \%$, and $19.0 \%$, respectively). Additionally, couples where only the wife migrated were also found to have a high divorce rate (13.6\%). Couples for which the husband migrated, either independently or as a pioneer (with his wife following), had a much lower prevalence of divorce $(8.2 \%$ and $7.8 \%$, respectively). The same pattern was observed when examining only couples with migration experience, where couples for which the husband was the only migrant or the pioneer migrant experienced less divorce compared to couples where the wife migrated, either independently or jointly with her husband.

We additionally estimated Kaplan-Meier curves (Singer \& Willett, 2003) to take into account the time varying nature of the migration experience (available in Appendix $C$ ). We examined the proportion of divorcees in the full sample for each year. After 5 years, $5.0 \%$ of the sample divorced; after 10 years, this percentage increased to $10.2 \%$, and after 15 years, $15.4 \%$ divorced. In total, $30.8 \%$ of the couples in the sample divorced. This percentage is in line with previous findings that $35 \%$ of first marriages of women in Ghana ended in divorce (Tabutin \& Schoumaker, 2004).

\section{Table 7.2. Divorce experience of Ghanaian couples with and without ever experiencing migration (time constant)}

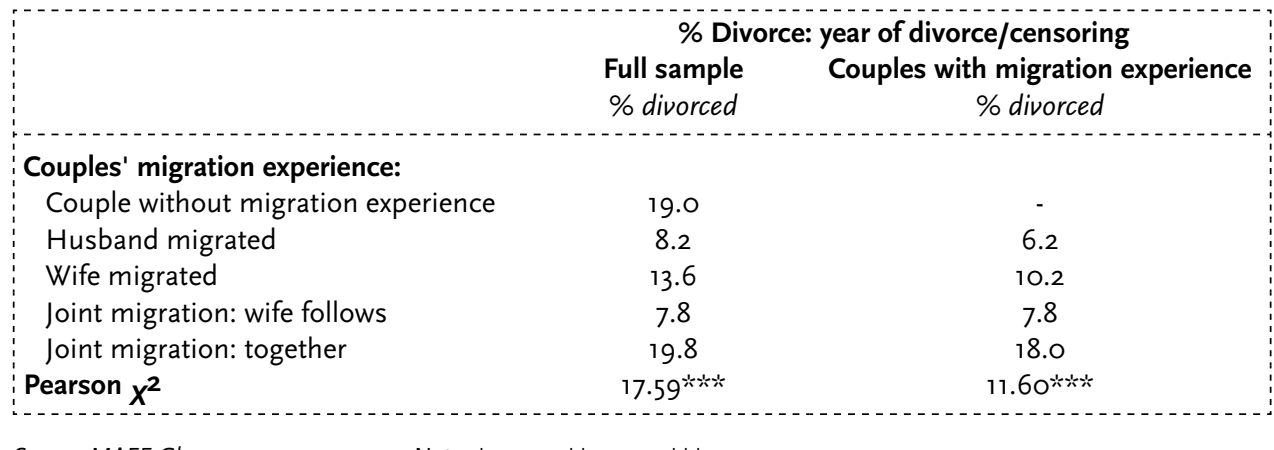

Source: MAFE-Ghana survey, 2009-2010; Notes: $* p<.10 . * * p<.05 . * * * p<.01$.

\section{Couples' Migration Experience and the Probability of Divorce}

A multivariate discrete-time event-history model was estimated to investigate the effect of couples' migration experience on the probability of divorce by including the variable of interest and the control variables. Table 7.3 presents the results of two complementary log-log regression models. Model $1 \mathrm{~A}$ assessed the unconditional effect of the key variable of interest, and in Model $1 \mathrm{~B}$, the control variables were included. 
Model $1 \mathrm{~A}$ shows that couples that experienced female migration only had a significantly higher risk of divorce than couples without migration experience. Similarly, the risk of divorce increased significantly when both partners migrated simultaneously. Couples for which the husband migrated and couples for which the wife followed her husband showed no significant difference compared to couples without migration experience. These findings remained after including the control variables in Model $1 \mathrm{~B}$.

Model $1 \mathrm{~B}$ shows a slight decrease in the probability of divorce for the period 1981 - 1990 compared to the reference period before 1970. Although previous studies found decreasing levels of divorce in Ghana over time (e.g. Takyi \& Gyimah, 2007), we found no significant effects for the other time periods. Considering the educational attainment of both spouses, there were no significant differences in the probability of divorce between women with no schooling compared to women with higher levels of education. For men, only primary education significantly increased the probability of divorce compared to having no schooling.

Respondents' age at the time of marriage did not affect the probability of divorce, which is surprising considering that most studies found that younger ages at the start of the marriage increases the risk of divorce (Amato, 2010). Having been in an unmarried union prior to the marriage also did not affect the risk of divorce. In the case of subjective wealth-status, the risk of divorce increased for those who considered themselves not well off compared to those who considered themselves well off, which is consistent with the literature that suggests that lower socio-economic status increases the risk of divorce (White, 1990). The presence of children in the marriage did not have a significant effect on the risk of divorce.

Predicted probabilities of divorce were calculated from Model $1 \mathrm{~B}$ in Table 7.3, for each of the 5 categories capturing couples migration experience. Average levels for all covariates were used (marriage cohort $=1981-1990$, ethnicity $=$ Akan, wife's education = secondary, husband's education = secondary, subjective wealth-status $=$ it depended, age marriage started $=27.33$, couple in union before marriage $=y e s$, number of children (mean at time of censoring/divorce) $=2.04$ ). Figure 7.1 shows the results for marriage durations between 1 and 25 years. All couples experienced the highest probabilities for divorce around 10 years of marriages. Figure 1 further shows that couples where both spouses migrated together, and the wife followed her husband, had slightly lower probabilities of divorce, while couples without migration experience and couples for which the husband migrated showed similar probabilities. On the other hand, much higher predicted probabilities for couples for which the wife migrated and couples for which both partners migrated simultaneously were observed. To summarize, couples' international migration experience is an important predictor of the probability of divorce. 
Tabel 7.3. Descriptive statistics of the independent variable at the start and end points of the observation period

\begin{tabular}{|c|c|c|c|c|}
\hline & \multicolumn{2}{|c|}{ Model $1 \mathrm{~A}$} & \multicolumn{2}{|c|}{ Model iB } \\
\hline & $\exp (b)$ & $S E$ & $\exp (b)$ & $S E$ \\
\hline \multicolumn{5}{|l|}{ Migration variables } \\
\hline \multicolumn{5}{|l|}{ Couples' migration experience } \\
\hline \multicolumn{5}{|l|}{ No migration (ref.) } \\
\hline Husband migrated & 0.930 & 0.296 & 1.073 & 0.358 \\
\hline Wife migrated & $2.591 * \cdots *$ & 0.934 & $2.507^{* * * *}$ & 0.912 \\
\hline Joint migration: wife follows & 0.750 & 0.376 & 0.785 & 0.401 \\
\hline Joint migration: together & $1.74 * *$ & 0.490 & $1.929 * * *$ & 0.616 \\
\hline \multicolumn{5}{|l|}{ Control variables } \\
\hline Duration of marriage ${ }^{a}$ & $4.462 * \cdots * *$ & 2.643 & $5.913^{*} * * * k$ & 3.901 \\
\hline Duration of marriage $\wedge 2$ & $0.391 * k *$ & 0.131 & $0.367 * \cdots *$ & 0.130 \\
\hline Duration of marriage $\wedge 3$ & $1.140 * * * *$ & 0.054 & $1.142 * * *$ & 0.057 \\
\hline \multicolumn{5}{|l|}{$\begin{array}{l}\text { Marriage cohort } \\
\leq 1970 \text { (ref.) }\end{array}$} \\
\hline $1971-1980$ & & & 0.669 & 0.226 \\
\hline $1981-1990$ & & & $0.561 *$ & 0.182 \\
\hline 1991-2000 & & & 0.743 & 0.263 \\
\hline$\geq 2001$ & & & 0.460 & 0.276 \\
\hline Ethnicity: Akan ${ }^{b}$ & & & 1.088 & 0.231 \\
\hline \multicolumn{5}{|l|}{ Wife's education } \\
\hline \multicolumn{5}{|l|}{ No schooling (ref.) } \\
\hline Primary & & & 1.621 & 0.722 \\
\hline Secondary & & & 1.661 & 0.650 \\
\hline Tertiary & & & 1.286 & 0.591 \\
\hline \multicolumn{5}{|l|}{ Husband's education } \\
\hline \multicolumn{5}{|l|}{ No schooling (ref.) } \\
\hline Primary & & & $3.633^{* * *}$ & 2.072 \\
\hline Secondary & & & 1.626 & 0.849 \\
\hline Tertiary & & & 1.418 & 0.761 \\
\hline \multicolumn{5}{|l|}{ Subjective wealth status } \\
\hline \multicolumn{5}{|l|}{ Absolutely (ref.) } \\
\hline It depended & & & 0.789 & 0.190 \\
\hline Not at all & & & $2.150 * * *$ & 0.855 \\
\hline Age marriage started (respondent) & & & 0.987 & 0.017 \\
\hline Couple in union before marriage ${ }^{c}$ & & & 0.730 & 0.153 \\
\hline Number of children & & & 0.901 & 0.071 \\
\hline \multicolumn{5}{|l|}{ Model characteristics } \\
\hline Log likelihood & -658.4223 & & -642.0693 & \\
\hline N (couple-years) & 12,481 & & 12,481 & \\
\hline $\mathrm{N}$ (couples) & 927 & & 927 & \\
\hline$\%$ divorced $^{d}$ & 30.8 & & 30.8 & \\
\hline $\mathrm{n}$ divorced & 144 & & 144 & \\
\hline
\end{tabular}

Source: MAFE-Ghana survey, 2009-2010; Notes: $* p<.10$. $* * p<.05 . *{ }^{*} * p<.01$. (Two-tailed); ${ }^{a}$ Duration of marriage was transformed using 'duration of marriage / 10 ' in order to avoid exponentiated coefficients of 1.000 for the cubic parameters. ${ }^{b}$ Ethnicity (respondent): $o=$ non-Akan, $1=$ Akan. ${ }^{c}$ Couple in union before marriage: $0=N o, 1=$ Yes. ${ }^{d} \%$ divorced based on Kaplan-Meier estimates that take into account censored observations. 
Figure 7.1. Predicted discrete hazard rates from Model 16

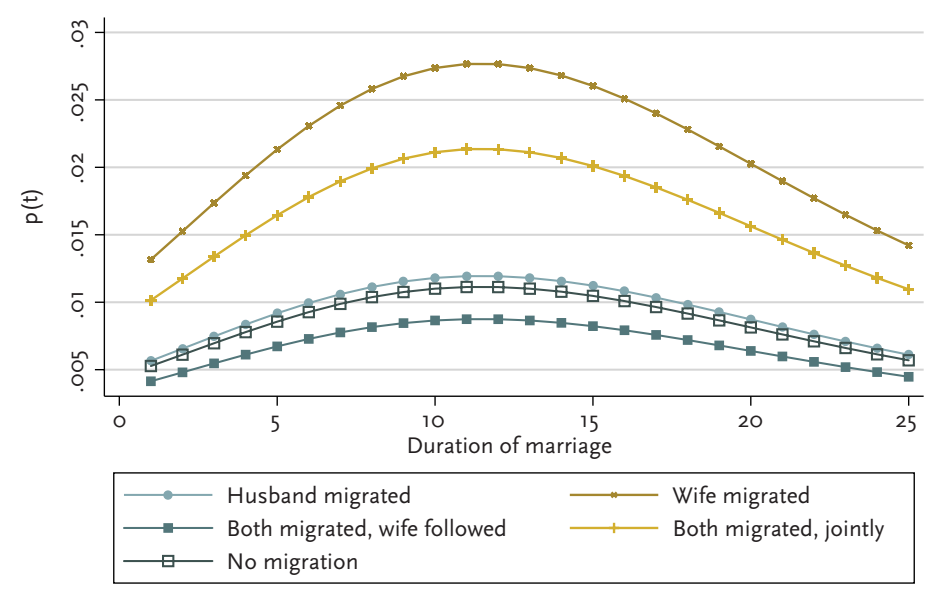

Source: MAFE-Ghana data, 2009-2010

Migration Characteristics and the Probability of Divorce

The second multivariate models examined couples with migration experience only. Migration-specific characteristics were included as follows: in Model 2A, the migration experience of the couple was included; in Model $2 \mathrm{~B}$ only couples where the wife experienced migration (i.e. excluding those where the husband experienced independent migration) were examined, to investigate the effect of the wife's migration to Europe or North America compared to her migration to African/other countries; in Model $2 \mathrm{C}$ only couples where the husband experienced migration (i.e. excluding those where the wife experienced independent migration) were examined, which allowed us to study the effect of the husband's migration to Europe or North America. Additionally, all Models 2 included the duration couples spent living geographically separated and whether the couple was geographically separated at the time the marriage started. The results are presented in Table 7.4. 


\section{Table 7.4. Discrete-time event-history analyses of the risk of divorce for Chanaian couples with migration experience (complementary log-log estimates)}

\begin{tabular}{|c|c|c|c|c|c|c|}
\hline & \multicolumn{2}{|c|}{ Model 2A } & \multicolumn{2}{|c|}{$\begin{array}{l}\text { Model 2B: wives' } \\
\text { migration }\end{array}$} & \multicolumn{2}{|c|}{$\begin{array}{l}\text { Model } 2 \mathrm{C} \text { : husbands' } \\
\text { migration }\end{array}$} \\
\hline & $\exp (b)$ & $S E$ & $\exp (b)$ & SE & $\exp (b)$ & $S E$ \\
\hline \multicolumn{7}{|l|}{ Migration variables } \\
\hline \multicolumn{7}{|l|}{ Couples' migration experience } \\
\hline Wife migrated & $2.205^{*}$ & 0.954 & - & - & - & - \\
\hline Joint migration: wife follows & $0.269 * *$ & 0.172 & - & - & - & - \\
\hline Joint migration: together & 0.845 & 0.426 & - & - & - & - \\
\hline \multicolumn{7}{|c|}{$\begin{array}{l}\text { Husband migrated to Europe/N.A. } \\
\text { No (ref.) }\end{array}$} \\
\hline Yes & - & - & - & - & 0.843 & 0.419 \\
\hline \multicolumn{7}{|l|}{$\begin{array}{l}\text { Wife migrated to Europe/N.A. } \\
\text { No (ref.) }\end{array}$} \\
\hline Yes & - & - & $2.653 *$ & 1.480 & - & - \\
\hline Duration of time spent apart & $0.915^{* * * *}$ & 0.027 & 0.946 & 0.037 & $0.940 *$ & 0.030 \\
\hline $\begin{array}{l}\text { Geographically separated at } \\
\text { marriage }^{a}\end{array}$ & 1.206 & 0.404 & $2.676 *$ & 1.392 & 0.610 & 0.288 \\
\hline \multicolumn{7}{|l|}{ Control variables } \\
\hline Duration since migration ${ }^{b}$ & $11.573^{* * *}$ & 9.988 & 3.203 & 2.919 & $5.189 *$ & 5.004 \\
\hline Duration since migration $\wedge 2$ & $0.427 * *$ & 0.159 & 0.665 & 0.230 & 0.524 & 0.228 \\
\hline \multicolumn{7}{|l|}{ Wife's education } \\
\hline Tertiary & 0.782 & 0.291 & 0.936 & 0.483 & 0.748 & 0.341 \\
\hline \multicolumn{7}{|l|}{ Husband's education } \\
\hline Tertiary & 1.108 & 0.348 & 2.080 & 0.975 & 0.861 & 0.323 \\
\hline \multicolumn{7}{|l|}{ Subjective wealth status } \\
\hline \multicolumn{7}{|l|}{ Absolutely enough (ref.) } \\
\hline It depended & 0.497 & 0.279 & 0.198 & 0.231 & 0.697 & 0.383 \\
\hline Not at all & $3.268 * *$ & 1.886 & 2.266 & 1.936 & 2.334 & 1.821 \\
\hline \multicolumn{7}{|l|}{ Model characteristics } \\
\hline Log likelihood & -222.70197 & & -107.64817 & & -174.19684 & \\
\hline N (couple-years) & 3,686 & & 1,285 & & 2,889 & \\
\hline N (couples) & 442 & & 146 & & 346 & \\
\hline$\%$ divorced $^{c}$ & 28.3 & & 37.9 & & 28.3 & \\
\hline $\mathrm{n}$ divorced & 44 & & 23 & & 33 & \\
\hline
\end{tabular}

Source: MAFE-Ghana survey, 2009-2010; Notes: $* p<.10 . * * p<.05 . * * * p<.01$. (Two-tailed); ${ }^{a}$ Geographically separated at marriage: $0=$ No, $1=$ Yes. ${ }^{b}$ Duration of marriage was transformed using 'duration of marriage $/ 10^{\prime}$ in order to avoid exponentiated coefficients of 1.000 for the cubic parameters. ${ }^{c} \%$ divorced based on Kaplan-Meier estimates that take into account censored observations.

Model $2 \mathrm{~A}$ in Table 7.4 revealed, similar to Models $1 \mathrm{~A}$ and $1 \mathrm{~B}$, that couples where the wife migrated independently have increased probabilities of divorce relative to couples 
where the husband migrated independently. The effect of joint migration experience disappeared, and instead we found that couples where the wife followed her husband were less likely to divorce. Surprisingly, the probability of divorce decreased when couples spent more time living apart due to migration. This might reflect that for some couples, living apart together has become a stable and long-term arrangement. Whether or not the couple lived geographically separated due to migration at the time the marriage started did not affect the probability of divorce.

In Models $2 \mathrm{~B}$ and $2 \mathrm{C}$, the variable couples' migration experience was replaced with two dummy variables, representing whether or not the husband and/or wife migrated to Europe/North America. For the husbands, there was no difference when considering migration to Europe/North America (Model $2 \mathrm{C}$ ), yet for the wives, migration to Europe or North America significantly increased the probability of divorce (Model $2 \mathrm{~B}$ ). Being geographically separated at the start of the marriage did increase the risk of divorce for couples where the wife migrated, but not for couples where the husband migrated. For couples where the husband migrated, we also found that a longer duration of time spent apart decreases the risk of divorce, while this effect was not present for couples where the wife migrated.

Since the sample size was greatly reduced for Models 2, compared to Models 1 , we controlled for a limited number of variables. The two variables capturing duration dependence revealed that the probability of divorce takes an U-shaped pattern in Model $2 \mathrm{~A}$, with an increased risk after the first years of migration, but then the risk of divorce decreases after a period of time. There was no effect of duration in Model $2 \mathrm{~B}$ and a linear effect in Model $2 \mathrm{C}$, indicating that the risk of divorce increases after the first years of migration. Contrary to the previous models in Table 3, no effects of the educational level of the husband were found; no effects for the educational level of the wife were found either. For the subjective wealth-status, not at all having a sufficient amount to live on significantly increased the probability of divorce, in Model 2A, in line with Models 1. This effect is present but not significant in Models $2 \mathrm{~B}$ and $2 \mathrm{C}$.

\subsection{Discussian}

The current study aimed to contribute to the literature on migration and divorce in several ways. First, this topic has remained relatively understudied (Glick, 2010). Second, most studies compared immigrant populations with native populations in the migrant-receiving country. In line with several studies (e.g. Frank \& Wildsmith, 2005; Hill, 2004), the current study examined migration from a bi-national perspective by 
comparing migrants with their non-migrant counterparts from the same origin country. Third, previous studies investigated either male migration or female migration only. The present study examined a couple's migration experience, allowing for the assessment of the different ways that a couple can experience migration. Fourth, the effects of migration were more closely scrutinized by considering certain migration characteristics pertaining to (a) the region of migration, (b) the duration the couple spent living apart due to migration, and (c) whether the couple married while living in different countries. A comparison of two receiving regions is original in that most studies focus on one receiving context (generally the US). This paper examined whether migration to a Western receiving region has different effects compared to migration to a non-Western country. Finally, studies dealing with migration and family life have been dominated by migration from Latin America and Asia, this study contributed by adding a case study from Sub-Saharan Africa.

The findings indicate that there are gender differences in the impact of migration on divorce. Migration increases the risk of divorce when women migrate without their husbands, or when both partners migrate simultaneously. Based on these findings, several hypotheses can be put forward. In many African contexts, norms concerning marriage and gender roles have been characterized as highly flexible. It is possible that those couples in which a husband migrates internationally experience this situation as similar to the traditional multilocal residency of spouses leading to no rise in the risk of divorce.

Women who migrate to a Western context are more prone to divorce, compared to those who migrate to other African countries, while no such results were found for men. This might be indicative of the importance of the receiving context in terms of altering gender norms or a desire to escape (restrictive) marriages (Hill, 2004; Hirsch, 2003; Jolly \& Reeves, 2005; Manuh, 1999; Zontini, 2010). Migration to Western countries can also create tensions between spouses due to changes in gender roles, for example, when the wife becomes the main breadwinner as a consequence of migration. Alternatively, these findings may be explained by other differences that exist between migration within Africa and migration to Europe or North America. People in African origin countries have lower expectations of the benefits to be obtained when a family member migrates within Africa. This may in turn lead to fewer tensions between spouses. Likewise, easier movement within Africa due to cheaper travel or more relaxed border enforcement may allow for more face-to-face contact, which can reduce marital stress. Overall, the current findings demonstrate the importance of taking the receiving context into account.

The probability of divorce decreases for couples where the husband migrated and the wife followed. This contradicts previous studies conducted in a European context that found that marriages in which the wife follows the husband are more unstable, likely due 
to marital stress caused by the wife's loss in labor market status after migrating (Boyle et al., 2008). Our different findings may be an indication that the labor force situation of the 'trailing' Ghanaian wife does not necessarily deteriorate in the European context. Alternatively, it might be the case that these marriages, where the wife is a 'trailing spouse', are more stable due to the fact that the wife is in a vulnerable position due to her dependence on her husbands' status (Kraler, 2010). However, further research is needed to examine the effect of the labor market status of both spouses before, during and after migration on the probability of divorce, as well as the possible vulnerable position of 'trailing wives'.

Previous studies (e.g. Hill, 2004; Frank \& Wildsmith, 2005) have indicated that a longer time period apart is related to an increase in divorce. For Ghanaian couples we found a reverse effect: longer periods apart decreased the risk of divorce. Importantly, though, in cases where the wife migrates, wife's region of migration is a more important predictor because duration of migration becomes insignificant when controlling for it. The effect of duration is likely to be captured by the variable of wife's migration region, as when a wife migrates to a Western context, the couple has on average a longer duration of time spent apart and a higher probability of divorce.

The finding reported above that in most cases there are no differences between divorce rates between couples with migration experience and without, except for when the wife migrates, highlight that high divorce rates are part and parcel of Ghanaian society and not necessarily brought on by international migration. Another way that this study took into account the importance of local context is through including information about whether the respondent is part of a matrilineal lineage, which is claimed to increase the probability of divorce (Boni, 2001; Takyi \& Gyimah, 2007). Although there are different pressures on a wife depending on whether she is part of a matriliny or patriliny (Clark, 1994; Oppong, 1970), the findings show that matriliny is not associated with a higher probability of divorce.

While we focused in this paper on the effect of migration on the probability of divorce, we additionally found some surprising results for our control variables. Two results are particularly worth mentioning, as they seem to deviate from what previous studies found. First, we found limited effects for the husband's educational level, and no effects for wife's educational level. Although research on the relationship between educational levels and divorce remains inconclusive, the majority of studies associate higher educational attainment with higher risks of divorce (Frank \& Wildsmith, 2005; Kalmijn et al., 2004; Takyi \& Gyimah, 2007). Possibly, two divergent effects operating in which the higher educated indeed have more means to escape unhappy marriages, but at the same time higher educated may wait longer and make more considered choices in partner leading to more marriage stability. The co-presence of both positive and negative 
effects of education on divorce in our sample might explain the non-significant effects for education. Second, the known relationship between age at marriage and divorce, with those marrying young having higher risks, was also not found in our study. Future research should further investigate these unexpected results.

This study has highlighted the importance of a gender perspective in analyzing the effects of international migration on divorce. There are two directions that can help carry this type of analysis forward. First, surveys can collect more information to assess whether changes in gender relations are part of the explanation of the elevated risk of divorce for couples for which a wife migrates. Such information includes the reasons for divorce and who initiated the divorce.

Second, it is also possible that a reverse relationship exists than the one considered in this study: that is, that divorce causes people to migrate. As some qualitative studies indicate, divorce may be a source of social stigma, and as such will induce people to migrate. In that case, the findings reported here are likely to underestimate the relationship between migration and divorce as they report only one part of this relationship. As this study did not account for unobserved heterogeneity, it might be the case that migrants are more likely to divorce due to unobserved characteristics that provide them with a latent propensity to divorce. If this would be the case, our results are likely to overestimate the effect of migration on divorce. This study has included some pre-migration characteristics of couples in order to establish causality between migration and divorce. Future studies can carry this further by including more variables concerning the period before migration to investigate the extent to which divorce and migration are interrelated events.

Despite these limitations, this study is one of the few that compared the probability of divorce between migrants and a non-migrant population. This was made possible due to the unique features of the MAFE-Ghana data. We have shown that, with this comparison, we are able to better identify the relationship of migration and the probability of divorce. A couples' perspective further refined our analyses, revealing that marital stability is also dependent on which spouse migrates. Finally, this paper stresses the importance of taking into account the context of both the sending and receiving country. 


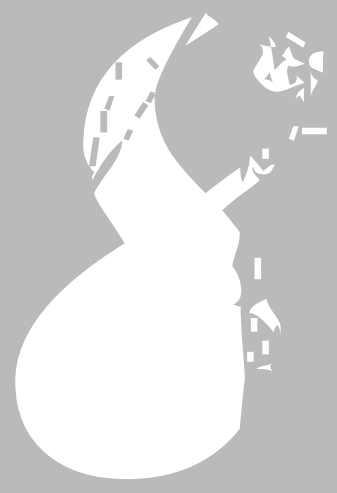

CONCLUSIONS 


\section{I Intraductian}

The overall aim of this thesis was to provide insight into the role of international migration in how Chanaian couples form, transform or dissolve. I investigated if, when and where families live geographically separate from each other and if, when and where they reunify. Employing a transnational approach, this dissertation incorporated the notion that migrants are embedded in multiple contexts (e.g., Basch et al., 1994; Glick Schiller et al., 1992; Levitt \& Jaworksy, 2007; Mazzucato et al., 2004). This means that I: 1) considered the contexts of the sending and receiving countries, 2) included couples that did not migrate, and 3) contextualized the findings by considering the cultural and familial norms of the sending country.

This thesis concentrated on African transnational family life. Although studies on family life between Africa and Europe have attracted more scholarly attention recently (see, e.g., Åkesson et al., 2012; Baizan et al., 2014; Beauchemin et al., 2014; Haagsman \& Mazzucato, 2014; Mazzucato et al., 2014a; Mazzucato et al., 2014b; Fleischer, 2008; Poeze \& Mazzucato, 2013; Ricco, 2008; Tiemoko, 2004), the majority of works on transnational families focus on migration from Asia or Latin America typically directed to the US (see, e.g., Dreby \& Atkins, 2010; Glick, 2010). However, Africans in Europe face different 'contexts of reception' (Portes \& Rumbaut, 1990), and familial norms are different in many African countries, characterized by extended family relationships and multilocal residence patterns. These differences affect the role of migration in family life.

The MAFE-Ghana survey allowed for several methodological innovations. First, the data were collected in one sending country and two receiving countries: Ghana, the Netherlands, and the UK, respectively. This allowed for an analysis of the role of international migration in the lives of Ghanaian families and couples from a transnational perspective. The quantitative analytical techniques applied in this thesis further facilitated the simultaneous examination of multiple factors so that the role of migration could be studied while controlling for other relevant characteristics.

Moreover, the MAFE-Ghana survey captured detailed retrospective biographical information on the relationships and living arrangements of migrants and non-migrants, which enabled the analysis of elements that have not yet received much attention, such as the prevalence of transnational family life, the linkages between union formation, living arrangements and international migration, the reunification behaviour of migrants, and the probability of divorce.

The retrospective data also allowed the investigation of transnational relationships from a longitudinal life course perspective (e.g., Billari \& Piccarreta, 2005; Elder, 1985; Giele \& Elder, 1998; Kohli, 2007; Kulu \& Milewski, 2007; Mayer, 2000; Mayer \& Tuma, 1990; Wingens et al., 2011). While previous studies typically study migration from a 
cross-sectional perspective, such as the pre- or post-migration situation of migrants, this thesis used the retrospective information to consider not only the changing geographical context but also the changing historical context in order to facilitate a better understanding of the implications of migration for family life.

This concluding chapter provides a summary of the main findings, and the implications of these findings for the study of transnational families are described in Section 8.2. In conclusion, Section 8.3 discusses some of the limitations of this research, thereby suggesting several interesting avenues for future research.

\subsection{Findings and implications for the study of transnational families}

Each of the empirical chapters (Chapters 4-7) concluded with a summary of the main empirical findings. These findings can be summarized according to five main implications. I will discuss the findings in light of each of the implications in the subsections below.

1) Contextualization of family life: the sending country context

When interpreting the findings of this study on families and international migration, it is crucial to consider $\mathrm{Chanaian}$ family life. Chanaian families are characterized by geographic dispersal. Multilocal residence between husbands and wives is common because spouses prefer living with their own lineage or in response to internal or international migration (Clark, 1994; Coe, 2011; Fortes, 1950; Manuh, 1999; Oppong, 1970). It is also important to take into account extended family members when considering Ghanaian family life. Despite on-going processes of modernization and trends towards more individualization, the role of the extended family remains pivotal. Extended families continue to play a role in child rearing and marital life, and familial rights and responsibilities are also directed towards extended family members (Awusabo-Asare, 1988; Takyi \& Dodoo, 2005; Takyi \& Gyimah, 2007).

While previous studies have shown that levels of internal migration are high (Anarfi et al., 2003; Reed et al., 2010), we have demonstrated in this thesis that international migration also affects the lives of many Chanaians. In Chapter 4, we showed that almost half of all households surveyed in the Accra and Kumasi regions had at least one household member living abroad. These household members included both nuclear and extended family members, emphasizing the importance of considering extended family members when studying transnational family life. Transnational family life, therefore, 
occurs within a diversity of relationships within the extended family.

While the prevalence of multilocal residence between spouses has been addressed in the historical and contemporary anthropological literature (Clark, 1994; Coe, 2011; Fortes, 1950; Manuh, 1999; Oppong, 1970), this study provided quantitative evidence about the widespread nature of this type of living arrangement. In Chapter 5, we demonstrated that non-residential unions of both married and unmarried couples prevail among Ghanaian couples. The fact that this type of living arrangement is commonplace among couples with and without migration experience illustrates that this phenomenon is not exclusively brought on by international migration.

Considering the Ghanaian background of non-residential family life, the way families form and transform under conditions of international migration can be seen as a continuation of previous lifestyles. At the same time, this thesis also showed that the international context presents new dimensions particular to living apart together across borders. The following sections will elaborate on this.

\section{2) Families Living Apart Together Across Borders}

International migration can impact the forms families take. Nuclear families can migrate as a whole, families can reunite in the receiving country, or families can be formed abroad. However, there is not much quantitative data about these different forms or about the relative importance of these forms (Levitt, 2001b; Portes, 2001; Vertovec, 2004 b). This thesis contributes to the literature on transnational families by investigating these different types of family forms in the context of international migration (Chapter 4). These different categorizations allow for an examination of how migration impacts the forms families take.

We investigated if, when and where families live geographically separate from each other and the forms these families take. A first finding (Chapter 4) was that a large share of migrants falls outside the category of migrants that can potentially reunify. Although policy and public discourse, as well as the academic literature, emphasize that family reunification is the ticket to entry into Europe (Kraler et al., 2011), it is important to note that among Ghanaians in the Netherlands and the UK, $27 \%$ were not married and did not have children (Chapter 4 ). This finding highlights the nuances of generalized notions of the extent to which migrants enter Europe via family reunification.

When living apart together across borders, families maintain contact with each other. They do so via various communication technologies and by means of remittances (Chapter 4). Although migrants received financial support for their trip abroad, usually from their nuclear family members, they also sent remittances to the family members left-behind, evidencing 'reverse remittance' flows (Mazzucato, 2009, 2011). Interestingly, this thesis showed that migrants sent remittances to their households even if they did 
not receive financial support. This might reflect that remittances are not necessarily a form of 'pay back', as has been suggested by previous migration research (e.g., Stark \& Lucas, 1988), and that migrants' remittance behaviour should be considered in the context of 'generalized' reciprocal relations, whereas 'paying back' is embedded in wider social systems (Mazzucato, 2009, 2011).

In order to better understand transnational family life, arrangements to 'live apart together across borders' should be considered as a separate category when describing migration patterns. Building on Hondagneu-Sotelo's (1994) typology, this thesis argued that two main additions further strengthen this categorization. We advanced previous works that have addressed the assumption that all families will eventually reunify (Baizan et al., 2014; Beauchemin et al., 2014; Bledsoe \& Sow, 2011; Landolt \& Wei Da, 2005; Riccio, 2008). Indeed, we have shown that living apart together across borders is a widespread and long-term living arrangement for some migrants. Both couples and parent-child dyads live geographically separate for extended periods of time.

Additionally, independent female migration is a common feature of contemporary migration flows in general and of Ghanaian migration flows in particular (Anarfi et al., 2003; Schans et al., 2013), contrary to the research context analysed by HondagneuSotelo (1994), where males have dominated migration between Mexico and the US to a large extent. Considering these findings, two additions can be made to expand Hondagneu-Sotelo's typology (Chapter 4). First, family stage migration should encompass independent female and male migration because women also migrate first and bring over their husbands and/or children in a later phase. Second, family stage migration can be categorized into families that reunify in the receiving country and those that reunify in the sending country. Third, considering the long-term separation of families and the fact that some do not reunify at all, an additional category consisting of families living apart together across borders is necessary.

The receiving country context also makes a difference in the forms that families take. In this thesis, we examined two receiving country contexts, the UK and the Netherlands, which are among the main European destination countries of Ghanaians (Akyeampong, 2000). First, we found that transnational family life is more prevalent amongst Ghanaians in the Netherlands than amongst those in the UK, and moreover, reunification is less likely in the Netherlands than it is the UK (Chapters 4 and 6). While our data cannot completely unravel the reasons behind the differences between these two receiving contexts, several factors are likely to influence migrants' decision (whether informed by choice or in response to constraints) to live transnationally.

First, migration policies have been more restrictive in the Netherlands than they have in the UK (Bonjour, 2008; De Hart et al., 2012; Strik et al., 2013). While both the UK and the Netherlands have seen an increase in requirements for family reunification, the 
Netherlands can be considered more difficult as a consequence of these requirements, such as a pre-entry integration test that includes knowledge about Dutch society in addition to basic knowledge of the language (the Integration Abroad Act, 2005), ' high income requirements (120\% of the net social welfare level in 2004), and high costs of residence permits (Bonjour, 2008; Groenendijk et al., 2007; De Hart et al., 2012; Strik et al., 2013).

Second, Ghanaians have been migrating to the UK for a longer period of time due to these countries' colonial ties. This means that on average, Ghanaians have spent more time in the UK than they have in the Netherlands. Consequently, Ghanaians in the Netherlands may have had less time to settle and therefore less time to reunify, also considering the fact that family reunification can be a lengthy procedure. Another consequence of the historical ties between Ghana and the UK is a shared language (i.e., English is the official language of education in Chana) and similar school systems. Previous research has indicated that Ghanaians in the Netherlands are less inclined to reunify because of problems with the Dutch language, at school, with the recognition of their educational credentials and in the labour market (Dito et al., in press; Mazzucato, 2008a). Because the criteria for family reunification are linked to the socio-economic and legal status of the sponsor, it is more difficult for migrants in the Netherlands to fulfil these conditions.

While difficulties with meeting the criteria for family reunification might withhold some migrants from reunifying in the receiving country, we found that for others, a higher socio-economic status relates to transnational family life. While in the UK, transnational family life is related to lower levels of education, we found a reverse relationship in the Netherlands. The conditions of the educational system and those in the labour market are more favourable for higher-educated Ghanaians in the UK, making it more attractive for them to reunify. Ghanaian migrants in the Netherlands might prefer that their children become educated in Ghana, avoiding difficulties with different school systems and learning a new language.

Considering these various forms of family migration allows for the inclusion of more diversity when analysing the role of migration, as the outcomes likely differ according to the different forms families take in the context of migration. Moreover, reunification in the sending country has typically been overlooked, and quantitative studies on living apart together across borders are limited. In the following section, I show how this thesis contributes to our understanding of transnational family life by considering couples' decisions to reunify.

1 The UK also has a pre-entry test, but only level-Aı speaking and listening is required; in the Netherlands, reading skills are required, as well as the so-called 'integration test' that tests knowledge about Dutch society (Strik et al., 2013). 


\section{3) Decisions to reunify}

This thesis also considered families that reunify after having lived geographically separate. The multi-sited data collection of the MAFE project allowed us to look at the question of where families reunify. This is a relatively new research area, as most research on reunification only focuses on the migrant-receiving country. We hereby contribute to emerging studies that stress that migrants do not necessarily reunify in the receiving country and that families may reunify by returning to the sending country (Baizan et al., 2014; Beauchemin et al., 2014; Landolt \& Wei Da, 2005; Riccio, 2008; Bledsoe \& Sow, 2011). Importantly, we show that reunification between migrants and their spouses, or children, also occurs to a large extent in the migrant-sending country (Chapter 4 ).

This thesis also questioned which characteristics are associated with a migrant's decision to reunify with his or her spouse (Chapter 6). As mentioned, living apart together across borders can be driven by a preferred choice, it can be the result of socioeconomic circumstances, or it can be the unwanted outcome of stringent reunification policies. While disentangling these separate influences remains a challenge, this thesis points to several important factors. As previous transnationalism scholars have argued, it is important to include those left-behind when aiming to understand migration-related processes (e.g., Levitt, 2001a, 2001b; Kanaiaupuni, 2000).

We examined the influence of the educational level of the left-behind spouse in assessing the probability to reunify, which proved to be an important factor to take into account. Migrants with higher-educated spouses are more likely to stay transnational, which contrasts with previous findings on Senegalese transnational couples, which are more likely to reunify when spouses are higher educated (Baizan et al., 2014). This might be associated with better opportunities in the labour market for the higher educated in Ghana compared to those in Senegal. The fact that Ghanaian spouses with higher levels of education have more labour opportunities in the sending country might make reunification less necessary and desirable. Additionally, this finding aligns with research on LAT relationships in Western countries, which are typically associated with higher levels of education (Strohm et al., 2009).

We also found evidence that indicates that family reunification policies are socially selective (Kraler, 2010), excluding more vulnerable groups from exercising their rights to family reunification (Chapter 6). For some migrants, transnational family life is associated with recent arrival and more vulnerability in terms of socio-economic and legal status. Additionally, transnational couples who migrated after 2004, a period characterized by more stringent legislation in most European countries (De Hart et al., 2012; Sibley et al., 2012), were less likely to reunify. Importantly, we found that migrants also reunify outside the legal framework. While transnational families are likely to be undocumented or have short-term visas, the documented status of migrants did not significantly affect 
reunification behaviour with their spouses. This confirms previous studies (GonzálezFerrer, 2011; Baizan et al., 2014) and suggests that both de jure and de facto reunification occurs.

With respect to the influence of family reunification policies on the probability of reunification for couples, this thesis put forth two hypotheses (Chapter 6). First, while we found that the period after more stringent policies were implemented resulted in the reunification of fewer couples, migrants' legal status did not affect their reunification behaviour. This indicates that more restrictive policies work to some extent in preventing couples from reunifying. It might also be the case that other criteria associated with family reunification policies are more effective, such as income requirements. Additionally, a limited income might also hamper reunification via informal channels, as this can be a costly business. Second, migrants who maintain transnational lifestyles, as evidenced by making short-term visits, are likely to have the necessary documents and finances to live transnationally. However, these migrants with transnational lifestyles are less likely to reunify, suggesting that they prefer to not reunify. This suggests that policies are not the only factor that affects migrants' reunification behaviour and that not all migrants desire to reunify. Together, our findings indicate that for some migrants, living transnationally is a choice, while for others it is the consequence of constraints, financially, legally or otherwise.

\section{4) Gender matters: considering who migrates when and where}

Previous studies have emphasized the intricate link between gender and migration (Donato et al., 2006; Hondagneu-Sotelo, 1999; Jolly \& Reeves, 2005; Pessar \& Mahler, 2003). Research has shown that men and women respond differently to their migration experiences (e.g., Anarfi et al., 2003; Hondagneu-Sotelo, 1999; Itzigsohn \& GiorguliSaucedo, 2005; Wong, 2006). Gender norms can affect the migration experience of both sexes (e.g., Gallo, 2006; Hirsch, 2003; Zontini, 2010; Poeze \& Mazzucato, 2012; Pribilsky, 2004; Wong, 2006), and living apart together across borders can have emotional ramifications for children and spouses (e.g., Fouron \& Glick Schiller, 2001; Lahaie, Hayes, Markham \& Heymann, 2009; Mahler, 2001; Manuh, 1999; Mazzucato et al., 2014b; Pribilsky, 2004; Suárez-Orozco et al., 2002). Advancing these previous works, we investigated the gendered nature of migration as much as possible. We demonstrated that it is crucial who in the couple migrates, to where, and when.

Ghanaians provided an interesting case study to investigate the difference between male and female migration in relation transnational family life, as Ghanaian migration flows consist almost equally of female and male migrants (Anarfi et al., 2003; Manuh, 1999; Oppong, 1970; Wong, 2006). In Chapter 5, we found that nonresidential living arrangements are more prevalent for Ghanaian women and migrant 
women in particular. Previous studies have also shown that female-headed households are a significant phenomenon in Ghana and might be associated with the reputedly autonomous character of Ghanaian women (Coe, 2011; Lloyd \& Gage-Brandon, 1993; Manuh, 1997, 1999; Oppong, 1970; Takyi, 2001; Takyi \& Gyimah, 2007). The high number of female-headed households has been associated with the high mobility of Ghanaian men both internally and internationally, high divorce rates, pre-marital childbearing, and large-scale economic restructuring programs, such as Structural Adjustment Programs (SAPs) (Coe, 2011; Manuh, 1997, 1999; Mikell, 1992, 1997; Lloyd \& Gage-Brandon, 1993; Oppong, 1970; Tabutin \& Schoumaker, 2004; Takyi \& Gyimah, 2007).

We also distinguished between male and female migration in terms of migrants' reunification behaviour (Chapter 6). No differences were found, similar to previous studies on reunification (e.g., González-Ferrer, 2011). Our small sample size did not allow us to further investigate differences between men and women. This would have been an interesting aspect to investigate as qualitative research has shown that reunification for women is more difficult because meeting the high income requirements poses more of a challenge for them (Kofman et al., 2011; Kraler, 2010; Van Walsum, 2006). However, previous research on Ghanaian migrants in the Netherlands has shown that women seemed to desire reunification more than men (Poeze \& Mazzucato, 2014). The fact that we found no difference between the reunification patterns of men and women might be the outcome of different processes: women are not able to reunify due to policy constraints, while men aspire less to reunify.

While previous studies have typically investigated either male migration or female migration (e.g., Frank \& Wildsmith, 2005; Hill, 2004; Landale \& Ogena; 1995), the present study assessed the different ways that a couple can migrate and how this relates to the probability of divorce (Chapter 7). We differentiated between male migration, female migration, trailing wives, trailing husbands and joint migration. There were several salient findings in this regard. First, the probability of divorce is higher when women migrate without their husbands or when a couple migrates jointly. Second, women who migrate to a Western context are more likely to divorce compared to women who migrate to other (mainly African) contexts. This might be indicative of changing gender roles, which can be influenced by gender norms in the receiving country (see, e.g., Hill, 2004; Hirsch, 2003; Jolly \& Reeves, 2005; Manuh, 1999; Zontini, 2010). Alternatively, female migration to African countries might differ from female migration to Western countries in other aspects. Often, with migration to African countries, distances are generally shorter and travel is cheaper, enabling more visits back and forth, which enable a transnational relationship. Third, migration decreases the risk of divorce for couples in which the husband migrated and his wife followed, while no differences were found between couples without migration and couples in which only the husband migrated. 
Our findings demonstrated that there are indeed gender differences when studying the role of migration on the probability of divorce. We will elaborate on these findings in the next section.

\section{5) The relationship between migration and divorce}

We contribute to the literature on migration and divorce, a topic that has remained relatively understudied (Glick, 2010) (Chapter 7). Instead of comparing immigrant populations with native populations, as is typically done, we compared migrants with their non-migrant counterparts from the same origin country (in line with e.g., Frank \& Wildsmith, 2005; Hill, 2004). Moving beyond only considering male migration or female migration, we examined different ways in which a couple can experience migration. Additionally, we considered several migration characteristics related to (a) the region of migration (a Western vis-à-vis a non-Western receiving region), (b) the duration of time the couple spent living apart due to migration, and (c) whether the couple married while living in different countries.

While migration is usually associated with more stressful marriages and therefore a greater likelihood of divorce (e.g., Boyle et al., 2008), we found that Ghanaian transnational couples are not necessarily less stable than couples that do not experience migration. Instead, migration leads to divorce only under specific conditions. As described in the previous section, migration increases the probability of divorce only when the wife migrates, either alone or jointly, and specifically when she migrates to a Western receiving country. These surprising results contradict previous studies carried out in a European context that indicate that couples with 'trailing wives' are more prone to divorce (Boyle et al., 2008). Considering the Ghanaian context, we put forth several hypotheses that might explain these findings.

First, Ghanaian wives' labour market situation might not necessarily worsen after migration, as is often the case for trailing wives in the European context. Second, 'trailing wives' might be more vulnerable, placed in a dependent position due to her husband's legal status, making divorce a less feasible option (Kraler, 2010). Third, given the context of high internal mobility, couples in which the husband migrates might present a continuation of previous living arrangements. Living apart together across borders might resemble the traditional multilocal residency of spouses that results in no increase in the probability of divorce. Fourth, men and women can respond differently to the context at arrival (e.g., Feliciano, 2008; Suárez-Orozco, Suárez-Orozco \& Todorova, 2008; SuárezOrozco \& Qin, 2006). Women might be more susceptible to changing gender norms, or they might migrate out of a desire to escape unhappy marriages (see also: Hill, 2004; Hirsch, 2003; Jolly \& Reeves, 2005; Manuh, 1999; Zontini, 2010). Lastly, migration can change gender roles, such as if wife becomes the main breadwinner. This might result in marital tensions that elevate the risk of divorce. 
Overall, the findings in the thesis demonstrate the importance of taking the sending country context as well as the receiving country context into account because both contexts affect the way in which families live transnationally or reunify. Comparing migrants and non-migrants showed that international migration shapes the transnational family, and it also reveals that some types of living arrangements are related to socio-cultural practices in the sending country, which emphasizes the importance of taking the sending country context into account when studying processes related to international migration. At the same time, restrictive policies and different normative contexts in receiving countries also influence the formation and transformation of transnational family life.

\subsection{Ideas far future research}

While trying to provide insight into the transnational family life of Chanaian migrants, I concentrated on several elements that have thus far received limited attention. These elements included a quantitative perspective on the prevalence and different forms of transnational family life, the relationship between family formation, living arrangements and international migration, couples' reunification behaviour and the effect of migration on the probability of divorce. However, studying these different elements also meant dealing with several methodological issues and limitations, not all of which could be solved. In this final section, I discuss some of these limitations and how these lead to ideas for future research.

The MAFE data offered unique opportunities to study the role of international migration on family life through the collection of detailed, multi-sited and retrospective information that allows for a comparison of migrants and non-migrants. However, the sample size, particularly the sample of current migrants, is relatively small. This limited the possibility of several analyses. First, separate analyses for men and women were not possible. Our results demonstrate the importance of considering gender, given the gendered nature of both migration and family life. These findings should encourage future research to continue this line of investigation by scrutinizing for which migration processes it makes a difference whether the migrant is male or female, when and in which order one migrates (i.e., comparing trailing spouses, joint migration, and independent migration), and from which sending context and to which receiving context male or female migrants move. Future surveys should collect more information on who in a couple migrates when and where to assess whether changes in gender relations motivate the different outcomes for men and women with regard to their transnational family life.

Second, the relatively small samples in the receiving countries also limited the 
possibility to study the receiving country context in greater detail. This seems particularly relevant in light of our findings that highlight two opposing explanations for migrants that opt for a transnational family life: for some, transnational family life might be the preferred choice, while for others, stringent migration policies might constrain them from reunifying with their families. Future research should advance this by further illuminating the conditions under which transnational family formations are preferred or imposed. While qualitative research may help generate insights on the underlying decision-making processes of migrants concerning family reunification (see for example Poeze \& Mazzucato, 2014), greater detail on policies would help identify the role of reunification policies.

Interesting research that facilitates cross-country comparisons of policies over time has emerged. Mezger \& González-Ferrer (2013) generated a new database (ImPol) that covers all immigration policies over time and that allows for cross-country comparisons. Thus far, the ImPol database is only available for Italy, Spain and France, but new receiving countries can be added in the future. The International Migration Policy and Law Analysis (IMPALA) database is a similar initiative; Harvard University, the University of Luxembourg, the University of Amsterdam, the London School of Economics, and the University of Sidney are currently collecting data on immigration policies that will be comparable across 25 countries and over time, from 1960 to 2010 . However, this dataset is not yet available. Another recent initiative is the Migrant Integration Policy Index (MIPEX), which provides information about the restrictiveness of family reunification policies and other indicators related to integration. However, this database covers only recent years. ${ }^{2}$ While ImPol, IMPALA, and MIPEX concentrate on policies in receiving countries, Vink, De Groot and Luk (2013) have created the Global Dual Citizenship Database, covering 200 countries from 1960 to 2013 , which allows for the assessment of the role of both sending and receiving country policies with respect to citizenship. These databases, in combination with larger samples in receiving countries, hold great promise for investigating the role of reunification and other relevant policies in transnational family life.

Third, random sampling in receiving countries is often impossible due to the lack of appropriate sampling frames, especially when undocumented migrants are included. The MAFE survey used quota sampling, a valid alternative; however, the consequence of non-random sampling in the receiving countries resulted in limited generalizability. Again, increasing the sample size would yield more power and thus be a great next step forward. Finally, it would be interesting to further expand on the longitudinal elements

2 More information on IMPALA can be found at: http://projects.iq.harvard.edu/impala, and more information on MIPEX is available at: http://www.mipex.eu. 
of the data. While the small sample size did not allow for such analysis, studying the dynamic aspects of reunification, hereby considering cycles of transnational periods, would provide an interesting avenue for future research.

Despite these limitations, this thesis makes an original contribution in that most studies on transnational families focus on one receiving context. We compared two receiving regions (Western versus non-Western countries) and two receiving countries (the UK and the Netherlands) in this thesis. Having demonstrated the importance of the receiving country context and the sending country context also calls for more comparative research to help carry this type of analysis forward. Considering the importance of the sending context and the receiving context urges future research to expand the geographical scope. The MAFE project offers this opportunity, as identical data have been collected in two additional sending countries (Senegal and Congo) and four European receiving countries (Italy, Spain, France, and Belgium). Such comparisons across different migration flows would allow for further identification of the factors that play a role in transnational family life from both the sending country perspective and the receiving country perspective. 


\section{REFERENCES}

Abbott, A. \& Tsay, A. (2000). Sequence analysis and optimal matching methods in Sociology.

Sociological Methods a Research, 29, 3-33.

Amsterdams Centrum Buitenlanders (ACB) (2011). Factsheet Ghanezen in Nederland.

Retrieved from $A C B$ kenniscentrum voor emancipatie en participatie website:

www.acbkenniscentrum.nl/public/Publicatie/54/download1/2011-14-09\%20Factsheet\%20

Ghanezen\%2oin\%2oNederland.pdf

Abrego, L. (2009). Economic well-being in Salvadorian transnational families:

How gender affects remittance practices. Journal of Marriage and Family, 71(4), 1070-1085.

Åkesson, L., Carling, J. \& Drotbohm, H. (2012). Mobility, moralities, and motherhood:

Navigating the contingencies of Cape Verdean lives. Journal of Ethnic and Migration Studies, 38(2), 237-260.

Akyeampong, E. (2000). Africans in the diaspora: The diaspora in Africa. African Affairs, 99, 183-215.

Al-Ali, N., Black, R. \& Koser, K. (2001). Refugees and transnationalism: The experience of Bosnians and Eritreans in Europe. Journal of Ethnic and Migration Studies, 27(4), 615-634.

Alber, E. (2003). Denying biological parenthood: Fosterage in Northern Benin. Ethnos, 68(4), 487-506.

Amato, P.R. (2010). Research on divorce: Continuing trends and new developments.

Journal of Marriage and Family, 72(3), 650-666.

Amoateng, A.Y. \& Heaton, T.B. (1989). The socio-demographic correlates of the timing of divorce in Ghana. Journal of Comparative Family Studies, 20(1), 79-96.

Anarfi, J.K., Kwankye, S., Ofoso-Mensah, A. \& Tiemoko, R. (2003). Migration from and to Ghana: A background paper (WP-C4). Brighton: University of Sussex, Development Research Centre on Migration Globalisation and Poverty.

Andersson, G. (2004) Childbearing after migration: Fertility patterns of foreign-born women in Sweden. International Migration Review, 38(2), 747-775.

Andersson, G. \& Scott, K. (2010, September). Divorce risks of immigrants in Sweden. Paper presented at the European Population Conference, Vienna. Retrieved from epc2010.princeton.edu/ papers/100175

Antoine, P., Adjamagbo, A., Amétépé, F., Béguy, D., Dial, F.B., Ferrand, M. \& Tichit, C. (2009). Union and separation: love stories are never simple. In P. Antoine \& E. Lelièvre (Eds.), Fuzzy states and complex trajectories. Observation, modelization and interpretation of life histories (pp. 55-76). Paris: INED. 
Anyadike-Danes, M. \& McVicar, D. (2010). My brilliant career: characterizing the labour market trajectories of British women of Generation X. Sociological Methods and Research, 58(3), 482-512.

Ardayfio-Schandorf, E. (Ed.) (1994). Family and development in Ghana. Accra: Ghana University Press. Ardayfio-Schandorf, E. \& Amissah, M. (1996). Incidence of child fostering among school children in Ghana. In E. Ardayfio-Schandorf (Ed.), The changing family in Ghana (pp. 179-200). Accra: Ghana University Press.

Asima, P.P.D. (2010). Continuities and discontinuities in gender ideologies and relations: Ghanaian migrants in London. Unpublished doctoral dissertation, University of Sussex. Awusabo-Asare, K. (1988). Interpretations of demographic concepts: The case of Ghana. Population and Development Review, 14(4), 675-687.

Baizan, P., Beauchemin, C. \& González-Ferrer, A. (2014). An Origin and Destination Perspective on Family Reunification: The Case of Senegalese Couples. European Journal of Population, 30(1), $65-87$.

Baldassar, L. \& Merla, L. (Eds.) (2014). Transnational Families, Migration and the Circulation of Care: Understanding Mobility and Absence in Family Life. New York: Routledge.

Basch, L., Glick Schiller, N. \& Szanton-Blanc, C. (1994). Nations Unbound: Transnational Projects, Postcolonial Predicaments, and Deterritorialized States. London: Gordon \& Breach.

Bean F.D., Berg R.R., \& Van Hook, J.V.W. (1996). Socioeconomic and cultural incorporation and marital disruption among Mexican Americans. Social Forces, 75(2), 593-617.

Beauchemin, C. (2012). Migrations between Africa and Europe: Rationale for a Survey Design (MAFE Methodological Note 5). Paris: INED. Retrieved from www.ined.fr/fichier/t_ telechargement/43982/telechargement_fichier_fr_note.5_mafe_rationale_for_a_survey_ design.pdf

Beauchemin, C. (Ed.) (in press). Migration between Africa and Europe. New York: Springer-Verlag Berlin Heidelberg.

Beauchemin, C., Caarls, K. \& Mazzucato, V. (2013). Senegalese migrants between here and there: An overview offamily patterns (MAFE Working Paper 33). Paris: INED. Retrieved from www.ined.fr/fichier/t_telechargement/60574/telechargement_fichier_fr_wp33_senegal_family.pdf

Beauchemin, C. \& González-Ferrer, A. (2011). Sampling international migrants with origin-based snowballing method: New evidence on biases and limitations. Demographic Research, 25(3), 103-134.

Beauchemin, C., Nappa, J., Schoumaker, B., Baizan, P., González-Ferrer, A., Caarls, K. $\&$ Mazzucato, V. (2014). Reunifying versus living apart together across borders: A comparative analysis of sub-Saharan migration to Europe. International Migration Review. Advance online publication. doi:10.1111/imre.12155

Bernardi, L. (2011). A mixed-methods social networks study design for research on transnational families. Journal of Marriage and Family, 73(4), 788-803. 
Bernhard, J.K., Goldring, L. \& Landolt, P. (2005). Transnational, multi-local motherhood: Experiences of separation and reunification among Latin American families in Canada (Working paper No. 40). Toronto: Centre of Excellence for Research on Immigration and Settlement (CERIS). Retrieved from www.ceris.metropolis.net/wp-content/uploads/pdf/ research_publication/working_papers/wp4o.pdf

Bernhard, J.K., Landolt, P. \& Goldring, L. (2009). Transnationalizing families:

Canadian immigration policy and the spatial fragmentation of care-giving among Latin American newcomers. International Migration, 47(2), 3-31.

Bhabha, J. \& Shutter, S. (1995). Women's movements: Women under immigration, nationality and refugee law. Staffordshire, Eng: Trentham Books.

Billari, F.C. \& Piccarreta, R. (2005). Analyzing demographic life courses through sequence analysis. Mathematical Population Studies, 12(2), 81-106.

Black, R., Quartey, P., Castagnone, E., Nazio, T., Schoumaker, B. \& Rakotonarivo, N. (2013). Understanding Afro-European labour trajectories: integration of migrants in the European labour market and re-integration in origin countries. The case of Ghana (MAFE Working Paper 28). Paris: INED. Retrieved from www.ined.fr/fichier/s_rubrique/22089/wp28._ghana_ economy.fr.pdf

Bledsoe, C. (1990). 'No success without struggle': Social mobility and hardship for foster children in Sierra Leone. Man, 25(1), 70-88.

Bledsoe, C. (1993). The politics of polygyny in Mende child fosterage transactions. In B.D. Miller (Ed.), Sex and gender hierarchies (pp. 170-192). Cambridge, Eng: Cambridge University Press.

Bledsoe, C. (2006). The demography of family reunification: from circulation to substitution in Gambian Spain (WP 2006-053). Rostock: the Max Planck Institute for Demographic Research. Retrieved from www.demogr.mpg.de/papers/working/wp2006-053.pdf

Bledsoe, C.H., \& Sow, P. (2008). Family reunification ideals and the practice of transnational reproductive life among Africans in Europe (WP 2008-001). Rostock: the Max Planck Institute for Demographic Research. Retrieved from www.demogr.mpg.de/papers/working/wp-2008-001.pdf

Bledsoe, C. \& Sow, P. (2011). Back to Africa: Second chances for the children of West African immigrants. Journal of Marriage and Family, 73(4), 747-762.

Bleek, W. (1987). Lying informants: A fieldwork experience from Ghana. Population and Development Review, 13(2), 314-322.

Blossfeld, H.P., Golsch, K. \& Rohwer, G. (2007). Event history analysis with Stata. Mahwah, N): Lawrence Erlbaum Associates.

Boni, S. (2001). Twentieth-century transformations in notions of gender, parenthood, and marriage in Southern Ghana: A critique of the hypothesis of 'Retrograde Steps' for Akan women. History in Africa, 28, 15-41.

Bonjour, S. (2008). Family migration policies in the Netherlands (New Orientations for Democracy Europe (NODE) Policy report). Vienna: Austrian Federal Ministry of Science and Research 
(Bmwf) /International Centre for Migration Policy Development (ICMPD).

Boyd, M. \& Grieco, E. (2003). Women and Migration: Incorporating Gender into International Migration Theory. Migration Information Source, 1.

Retrieved from www.migrationpolicy.org/article/women-and-migration-incorporating-genderinternational-migration- theory

Boyle, P.J., Cooke, T., Halfacree, K.H. \& Smith, D. (1999). Gender Inequality in Employment Status

Following Family Migration in GB and the US: The effect of relative occupational status. International Journal of Sociology and Social Policy, 19, 109-43.

Boyle, P.J., Cooke, T., Halfacree, K.H. \& Smith, D. (2001). A cross-national comparison of the impact of family migration on women's employment status. Demography, 38(2), 201-13.

Boyle, P.J., Feng, Z. \& Gayle, V. (2009). A New Look at Family Migration and Women's Employment Status. Journal of Marriage and Family, 71(2), 417-431.

Boyle, P.J., Kulu, H., Cooke, T., Gayle, V. \& Mulder, C.H. (2008). Moving and union dissolution. Demography, 45(1), 209-222.

Box-Steffensmeier, J.M. \& Jones, B.S. (2004). Event history modeling: a guide for social scientists. Cambridge, Eng: Cambridge University Press.

Bryceson, D. \& Vuorela, U. (Eds.) (2002). The Transnational family. New European frontiers and global networks. Oxford: Berg.

Brzinsky-Fay, C., Kohler, U. \& Luniak, M. (2006). Sequence analysis with Stata.

The Stata Journal, 6(4), 435-460.

Brzinsky-Fay, C. \& Kohler, U. (2010). New Developments in Sequence Analysis.

Sociological Methods Q Research, 38(3), 359-364.

Bures, R.M. (2009). Living arrangements over the life course: families in the 21st century. Journal of Family Issues, 30(5), 579-585.

Ministerie van Binnenlandse Zaken en Koninkrijksrelaties. (2001). Chanezen in Nederland, een profiel. Den Haag, 1-27.

Caarls, K. \& Mazzucato, V. (in press). Does international migration lead to more divorce? Ghanaian couples in Ghana and abroad. Population-E.

Caarls, K., Schans, D., Mazzucato, V., Quartey, P. \& Tagoe, C.A. (in press). Transnational families between Ghana, the Netherlands and the UK. In C. Beauchemin (Ed.), Migration between Africa and Europe. New York: Springer-Verlag Berlin Heidelberg.

Carling, J., Menjívar, C. \& Schmalzbauer, L. (2012). Central themes in the study of transnational parenthood. Journal of Ethnic and Migration Studies, 38(2), 191-217.

Castles, S. \& Miller, M.J. (2009). The Age of Migration. International Population Movements in the Modern World. Hampshire: Palgrave Macmillan.

Castagnone, E., Mezger, C., Schoumaker, B., Nazio, T. \& Rakotonarivo, N. (2013). Understanding Afro-European labour trajectories: integration of migrants into the European labour market, transnational economic participation and economic reintegration into the 
country of origin. A Comparative Study (MAFE Working Paper 26). Paris: INED. Retrieved from www.ined.fr/fichier/s_rubrique/22089/wp26_understandingafro.eulabourtrajectories.en.fr.pdf

Centraal Bureau voor de Statistiek (CBS). (2009a). Bevolking; leeftijd, herkomstgroepering, geslacht en regio, 1 januari. Retrieved from statline.cbs.nl/Statweb/publication/?DM=SLNL\&PA=3 $7713 \& D_{1}=0 \& D_{2}=0 \& D_{3}=0,4,19 \& D_{4}=0,115,126,313 \& D_{5}=12 \& H D R=T, G_{2} \& S T B=G_{1}, G_{3}, G_{4} \& V W=T$

Centraal Bureau voor de Statistiek (CBS). (2009b). Bevolking; leeftijd, herkomstgroepering, geslacht en regio, 1 januari. Retrieved from statline.cbs.nl/Statweb/publication/?DM=SLNL\&PA=37713 $\& D_{1}=0 \& D_{2}=120 \& D_{3}=0,4,19 \& D_{4}=O \& D_{5}=12 \& H D R=T, G_{2} \& S T B=G_{1}, G_{3}, G_{4} \& V W=T$

Centraal Bureau voor de Statistiek (CBS). (2011). Bevolking; leeftijd, herkomstgroepering geslacht en regio, 1 januari. Retrieved from statline.cbs.nl/Statweb/publication/?DM=SLNL\&PA=37713\&D1= $\mathrm{O} 2 \& D_{2}=0 \& D_{3}=19 \& D_{4}=0,5,9,13,15 \& D_{5}=15 \& H D R=T \& S T B=G_{1}, G_{3}, G_{4}, G_{2} \& V W=T$

Charsley, K. (2005). Unhappy husbands: Masculinity and migration in transnational Pakistani marriages. Journal of the Royal Anthropological Institute, 11(1), 85-105.

Clark, G. (1994). Onions are my husband: Survival and accumulation by West African market women. Chicago: University of Chicago Press.

Clark, R. L., Glick, J. E. \& Bures, R. M. (2009). Immigrant families over the life course: Research directions and needs. Journal of Family Issues, 30(6), 852-872.

Clark, W.A.V. \& Withers, S.D. (2007). Family migration and mobility sequences in the United States: Spatial mobility in the context of the life course. Demographic Research, 17(20), 591-622.

Coe, C. (2011). What is the impact of transnational migration on family life? Women's comparisons of internal and international migration in a small town in Chana. American Ethnologist, 38(1), $148-163$.

Coe, C. (2014). The scattered family: parenting, African migrants, and global inequality. Chicago: University of Chicago Press.

Cohen, R. (1996). Introduction. In R. Cohen (Ed.), Theories of Migration (pp. xi-xvii). Cheltenham: Edward Elgar.

Constable, N. (2003). A transnational perspective on divorce and marriage: Filipina wives and workers. Identities, 10(2), 163-180.

Cooke, T.J. (2003). Family migration and the relative earnings of husbands and wives. Annals of the Association of American Geographers, 93(2), 338-349.

Curran, S.R., Shafer, S., Donato, K.M. \& Garip, F. (2006). Mapping gender and migration in sociological scholarship: Is it segregation or integration? International Migration Review, 40(1), 199-223.

Dahinden, J. (2009). Are we all transnationals now? Network transnationalism and transnational subjectivity: the differing impacts of globalization on the inhabitants of a small Swiss city. Ethnic and Racial Studies, 32(8), 1365-1386.

Dankyi, E. (2012, July). Transnational child raising arrangements and changes in child fosterage in Chana. Paper presented at the Transnational Child Raising Arrangements Workshop, Aburi, Chana. 
De Haas, H. (2005). International migration, remittances and development: myths and Facts. Third World Quarterly, 26(8), 1269-1284.

De Hart, B., Strik, T. \& Pankratz, H. (2012). Family reunification: A barrier or facilitator of integration? Country report of the Netherlands. Nijmegen: Radboud University, Nijmegen. Retrieved from familyreunification.eu/wp/content/uploads/2013/03/Dutch3.pdf

Dekker, R. \& Engbersen, G. (2014). How social media transform migrant networks and facilitate migration. Global Networks, 14(4), 401-418.

Demographic Health Survey (2008). Ghana 2008: Demographic Health Survey [data file]. Available from dhsprogram.com/data/dataset/Ghana_Standard-DHS_2008.cfm?flag=0

Dito, B., Mazzucato, V. \& Schans, D. (in press). The effects of transnational parenting on the subjective health and well-being of Chanaian migrant parents in the Netherlands. Population, Space, and Place.

Donato, K.M., Gabaccia, D., Holdaway, J., Manalansan, M. \& Pessar, P.R. (2006). A glass half full? Gender in migration studies. International Migration Review, 4O(1), 3-26.

Donato, K., Trent, J.A., Gabaccia, D. \& Leinonen, J. (2011). Variations in the gender composition of immigrant populations: How and why they matter. International Migration Review, 45(3), 495-525.

Dreby, J. (2006). Honor and virtue - Mexican parenting in the transnational context. Gender a Society, 20(1), 32-59.

Dreby, J. (2007). Children and power in Mexican transnational families. Journal of Marriage and Family, 69(4), 1050-1064.

Dreby, J. \& Adkins, T. (2010). Inequalities in transnational families. Sociology Compass, 4(8), 673-689.

Duncan, S. \& Phillips, M. (2011). People who live apart together (LATs): new family form or just a stage? International Review of Sociology, 21(3), 513-532.

Elder, G.H. (1985). Perspectives on the life course. In G.H. Elder (Ed.), Life course dynamics: Trajectories and transitions 1968-1980 (pp. 23-49). Ithaca: Cornell University Press.

Elder, G., Johnson, M., \& Crosnoe, R. (2003). The emergence and development of life course theory. In J. Mortimer \& M. Shanahan (Eds.), Handbook of the life course (pp. 3-19). New York: Kluwer/ Plenum Publishers.

European Council (2003). Council Directive on the Right to Family Reunification 2003/86/EC. Official Journal of the European Communities, L251, 12-18.

Evergeti, V. \& Ryan, L. (2011). Negotiating transnational caring practices among migrant families. In A. Kraler, E. Kofman, M. Kohli \& C. Schmoll (Eds.), Gender, generations and the family in international migration (pp. 355-373). Amsterdam: Amsterdam University Press.

Fair, J.E. (2004). "Me do wu", my Val: The creation of Valentine's Day in Accra, Ghana. African Studies Review, 47(3), 23-49.

Faist, T. (2000). Transnationalization in international migration: Implications for the study of citizenship and culture. Ethnic and Racial Studies, 23(2), 189-222.

Fargues, P. (2011). Immigration Without Inclusion: Non- Nationals in Nation-Building 
in the Gulf States. Asian and Pacific Migration Journal, 20(3-4), 273-289.

Feliciano, C. (2008). Gendered selectivity: U.S. Mexican immigrants and Mexican non migrants, 1960-2000. Latin American Research Review, 43(1), 139-160.

Findley, S.A. (1997). Migration and family interaction in Africa. In A. Adepoju (Ed.), Family, Population and Development in Africa (pp. 109-138). London and New Jersey: Zed Books.

Fleischer, A. (2008). Marriage over space and time among male migrants from Cameroon to Germany (WP 2008-006). Rostock: the Max Planck Institute for Demographic Research. Retrieved from www.demogr.mpg.de/papers/working/wp2008-006.pdf

Flowerdew, R. T. N. \& Al-Hamad, A. (2004). The relationship between marriage, divorce and migration in a British data set. Journal of Ethnic and Migration Studies, 30(2): 339-351.

Fokkema, T. \& Liefbroer, A.C. (2008). Trends in living arrangements in Europe: Convergence or divergence? Demographic Research, 19(36), 1351-1418.

Foner, N. (1997). What's New About Transnationalism?: New York Immigrants Today and at the Turn of the Century. Diaspora: A Journal of Transnational Studies, 6(3), 355-375.

Fortes, M. (1950). Kinship and marriage among the Ashanti. In A. R. Radcliffe-Brown \& C.D. Forde (Eds.), African systems of kinship and marriage (pp. 252-285). London: Oxford University Press.

Fouron, G. \& Schiller, N.G. (2001). All in the family: Gender, transnational migration, and the nation-state. Identities, 7(4), 539-582.

Frank, R. \& Wildsmith, E. (2005). The grass widows of Mexico: Migration and union dissolution in a binational context. Social Forces, 83(3), 919-947.

Fresnoza-Flot, A. (2009). Migration status and transnational mothering: the case of Filipino migrants in France. Clobal Networks, 9(2), 252-270.

Gabadinho, A., Ritschard, G., Müller, N.S. \& Studer, M. (2011). Analyzing and Visualizing State Sequences in R with TraMineR. Journal of Statistical Software, 40(4), 1-37.

Gallo, E. (2006). Italy is not a good place for men: narratives of places, marriage and masculinity among Malayali migrants. Global Networks, 6(4), 357-372.

Gambaurd, M.R. (2000). The kitchen spoon's handle. Transnationalism and Sri Lanka's migrant housemaids. Ithaca: Cornell University Press.

Geist, C. \& McManus, P.A. (2008). Geographical mobility over the life course: motivations and implications. Population, Space and Place, 14(4), 283-303.

George, S. (2000). "Dirty nurses" and man who play: Gender and class in transnational Migration. In M. Burawoy (Ed.), Global ethnography: Forces, connections and imaginations in a postmodern world (pp. 144-174). Berkeley, CA: University of California Press.

Ghana Statistical Service (GSS) (2012). 2010 Population and housing census. Summary report of final results. Accra: Ghana Statistical Service.

Ghana Statistical Service (CSS), Ghana Health Service (GHS), and ICF Macro (2009). Ghana Demographic and Health Survey 2008. Accra: GSS, GHS, and ICF Macro.

Ghosh, J. (2009). Migration and gender empowerment: recent trends and emerging issues. 
Human Development Research Paper 2009/04. United Nations Development Programme.

Giele, J.Z. \& Elder, G.H., Jr. (1998). Methods of life course research: Qualitative and quantitative approaches. Thousand Oaks, CA: Sage.

Glick, J. E. (2010). Connecting complex processes: A decade of research on immigrant families. Journal of Marriage and Family, 72(3), 498-515.

Glick Schiller, N., Basch, L. \& Blanc-Szanton, C. (1992). Transnationalism: A New Analytic Framework for Understanding Migration. Annals of the New York Academy of Sciences, 645: 1-24. doi: 10.1111/j.1749-6632.1992.tb33484.x

Glick Schiller, N., Basch, L. \& Blanc-Szanton, C. (1995). From immigrant to transmigrant: theorizing transnational migration. Anthropology Quarterly, 68(1), 48-63.

Glick Schiller, N. \& Levitt, P. (2006). Haven't we heard this somewhere before? A substantive review of transnational migration studies by way of a reply to Waldinger and Fitzgerald (Working paper 06-01). Princeton, NJ: Princeton University, Center for Migration and Development.

Goldring, L. (2001). The gender and geography of citizenship in Mexico-U.S. transnational spaces. Identities: Global Studies in Culture and Power, 7(4), 501-537.

González-Ferrer, A. (2007). The process of family reunification among original guest workers in Germany. Journal of Family Research, 19(1), 10-33.

González-Ferrer, A. (2011). Spousal reunification among recent immigrants in Spain: Links with undocumented migration and the labour market. In A. Kraler, E. Kofman, M. Kohli \& C. Schmoll (Eds.), Gender, generations and the family in international migration (pp. 193-218). Amsterdam: Amsterdam University Press.

Goody, E.N. (1982). Parenthood and social reproduction. Fostering and occupational roles in West Africa. Cambridge: Cambridge University Press.

Graham, E. \& Jordan, L. P. (2011). Migrant Parents and the Psychological Well-Being of Left-Behind Children in Southeast Asia. Journal of Marriage and Family, 73(4), 763-787.

Grillo, R. (2008). The family in question: immigrant and ethnic minorities in multicultural Europe. Amsterdam: Amsterdam University Press.

Grillo, R. \& Mazzucato, V. (2008). Africa<> Europe: A double engagement. Journal of Ethnic and Migration Studies, 34(2): 175-198.

Groenendijk, K., Fernhout, R., Van Dam, D., Van Oers, R. \& Strik, T. (2007). The Family Reunification Directive in EU Member States. The First Year of Implementation. Nijmegen: Wolf Legal Publishers.

Groenewold, W.G.F. \& Bilsborrow, R. (2008). Design of samples for international migration surveys: methodological considerations and lessons learned from a multi-country study in Africa and Europe. In C. Bonifazi, M. Okólski, J. Schoorl \& P. Simon (Eds.), International migration in Europe: new trends and new methods of analysis (pp. 293-312). Amsterdam: Amsterdam University Press: Amsterdam.

Guarnizo, L.E., Sánchez, A.I. \& Roach, E.M. (1999). Mistrust, fragmented solidarity, and transnational migration: Colombians in New York City and Los Angeles. Ethnic and Racial Studies, 22(2), 367-96. 
Gupta, P. (2002). Marriage at a distance: Spouse separation and the migrant family.

Unpublished doctoral dissertation, University of Pennsylvania.

Haagsman, K. \& Mazzucato, V. (2014). The quality of parent-child relationships in transnational families: Angolan and Nigerian migrant parents in the Netherlands. Journal of Ethnic and Migration Studies, 40(11), 1677-1696.

Heckathorn, D.D. (1997). Respondent-driven sampling: A new approach to the study of hidden populations. Social Problems, 44(2), 174-199.

Heymann, J., Flores-Macias, F., Hayes, J. A., Kennedy, M., Lahaie, C. \& Earle, A. (2009). The impact of migration on the well-being of transnational families: new data from sending communities in Mexico. Community, Work Q Family, 12(1), 91 - 103.

Hill, L.E. (2004). Connections between U.S. female migration and family formation and dissolution. Migraciones Internacionales, 2(3), 60-82.

Hirsch, J. S. (2003). A courtship after marriage: Sexuality and love in Mexican transnational families. Berkeley: University of California Press.

Hondagneu-Sotelo, P. (1994). Gendered transitions. Mexican experiences of immigration. Berkeley: University of California Press.

Hondagneu-Sotelo, P. (1999). Gender and immigration: A retrospective and introduction. In P. Hondagneu-Sotelo (Ed.), Gender and U.S. immigration. Contemporary trends, (pp. 3-42). Berkeley: University of California Press.

Horton, S. (2009). A mother's heart is weighed down with stones: A phenomenological approach to the experience of transnational motherhood. Culture Medicine and Psychiatry, 33(1), 21-40.

Horst, H.A. (2006). The blessings and burdens of communication: cell phones in Jamaican transnational social fields. Global Networks, 6(2), 143-159.

Hyman, I., Guruge, S. \& Mason, R. (2008). The impact of migration on marital relationships: A study of Ethiopian immigrants in Toronto. Journal of Comparative Family Studies, 39(2), 149-163.

Itzigsohn, J., Dore Cabral, C., Hernandez Medina, E. \& Vazquez, O. (1999). Mapping Dominican transnationalism: Narrow and broad transnational practices. Ethnic and Racial Studies, 22(2), 316-339.

Itzigsohn, J. \& Giorguli-Saucedo, S. (2005). Incorporation, transnationalism, and gender: Immigrant incorporation and transnational participation as gendered processes. International Migration Review, 39(4), 895-920.

Jenkins S. P. (1997). Discrete time proportional hazards regression (pgmhaz). Stata Technical Bulletin, $7(39), 22-32$

Jenkins S. P. (2005). Survival Analysis. Manuscript in preparation. Retrieved from www.iser.essex.ac.uk/ files/teaching/stephenj/ec968/pdfs/ec968lnotesv6.pdf

Jolly, S. \& Reeves, H. (2005). Gender and migration, an overview report. Brighton: University of Sussex, Institute of Development Studies (BRIDGE). 
Jones-Bos, R. (2005). The Dutch Perspective in Contemporary Migration. In T. Manuh (Ed.),

At Home in the World. International Migration and Development in Contemporary Chana and West Africa (pp. 103-117). Accra: Sub-Saharan Publishers.

Jordan, L.P. \& Graham, E. (2012). Resilience and Well-Being Among Children of Migrant Parents in South-East Asia. Child Development, 83(5), 1672-1688.

Kalmijn M., De Graaf P. M. \& Poortman A-R. (2004). Interactions between cultural and economic determinants of divorce in the Netherlands. Journal of Marriage and Family, 66(1), 75-89.

Kanaiaupuni, S.M. (1999). Reframing the migration question: An empirical analysis of men, women and gender in Mexico (Working paper No. 99-15). Madison, WI: University of Wisconsin-Madison, Center for Demography and Ecology.

Kanaiaupuni, S.M. (2000). Sustaining families and communities: Nonmigrant women and Mexico-U.S. migration processes (Working paper No. 2000-13). Madison, WI: University of Wisconsin, Centre for Demography and Ecology.

Kaufman, L. \& Rousseeuw, P.J. (1990). Finding groups in data. New York: John Wiley \& Sons.

King, R. (2002). Towards a new map of European migration. International Journal of Population Geography, 8(2), 89-106.

Kivisto, P.J. (2001). Theorizing Transnational Immigration: A Critical Review of Current Efforts. Ethnic and Racial Studies, 24(4), 549-78.

Kleinepier, T., De Valk, H.A.G. \& Van Gaalen, R.I. (2014, May). Life paths of migrants: A sequence analysis of Polish labor migrants' family-life trajectories. Paper presented at the Population Association of America, Boston. Retrieved from paa2014.princeton.edu/papers/140601

Kofman, E., Kraler, A., Kohli, M. \& Schmoll, C. (2011). Introduction. Issues and debates on familyrelated migration and the migrant family. In A. Kraler, E. Kofman, M. Kohli \& C. Schmoll (Eds.), Gender, generations and the family in international migration (pp 13-54). Amsterdam: Amsterdam University Press.

Kofman, E., Lukes, S., Meetoo, V. \& Aaron, P. (2008). Family migration to United Kingdom: Trends, statistics and policies. (New Orientations for Democracy Europe (NODE) Policy report). Vienna: Austrian Federal Ministry of Science and Research (Bmwf) /International Centre for Migration Policy Development (ICMPD).

Kofman, E., Phizacklea, A., Raghuram, P. \& Sales, R. (2000). Gender and international migration in Europe: Employment, welfare and politics. London: Routledge.

Kofman, E. \& Raghuram, P. (2015). Gendered migrations and global processes. In Kofman, E. and Raghuram, P. (Eds.) Gendered migrations and global social reproduction (pp. 18-39). Palgrave Macmillan: New York, Hampshire.

Kofman, E., Saharso, S. \& Vacchelli, E. (2013). Gendered perspectives on integration discourses and measures. International Migration. Advance online publication. doi: 10.1111/imig.12102

Kohli, M. (2007). The institutionalization of the life course: Looking back to look ahead. Research in Human Development, 4(3-4), 253-271. 
König, R.S. \& De Regt, M. (2010). Family dynamics in transnational African migration to Europe:

An introduction. African and Black Diaspora: An International Journal, 3(1), 1-13.

Koser, K. (Ed.) (2003). New African Diasporas. Routledge: London.

Kraler, A., (2010). Civic stratification, gender and family migration policies in Europe.

Vienna: International Centre for Migration Policy Development (ICMPD).

Kraler, A. \& Kofman, E. (2009). Family migration in Europe: policies vs. reality (Policy brief nr. 16). International Migration, Integration and Social Cohesion in Europe.

Kraler, A., Kofman, E., Kohli, M. \& Schmoll, C. (2011). Gender, Generations and the Family in International Migration. Amsterdam: Amsterdam University Press.

Kraler, A. (2014). A liberal paradox: Expanding rights, reducing access? Contemporary patterns of family migration policies in the EU. In T. Geisen, T. Studer \& E. Yildiz (Eds.), Migration, Familie und Gesellschaft. Beiträge zu Theorie, Kultur und Politik (pp. 357-378). Wiesbaden: Springer Fachmedien Wiesbaden.

Kulu, H. \& Boyle, P.J. (2010). Premarital cohabitation and divorce: Support for the "Trial Marriage" Theory? Demographic Research, 25(31), 879-904.

Kulu, H. \& González-Ferrer, A. (2014). Family dynamics among immigrants and their descendants in Europe: current research and opportunities. European Journal of Population, 30(4), 411-435.

Kulu, H. \& Milewski, N. (2007). Family change and migration in the life course: an introduction. Demographic Research, 17(19), 567-590.

Lahaie, C., Hayes, J.A., Markham, P.T. \& Heymann, J. (2009). Work and family divided across borders: The impact of parental migration on Mexican children in transnational families. Community, Work Q Family, 12, 299-312.

Landale, N.S. (1994). Migration and the Latino family: The union formation behavior of Puerto Rican women. Demography, 31(1), 133-157.

Landale, N. S., \& Ogena, N. B. (1995). Migration and union dissolution among Puerto Rican women. International Migration Review, 29(3), 671-692.

Landolt, P. \& Wei Da, W. (2005). The spatially ruptured practices of transnational migrant families: Lessons from the case of El Salvador and the People's Republic of China. Current Sociology, 53(4), 625-653.

Latten, J.J. \& Mulder, C.H. (2013). Partner relationships in the Netherlands: new manifestations of the Second Demographic Transition. Genus, 69(3), 2035-5556.

Leerkes, A.S. \& Kulu-Glasgow, I. (2011). Playing hard(er) to get. The State, International Couples, and the Income Requirement. European Journal of Migration and Law, 13(1), 95-121.

Levin, I. (2004). Living apart together: A new family form. Current Sociology, 52(2), 223-240.

Levitt, P. (1998). Social remittances: Migration driven local-level forms of cultural diffusion. International Migration Review, 32(4), 926-948.

Levitt, P. (2001a). The transnational villagers. Berkeley: University of California Press.

Levitt, P. (2001b). Transnational migration: taking stock and future directions. 
Global Networks, 1 (3), 1470-2266.

Levitt, P. \& Glick Schiller, N. (2004). Conceptualizing simultaneity: A transnational social field perspective on society. International Migration Review, 38(3), 1002-1039.

Levitt, P. \& Jaworksy, N. (2007). Transnational migration Studies: Past developments and future trends. Annual Review of Sociology, 33, 129-156.

Lloyd, C.B. \& Gage-Brandon, A.J. (1993). Women's role in maintaining households: Family welfare and sexual inequality in Ghana. Population Studies, 47, 115-131.

Long, J. S. \& Freese, J. (2006). Regression models for categorical and limited dependent variables using Stata (Second Edition). College Station, Texas: Stata Press.

Lori, N. (2012). Temporary Workers or Permanent Migrants? The Kafala system and contestations over residency in the Arab Gulf states. Center for Migration and Citizenship, Paris.

Lutz, H. (2010). Gender in the migratory process. Journal of Ethnic and Migration Studies, 36(10), 1647-1663.

Macmillan, R. (2005). The structure of the life course: classic issues and current controversies. In R. Macmillan (Ed.), The structure of the life course: Standardized? Individualized? Differentiated? (pp. 3-24). Oxford: Elsevier Ltd.

Madianou, M. (2012), Migration and the accentuated ambivalence of motherhood: the role of ICTs in Filipino transnational families. Global Networks, 12(3), 277-295. Mahler, S.J. (2001).

Transnational relationships: The struggle to communicate across borders. Identities, 7(4), $583-619$.

Maimbo, S.M. \& Ratha, D. (Eds.) (2005). Remittances. Development Impact and Future Prospects. Washington D.C.: World Bank.

Manuh, T. (1997). Wives, children, and intestate succession in Ghana. In G. Mikell (Ed.), African feminism (pp. 77-95). Philadelphia: University of Pennyslyvnia Press.

Manuh, T. (1999). "This place is not Ghana": Gender and rights discourse among Ghanaian men and women in Toronto. Ghana Studies, 2, 77-95.

Manuh, T. (2001). Ghanaian migrants in Toronto, Canada: Care of kin and gender relations.

Research review, NS 17.2, 17-26.

Martin, S.F. (2004). Women and migration (CM/MMW/2003/WP.1). Paper prepared for consultative meeting on 'Migration and mobility and this movement affects women', Malmö, Sweden, United Nations Division for the Advancement of Women.

Massey, D. S. (1987). The ethnosurvey in theory and practice. International Migration Review, 21 Special Issue Winter, 1498-1522.

Massey, D.S., Fischer, M.J. \& Capoferro, C. (2006). International migration and gender in Latin America: A Comparative Analysis. International Migration, 44(5), 63-91.

Mayer, K. (2000). Promises fulfilled? A review of 20 years of life course research. European Journal of Sociology, 41(2), 259-282.

Mayer, K.U., \& Tuma, N.B. (1990). Life course research and event history analysis: An overview. In K. U. 
Mayer \& N. B. Tuma (Eds.), Event history analysis in life course studies (pp. 1-20). Madison, WI: University of Wisconsin Press.

Mazzucato, V. (2008a). The double engagement: Transnationalism and integration - Ghanaian migrants' lives between Ghana and The Netherlands. Journal of Ethnic and Migration Studies, 34(2), 199-216.

Mazzucato, V. (2008b). Simultaneity and networks in transnational migration:

Lessons learned from a simultaneous matched sample methodology. In J. DeWind \& J. Holdaway (Eds.), Migration and development within and across borders: Research and policy perspectives on internal and international migration (pp. 69-100). Geneva: International Organization for Migration.

Mazzucato, V. (2008c). Transnational reciprocity: Ghanaian migrants and the care of their parents back home. In E. Alber, S. van der Geest, W. Geissler \& S. Whyte (Eds.), Generations in Africa: Connections and Conflicts (pp. 111-133). Münster: LIT Verlag.

Mazzucato, V. (2009). Informal insurance arrangements in Ghanaian migrants' transnational networks: The role of reverse remittances and geographic proximity. World Development, 37(6), 1105-15. Mazzucato, V. (2011). Reverse remittances in the migration - development nexus: Two way flows between Ghana and the Netherlands. Population, Space and Place, 17(5), 454-468.

Mazzucato, V. (2013). Transnational families, research and scholarship. The Encyclopedia of Clobal Human Migration: Blackwell Publishing Ltd.

Mazzucato, V. \& Cebotari, V. (2012, December). Emotional Well Being of Chanaian School Children in Different Child Raising Arrangements (TCRAs). Paper presented at MAFE-Conference Comparative and Multi-sited Approaches to International Migration, Paris.

Mazzucato, V., Cebotari, V., Veale, A., White, A., Grassi, M. \& Vivet, J. (2014b). International parental migration and the psychological well-being of children in Ghana, Nigeria, and Angola. Social Science Q Medicine. Advance online publication, doi:10.1016/j.socscimed.2014.10.058 Mazzucato, V., \& Schans, D. (2011). Transnational families and the well-being of children: conceptual and methodological challenges. Journal of Marriage and Family, 73(4): 704-712.

Mazzucato, V., Schans, D., Caarls, K. \& Beauchemin, C. (2014a). Transnational families between Africa and Europe. International Migration Review. Advance online publication, doi: 10.1111/imre.12153 Mazzucato, V., Schans, D., Caarls, K. \& Beauchemin, C. (in press). Migrant families between Africa and Europe: Comparing Chanaian, Congolese and Senegalese migration flows. In C. Beauchemin (Ed.), Migration between Africa and Europe. New York: Springer-Verlag Berlin Heidelberg. Mazzucato, V., Van den Boom, B. \& Nsowah-Nuamah, N.N.N. (2008). Remittances in Chana: Origin, destination and issues of measurement. International Migration, 46(1), pp.103-122. Mazzucato, V., Van Dijk, R., Horst, C. \& De Vries, P. (2004). Transcending the nation: Explorations of transnationalism as a concept and phenomenon. In D. Kalb, W. Pansters \& H. Siebers (Eds.), Globalization and development: Themes and concepts in current research (pp. 131-162). Dordrecht: Kluwer Academic Publishers. 
McKenzie, D.J. \& Mistiaen, J. (2009). Surveying migrant households: A comparison of census-based, snowball and intercept point surveys. Journal of the Royal Statistical Society, 172(2), 339-360.

McKenzie, D. \& Sasin, M.J. (2007). Migration, remittances, poverty, and human capital: conceptual and empirical challenges (Policy Research Working Paper Series 4272). Washington D.C.: World Bank.

Meekers, D. (1992). The process of marriage in African societies: A multiple indicator approach. Population and Development Review, 18(1), 61-78.

Mensa-Bonsu, H.J.A.N. \& Dowuona-Hammond, C. (1994). The rights of the child in Chana: Perspectives. Accra: Woeli Pub. Services.

Mezger, C. \& González-Ferrer, A. (2013). The ImPol Data-base: A new tool to measure immigration policies in France, Italy and Spain since the 1960s (MAFE Working Paper No. 34). Paris: INED. Retrieved from www.ined.fr/fichier/s_rubrique/22089/wp_34_mezger_gonzalez.en.fr.pdf

Mikell, G. (1992). Cocoa and chaos in Ghana. Washington, DC: Howard University Press.

Mikell, G. (Ed.) (1997). African feminism: The politics of survival in sub-Saharan Africa. Philadelphia: University of Pennsylvania Press.

Morris, E. (2014). Family reunification and integration policy in the EU: Where are the women? Journal of International Migration a Integration, 1-22.

Mulder, C.H., \& Wagner, M. (1998). First-time home-ownership in the family life course:

A West German-Dutch comparison. Urban Studies, 35(4), 687-713.

Nukunya, G.K. (1992). Tradition and change in Ghana: An introduction to sociology. Accra: Ghana Universities Press.

Oppong, C. (1970). Conjugal power and resources: An urban African example. Journal of Marriage and Family, 32(4), 676-680.

Oppong, C. (1974). Marriage among a matrilineal elite: A family study of Ghanaian senior civil servants. London: Cambridge University Press.

Oppong, C. (1980). From love to institution: Indications of change in Akan marriage. Journal of Family History, 5(2), 197-209.

Oppong, C. (1983). Women's roles, opportunity costs, and fertility. In R.A.Bulatao \& R.D. Lee (Eds.), Determinants of fertility in developing countries (pp. 547-589), New York: Academic Press.

Oppong, C., Okali, C. \& Houghton, B. (1975). Woman power: Retrograde steps in Ghana. African Studies Review, 18(3), 71-84.

Organisation for Economic Co-operation and Development (OECD) (2014). Is migration really increasing? Migration Policy Debates. Retrieved from www.oecd.org/berlin/ls-migrationreally-increasing.pdf.

Orozco, M. (2002). Globalization and migration: The impact of family remittances in Latin America. Latin American Politics and Society, 44, 41-66.

Orozco, M. (2005). Diasporas, development and transnational integration: Ghanaians in the U.S., U.K. and Germany. Washington D.C.: Institute for the Study of International Migration and InterAmerican Dialogue, report commissioned by Citizen International through the U.S. agency for 
International Development. Retrieved from www.thedialogue.org/PublicationFiles/

Ghanaian\%2otransnationalism.pdf

Panagakos, A.N. \& Horst, H.A. (2006). Return to Cyberia: technology and the social worlds of transnational migrants. Global Networks, 6(2), 109-124.

Parreñas, R.S. (2001). Mothering from a distance: Emotions, gender, and intergenerational relations in Filipino transnational families. Feminist Studies, 27(2), 361-390.

Parreñas, R.S. (2005). Long distance intimacy: class, gender and intergenerational relations between mothers and children in Filipino transnational families. Global Networks, 5: 317-336.

Pessar, P.R. \& Mahler, S.J. (2003). Transnational migration: Bringing gender in. International Migration Review, 37(3), 812-846.

Phillips J.A. \& Sweeney M.M. (2006). Can differential exposure to risk factors explain recent racial and ethnic variation in marital disruption? Social Science Research, 35(2), 409-434.

Poeze, M. \& Mazzucato, V. (2012, December). Beyond gender norms: Obstacles and opportunities in transnational fathering between Chana and The Netherlands. Paper presented at the conference Rethinking Care: Anthropological perspectives on life courses, kin-work and their trans-local entanglements, Berlin.

Poeze, M. \& Mazzucato, V. (2013). Ghanaian children in transnational families: understanding the experiences of left-behind children through local parenting norms. In L. Baldassar \& L. Merla (Eds.) Transnational families, migration and the circulation of care. Understanding mobility and absence in family life (pp. 149-169). London: Routledge.

Poeze, M. \& Mazzucato, V. (2014, June). Transnational mothering and the law: Ghanaian women's restrictions to family reunion and consequences for family life. Paper presented at conference Transnational families: Multi-actor, multi-sited and institutional perspectives, Amsterdam.

Portes A. (2001). Introduction: The debates and significance of immigrant transnationalism.

Global Networks, 1, 181-193.

Portes, A. \& Rumbaut, R.G. (1990). Immigrant America. Berkeley: University of California Press.

Portes, A., Guarnizo, L. E. \& Landolt, P. (1999). The study of transnationalism: pitfalls and promises of an emergent research field. Ethnic and Racial Studies, 22(2), 217-237.

Portes, A., Guarnizo, L.E. \& Haller, W.J. (2002). Transnational entrepreneurs: an alternative form of immigrant economic adaptation. American Sociological Review, 67(2), 278-98.

Pribilsky, J. (2004). 'Aprendemos a convivir': conjugal relations, co-parenting, and family life among Ecuadorian transnational migrants in New York City and the Ecuadorian Andes. Global Networks, 4(3), 313-334.

Reed, H.E., Andrzejewski, C.S. \& White, M.J. (2010). Men's and women's migration in coastal Ghana: an event history analysis. Demographic Research, 22, 771-812.

Riccio, B. (2001). From "ethnic group" to "transnational community"? Senegalese migrants' ambivalent experiences and multiple trajectories. Journal of Ethnic and Migration Studies, 27(4), 583-599. 
Riccio, B. (2008). West African transnationalisms compared: Ghanaians and Senegalese in Italy. Journal of Ethnic and Migration Studies, 34(2), 217-234.

Robette N. \& Thibault N. (2008). Comparing qualitative harmonic analysis and optimal matching. An exploratory study of occupational trajectories. Population-E, 64(3), 533-556.

Roseneil, S. (2006). On not living with a partner: unpicking coupledom and cohabitation. Sociological Research Online, 11(3), 1-14.

Sassen, S. (2003). Strategic instantiations of gendering in the global economy. In P. Hondagneu-Sotelo (Ed.), Gender and U.S. immigration: Contemporary trends (pp. 43-60). Berkeley: University of California Press.

Schans, D., Mazzucato, V., Schoumaker, B. \& Flahaux, M.-L. (2013). Changing patterns of Ghanaian migration (MAFE Working Paper 20). Paris: INED. Retrieved from www.ined.fr/fichier/s_ rubrique/22089/wp2O_ghana_patterns.fr.pdf

Schmalzbauer, L. (2004). Searching for wages and mothering from afar: The case of Honduran transnational families. Journal of Marriage and Family, 66(5), 1317-1331.

Schoumaker, B. \& Diagne, A. (2010). Migrations between Africa and Europe: Data Collection Report (MAFE Methodological Note 2). Paris: INED. Retrieved from www.ined.fr/fichier/t_ telechargement/41100/telechargement_fichier_fr_note.2_schoumaker_diagne_2011.pdf

Schoumaker, B., Mezger, C., Razafindratsima, N. \& Bringé, A. (2013a). Sampling and Computation Weights in the MAFE Surveys (MAFE Methodological Note 6). Paris: INED. Retrieved from www.ined.fr/fichier/s_rubrique/21396/note_6_mafe_nale_for_ samplingandcomputationweights.fr.pdf

Schoumaker, B., Flahaux, M.-L., Schans, D., Beauchemin, C., Mazzucato, V. \& Sakho, P. (2013b). Changing patterns of African Migration: a Comparative Analysis (MAFE Working Paper No. 18). Paris: INED. Retrieved from www.ined.fr/fichier/s_rubrique/22089/wp18_ patternssynthesis.fr.pdf

Sibley, E., Fenelon, E. \& Mole, N. (2012). Family Reunification Requirements: A Barrier or a Facilitator to Integration? United Kingdom Country Report. London: AIRE Centre.

Singer J. \& Willett, J. (2003). Applied longitudinal data analysis: modeling change and event occurrence. New York: Oxford University Press.

Skinner, C.J. (2006). Probability Proportional to Size (PPS) Sampling. Encyclopedia of Statistical Sciences, 10. Smith, D.P. (2004). An 'untied' research agenda for family migration: loosening the 'shackles' of the past. Journal of Ethnic and Migration Studies, 30(2), 263-282.

Sørensen, N.N. \& Guarnizo, L.E. (2007). Transnational family life across the Atlantic. The experience of Colombian and Dominican migrants in Europe. In N.N. Sørensen (Ed.), Living across worlds: Diaspora, development and transnational engagement (pp. 151-176). Geneva: International Organization for Migration.

Stark, O. \& Lucas, R. (1988). Migration, remittances and the family. Economic Development and Cultural Change, $36(3), 465-481$. 
Strik, T., De Hart, B. \& Nissen, E. (2013). Family Reunification Requirements: A Barrier or a Facilitator to Integration? A Comparative Study. Oisterwijk: Wolf Legal publishers HW.

Strohm, C.Q., Seltzer, J.A., Cochran, S.D. \& Mays, V.M. (2009). "Living Apart Together" relationships in the United States. Demographic Research, 21(7), 177-214.

Studer, M. (2013). WeightedCluster Library Manual: A practical guide to creating typologies of trajectories in the social sciences with R. LIVES Working Papers, 24, 1-34.

Suárez-Orozco, C., Todorova, I. L. G., \& Louie, J. (2002). Making up for lost time: The experience of separation and reunification among immigrant families. Family Process, 41(4), 625-643.

Suárez-Orozco, C. \& Qin, D.B. (2006). Gendered Perspectives in Psychology: Immigrant Origin Youth. International Migration Review, 40(1), 165-198.

Suárez-Orozco, C., Suárez-Orozco, M. \& Todorova, I. (2008). Learning a New Land: Immigrant Students in American Society. Cambridge, Mass.: Harvard University Press.

Tabutin, D. \& Schoumaker, B. (2004). The demography of Sub-Saharan Africa from the 1950 s to the 2000s. A survey of changes and a statistical assessment. Population-E, 59(3/4), 457-555.

Takyi, B.K. (2001). Marital stability in an African society: Exploring the factors that influence divorce processes in Ghana. Sociological Focus, 34, 77-96.

Takyi, B.K. \& Broughton, C.L. (2006). Marital Stability in Sub-Saharan Africa: Do Women's Autonomy and Socioeconomic Situation Matter? Journal of Family and Economic Issues, 27(1), 113-132.

Takyi, B.K. \& Dodoo, N.F. (2005). Gender, lineage, and fertility-related outcomes in Ghana. Journal of Marriage and Family, 67(1), 251-257.

Takyi B.K. \& Gyimah, S.O. (2007). Matrilineal family ties and marital dissolution in Ghana. Journal of Family Issues, 28(5), 682-705.

Tiemoko, R. (2004), Migration, return and socio-economic change in West Africa: the role of family. Population, Space and Place, 10, 155-174.

Toma, S. \& Vause, S. (2014). Gender differences in the role of migrant networks: Comparing Congolese and Senegalese migration Flows. International Migration Review, 48(4), 972-997.

Toyota, M., Yeoh, B.S.A. \& Nguyen, L. (2007). Bringing the 'left behind' back into view in Asia: a framework for understanding the 'migration-left behind nexus. Population, Space and Place, 13(3), 157-161.

Twum-Baah, K. (2005). Volume and Characteristics of International Chanaian Migration. In T. Manuh (Ed.), At Home in the World. International Migration and Development in Contemporary Ghana and West Africa (pp. 55-77). Accra: Sub-Saharan Africa Press: Accra.

United Nations (2006). 2004 World Survey on the role of women in development. New York: United Nations.

Van der Geest, S. (1976). Role relationships between husband and wife in rural Ghana. Journal of Marriage and Family, 38(3), 572-578.

Van der Klis, M., \& Mulder, C.H. (2008). Beyond the trailing spouse: The commuter partnership as an alternative to family migration. Journal of Housing and the Built Environment, 23(1), 1-19. 
Van Dijk, R. (2004). Negotiating marriage: questions of morality and legitimacy in the Ghanaian pentecostal diaspora. Journal of Religion in Africa, 34(4), 438-467.

Van Walsum, S. (2006). Transnational mothering, national immigration policy and the European Court of Human Rights. In P. Shah \& W. Menski (Eds.), Migration, diasporas and legal systems in Europe (pp. 185-203). London: Routledge-Cavendish.

Vertovec, S. (1999). Conceiving and researching transnationalism. Journal of Ethnic and Racial Studies, 22(2), 447-462.

Vertovec, S. (2001). Transnationalism and identity. Journal of Ethnic and Migration Studies 27(4), 573-82.

Vertovec, S. (2004a). Migrant Transnationalism and Modes of Transformation. International Migration Review, 38(3): 970-1001.

Vertovec, S. (2004b, May). Trends and Impacts of Migrant Transnationalism. Paper presented at the International Migration Review conference on Conceptual and Methodological Developments in the Study of International Migration, Princeton University.

Vertovec, S. (2004c). Cheap calls: the social glue of migrant transnationalism. Global Networks, 4(2), 219-224.

Vickstrom, E. (2014). Pathways into Irregular Status Among Senegalese Migrants in Europe. International Migration Review, 48(4), 1062-1099.

Vink, M., De Groot, G.R. \& Luk, C. (2013). Global Dual Citizenship Database (version 1.00). Updated until 1 January 2013. Maastricht: Maastricht University https://macimide.maastrichtuniversity.nl/dual-citizenship-database/

Wagner, M. \& Mulder, C.H. (1993). Migration and Marriage in the Life Course: A Method for Studying Synchronized Events. European Journal of Population, 9, 55-76.

Waldinger, R. \& Fitzgerald, D. (2004). Transnationalism in question. American Journal of Sociology, 109(5), 1177-1195.

Waters, J.L. (2010). Becoming a father, missing a wife: Chinese transnational families and the male experience of lone parenting in Canada. Population, Space and Place, 16, 63-74.

White, L.K. (1990) Determinants of divorce: A review of research in the Eighties. Journal of Marriage and Family, 52(4), 904-912.

Wilding, R. (2006). 'Virtual' intimacies? Families communication across transnational contexts. Global Networks, 6(2), 125-142.

Willis, K.D. \& Yeoh, B.S.A. (2000). Gender and transnational household strategies: Singaporean migration to China. Regional Studies, 34(3), 253-264.

Wimmer, A. \& Glick Schiller, N. (2002). Methodological nationalism and beyond: nation-state building, migration and the social sciences. Global Networks, 2(4), 301-334.

Wingens, M., Windzio, M., De Valk, H. \& Aybek, C. (Eds.) (2011). A life-course perspective on migration and integration. Dordrecht: Springer.

Wong, M. (2006). The gendered politics of remittances in Ghanaian transnational families.

Economic Geographies, 82(4), 355-381. 
World Bank (2008) Country brief: Ghana. Washington D.C.: World Bank.

Zentgraf, K.M. \& Chinchilla, N.S. (2012). Transnational family separation: A framework for analysis. Journal of Ethnic and Migration Studies, 38(2), 345-366.

Zlotnik, H. (2003). The global dimension of female migration. Migration Information Source. Retrieved from www.migrationpolicy.org/article/global-dimensions-female-migration

Zontini, E. (2010). Transnational families, migration and gender. Moroccan and Filipino women in Bologna and Barcelona. Berghahn Books: New York. 


\section{APPENDICES}

\section{Appendix $A$. Living arrangements of Ghanaian migrants in Eurape}

Table A.1. Living arrangements of Ghanaian migrants in Europe, children Q spouses

\begin{tabular}{|c|c|c|c|c|c|}
\hline \multicolumn{6}{|c|}{ Full Sample } \\
\hline Ego's children & $n$ & $\%$ & Ego's spouse & $n$ & $\%$ \\
\hline No children (under-18) & 200 & 43 & No spouse & 187 & 46 \\
\hline Cohabiting children (always unified) & 123 & 39 & Cohabiting spouse (always unified)* & 98 & 31 \\
\hline $\begin{array}{l}\text { Cohabiting children } \\
\text { (after period of separation) }\end{array}$ & 23 & 7 & $\begin{array}{l}\text { Cohabiting spouse } \\
\text { (after period of separation) }\end{array}$ & 66 & 15 \\
\hline Non-cohabiting children abroad & 64 & 11 & Non-cohabiting spouse abroad & 59 & 8 \\
\hline Total & 410 & 100 & Total & 410 & 100 \\
\hline \multicolumn{6}{|c|}{ The Netherlands } \\
\hline No children (under-18) & 128 & 41 & No spouse & 113 & 39 \\
\hline Cohabiting children (always unified) & 70 & 30 & Cohabiting spouse (always unified)* & 53 & 20 \\
\hline $\begin{array}{l}\text { Cohabiting children } \\
\text { (after period of separation) }\end{array}$ & 15 & 7 & $\begin{array}{l}\text { Cohabiting spouse } \\
\text { (after period of separation) }\end{array}$ & 47 & 20 \\
\hline Non-cohabiting children abroad & 50 & 22 & Non-cohabiting spouse abroad & 50 & 21 \\
\hline Total & 263 & 100 & Total & 263 & 100 \\
\hline \multicolumn{6}{|c|}{ The UK } \\
\hline Ego's children & $n$ & $\%$ & Ego's spouse & $n$ & $\%$ \\
\hline No children (under-18) & 72 & 44 & No spouse & 74 & 47 \\
\hline Cohabiting children (always unified) & 53 & 41 & Cohabiting spouse (always unified)* & 45 & 33 \\
\hline $\begin{array}{l}\text { Cohabiting children } \\
\text { (after period of separation) }\end{array}$ & 8 & 6 & $\begin{array}{l}\text { Cohabiting spouse } \\
\text { after period of separation) }\end{array}$ & 19 & 14 \\
\hline Non-cohabiting children abroad & 14 & 9 & Non-cohabiting spouse abroad & 9 & 6 \\
\hline Total & 147 & 100 & Total & 147 & 100 \\
\hline \multicolumn{6}{|c|}{$\begin{array}{l}\text { * We look at cohabitation/non-cohabitation of ego with his/her spouse from the time they were married (i.e. not from the time the } \\
\text { union started) }\end{array}$} \\
\hline \multicolumn{6}{|c|}{ Notes: weighted percentages Q unweighted numbers; Source: MAfE-Ghana, 2009-2010, Biographic survey; } \\
\hline \multicolumn{6}{|c|}{ Population: Ghanaian migrants in the UK and the Netherlands $(n=410)$} \\
\hline Interpretation: $43 \%$ of Chanaian migrants in th & & + & I & & \\
\hline
\end{tabular}




\section{Table A.2. Family arrangements typology of Chanaian migrants in Europe}

\begin{tabular}{|c|c|c|c|c|}
\hline & & nple & & \\
\hline Ego's Spouse* & Ego's Children*** & & & \\
\hline & No child(ren) $<18$ & $\begin{array}{l}\text { Cohabitating } \\
\text { child(ren) } \\
\text { (always unified) }\end{array}$ & $\begin{array}{l}\text { Cohabitating } \\
\text { child(ren) } \\
\text { (after period of } \\
\text { separation) }\end{array}$ & $\begin{array}{c}\text { Non- } \\
\text { Cohabitating } \\
\text { child(ren) }\end{array}$ \\
\hline No spouse & $121(27 \%)$ & 31 (11\%) & $8(2 \%)$ & $27(6 \%)$ \\
\hline $\begin{array}{l}\text { Cohabitating spouse } \\
\text { (always unified) } * * *\end{array}$ & $27(7 \%)$ & $61(21 \%)$ & $4(1 \%)$ & $6(2 \%)$ \\
\hline $\begin{array}{l}\text { Cohabitating spouse } \\
\text { (after period of separation) }\end{array}$ & $28(6 \%)$ & $20(5 \%)$ & $9(3 \%$ & $9(1 \%)$ \\
\hline Non-cohabitating spouse & $24(3 \%)$ & $11(2 \%)$ & $2(0 \%)$ & $22(3 \%)$ \\
\hline & The $\mathrm{N}$ & etherlands & & \\
\hline Ego's Spouse* & Ego's Children*** & & & \\
\hline & No child(ren) $<18$ & $\begin{array}{l}\text { Cohabitating } \\
\text { child(ren) } \\
\text { (always unified) }\end{array}$ & $\begin{array}{l}\text { Cohabitating } \\
\text { child(ren) } \\
\text { (after period of } \\
\text { separation) }\end{array}$ & $\begin{array}{c}\text { Non- } \\
\text { Cohabitating } \\
\text { child(ren) }\end{array}$ \\
\hline No spouse & $74(23 \%)$ & $15(6 \%)$ & $5(2 \%)$ & $19(8 \%)$ \\
\hline $\begin{array}{l}\text { Cohabitating spouse } \\
\text { (always unified) } * * *\end{array}$ & $15(5 \%)$ & 32 (13\%) & $3(2 \%)$ & $3(1 \%)$ \\
\hline $\begin{array}{l}\text { Cohabitating spouse } \\
\text { (after period of separation) }\end{array}$ & $19(6 \%)$ & $14(7 \%)$ & $5(2 \%)$ & $9(5 \%)$ \\
\hline Non-cohabitating spouse & $20(7 \%)$ & $9(4 \%)$ & $2(1 \%)$ & $19(8 \%)$ \\
\hline & & ne UK & & \\
\hline Ego's Spouse** & $\begin{array}{l}\text { Ego's Children***; } \\
\text { No child(ren) <18 }\end{array}$ & $\begin{array}{l}\text { Cohabitating } \\
\text { child(ren) } \\
\text { (always unified) }\end{array}$ & $\begin{array}{l}\text { Cohabitating } \\
\text { child(ren) } \\
\text { (after period of } \\
\text { separation) }\end{array}$ & $\begin{array}{l}\text { Non- } \\
\text { Cohabitating } \\
\text { child(ren) }\end{array}$ \\
\hline No spouse & $47(27 \%)$ & $16(12 \%)$ & $3(2 \%)$ & $8(5 \%)$ \\
\hline $\begin{array}{l}\text { Cohabitating spouse } \\
\text { (always unified)*** }\end{array}$ & $12(8 \%)$ & $29(22 \%)$ & $1(1 \%)$ & $3(2 \%)$ \\
\hline $\begin{array}{l}\text { Cohabitating spouse } \\
\text { (after period of separation) }\end{array}$ & $9(6 \%)$ & $6(4 \%)$ & $4(3 \%)$ & ० (०\%) \\
\hline Non-cohabitating spouse & $4(3 \%)$ & $2(2 \%)$ & ० (०\%) & $3(2 \%)$ \\
\hline
\end{tabular}

* Informal unions are not considered, i.e. 'spouse' always refers to marriage, and conversely, 'no spouse' also includes those within an informal union; we look at cohabitation/non-cohabitation of ego with his/her spouse from the time they were married (i.e. not from the time the union started); * $x^{*} *$ Children over-18 (and their whereabouts) are not considered, i.e. 'no child' also includes those with only children over-18; In the case of migrants with children under-18 who are living at different locations, we consider this migrant as 'non-cohabiting when at least 1 child under-18 is not living with ego.

Note: unweighted numbers Q weighted percentages; Source: MAfE-Ghana, 2009-2010, Biographic survey; Population: Ghanaian migrants in the UK and the Netherlands $(n=410)$

Interpretation: Of the Ghanaian migrants in the UK and the Netherlands, $27 \%$ have no spouse and no children. $11 \%$ have children with whom they are living together, but they do not have a spouse. 


\section{Table A.3. Family arrangements typology}

\begin{tabular}{|c|c|c|c|c|}
\hline \multirow[t]{2}{*}{ Ego's Spouse* } & \multicolumn{4}{|l|}{ Ego's Children*** } \\
\hline & No child(ren) $<18$ & $\begin{array}{l}\text { Cohabitating } \\
\text { child(ren) } \\
\text { (always unified) }\end{array}$ & $\begin{array}{l}\text { Cohabitating } \\
\text { child(ren) } \\
\text { (after period of } \\
\text { separation) }\end{array}$ & $\begin{array}{l}\text { Non-Cohabitating } \\
\text { child(ren) }\end{array}$ \\
\hline No spouse & $\begin{array}{l}\text { 1. No nuclear } \\
\text { family }\end{array}$ & $\begin{array}{l}\text { 2. Totally unified } \\
\text { family }\end{array}$ & 3. Reunified & $\begin{array}{l}\text { 4. Transnational } \\
\text { family }\end{array}$ \\
\hline $\begin{array}{l}\text { Cohabitating } \\
\text { spouse (always } \\
\text { unified) }\end{array}$ & $\begin{array}{l}\text { 2. Totally unified } \\
\text { family }\end{array}$ & $\begin{array}{l}\text { 2. Totally unified } \\
\text { family }\end{array}$ & 3. Reunified & $\begin{array}{l}\text { 4. Transnational } \\
\text { family }\end{array}$ \\
\hline $\begin{array}{l}\text { Cohabitating } \\
\text { spouse (after } \\
\text { period of } \\
\text { separation) }\end{array}$ & 3. Reunified & 3. Reunified & 3. Reunified & $\begin{array}{l}\text { 4. Transnational } \\
\text { family }\end{array}$ \\
\hline $\begin{array}{l}\text { Non-cohabitating } \\
\text { spouse }\end{array}$ & $\begin{array}{l}\text { 4. Transnational } \\
\text { family }\end{array}$ & $\begin{array}{l}\text { 4. Transnational } \\
\text { family }\end{array}$ & $\begin{array}{l}\text { 4. Transnational } \\
\text { family }\end{array}$ & $\begin{array}{l}\text { 4. Transnational } \\
\text { family }\end{array}$ \\
\hline
\end{tabular}

* Informal unions are not considered, i.e. spouse always refers to marriage, and conversely, no spouse also includes those within an informal union $*$ Children $>18$ (and their whereabouts) are not considered, i.e. no child also includes those with only children > 18; In case of children $<18$ who are living at different locations, when at least 1 child $<18$ is not living with ego, it is considered 'noncohabiting'. 


\section{Appendix B. Estimating the prabability of reunification in the receiving cauntry}

Table B.1. Estimating the probability of reunification in the receiving country

\begin{tabular}{|c|c|c|}
\hline \multicolumn{3}{|c|}{$\begin{array}{lll}1 & -2-1\end{array}$} \\
\hline & Coef. & SE \\
\hline Duration of LATAB & $0.734^{* * * *}$ & 0.164 \\
\hline Duration of LATAB (squared) & $-0.041^{* * * *}$ & 0.011 \\
\hline \multicolumn{3}{|l|}{ Socio-demographic variables } \\
\hline \multicolumn{3}{|l|}{ Sex (Male, ref.) } \\
\hline Female & -0.122 & 0.453 \\
\hline \multicolumn{3}{|l|}{ Education (Secondary or less, ref.) } \\
\hline Tertiary & 0.234 & 0.462 \\
\hline \multicolumn{3}{|c|}{ Spouse's education (Secondary or less, ref.) } \\
\hline Tertiary & $-1.149 * * * *$ & 0.527 \\
\hline \multicolumn{3}{|c|}{ Subjective wealth status (Depended/Not at all, ref.) } \\
\hline Absolutely & 0.886 & 0.554 \\
\hline \multicolumn{3}{|c|}{ Multilocal residence before migration (No, ref.) } \\
\hline Yes & $1.384^{* * *}$ & 0.659 \\
\hline \multicolumn{3}{|l|}{ Couple's characteristics } \\
\hline \multicolumn{3}{|l|}{ Marital status (Unmarried, ref.) } \\
\hline Married & $1.397 * *$ & 0.659 \\
\hline \multicolumn{3}{|l|}{ Children (No children, ref.) } \\
\hline At least one child in Ghana & $-1.919 * * * *$ & 0.597 \\
\hline All children in receiving country & $-1.930 * * * *$ & 0.791 \\
\hline Duration of the union & $0.058 * *$ & 0.030 \\
\hline \multicolumn{3}{|l|}{ Receiving country characteristics } \\
\hline \multicolumn{3}{|l|}{ Receiving country (UK, ref.) } \\
\hline the Netherlands & $-1.807^{* * * *}$ & 0.674 \\
\hline \multicolumn{3}{|l|}{ Period (2003, ref.) } \\
\hline 2004 & $-1.349 * * * *$ & 0.570 \\
\hline \multicolumn{3}{|l|}{ Legal status (Undocumented, ref.) } \\
\hline Documented & -0.344 & 0.538 \\
\hline \multicolumn{3}{|l|}{ Remittances (No, ref.) } \\
\hline Yes & -0.640 & 0.604 \\
\hline Constant & $-4.961 * * * *$ & 1.045 \\
\hline \multicolumn{3}{|l|}{ Model characteristics } \\
\hline Log likelihood & -98.995601 & \\
\hline N (couple-years) & 868 & \\
\hline $\mathrm{N}$ (couples) & 278 & \\
\hline Pseudo R2 & 0.24 & \\
\hline
\end{tabular}

Source: MAFE-Ghana data, 2009-2010

Notes: Robust standard errors reported; ***p<0.01, **p<0.05, *p<0.10 (two-tailed) 


\section{Appendix C. Sime ta diwarce \\ (Taplan-Mleier estimates)}

Figure C.1. Time to divorce (Kaplan-Meier survival estimate)

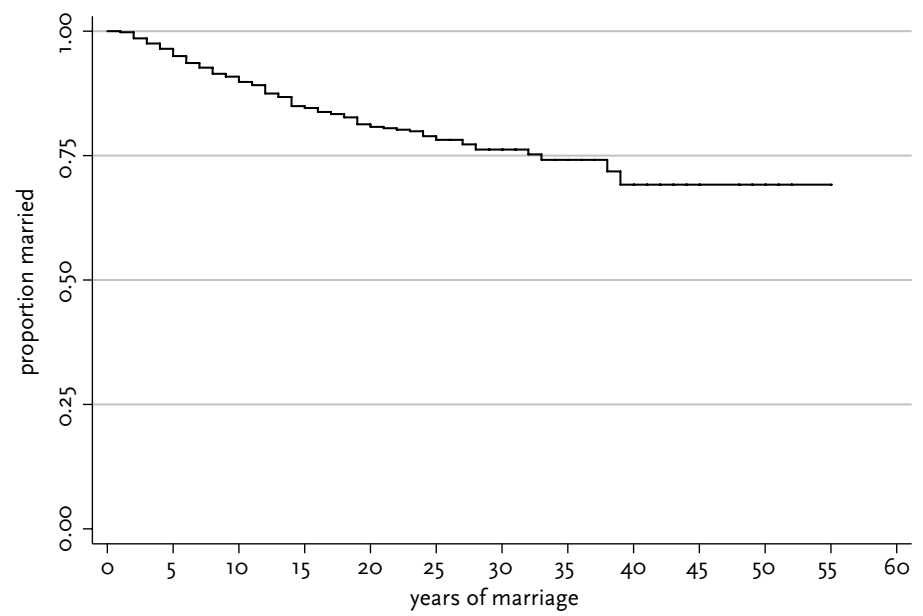

Source: MAFE-Ghana data, 2009-2010 


\section{NEDERLANDSE SAMENVATTING}

\section{Inleiding}

In deze dissertatie onderzoek ik verschillende manieren waarop internationale migratie het familieleven van migranten kan beïnvloeden. Vaak is het zo dat niet het hele gezin migreert, maar slechts één of meerdere leden van het gezin. De redenen hiervoor kunnen verschillend zijn. Het feit dat van elkaar gescheiden gezinsleden voor kortere of langere tijd apart van elkaar leven, verspreid over meerdere (vaak twee) landen, heeft vaak gevolgen voor de relaties tussen deze mensen In mijn onderzoek richt ik mij specifiek op de wijze waarop koppels en gezinnen uit Ghana door deze internationale migratie worden gevormd, veranderen of zelfs worden beëindigd.

Aan de genoemde geografische scheiding van migranten kunnen verschillende motivaties ten grondslag liggen. Het kan een bewuste keuze zijn, gemotiveerd door bijvoorbeeld de kans op werk, of omdat samen migreren vanwege de baan van een van de gezinsleden, of de scholing van de kinderen in het land van herkomst, als onwenselijk wordt beschouwd. Anderzijds kan een streng migratiebeleid in het beoogde land van aankomst een dergelijke scheiding als ongewenste uitkomst hebben.

Het bestuderen van transnationale families vraagt om een transnationale benadering. Een van de centrale uitgangspunten van mijn onderzoek is de notie dat migranten altijd in meerdere contexten ingebed zijn. Migranten gaan een relatie aan met het leven in het land van aankomst en tegelijkertijd zijn en blijven zij vaak intensief betrokken bij de levens van familie en vrienden in het land van herkomst. Voor mijn onderzoek betekent dit dat ik a) zowel de context van het land van herkomst als die het land van aankomst heb meegenomen, b) ook gezinnen en/of partners heb meegenomen die niet gemigreerd zijn, en c) mijn bevindingen zoveel mogelijk heb voorzien van context, door de culturele en familiale normen van het land van herkomst mee in ogenschouw te nemen.

Hiervoor heb ik gebruikgemaakt van de Ghanese data van het 'Migrations between 
Africa and Europe' (MAFE) project. Deze data heeft enkele methodologische innovaties mogelijk gemaakt. In de eerste plaats is de data verzameld in het land van herkomst (Ghana) en in twee landen van aankomst (Nederland en Engeland). Deze manier van dataverzameling maakte het mogelijk om enerzijds Ghanese families gelijktijdig hier en daar te onderzoeken, en anderzijds een vergelijking te maken van Chanezen met en zonder migratie-ervaring. In de MAFE-Chana survey is ook de biografische levensgeschiedenis van de geïnterviewde Ghanezen bevraagd. Hiervoor is een retrospectieve vragenlijst gebruikt, waarin naar gedetailleerde informatie werd gevraagd over verschillende levensdomeinen, zoals relatiegeschiedenissen, kinderen, samenlevingsvormen, gezinshereniging en scheiding. Dankzij deze retrospectieve biografische survey was het voor mij mogelijk om de situatie van Chanezen gedurende een langere periode te bekijken, waarbij rekening kon worden gehouden met de veranderende historische en geografische context. Een beter begrip van de gevolgen van internationale migratie voor het familieleven van migranten is hiervan het resultaat.

\section{Bewindingen en canclusies}

Het proefschrift bevat vier empirische hoofdstukken (hoofdstuk 4-7). De vijf belangrijkste bevindingen van deze hoofdstukken worden hier kort uiteengezet.

\section{1) Het belang van contextualiseren: het land van herkomst}

$\mathrm{Er}$ is nog relatief weinig aandacht voor Afrikaanse transnationale families geweest. De meeste onderzoeken naar transnationale families richten zich op Aziatische en Latijns Amerikaanse families, die voornamelijk naar de VS migreren. Ook is in het verleden veel onderzoek gedaan naar migratie naar Europa, maar dit onderzoek richt zich veelal op de meer traditionele gastarbeiders. Ondanks het feit dat Afrikaanse transnationale families in steeds toenemende mate naar Europa zijn gemigreerd, is gedegen onderzoek ernaar tot dusver schaars geweest.

Een sprekend voorbeeld voor het belang van context is de rol die familiale normen en waarden spelen: terwijl in Westerse landen vaak de nadruk wordt gelegd op het individu en het kerngezin, wordt het Afrikaanse familieleven vaak gekarakteriseerd door familiebanden die verder reiken dan het kerngezin. In deze zogenaamde extended families omvat een huishouden vaak ook de grootouders, ooms, tantes en overige familieleden. In mijn onderzoek komt duidelijk naar voren dat een dergelijke uitgebreide opvatting van familieleven ertoe leidt dat bijna de helft van alle huishoudens die in de steden Accra en Kumasi zijn onderzocht met migratie van doen heeft, dat wil zeggen ten minste een lid 
van het huishouden heeft dat gemigreerd is. Het transnationale familieleven speelt zich dus af binnen een diversiteit van familierelaties.

In veel Westerse landen is het ook in grotere mate vanzelfsprekend dat leden van het kerngezin onder één dak leven, terwijl deze fysieke nabijheid in de Afrikaanse context niet als noodzakelijke voorwaarde wordt gezien voor het functioneren van een gezin. Partners leven vaker gescheiden van elkaar en ook jonge kinderen wonen niet altijd bij hun ouders, wat niet per se het gevolg is van een echtscheiding. Deze studie heeft laten zien dat het geografisch gescheiden leven tussen partners veel voorkomt in Afrika, zowel onder migranten als onder niet-migranten, en dat internationale migratie dus geen exclusieve oorzaak is van deze levensstijl. Een transnationale relatie, ofwel 'living apart togehter across borders' (LATAB), kan zo worden beschouwd als een voortzetting van het wijdverbreide 'living apart together' (LAT). Tegelijkertijd laat deze studie zien dat de internationale context ook nieuwe familievormen met zich meebrengt.

\section{2) Living apart together across borders}

Deze dissertatie toont aan dat er diverse familievormen kunnen ontstaan in de context van internationale migratie. Zo kunnen gezinnen als geheel migreren, kan gezinshereniging plaatsvinden in het land van aankomst of kunnen gezinnen gevormd worden in het land van aankomst. Er is nog weinig data over deze verschillende familievormen, noch over de mate waarin zij voorkomen. In het huidige debat rondom familie en migratie wordt gezinsmigratie vaak geproblematiseerd en gebracht als de meest voorkomende route van migranten naar Europa. Bovendien wordt vaak gedacht dat alle migranten willen herenigen met hun families en dat ze dat willen doen in het land van aankomst. Een aantal bevindingen in dit proefschrift kan nuance aanbrengen in dit gevoelige debat.

Deze studie heeft aangetoond dat transnationale relaties veel voorkomen en dat zij langdurig onderhouden kunnen worden. Zowel ouders en kinderen als partners kunnen geografisch gescheiden leven gedurende vele (soms tientallen) jaren.

Twee van de belangrijkste migratielanden voor Ghanezen, Nederland en Engeland, zijn met elkaar vergeleken. Hieruit blijkt dat transnationale families in Nederland meer voorkomen dan in Engeland. Ook is gebleken dat gezinshereniging hier minder waarschijnlijk is dan in Engeland. Beide landen zijn de laatste jaren een restrictiever migratiebeleid gaan hanteren, maar in Nederland worden in vergelijking strengere condities aan gezinshereniging gekoppeld, zoals onder andere een integratie- en taaltest in het buitenland, hoge inkomenseisen (120\% boven het sociaal minimum) en hoge kosten voor verblijfsvergunningen. Historisch gezien is al langer sprake van migratie tussen Ghana en Engeland, met als gevolg dat Ghanezen gemiddeld genomen langer in Engeland verblijven. Vanwege de lange duur van gezinsherenigingsprocessen zijn Ghanezen in Engeland meer in de gelegenheid geweest tot gezinshereniging. Ook is 
de Engelse taal minder een barrière, aangezien dat ook de officiële taal in het Ghanese onderwijs is. Bovendien is het nationale onderwijssysteem in Ghana vergelijkbaar met dat in Engeland, waardoor opleidingen en opleidingsniveaus beter op elkaar aansluiten. Doordat de opleidingen van Ghanezen hier niet altijd worden erkend, zoals onderzoek heeft aangetoond, kiezen Ghanezen minder snel voor gezinshereniging in Nederland. Aangezien de condities voor gezinshereniging nauw verbonden zijn met de sociaaleconomische status van de migrant, is het voor Ghanezen in Nederland moeilijker om te herenigen dan in Engeland.

Hoewel de sociaaleconomische status in Nederland voor bepaalde migranten een barrière opwerpt voor gezinshereniging, zien we dat een hoge sociaaleconomische status voor andere migranten juist mogelijkheden voor een transnationale levensstijl hebben gecreëerd. Met name in Nederland is te observeren dat hoger opgeleide Ghanezen ervoor kiezen om in transnationaal verband te leven. In Engeland is het omgekeerde te zien, wat mogelijk te maken heeft met het eerder genoemde feit dat hoger opgeleide Ghanezen daar meer kansen op de arbeidsmarkt hebben, wat hereniging vergemakkelijkt.

\section{3) Beslissingen rondom gezinshereniging}

In mijn onderzoek heb ik me ook gericht op de factoren die van belang zijn bij het al dan niet herenigen na een periode van transnationaal familieleven. Gezien de politieke en publieke controversen over gezinshereniging van migranten in Nederland is er verrassend genoeg - nog maar weinig onderzoek gedaan naar de feitelijke hereniging van migrantenfamilies. $\mathrm{Er}$ is zowel gekeken naar geregistreerde gezinshereniging als naar feitelijke gezinshereniging. De belangrijkste bevindingen hierbij zijn a) dat migranten niet altijd kiezen voor gezinshereniging, b) dat transnationale families voor een aanzienlijk deel herenigen door middel van terugkeer naar het land van herkomst, en c) dat migranten niet uitsluitend via het gezinsherenigingsbeleid herenigd worden met familieleden.

In mijn onderzoek heb ik een aantal eigenschappen gevonden die bijdragen aan de kans op hereniging tussen de migrant en zijn of haar partner in het land van aankomst. Zo blijkt het opleidingsniveau van de achtergebleven partner van groot belang te zijn. Hoe hoger opgeleid hij/zij is, des te kleiner is de kans op hereniging. Hoewel dit de resultaten van ander migratieonderzoek tegenspreekt, is het wel in overeenstemming met onderzoek naar Westerse LAT relaties. Een van de redenen hiervoor kan zijn dat hoger opgeleide Ghanezen betere kansen hebben op de Ghanese arbeidsmarkt, in vergelijking met andere West-Afrikaanse landen. Bovendien kunnen hoger opgeleide migranten zich vaker een transnationale levensstijl veroorloven. De resultaten laten echter ook zien dat gezinshereniging moeilijk haalbaar is voor de meer kwetsbare migranten met een lagere sociaaleconomische situatie. Migranten die na 2004 in Europa arriveerden, een 
periode die gekenmerkt wordt door een steeds restrictiever beleid, hebben ook een sterk verminderde kans op hereniging. Tezamen laten de resultaten zien dat voor sommigen een transnationale relatie het gevolg is van een keuze, terwijl het voor anderen de uitkomst is van het migratiebeleid en/of de sociaaleconomische omstandigheden.

\section{4) Het belang van gender}

Omdat gender een cruciale rol speelt in de wijze waarop families worden gevormd, heb ik in dit proefschrift zoveel mogelijk onderzocht wat de invloed van gender is op migratie- en herenigingsprocessen. De resultaten laten zien dat het voor een beter begrip van transnationale families van groot belang is om mee te nemen wie van de partners (de man of vrouw) migreert.

In tegenstelling tot veel andere migratiestromen is van alle Ghanese migranten bijna de helft vrouw. Bovendien staan Ghanese vrouwen bekend als autonoom en zijn huishoudens waarbij de vrouw aan het hoofd staat niet ongewoon in Ghana. Kijkend naar de relatie tussen internationale migratie en het familieleven, zien we echter geen relatie tussen de kans op hereniging en sekse van de migrant. Helaas is onze sample te klein om de kans op hereniging voor mannen en vrouwen apart te onderzoeken. Een verdere, mogelijke verklaring voor het feit dat er geen verschil gevonden werd tussen mannen en vrouwen, is dat hier twee tegengestelde processen werkzaam zijn, waardoor significante verschillen in de data uitblijven: eerder onderzoek onder Ghanese migranten in Nederland heeft aangetoond dat vrouwen meer dan mannen de intentie hebben om te herenigen, wat echter bemoeilijkt wordt door het Nederlandse migratiebeleid. Mannen daarentegen willen dit in mindere mate, maar zij worden ook minder belemmerd. Eerder onderzoek heeft namelijk beargumenteerd dat het binnen het huidige beleid voor vrouwen moeilijker is om hier met hun partner en familie te herenigen, onder andere doordat het voor vrouwen vaak lastiger is om te voldoen aan de hoge inkomenseisen.

Ook is aangetoond dat het voor het familieleven uitmaakt wie wanneer migreert. Kijkend naar de kans op echtscheiding is duidelijk geworden dat deze groter is voor koppels waarbij de vrouw migreert en de man achterblijft in Ghana. Bovendien is de kans op echtscheiding groter wanneer deze vrouwen naar een Westers land migreren, dan wanneer vrouwen naar een ander Afrikaans land migreren. Mogelijke redenen hiervoor zijn dat door migratie de rolverdeling binnen de familie verandert (de vrouw als kostwinner, de man die zorgdraagt voor het huishouden), en dat deze vrouwen in aanraking komen met nieuwe gendernormen. Ook is gebleken dat de kans op echtscheiding het kleinst is voor koppels waarvan de man eerst migreert en de vrouw later volgt.

\section{5) De relatie tussen migratie en echtscheiding}

De relatie tussen migratie en echtscheiding is eveneens een onderwerp dat tot nu 
toe onderbelicht is gebleven. Vaak wordt een immigrantenpopulatie in een land vergeleken met de autochtone bevolking, om zo te onderzoeken of migranten meer of minder scheiden. In dit proefschrift heb ik Ghanese migranten kunnen vergelijken met migranten die niet gemigreerd zijn, waardoor ik de invloed van internationale migratie op echtscheiding beter in kaart heb kunnen brengen.

Hoewel migratie doorgaans wordt geassocieerd met een grotere kans op echtscheiding, tonen mijn resultaten aan dat dit niet noodzakelijk voor Ghanese koppels geldt. In tegendeel, migratie leidt enkel onder specifieke condities tot meer echtscheiding, namelijk - zoals eerder reeds genoemd - wanneer de vrouw migreert, met name naar een Westers land. Het kan zo zijn dat de vrouw alleen migreert, of dat het koppel tegelijkertijd migreert; in beide gevallen is de kans op echtscheiding hoger dan voor koppels zonder migratie-ervaring. Opvallend genoeg is de kans op echtscheiding niet hoger wanneer de man alleen migreert, en is de kans zelfs kleiner wanneer de man migreert en zijn vrouw later volgt. In mijn proefschrift geef ik hiervoor een vijftal verklaringen.

\section{Canclusie}

Wanneer alle bevindingen van dit proefschrift bij elkaar genomen worden, wordt duidelijk hoe belangrijk het voor een beter begrip van het familieleven van migranten is, dat rekenschap wordt afgelegd voor de verschillende contexten waarbinnen dit familieleven plaatsvindt.

Ten eerste is inzicht in de culturele en familiale context van het land van herkomst hiervoor van onmisbaar belang. Met de vergelijking van migranten en niet-migranten heb ik niet alleen kunnen aantonen dat internationale migratie van invloed is op de wijze waarop een transnationale familie samenleeft, maar ook dat sommige migratiegerelateerde bevindingen een gevolg kunnen zijn van gangbare sociaal-culturele praktijken in het land van herkomst. Met andere woorden: om de effecten van migratie op het familieleven van migranten te begrijpen, is het noodzakelijk om de context van het land van herkomst mee te nemen.

Ten tweede heeft de culturele, juridische en beleidsmatige context van het land van aankomst een invloed op de manier waarop transnationale families leven. Zoals bijvoorbeeld door middel van het restrictieve migratiebeleid, dat in hoge mate de wijze beïnvloedt waarop Ghanese migranten hun levens leiden, hoe de transnationale families waarvan zij deel uitmaken worden gevormd, zich ontwikkelen, veranderen of ook uiteenvallen. 


\section{VALORISATION ADDENDUM}

\section{Societal relevance}

This thesis addressed the role of international migration on how families, and couples in particular, are formed, transformed or dissolved. Family migration is a major policy concern as it relates to issues of border security, integration and multiculturalism. In the current context of stringent migration policies, family-related migration has become one of the last options for migrants to legally enter Europe (Kraler et al., 2011; OECD, 2014). Policy debates often discuss family reunification as problematic, associating it with mostly male migrants who bring their subordinate and dependent spouses to the receiving country, or with forced, arranged, or fraudulent marriages (Grillo, 2008; Fleisher, 2008; Kofman et al., 2013; Van Dijk, 2004). Despite these concerns, we still know little about family migration patterns or about how transnational families function. By providing a better understanding of migrants' familial lives in the context of international migration, this thesis informs these public and political debates.

International migration can impact the forms families take. The context of migration often makes it difficult for families to travel together, resulting in families living geographically separated. Yet nuclear families can also migrate as a whole, families can reunite in the receiving country, or families can be formed abroad. There is not much quantitative data about these different forms or about the prevalence of these forms (Levitt, 2001b; Portes, 2001; Vertovec, 2004b). This thesis contributes to this lacuna by investigating if, when, and where families live geographically separate from each other, the forms these families take, and if, when, and where they reunify.

This thesis has demonstrated that living apart together across borders is a widespread and common feature of many migrants' familial lives. Spouses as well as parents and their children live physically separated for extended periods of time. As these familial arrangements take place across nation states, conditions in both sending and receiving countries affect migrants' and their families. It is therefore crucial to take both 
these contexts into account when advancing our understanding about transnational family life, or when designing policies and programs.

Comparing Ghanaian migrants with non-migrants in Ghana revealed that international migration influences transnational family life. It further showed how sociocultural practices from the sending country, such as the prevalence of multilocal living arrangements, as well as the receiving country context, through restrictive policies and different normative contexts play a role in the formation and transformation of transnational family life.

\section{Policy implications}

Estimates say that about $60 \%$ of all third-country immigrants in Europe came through family reunification (King et al., 2010). Family-linked migration is expected to have a multiplier effect, whereby migrants settle permanently at destination and subsequently bring over their family members. Resulting from concerns about family migration, migration policies have become stricter over the years in most European countries, and opportunities for families to reunify have increasingly become more difficult. These concerns are motivated by a notion of transnational family life as a temporary arrangement, with two implicit assumptions: 1) migrants' desire to reunify with their family, and 2) that this desire is always directed towards the country of destination.

This thesis has shown that these assumptions are not necessarily correct. Instead, we found that a large share of Ghanaian migrants arrives as singles without children, and that many migrants with families live transnationally for extended periods of time instead of reunifying. Moreover, many migrants do not reunify in the country of destination, but they also return to their origin country, where they reunify with their family. These findings highlight that the extent to which migrants enter Europe via family reunification is less than is believed.

Yet policies are not the only factor affecting migrants' reunification behaviour, and not all migrants desire to reunify. Together, our findings indicate that for some migrants, living transnationally is a choice, while for others it is the consequence of constraints, financially, legally or otherwise. We have argued that living apart together across borders can be a preferred choice. In Ghana, like many other West African countries, living apart together is a widespread practice among spouses as well as parents and children. For some, transnational living arrangements are a continuation of their previous lifestyle and as such, not necessarily problematic and reunification is not always desired. However, living apart together across borders can also be the result of socio-economic circumstances or the unwanted outcome of stringent reunification policies. This implies that in addition to the individual motivations of migrants and their left-behind family 
members, state policies influence decisions on reunification. Family reunification also takes place outside the legal framework. Additionally, it is important to realize that family reunification processes can be lengthy and stressful even for those with the necessary documents. Other research has shown the emotional difficulties that families endure after and during long separations (Bernhard et al., 2008). We have also found that transnational family life is associated with recent arrival, undocumented status, and short term permits, indicating that family reunification policies are socially selective (Kraler, 2010), excluding more vulnerable groups from exercising their rights to family reunification.

Our results also show that migrants generally remain in touch with households in the sending countries. They do so by means of frequent phone calls, but also through remittances. We found that migrants send remittances to a wide range of people, such as nuclear family members, extended family and friends. Despite the proliferation of modern financial and communication technologies or cheaper travel opportunities, which typically eased the way migrants remit and keep in contact with those left-behind, these technologies do not benefit all migrants equally (see also Bledsoe \& Sow, 2008).

In sum, this thesis has shown the existence of transnational families and the various means by which families maintain active ties between those who migrate and those who remain in the origin country. Yet despite this prevalence, there are no policies, either in sending or receiving countries that deal with this reality (see also Bernhard et al., 2008; Mazzucato \& Schans, 2011). Instead, restrictive migration policies make it difficult to actively engage in transnational family life, as they limit the freedom to travel back and forth to visit family.

There are several ways in which policies can address transnational family life. On the one hand, the stringent conditions for family reunification, such as pre-entry tests, highincome requirements and higher age limits for spouses, make reunification difficult for those who wish to do so. By easing the conditions for eligibility, and recognizing different notions of the 'family', such as transnational families or extended families, reunification becomes equally accessible for more migrants. On the other hand, visas are usually quite expensive and difficult to obtain for family members in the sending countries, hindering their possibilities to travel for visits to their migrant family member in the receiving country. As this study has shown, short return visits facilitate transnational family life. Policies could therefore aim at facilitating traveling back-and-forth by lowering the costs for visas, or by issuing special visas for family members.

\section{Innovation}

Even though migration by its very nature involves two or more countries, this multi-sited nature has rarely been taken into account in migration research. Instead, studies on 
migration typically have focused either on immigration and integration in the receiving countries, or on the consequences of migration for sending countries, resulting in a limited understanding of return and circular migration, and transnational practices (Beauchemin, 2014; Mazzucato \& Schans, 2011; Mazzucato, 2008b). Gaining insight into the consequences of migration on family life requires a counterfactual: a comparison between those who migrated and those who did not. The fact that these two groups are by definition in two different countries (migrants in receiving countries and non-migrants in sending countries) justifies a multi-sited survey. In addition, this comparison should not be made only at the time of survey. Instead, migrants and non-migrants should be compared over a similar time period, for which a longitudinal survey design is necessary (Beauchemin, 2014).

This thesis makes use of the MAFE-Ghana data, which entailed several methodological innovations. First, it has applied a multi-sited approach. Data was collected in the sending country, Ghana, and in two receiving countries, the UK and the Netherlands. This allowed for comparing migrants in the receiving countries with nonmigrants in the sending country. Second, the MAFE-Ghana survey collected longitudinal information through a retrospective survey, asking detailed biographical questions about relationships and living arrangements. Identical questions were asked to migrants, non-migrants and returnees, which allowed for analyzing the linkages between union formation, living arrangements and international migration, the reunification behaviour of migrants, and the probability of divorce. The retrospective data also facilitated studying transnational relationships from a life course perspective (e.g Kulu \& Milewski, 2007; Wingens et al., 2011). While previous studies typically studied the pre- or post-migration situation of migrants, this thesis used the retrospective information to consider both the changing geographical and historical contexts in order to facilitate a better understanding of the implications of migration for family life.

\section{Dissemination of results}

The results of this research have been made available to both academics and a larger non-academic audience. In addition to presenting the findings of this thesis at various international conferences and publishing in international peer-reviewed journals, this thesis is also embedded in a wider project: the MAFE-project. From the start of this project, researchers have been engaged in discussions with civil society, policy makers and other public institutions.' Several activities have been employed to reach various audiences. First, a detailed project description and all publications, scientific and non-scientific, can be found on the project website: http://mafeproject.site.ined.fr/en. Importantly, the data

1 mafeproject.site.ined.fr/en/partners/civil_society/\#r20370 
have been made available freely accessible for research and educational purposes and can be accessed through this website. Second, several roundtables were held in which policy makers, NGOs, and academics engaged in discussions about the project and its implications. ${ }^{2}$ Third, policy briefs were created to summarize the main findings for each working package, including the working package on transnational families. ${ }^{3}$ Fourth, for educational purposes, several training sessions were organized, including one at Maastricht University. ${ }^{4}$

I have been involved in various teaching activities where I have used the MAFEsurvey and my findings. Additionally, Miranda Poeze and I gave a workshop for the Belgian organization Kleurrijk, where we discussed our findings with a small group of men and women who were involved in transnational families. ${ }^{5}$ I have been requested to write an article in Demos, ${ }^{6}$ a Dutch magazine aimed at academic, policy makers, governmental bodies and others interested in population questions. Additionally, I will organize a special issue on family reunification for Versvak, a Dutch online platform that aims to make scientific research available for a wider non-scientific audience. ${ }^{7}$

\footnotetext{
2 mafeproject.site.ined.fr/en/events/policy_dialogue_meetings/

3 mafeproject.site.ined.fr/en/publications/briefs/

4 mafeproject.site.ined.fr/en/events/train/

5 www.kleur-rijk.be/gezinsstructuren

6 www.nidi.nl/nl/demos

7 www.nidi.nl/nl/demos
} 


\section{ABOUT}

\section{THE AUTHOR}

Kim Caarls (Veghel, 1979) completed her Bachelor's degree in Cultural Anthropology and Development Studies at the Radboud University Nijmegen. Her research interests were sparked during her fieldwork in Chana, which inspired her to enroll in the Research Master Social and Cultural Sciences at the same university. For her Master thesis, she carried out fieldwork in Rwanda about the role of the Rwandan migrant community on the process of reconciliation. Having completed the Research Master (cum laude), her growing interest in migration research brought her to Maastricht University, where she started as a PhD researcher in September 2009. Her PhD research was part of the 'Migration between Africa and Europe' (MAFE) project, which is a large international research program in which data are collected in three African sending countries and six major European receiving countries. Concentrating on the case of Ghana, Kim's $\mathrm{PhD}$ research provided insight into the role of international migration in how Ghanaian families form, transform or dissolve. Kim currently works as a postdoctoral researcher at the Netherlands Interdisciplinary Demographic Institute (NIDI), where she is part of the 'Families of migrant origin - a life course perspective' (FaMiLife) project. Here, she continues to investigate the role of international migration on the lives of migrants and their families, emphasizing the need for a sending and receiving country perspective in order to fully understand the functioning of family life across borders. 


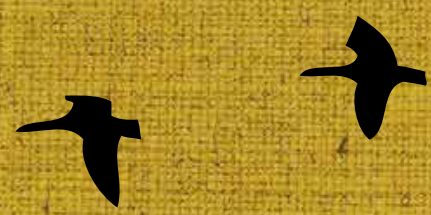

This thesis provides insight into the role of international migration in how Ghanaian couples form, transform or dissolve. It investigates if, when and where families live geographically separate from each other and if, when and where they reunify. Employing a transnational approach, this dissertation incorporated the notion that migrants are embedded in multiple contexts. This means that y the contexts of the sending and receiving countries are. taken into account, 2) couples that did not migrate are included, and 3 ) the findings are contextualized by considering the cultural and familial norms of the sending country.

This thesis demonstrates that the sending country context as well as the receiving country context affects the way in which families live transnationally or reunify. Comparing migrants and non-migrants showed that international migration shapes the transnational family, and it also reveals. that some types of living arrangements are related to socio-cultural practices in the sending country, which emphasizes the importance of taking the sending country context into account when studying processes related to international migration. At the same time, restrictive policies and different normative contexts in receiving countries also influence the formation and transformation of transnational family life.

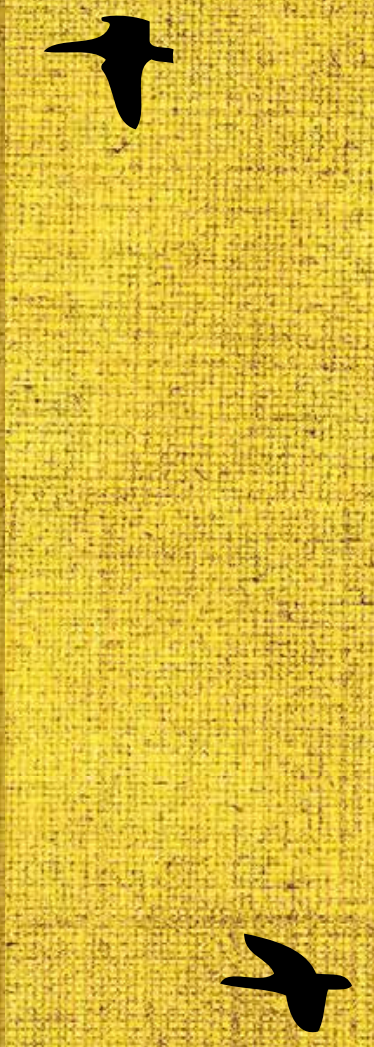

